CLÁUDIA MARIA GASPARDO

\title{
Alívio de dor em neonatos pré-termo: avaliação da eficácia do uso continuado de sacarose
}

Tese apresentada à Faculdade de Medicina de Ribeirão Preto da Universidade de São Paulo para obtenção do título de Doutor em Ciências Médicas.

Área de Concentração: Saúde Mental

Orientadora: Profa ${ }^{a}$ Dra . Maria Beatriz Martins Linhares

Ribeirão Preto 
Autorizo a reprodução e divulgação total ou parcial deste trabalho, por qualquer meio convencional ou eletrônico, para fins de estudo e pesquisa, desde que citada a fonte.

Biblioteca Central do Campus Administrativo de Ribeirão Preto

Universidade de São Paulo

Gaspardo, Cláudia Maria

Alívio de dor em neonatos pré-termo: avaliação da eficácia do uso continuado de sacarose. Ribeirão Preto, 2010.

248 p. : il. ; $30 \mathrm{~cm}$

Tese de Doutorado, apresentada à Faculdade de Medicina de Ribeirão Preto/USP. Área de concentração: Saúde Mental.

Orientadora: Linhares, Maria Beatriz Martins

1. Nascimento prematuro. 2. Dor. 3. Sacarose. 
Nome: GASPARDO, Cláudia Maria

Título: Alívio de dor em neonatos pré-termo: avaliação da eficácia do uso continuado de sacarose.

Tese apresentada à Faculdade de Medicina de Ribeirão Preto da Universidade de São Paulo para obtenção do título de Doutor em Ciências Médicas.

Aprovado em: 1

Banca Examinadora

Prof. Dr. Instituição:

Julgamento: Assinatura:

Prof. Dr. Instituição:

Julgamento: Assinatura:

Prof. Dr. Instituição:

Julgamento: Assinatura:

Prof. Dr. Instituição:

Julgamento: Assinatura:

Prof. Dr. Instituição: Assinatura: 
Queridos pais, Cláudio e Célia, obrigada por colocarem minha educação como prioridade em suas vidas, por guiarem meus passos no caminho da verdade e da fé, por todos os esforços para que eu pudesse realizar os meus sonhos, por sempre estarem ao meu lado, me amando e respeitando.

Querida irmã Juliana, meu maior presente, obrigada por dividir comigo os bons momentos, e nunca permitir que eu me sentisse só nos momentos difíceis, por sua alegria, amizade e confiança.

A vocês, família amada, dedico este trabalho. 
Agradeço de maneira especial à minha orientadora, Profa. Dra. Maria Beatriz Martins Linhares

Por ser fundamental na construção da minha formação acadêmica e profissional. Obrigada por acreditar em mim e me ajudar no desenvolvimento de minhas potencialidades, por sua postura ética, amizade e respeito, por tudo o que me ensinou e por tudo o que ainda me ensinará. 


\section{Agradecimentos}

A Deus, agradeço eternamente por me conceder uma existência abençoada, com saúde, família, amigos e oportunidades de estudo e trabalho.

Ao Departamento de Neurociências e Ciências do Comportamento e ao Departamento de Puericultura e Pediatria da FMRP/USP, obrigada pelo apoio na realização deste trabalho.

Ao Prof. Dr. Francisco Eulógio Martinez, obrigada pela atenção, dedicação, disponibilidade e respeito por este trabalho, desde o seu início.

Ao Prof. Dr. Salim Moysés Jorge e à Profa ${ }^{a}$ Dra . Gimol Benzaquen Perosa, obrigada pela valiosa contribuição prestada por ocasião da defesa da Dissertação de Mestrado, muito importante para a continuidade do trabalho de Doutorado.

Ao Geraldo Cássio dos Reis, estaticista do Departamento de Neurociências e Ciências do Comportamento da FMRP/USP, obrigada pela contribuição nas análises estatísticas.

À Secretaria de Pós-graduação e à Secretaria de Pós-graduação em Saúde Mental da FMRP/USP, agradeço pela atenção e disponibilidade com que atenderam a todas as minhas solicitações.

À Pró-Reitoria de Pós-graduação da USP, agradeço a oportunidade de realizar o Programa de Aperfeiçoamento de Ensino - PAE, experiência que considero muito importante para a minha formação acadêmica.

À Fundação de Apoio ao Ensino, Pesquisa e Assistência - FAEPA do HCFMRP/USP, agradeço pelo auxílio financeiro concedido para a coleta de dados e divulgação dos resultados deste estudo. 
Às mães, obrigada pela confiança com que permitiram que seus filhos participassem deste trabalho.

Aos bebês prematuros, obrigada por me ensinarem a cada dia como superar as adversidades com resignação, coragem e vontade de viver.

Às equipes médica e de enfermagem da Unidade de Terapia Intensiva Neonatal UTIN do HCFMRP/USP, obrigada pela imensa colaboração prestada durante a realização da coleta de dados deste estudo.

À $\mathrm{Dr}^{\mathrm{a}}$. Walusa, obrigada pela parceria no trabalho prestado às famílias e aos bebês internados na UTIN e por todo o empenho voltado para a implantação do uso da sacarose como procedimento de rotina na UTIN do HCFMRP/USP.

Ao Prof. Dr. Arthur Lopes Gonçalves, à Profa ${ }^{\text {. Dra }}$. Maria Lucia Silveira Ferlin e às equipes dos Ambulatórios ANE2 e ANEP do HCFMRP/USP, obrigada pela troca de experiência tão importante para o meu aprendizado no trabalho com as crianças nascidas prematuras.

À Renata e Fabíola, obrigada pelo companheirismo nos momentos dedicados à Psicologia Pediátrica e especialmente pela amizade sincera de todas as horas.

À Bia, Juliana, Vivian, Thaís, Catia, Rodrigo, Márcia e Larissa, obrigada pela competência, disponibilidade e valiosa contribuição em muitas etapas deste trabalho.

À Valéria, Paula, Lu Leonetti, Lu Cosentino, Margareth, Cibelle, Stella, Fernanda e Rafaela, obrigada pela convivência e apoio ao longo da pós-graduação.

Às aprimorandas Paula e Liliana, e ex-aprimorandas Marcela, Daniele, Tenille, Lara, Letícia e Ana Cláudia, do Curso de Aprimoramento em Psicologia do Desenvolvimento na Área da Saúde do HCFMRP/USP, agradeço pela troca de 
experiências que faz do nosso convívio uma oportunidade de aprendizado constante.

À Ana Emília, obrigada por me inserir de maneira tão cuidadosa no mundo psicológico do bebê prematuro e de suas mães.

À Flávia, abrigada pela amizade tão presente, mesmo distante, e por ser para mim um exemplo a ser seguido.

À Karina e Larissa, minhas "irmãs" de Ribeirão Preto, obrigada pela convivência, amizade e companheirismo ao longo dos anos que moramos juntas.

A todos que, de alguma maneira me ajudaram para que eu chegasse até aqui, meu sincero agradecimento. 


\section{Declaração Universal dos Direitos do Bebê Prematuro}

Artigo I - Todos os prematuros nascem livres e iguais em dignidade e direitos. São dotados de razão e consciência. Possuem vida anterior ao nascimento.

Artigo II - Todo prematuro tem o direito de ser reconhecido como pessoa perante a lei.

Artigo III - Nenhum prematuro será arbitrariamente exilado de seu contexto familiar de modo brusco ou por tempo prolongado. A preservação deste vínculo, ainda quando silenciosa e discreta, é parte fundamental de sua vida.

Artigo IV - Todo prematuro tem o direito de ser cuidado por uma equipe multidisciplinar capacitada a compreendê-lo, interagir com ele e a tomar decisões harmônicas em seu beneficio e em prol de seu desenvolvimento.

Artigo $\mathrm{V}$ - Todo prematuro tem direito à liberdade de opinião e expressão, portanto deverá ter seus sinais de aproximação e afastamento identificados, compreendidos, valorizados e respeitados pela equipe que o cuida.

Artigo $\mathrm{VI}$ - Nenhum prematuro será submetido à tortura, nem a tratamento ou castigo cruel, desumano ou degradante. Sua dor deverá ser sempre considerada, prevenida e tratada através dos processos disponibilizados pela ciência atual.

Artigo VII - Todo prematuro tem direito ao repouso, devendo por isso ter respeitados seus períodos de sono superficial e profundo que doravante serão tomados como essenciais para seu desenvolvimento.

Artigo VIII - Todo prematuro tem o direito inalienável ao silêncio que o permita sentir-se o mais próximo possível do ambiente sonoro intra-uterino.

Artigo IX - Nenhum prematuro deverá, sob qualquer justificativa, ser submetido a procedimento estressante aplicado de forma displicente e injustificada pela equipe de saúde.

Artigo X - Todo prematuro tem direito a perceber a alternância entre a claridade e a penumbra, que passarão a representar para ele a noite e o dia.

Artigo XI - Todo prematuro tem o direito, uma vez atingidas as condições básicas de equilíbrio e vitalidade, ao amor, ao calor e leite maternos que lhe são oferecidos por meio do método canguru.

Artigo XII - Todo prematuro tem o direito de ser alimentado com o leite de sua própria mãe ou, na falta deste, com o de outra mulher tão logo suas condições clinicas assim o permitirem. Deverá ter sua sucção corretamente trabalhada desde o inicio da vida e caberá à equipe de saúde garantir-lhe esse direito.

Dr. Luis Alberto Mussa Tavares 


\section{RESUMO}

GASPARDO, C. M. Alívio de dor em neonatos pré-termo: avaliação da eficácia do uso continuado de sacarose. 2010. 248 f. Tese (Doutorado) - Faculdade de Medicina de Ribeirão Preto, Universidade de São Paulo, Ribeirão Preto, 2010.

A trajetória de desenvolvimento do neonato pré-termo se inicia no contexto da Unidade de Terapia Intensiva Neonatal, permeado pela presença contínua de diversos estímulos dolorosos. As experiências iniciais e repetidas de dor podem ter efeito em longo prazo para os neonatos vulneráveis. A Academia Americana de Pediatria e a Sociedade Pediátrica Canadense recomendam o uso da solução de sacarose como intervenção não-farmacológica para alívio de dor em neonatos, entretanto, a eficácia e segurança do uso continuado da sacarose necessitam de investigação. O presente estudo randomizado controlado duplo-cego teve por objetivos avaliar a eficácia da administração via oral da solução de sacarose a $25 \%$, em esquema de doses repetidas no alívio da dor em neonatos pré-termo e avaliar os possíveis efeitos colaterais advindos do uso continuado da sacarose para os neonatos. Trinta e três neonatos pré-termo com muito baixo peso ao nascer foram distribuídos em dois grupos: Grupo Sacarose $(n=17)$ e Grupo Água $(n=16)$. Os neonatos foram avaliados durante quatro dias consecutivos, durante procedimento de punção para coleta de sangue. Cada avaliação foi dividida em cinco fases: Linha de Base, Preparação para Punção (antissepsia), Punção, Recuperação com Manuseio (curativo) e Recuperação sem Manuseio. O indicador de dor foi avaliado pela atividade facial, mensurada pelo Neonatal Facial Coding System (NFCS). O nível de ativação dos neonatos foi mensurado pelo estado de vigília e sono e pela frequência cardíaca. Na primeira avaliação, os neonatos de ambos os grupos não receberam nenhuma substância antes do procedimento doloroso. Nos três dias seguintes, o Grupo Sacarose recebeu $0,5 \mathrm{ml} / \mathrm{kg}$ de sacarose oral e o Grupo Água recebeu água estéril, dois minutos antes de cada procedimento doloroso. Foram obtidos dados de evolução clínica dos neonatos nos prontuários médicos. Os resultados encontrados revelaram que no primeiro dia de avaliação os neonatos de ambos os grupos anteciparam a reação ao estímulo doloroso de punção, apresentando elevação significativa do escore do NFCS, do estado de vigília e sono 
e da frequência cardíaca, já na antissepsia, sendo que durante a recuperação a frequência cardíaca continuou elevada em comparação à fase de Linha de Base. A partir do segundo dia de avaliação, o Grupo Sacarose apresentou menores escores do NFCS e do estado de vigília e sono, durante o procedimento, em comparação ao Grupo Água. O indicador fisiológico de frequência cardíaca não apresentou diferença significativa entre os grupos, entretanto, a sacarose reduziu o tempo necessário para o neonato se recuperar e atingir a estabilidade fisiológica após passar pelo procedimento doloroso de punção. Não houve diferença significativa na evolução clinica dos neonatos de ambos os grupos, o que demonstra que a sacarose não causou efeitos colaterais em curto prazo aos neonatos. Conclui-se que a dose de $0,5 \mathrm{ml} / \mathrm{kg}$ de solução de sacarose a $25 \%$ administrada em esquema de doses repetidas foi eficaz para o alívio da dor em neonatos pré-termo e não trouxe efeitos colaterais imediatos para o estado de saúde dos neonatos.

Palavras-chave: Nascimento prematuro. Dor. Sacarose. 


\section{ABSTRACT}

Gaspardo, C. M. Pain relief in preterm neonates: assessment of the efficacy of sucrose used in continued form. 2010. $248 \mathrm{f}$. Thesis (Doctoral Degree) - Faculty of Medicine of Ribeirão Preto, University of São Paulo, Ribeirão Preto, 2010.

The development pathway of the preterm neonate begins in the context of the Neonatal Intensive Care Unit, permeated by the presence of several painful stimuli. Initial and repetitive pain may have long-term effect for vulnerable newborns. The American Academy of Pediatrics and Canadian Pediatric Society recommends the use of sucrose solution as non-pharmacological intervention for pain relief in neonates, however, the efficacy and safety of continued use of sucrose needs investigation. The present randomized controlled double-blind study aimed to assess the efficacy of oral administration of sucrose solution to $25 \%$ in repeated doses to relief pain in preterm neonates and to assess the possible side effects arising from the continued use of sucrose to newborns. Thirty-three preterm neonates with very low birth weight were divided into two groups: Sucrose Group $(n=17)$ and Water Group $(n=16)$. The newborns were assessed during four consecutive days during puncture procedure for blood collection. Each assessment was divided into five phases: Baseline, Antisepsis, Puncture, Dressing, and Recovery. The indicator of pain was assessed by facial activity, measured by the Neonatal Facial Coding System (NFCS). The level of activation of the neonates was measured by the sleepwake states and heart rate. In the first assessment, the newborns of both groups did not receive any substance before the painful procedure. During the next three days, Sucrose Group received $0.5 \mathrm{ml} / \mathrm{kg}$ of oral sucrose and Water Group received sterile water two minutes before each painful procedure. Clinical outcomes data of newborns were obtained in the medical records. The results showed that on the first day of assessment newborns of both groups have anticipated the reactivity to painful stimuli, with significant increase of NFCS score, sleep-wake states and heart rate as early as antisepsis, and during recovery heart rate remained increased in comparison to the Baseline phase. From the second day of assessment, the Sucrose Group had lower NFCS scores and sleep-wake states during the procedure, compared to the Water Group. The physiological indicator of heart rate showed no significant difference between groups, however, sucrose has reduced the time required for the 
infant to recover and achieve physiological stability after passing through the painful procedure of puncture. There was no significant difference in clinical outcome of newborn in both groups, demonstrating that sucrose did not cause short term side effects in neonates. The finding was that the dose of $0.5 \mathrm{ml} / \mathrm{kg}$ of sucrose solution to $25 \%$ administered in repeated doses was effective for pain relief in preterm and did not caused short term side effects to the health of newborns.

Keywords: Premature birth. Pain. Sucrose. 


\section{LISTA DE ILUSTRAÇÕES}

Figura 1 - Percurso de composição da amostra.

Figura 2 - Indicador biocomportamental de atividade facial (escore NFCS), no Grupo Sacarose (GS) e Grupo Água (GA) entre as fases Linha de Base (LB), Preparação para Punção (PP), Punção (P), Recuperação com Manuseio (RCM) e Recuperação sem Manuseio (RSM), em cada dia de avaliação

Figura 3 - Indicador biocomportamental de estado de vigília e sono, no Grupo Sacarose (GS) e Grupo Água (GA) entre as fases Linha de Base (LB), Preparação para Punção (PP), Punção (P), Recuperação com Manuseio (RCM) e Recuperação sem Manuseio (RSM), em cada dia de avaliação

Figura 4 - Indicador fisiológico de frequência cardíaca média, no Grupo Sacarose (GS) e Grupo Água (GA) entre as fases Linha de Base (LB), Preparação para Punção (PP), Punção (P), Recuperação com Manuseio (RCM) e Recuperação sem Manuseio (RSM), em cada dia de avaliação

Figura 5 - Porcentagem de neonatos (\%) com escore do NFCS igual ou acima de três pontos no Grupo Sacarose (GS) e Grupo Água (GA) nas fases de Linha de Base (LB), Preparação para Punção (PP), Punção $(P)$, Recuperação com Manuseio (RCM) e Recuperação sem Manuseio (RSM), nos quatro dias de avaliação

Figura 6 - Porcentagem de neonatos com alto nível de ativação no Grupo Sacarose (GS) e Grupo Água (GA) nas fases de Linha de Base (LB), Preparação para Punção (PP), Punção (P), Recuperação com Manuseio (RCM) e Recuperação sem Manuseio (RSM), durante os quatro dias de avaliação 
Figura 7 - Porcentagem de neonatos com estado biocomportamental de choro no Grupo Sacarose (GS) e Grupo Água (GA) nas fases de Linha de Base (LB), Preparação para Punção (PP), Punção (P), Recuperação com Manuseio (RCM) e Recuperação sem Manuseio (RSM), nos quatro dias de avaliação

Figura 8 - Porcentagem de neonatos com média da frequência cardíaca igual ou acima de 160 batimentos por minuto no Grupo Sacarose (GS) e Grupo Água (GA) nas fases de Linha de Base (LB), Preparação para Punção (PP), Punção (P), Recuperação com Manuseio (RCM) e Recuperação sem Manuseio (RSM), nos quatro dias de avaliação.

Figura 9 - Indicador fisiológico de frequência cardíaca $(F C)$, no Grupo Sacarose, entre a fase Linha de Base e minuto a minuto da fase de Recuperação (Recuperação com Manuseio e Recuperação sem Manuseio)

Figura 10 - Indicador fisiológico de frequência cardíaca (FC), no Grupo Água, entre a fase Linha de Base e minuto a minuto da fase de Recuperação (Recuperação com Manuseio e Recuperação sem Manuseio) 


\section{LISTA DE TABELAS}

Tabela 1 - Características da amostra e da evolução clínica dos neonatos do Grupo Sacarose (GS) e do Grupo Água (GA) 106

Tabela 2 - Características da história de exposição a procedimentos dolorosos dos neonatos anterior às avaliações, no Grupo Sacarose (GS) e no Grupo Água (GA) 108

Tabela 3 - Características do procedimento de punção do Grupo Sacarose (GS) e Grupo Água (GA) nos quatro dias de avaliação.

Tabela 4 - Indicadores biocomportamentais de atividade facial (escore do NFCS), estado de vigília e sono e frequência cardíaca média, do Grupo Sacarose e Grupo Água, na fase de Linha de Base, nos quatro dias de avaliação

Tabela 5 - Indicadores biocomportamentais de atividade facial (escore do NFCS), estado de vigília e sono e frequência cardíaca média, do Grupo Sacarose e Grupo Água, na fase de Preparação para Punção, nos quatro dias de avaliação

Tabela 6 - Indicadores biocomportamentais de atividade facial (escore do NFCS), estado de vigília e sono e frequência cardíaca média, do Grupo Sacarose e Grupo Água, na fase de Punção, nos quatro dias de avaliação

Tabela 7 - Indicadores biocomportamentais de atividade facial (escore do NFCS), estado de vigília e sono e frequência cardíaca média, do Grupo Sacarose e Grupo Água, na fase de Recuperação com Manuseio, nos quatro dias de avaliação 
Tabela 8 - Indicadores biocomportamentais de atividade facial (escore do NFCS), estado de vigília e sono e frequência cardíaca média, do Grupo Sacarose e Grupo Água, na fase de Recuperação sem Manuseio, nos quatro dias de avaliação

Tabela 9 - Características de evolução clínica dos neonatos do Grupo Sacarose (GS) e do Grupo Água (GA), avaliadas desde o nascimento até as últimas 24 horas anteriores à primeira avaliação . 151

Tabela 10 - Características de evolução clínica dos neonatos do Grupo Sacarose (GS) e do Grupo Água (GA), avaliadas nas últimas 24 horas anteriores a cada dia de avaliação

Tabela 11 - Características de evolução clínica e de padrão de alimentação dos neonatos do Grupo Sacarose (GS) e do Grupo Água (GA), avaliadas durante o período de hospitalização 


\section{LISTA DE ABREVIATURAS E SIGLAS}

$\begin{array}{ll}\text { AIG } & \text { Adequado para a idade gestacional } \\ \text { CRIB } & \text { Clinical Risk Index for Babies } \\ \text { FMRP/USP } & \text { Faculdade de Medicina de Ribeirão Preto da } \\ & \text { Universidade de São Paulo } \\ \text { GA } & \text { Grupo Água } \\ \text { GIG } & \text { Grande para a idade gestacional } \\ \text { GN } & \text { Grupo Não Participante } \\ \text { GP } & \text { Grupo Participante } \\ \text { GS } & \text { Grupo Sacarose } \\ \text { HCFMRP/USP } & \text { Hospital das Clínicas da Faculdade de Medicina } \\ & \text { de Ribeirão Preto da Universidade de São Paulo } \\ \text { LB } & \text { Linha de Base } \\ \text { NFCS } & \text { Neonatal Facial Coding System } \\ \text { NIDCAP } & \text { Neonatal Individualized Developmental Care and } \\ & \text { Assessment Program } \\ \text { OMS } & \text { Organização Mundial de Saúde } \\ \text { P } & \text { Punção } \\ \text { PIG } & \text { Pequeno para a idade gestacional } \\ \text { PP } & \text { Preparação para Punção } \\ \text { RCM } & \text { Recuperação com Manuseio } \\ \text { RSM } & \text { Recuperação sem Manuseio } \\ \text { SNAP } & \text { Score for Neonatal Acute Physiology } \\ \text { SPSS } & \text { Statistical Package for Social Science } \\ \text { SUS } & \text { Sistema Único de Saúde } \\ \text { TCLE } & \text { Termo de Consentimento Livre e Esclarecido } \\ \text { USP } & \text { Universidade de São Paulo } \\ \text { UTIN } & \text { Unidade de Terapia Intensiva Neonatal } \\ & \end{array}$




\section{SUMÁRIO}

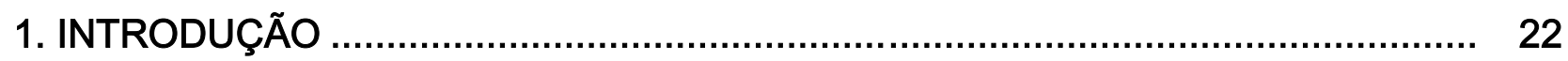

1.1. O nascimento pré-termo como fator de risco ao desenvolvimento ...................... 23

1.2. A Unidade de Terapia Intensiva Neonatal e as experiências de estresse e dor na trajetória inicial de desenvolvimento do neonato pré-termo............................ 37

1.3. Avaliação de dor em neonatos: instrumentos e medidas ............................... 54

1.4. Intervenção não-farmacológica para alívio da dor em neonatos ........................ 58

1.5. O uso da sacarose no alívio da dor em neonatos........................................ 61

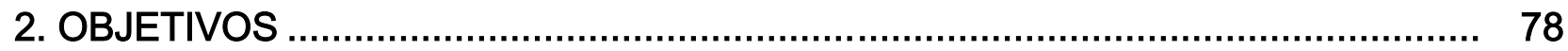

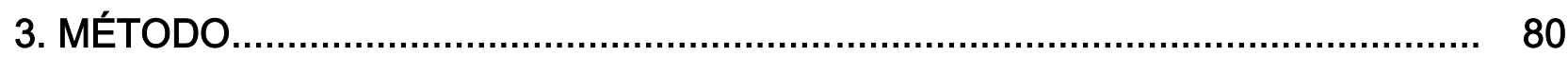

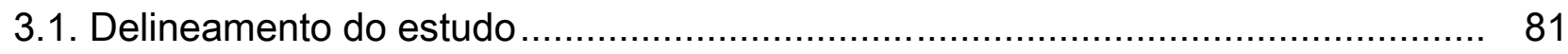

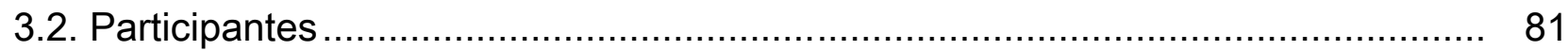

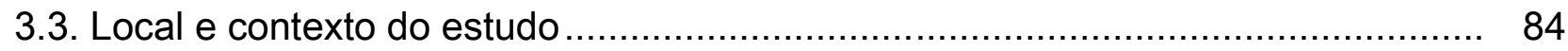

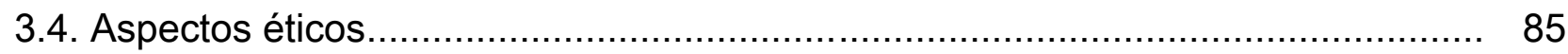

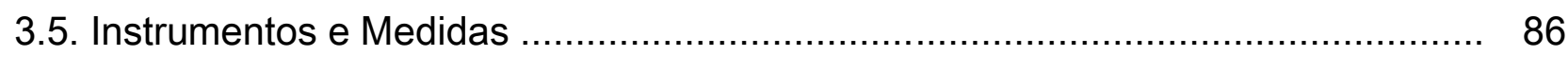

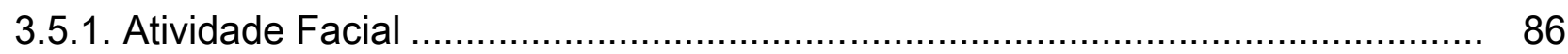

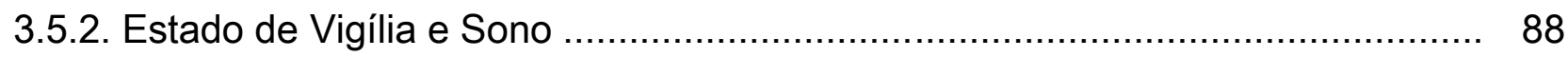

3.5.3. Frequência Cardíaca .......................................................................... 89

3.5.4. Prontuários do paciente ......................................................................... 89

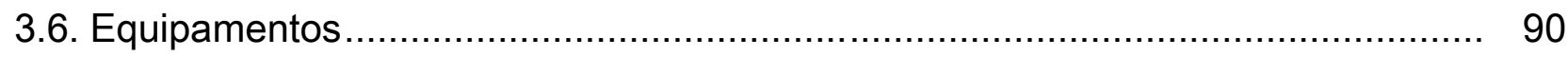

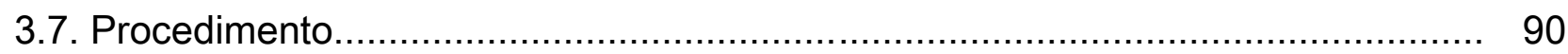

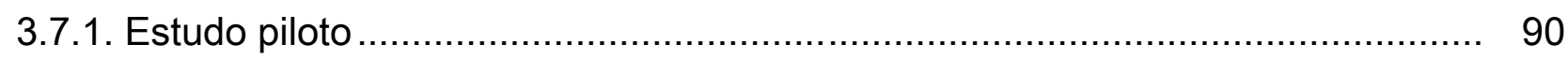

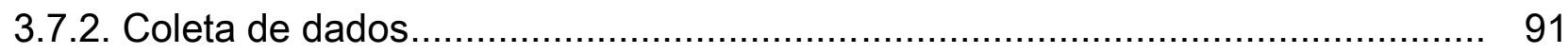

3.7.2.1. Esquema de coleta de dados .......................................................... 91

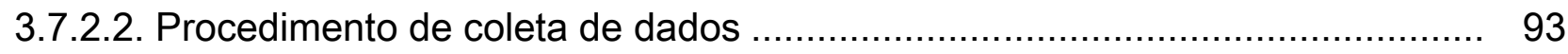

3.7.2.3. Coleta de dados do prontuário médico ............................................ 97

3.7.3. Preparação e Análise dos dados ...................................................... 99

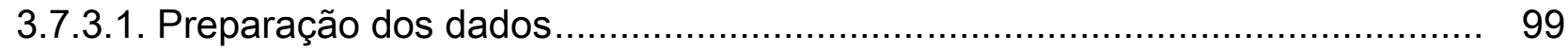

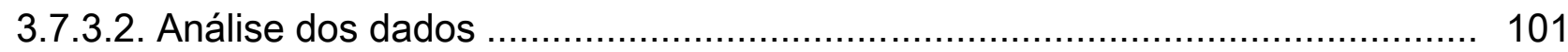

3.7.3.3. Tratamento estatístico dos dados .................................................... 102

4. RESULTADOS ................................................................................... 103

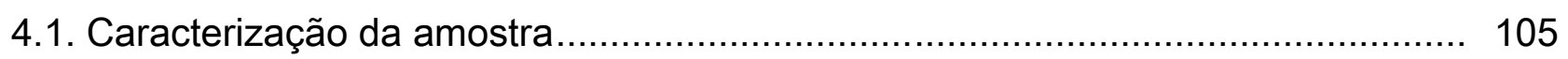


4.2. História de experiências dolorosas dos recém-nascidos do Grupo Sacarose e Grupo Água 107

4.3. Reatividade biocomportamental dos recém-nascidos à dor

4.3.1. Comparação entre os dias de avaliação, considerando-se cada fase e cada grupo

4.3.1.1. Linha de Base 112

4.3.1.2. Preparação para Punção 114

4.3.1.3. Punção 116

4.3.1.4. Recuperação com Manuseio 118

4.3.1.5. Recuperação sem Manuseio 120

4.3.2. Comparação entre as fases do procedimento de coleta de sangue de cada dia de avaliação.

4.3.2.1. Atividade Facial 123

4.3.2.2. Estado de Vigília e Sono 126

4.3.2.3. Frequência Cardíaca Média 130

4.3.3. Comparação entre os grupos Sacarose e Água, nos quatro dias de avaliação . 134

4.3.3.1. Atividade Facial 134

4.3.3.2. Estado de Vigília e Sono 138

4.3.3.3. Frequência Cardíaca Média

4.3.4. Indicador fisiológico de frequência cardíaca avaliado na fase de recuperação do primeiro dia de intervenção Grupo Sacarose / Grupo Água

4.4. Evolução clínica dos neonatos durante a hospitalização e possíveis efeitos colaterais advindos do uso da solução de sacarose.

5. DISCUSSÃO 157

6. CONSIDERAÇÕES FINAIS. 180

6.1. Considerações metodológicas 181

6.2. Desdobramentos para a prática. 186

6.3. Desdobramentos para a pesquisa - questões futuras. 188

REFERÊNCIAS BIBLIOGRÁFICAS. 189 APÊNDICES. 219

ANEXOS 235 


\section{PRÓLOGO}

A presente Tese de Doutorado está inserida na linha de pesquisa denominada "Sobrevivência, desenvolvimento e qualidade de vida de crianças nascidas pré-termo", a qual tem por objetivo integrar o conhecimento psicológico ao conhecimento médico acerca de questões sobre os efeitos do fator de risco biológico da prematuridade no desenvolvimento da criança. Esta linha de pesquisa teve início em 1996, sob a coordenação da Profa. Dra . Maria Beatriz Martins Linhares e do Prof. Dr. Francisco Eulógio Martinez, docentes da Faculdade de Medicina de Ribeirão Preto da Universidade de São Paulo.

A inserção da temática "Dor em recém-nascido pré-termo em Unidade de Terapia Intensiva Neonatal e desenvolvimento" nesta linha de pesquisa ocorreu em 2002, com o Pós-Doutorado realizado pela Profa. Dra. Maria Beatriz Martins Linhares, junto ao grupo de pesquisa da Profa. Dra. Ruth Grunau, na University of British Columbia e no British Columbia Children's Hospital, em Vancouver, Canadá.

O presente estudo também se vincula à linha de pesquisa "Dor, desenvolvimento e saúde mental da criança", que integra a produção de conhecimento científico do Laboratório de Pesquisa em Prevenção de Problemas de Desenvolvimento e Comportamento da Criança, coordenado pela Profa ${ }^{\text {. Dra }}$. Maria Beatriz Martins Linhares, e apoiado pelo Conselho Nacional de Desenvolvimento Científico e Tecnológico (CNPq). 
Desde o ano de 2003, até o presente momento, participo deste grupo de pesquisa. Inicialmente, realizei o treinamento em avaliação de dor em neonatos prétermo internados em Unidade de Terapia Intensiva Neonatal (UTIN), focalizando a coleta e análise de dados relacionados às respostas biocomportamentais de reatividade e recuperação à dor e ao estresse no período neonatal. De 2004 a 2006 realizei Mestrado em Ciências Médicas, na Área de Saúde Mental, como bolsista da Fundação de Amparo à Pesquisa do Estado de São Paulo (FAPESP).

No ano de 2006, iniciei o estudo de Doutorado, o qual procurou investigar a eficácia e segurança do uso continuado da solução de sacarose como uma intervenção não-farmacológica para o alívio da dor em recém-nascidos pré-termo internados em UTIN. A partir deste ano também passei a atuar como psicóloga junto à equipe multidisciplinar da UTIN do Hospital das Clínicas da Faculdade de Medicina de Ribeirão Preto da Universidade de São Paulo (HCFMRP/USP).

A Tese de Doutorado ora apresentada é uma continuidade do estudo de Mestrado intitulado "Dor em neonatos pré-termo em Unidade de Terapia Intensiva Neonatal: avaliação e intervenção com sacarose" (GASPARDO, 2006).

Assim, pretende-se com o presente estudo avançar no conhecimento sobre o uso de intervenções não-farmacológicas para o alívio da dor neonatal, contribuindo para a redução dos riscos ao desenvolvimento adaptativo futuro das crianças nascidas prematuras egressas da UTIN. 


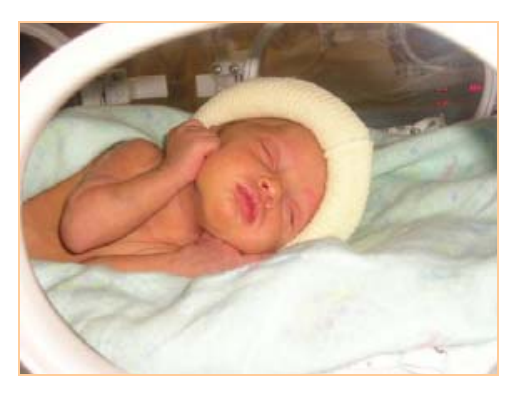

1. INTRODUÇÃO 
A introdução do presente estudo está organizada em cinco tópicos. O primeiro tópico aborda o nascimento pré-termo como fator de risco ao desenvolvimento. $\mathrm{O}$ segundo tópico apresenta características da Unidade de Terapia Intensiva Neonatal (UTIN) como primeiro microcontexto do desenvolvimento do recém-nascido prematuro, assim como as experiências de estresse e dor. O terceiro tópico focaliza os instrumentos e medidas na avaliação de dor em recém-nascidos. O quarto tópico aborda as intervenções não-farmacológicas para o alívio da dor em recém-nascidos. Por fim, o quinto tópico trata do uso da substância sacarose no alívio da dor agudaprocedural em recém-nascidos.

\subsection{O nascimento pré-termo como fator de risco ao desenvolvimento}

No nascimento de uma criança, a idade gestacional de 40 semanas e o peso ao nascer acima de 2.500 gramas constitui-se em variáveis biológicas importantes, relacionadas ao desenvolvimento sadio da criança, devido ao papel relevante que desempenham na maturidade de vários sistemas do organismo. Possíveis desvios em qualquer um desses parâmetros para fora da faixa de normalidade são considerados fatores de alto risco para complicações neonatais, além de consequentemente expor a criança a uma cadeia de eventos adversos ao seu crescimento físico e desenvolvimento pleno (AYLWARD, 2005; LINHARES et al., 2004; MINDE, 2000). 
A Organização Mundial de Saúde (OMS) classifica o recém-nascido, a partir da idade gestacional, em: recém-nascido pré-termo, quando o nascimento ocorre com menos de 37 semanas de gestação, recém-nascido a termo, quando o nascimento ocorre entre 37 e 42 semanas de gestação, e recém-nascido pós-termo, quando o nascimento ocorre com mais de 42 semanas de gestação. Em relação ao peso de nascimento, o recém-nascido pode ser classificado em recém-nascido baixo peso, quando nasce com peso inferior a 2.500 gramas, recém-nascido muito baixo peso, quando nasce com peso igual ou inferior a 1.500 gramas, e recém-nascido extremo baixo peso, quando nasce com peso igual ou inferior a 1.000 gramas (LIMA et al., 2006).

Um dos fatores principais de avaliação da dimensão do risco neonatal referese à relação entre a idade gestacional e o peso de nascimento, que classifica o recém-nascido em pequeno para a idade gestacional (PIG), adequado para a idade gestacional (AIG) e grande para a idade gestacional (GIG). O PIG, que corresponde aos neonatos com peso de nascimento abaixo do percentil 10 para a idade gestacional, representa um indicador clínico importante de morbidade neonatal, além de ser um fator de risco para mortalidade e atrasos no desenvolvimento (GOULART, 2004a).

Entretanto, Goulart (2004a) salienta que a idade gestacional e o peso ao nascimento não são parâmetros suficientes para a correta avaliação do risco de mortalidade e morbidade neonatal. Atualmente, os escores de risco neonatal estabelecidos para avaliar as condições fisiológicas do recém-nascido, o tipo e a 
intensidade terapêutica utilizada na conduta médica adotada nas primeiras horas após o nascimento são o Clinical Risk Index for Babies (CRIB) (INTERNATIONAL NEONATAL NETWORK, 1993), posteriormente revisado (CRIB II) (PARRY; TUCKER; TARNOW-MORDI, 2003) e o Score for Neonatal Acute Physiology (SNAP) (RICHARDSON et al., 1993), também posteriormente revisado (SNAP-II) (RICHARDSON et al., 2001). O CRIB é aplicável a crianças com peso ao nascer inferior a 1.500 gramas ou idade gestacional menor que 31 semanas e consiste na avaliação de seis itens fisiológicos, a saber: peso ao nascimento, idade gestacional, presença de anomalias congênitas, fração inspirada de oxigênio máxima e mínima e o pior déficit de base nas primeiras 12 horas após o nascimento. Um escore alto no CRIB, acima de quatro pontos, correlaciona-se com altas taxas de mortalidade e morbidade infantil (BRITO et al., 2003). O SNAP é aplicável a crianças com qualquer peso de nascimento e utiliza 34 medidas de sinais vitais e exames laboratoriais, que recebem pontuação de zero a cinco para a pior medida nas primeiras 24 horas após a admissão no hospital.

Além disso, um importante método de avaliação sistemática do recémnascido realizado frequentemente logo após o parto é o Índice de Apgar (APGAR, 1953), que avalia as condições fisiológicas e a capacidade de resposta do neonato. O teste é usualmente realizado no $1^{\circ}, 5^{\circ}$ e $10^{\circ}$ minutos de vida do recém-nascido e avalia os seguintes sinais: frequência cardíaca, esforço respiratório, tônus muscular, irritabilidade reflexa e coloração da pele. Para cada um dos cinco itens avaliados é atribuída uma pontuação que varia de zero a dois pontos, sendo que um escore total 
acima de oito pontos é considerado como ausência de risco neonatal, de quatro a sete pontos considera-se risco, sendo necessário a intervenção de cuidados especiais ao neonato, e para escores de zero a três pontos há a indicação de procedimento de ressuscitação imediato (PINHEIRO, 2009).

De acordo com Aylward (2002), uma adequada avaliação do risco neonatal para problemas no desenvolvimento futuro dos recém-nascidos deve considerar as características relacionadas ao nascimento (idade gestacional, peso de nascimento, índice de Apgar e índice de risco neonatal), os tipos de intervenções médicas necessárias durante a internação (procedimentos invasivos e dolorosos, intubação e aspiração endotraqueal, ventilação mecânica, cirurgias) e as sequelas no momento da alta hospitalar (necessidade de oxigênio e reinternações hospitalares, presença de déficit neurosensorial, broncodisplasia pulmonar, retinopatia da prematuridade).

O recém-nascido pré-termo representa a principal população atendida nas unidades de terapia intensiva neonatais. Quanto à etiologia do nascimento prematuro, Almeida (2003) classifica as principais causas como sendo obstétricas, como por exemplo, mães primigestas, mães jovens ou idosas, pequeno intervalo entre os partos, abortamento tardio prévio, história anterior de prematuridade, gravidez múltipla, parto cesáreo; causas ginecológicas, como a malformação uterina; e causas extratocoginecológicas, tais como desnutrição, falta de assistência prénatal, alcoolismo, tabagismo, uso de drogas, estresse, infecção vaginal, diabetes e hipertensão. 
Os avanços significativos na área da Neonatologia, em relação aos cuidados médico-hospitalares a recém-nascidos pré-termo com muito baixo peso ao nascimento, permitiram o aumento substancial da sobrevivência desta população em risco para problemas de saúde e desenvolvimento (GRUNAU; HOLSTI; PETERS, 2006; LORENZ, 2000). Em países desenvolvidos, a sobrevida de prematuros extremos aumentou significativamente a partir do final da década de 1980, devido à disponibilidade de surfactante exógeno e ao aumento da administração antenatal de corticosteróides. A estatística de sobrevida de prematuros extremos nascidos nos Estados Unidos e no Canadá na década de 1990 mostram que a sobrevida de recém-nascidos com idade gestacional entre 23 e 24 semanas variou de 5 a $68 \%$, com 25 semanas de 60 a $79 \%$, com 26 semanas de 75 a $87 \%$, com 27 semanas de 71 a $88 \%$ e com 28 semanas, de 87 a 91\% (GOULART, 2004b).

No Brasil, os dados mais recentes do Sistema Único de Saúde (SUS) mostram que, em 2008, para um total de 2.917 .432 nascidos vivos, $195.468(6,7 \%)$ bebês nasceram com menos de 37 semanas de gestação. Especificamente na Região Sudeste, de um total de 1.127 .424 nascidos vivos, 89.066 (7,9\%) bebês nasceram pré-termo. No Estado de São Paulo, de um total de 601.376 nascidos vivos, $49.312(8,2 \%)$ bebês nasceram pré-termo. No município de Ribeirão Preto, este índice sobe para 9,4\%, sendo que de um total de 7.668 nascimentos, 720 foram de neonatos pré-termo (BRASIL, 2009).

A Academia Americana de Pediatria define quatro categorias de variáveis biológicas e ambientais como fatores de risco na infância, a saber: o nascimento de 
um bebê prematuro, o nascimento de um bebê que necessite de suporte tecnológico; o nascimento de um bebê com problemas irreversíveis ou expectativa de morte, e um bebê que nasce em condições familiares adversas (AYLWARD, 2002). O recém-nascido prematuro e com baixo peso enquadra-se, no mínimo, em três dessas quatro categorias, o que os colocam em condição de múltiplo risco, uma vez que estão expostos involuntariamente a condições biológicas, psicológicas e sociais adversas que os tornam vulneráveis e em desvantagem para o desenvolvimento (LINHARES, 2009; RESEGUE; PUCCINI; SILVA, 2008). A prematuridade constitui-se em um fator de alto risco para problemas de saúde e desenvolvimento em crianças, especialmente as provenientes de famílias com risco psicossocial e baixo nível socioeconômico, situações estas que limitam o potencial das crianças para o pleno desenvolvimento (NURU-JETER et al., 2010; PRIOR et al., 2008).

De acordo com a abordagem teórico-conceitual da Psicopatologia do Desenvolvimento (LUTHAR; SAWYER; BROWN, 2006; MASTEN; GERWITZ, 2006; RUTTER; SROUFE, 2000; SAMEROFF, 2000), os fatores de risco consistem em influências estressoras e adversas ao desenvolvimento do organismo, podendo ser de natureza biológica, psicológica ou social, e identificados tanto no indivíduo como no ambiente, ou ainda resultantes da combinação entre ambos (MASTEN; GERWITZ, 2006).

Os efeitos negativos dos fatores de risco podem ser identificados em diversos indicadores de desenvolvimento, bem como nos processos psicológicos de 
autorregulação emocional e cognitiva do indivíduo (SAMEROFF, 2010). Além disso, quando se tem o risco identificado no indivíduo, constitui-se uma condição de vulnerabilidade deste para o enfrentamento das tarefas evolutivas que estarão presentes na sua trajetória de desenvolvimento (HALPERN; FIGUEIRAS, 2004; LINHARES, 2009; RUTTER, 2006; SAMEROFF; ROSENBLUM, 2006).

Muitos estudos que avaliam a trajetória de desenvolvimento de crianças nascidas pré-termo indicam que, quando comparadas às crianças nascidas a termo, aquelas são mais propensas a apresentar atraso neurocomportamental (BARBOSA; FORMIGA; LINHARES, 2007; BRUGGINK et al., 2008; HALPERN et al., 2000, 2002; MARTINS; LINHARES; MARTINEZ, 2005; TAYLOR et al., 2006), problemas cognitivos (ANDERSON et al., 2004; do ESPÍRITO SANTO; PORTUGUEZ, NUNES; 2009; HACK et al., 2005; JOHNSON, 2007; LINHARES et al., 2005; LUU et al., 2009; NEUBAUER; VOSS; KATTNER, 2008; RUGOLO, 2005; WOLKE et al., 2008), dificuldade de linguagem (LUU et al., 2009; WOLKE et al., 2008), problemas de aprendizagem (CARVALHO; LINHARES; MARTINEZ, 2001; MARLOW et al., 2005; SALT; REDSHAW, 2006; SPITTLE et al., 2009; WOLKE et al., 2008), dificuldades comportamentais (BORDIN; LINHARES; JORGE, 2001; do ESPÍRITO SANTO; PORTUGUEZ; NUNES, 2009; HACK et al., 2009; JOHNSON, 2007; SAMARA; MARLOW; WOLKE, 2008) e problemas emocionais (WHITFIELD; GRUNAU, 2000).

A partir de uma revisão sistemática da literatura, de estudos publicados de 2000 a 2007, sobre o desenvolvimento de crianças nascidas prematuras, Zomignani, Zambelli e Antonio (2009) identificaram que, em comparação à população nascida a 
termo, os recém-nascidos prematuros apresentaram alterações anatômicas cerebrais que estão diretamente relacionadas a prejuízos cognitivos. Além disso, crianças nascidas prematuras, avaliadas na infância e adolescência, demonstraram dificuldades de memorização, de planejamento, déficit motor e de atenção.

No estudo de Gray, Indurkhya e McCormick (2004), verificou-se uma prevalência de aproximadamente $20 \%$ de problemas de comportamento em crianças nascidas pré-termo com muito baixo peso nas idades de três, cinco e oito anos, sendo esta prevalência o dobro da população geral. Além disso, os autores encontraram que o nascimento abaixo de 1.000 gramas aumentou o risco para prejuízos neurodesenvolvimentais da criança na idade escolar.

Em um estudo longitudinal, Hack et al. (2005) examinaram as condições neurosensoriais, de desenvolvimento e de saúde de crianças aos oito anos de idade que nasceram prematuras com extremo baixo peso e as compararam com crianças nascidas a termo. As crianças nascidas prematuras apresentaram significativamente maior necessidade de cuidados especiais à saúde, devido a diagnósticos de paralisia cerebral, asma e baixa visão, além de maior limitação nas habilidades motoras e acadêmicas em comparação às crianças nascidas a termo.

Com o objetivo de verificar o crescimento, desenvolvimento motor e cognitivo e desempenho escolar em crianças nascidas pré-termo, aos sete anos de idade, Cooke e Foulder-Hughes (2003) avaliaram crianças que nasceram com 32 semanas de idade gestacional e as compararam com crianças nascidas a termo. Os resultados indicaram que as crianças nascidas prematuras apresentavam tanto 
menos peso e baixa estatura quanto pior desempenho na avaliação cognitiva, ao serem comparadas às crianças nascidas a termo.

Pode-se observar, portanto, que muitos estudos avaliam indicadores de desenvolvimento em crianças nascidas pré-termo. Atualmente, os estudos buscam avaliar, além desses indicadores, os processos psicológicos no desenvolvimento de crianças nascidas prematuras. Dentre os processos psicológicos de desenvolvimento nos quais as crianças nascidas pré-termo encontram-se mais vulneráveis, são destacados como principais a autorregulação fisiológica, emocional e comportamental (CLARK et al., 2008; FELDMAN, 2009; KLEIN et al., 2009), a atenção (LUU et al., 2009; VAN DE WEIJER-BERGSMA; WIJNROKS; JONGMANS, 2008) e a função executiva (BAYLESS; STEVENSON, 2007; SUN; MOHAY; O'CALLAGHAN, 2008; TAYLOR et al., 2006).

Nos estudos sobre autorregulação, realiza-se a avaliação do temperamento, que pode ser entendido, a partir de uma abordagem psicobiológica, como diferenças individuais estáveis que aparecem a partir do nascimento, com forte base genética e neurobiológica, influenciadas ao longo do tempo tanto pela maturação fisiológica como pela experiência (ROTHBART; BATES, 2006). O temperamento destaca-se entre as variáveis da pessoa que exercem influência relevante no desenvolvimento e se relacionam a desfechos adaptativos ou desadaptativos (CALKINS, 2009).

O estudo prospectivo-longitudinal de Klein (2009) acompanhou 38 neonatos pré-termo, desde o nascimento até a fase pré-escolar, a fim de avaliar o temperamento das crianças por meio de entrevistas com as mães com a aplicação 
dos questionários Early Childhood Behavior Questionnaire e Children's Behavior Questionnaire, e o comportamento das crianças por meio de entrevistas com as mães com a aplicação do questionário Child Behavior Checklist $11 / 2-5$. Os resultados mostraram que o menor peso ao nascimento foi preditor de características de temperamento com maior dimensão do afeto negativo e de problemas de comportamento, do tipo atenção, reação emocional e sono, nas crianças nascidas pré-termo em fase pré-escolar. Além disso, as crianças nascidas pré-termo apresentaram temperamento com mais sensibilidade perceptual, prazer com estímulos de alta intensidade e ativação motora, menos aconchego ao cuidador e mais problemas de atenção quando comparadas a crianças nascidas a termo. Neste estudo, o fator prematuridade mostrou influência tanto no comportamento quanto nos processos de regulação das crianças, avaliados por meio do temperamento.

Por outro lado, na interação entre o organismo e o ambiente, atuam recursos do próprio indivíduo, bem como mecanismos protetores advindos dos contextos de desenvolvimento que podem neutralizar os efeitos dos riscos e adversidades ao desenvolvimento adaptativo do indivíduo (LUTHAR; SAWYER; BROWN, 2006; MASTEN; GERWITZ, 2006; RUTTER; SROUFE, 2000; SAMEROFF, 2010). A compreensão do desenvolvimento de uma criança nascida com o risco estabelecido, como o da prematuridade, requer a adoção da perspectiva desenvolvimental, que permite identificar e analisar o interjogo entre fatores de risco e mecanismos de proteção presentes nos diferentes contextos de desenvolvimento. Desse modo, os 
fatores facilitadores do desenvolvimento precisam ser ativados e os complicadores neutralizados, tanto no indivíduo quanto no seu contexto ambiental de desenvolvimento (LINHARES et al., 2004).

Dessa forma, apesar de crianças nascidas prematuras terem maior probabilidade para apresentar problemas de desenvolvimento, a presença de fatores protetores, identificados na criança, no meio ambiente, ou na interação entre eles, pode modificar os efeitos adversos da prematuridade, desencadeando um desfecho desenvolvimental positivo (GUTMAN; SAMEROFF; COLE, 2003; LUTHAR; SAWYER; BROWN, 2006).

Para a melhor compreensão dos processos envolvidos na relação entre fatores de risco e mecanismos de proteção na trajetória de desenvolvimento, têm-se destacados os processos de regulação, os quais amadurecem ao longo do desenvolvimento, especialmente nos primeiros seis anos de idade (FELDMAN, 2009; SAMEROFF, 2009).

O amadurecimento dos processos de autorregulação, segundo Olson et al. (2009), desenvolve-se da seguinte maneira: a) do nascimento aos três meses de idade, o controle toma a forma de modulação dos estados de alerta fisiológicos, como reatividade emocional aos estímulos sensoriais, incluindo duração e intensidade do choro, tempo para se recuperar, capacidade para se acalmar e resposta do hormônio cortisol frente a estímulos estressores; b) entre os três e 12 meses de idade, os bebês apresentam um aumento na capacidade de ajustar suas respostas afetivas, de atenção e de comportamento motor voluntário de forma 
dirigida ao alcance de objetivos; c) nos três primeiros anos de vida, as crianças tornam-se conscientes das demandas sociais e são capazes de ajustar seus comportamentos de acordo com estas demandas, devido ao amadurecimento rápido de suas habilidades cognitivas e motoras; d) nos anos pré-escolares, a criança torna-se cada vez mais capaz de automonitorar o seu comportamento em resposta a diferentes demandas situacionais.

Sendo assim, considerando que o desenvolvimento das capacidades de autorregulação faz parte de um processo maturacional normativo, é esperado que fatores que afetam de maneira positiva ou negativa o desenvolvimento da criança, como o nascimento prematuro, sejam capazes de influenciar os processos maturacionais relacionado à autorregulação (KEENAN et al., 2009, KLEIN; GASPARDO; LINHARES, no prelo; KLEIN; LINHARES, 2007, 2010; SAMEROFF, 2010).

As trajetórias resultantes em desenvolvimento adaptativo, na presença de fatores de risco, envolvem o processo de resiliência, que consiste em um processo dinâmico por meio do qual as adaptações positivas podem ser alcançadas em contextos de adversidade (LUTHAR; SAWYER; BROWN, 2006; MASTEN; OBRADOVI'C, 2006; YUNES; ZYMANSKI, 2001). O conceito de resiliência refere-se à combinação entre experiências adversas e desenvolvimento psicológico posterior positivo, inferido a partir do interjogo entre os fatores de risco e os mecanismos de proteção (RUTTER, 2006). A resiliência ocorre quando se tem a exposição do indivíduo a uma ameaça significativa ou a uma adversidade grave, e a concretização 
de uma adaptação efetiva, apesar do dano em potencial que ameaça o desenvolvimento deste indivíduo.

Dessa forma, além da adequada avaliação dos aspectos relacionados ao desenvolvimento das crianças nascidas pré-termo, também é de grande importância a avaliação de condições do contexto ambiental que podem influenciar positiva, ou negativamente, a trajetória de desenvolvimento dessas crianças (LINHARES et al., 2006; LINHARES, 2009). Por exemplo, em um conjunto de estudos sobre o desenvolvimento de bebês nascidos pré-termo, integrantes de programas de seguimento longitudinal do desenvolvimento no primeiro ano de idade corrigida para a prematuridade, revelou que estes, em sua maioria, apresentavam indicadores de desenvolvimento mental, motor e comportamental dentro da faixa da normalidade (NOBRE et al., 2009; FRAGA et al., 2008a, 2008b; LINHARES et al., 2003; VOLPI et al., 2010).

Nobre et al. (2009) avaliaram indicadores de desenvolvimento de 30 crianças nascidas pré-termo, inseridas em um programa de seguimento longitudinal do desenvolvimento psicológico de prematuros, por meio da aplicação do Teste de Triagem do Desenvolvimento Infantil Denver II, e encontraram que apenas $20 \%$ das crianças na faixa de cinco a sete meses e $27 \%$ das crianças na faixa de 10 a 14 meses de idade corrigida para a prematuridade apresentaram risco para problemas de desenvolvimento. Entretanto, as crianças nascidas com menor peso e idade gestacional, que permanecem mais tempo hospitalizadas e com situações familiares adversas apresentaram mais problemas de desenvolvimento. 
Em um recente estudo, Volpi et al. (2010) tiveram por objetivo determinar as idades cronológica e corrigida para a prematuridade de aquisição das habilidades motoras até a marcha independente, em bebês nascidos prematuros com muito baixo peso, em um ambulatório de seguimento de bebês de alto risco. Os resultados revelaram que os bebês prematuros controlaram a cabeça no segundo mês, sentaram sem apoio aos sete meses e andaram com 12 meses de idade corrigida para a prematuridade, correspondendo, respectivamente, ao $4^{\circ}, 9^{\circ}$ e $15^{\circ}$ meses de idade cronológica. Além disso, bebês que nasceram pequenos para a idade gestacional adquiriram suas habilidades mais tardiamente, porém dentro do limite de idade esperado.

Portanto, de acordo com a abordagem da Psicopatologia do Desenvolvimento, considera-se importante compreender as desordens de adaptação do indivíduo, focalizando os intercâmbios probabilísticos entre dinâmicas individuais e dinâmicas dos contextos que compreendem o comportamento humano, sem estabelecer predições deterministas, isomórficas e relações de causa e efeito (ACHENBACH, 1992; RUTTER, 2006; SAMEROFF, 2009). Frente à adversidade do nascimento prematuro, que torna o neonato vulnerável, deve-se levar em conta a análise dos fatores de risco e mecanismos protetivos que auxiliem o enfrentamento das adversidades, possibilitando a sua regulação fisiológica, emocional e comportamental. O recém-nascido prematuro tem características neurodesenvolvimentais semelhantes às do feto, porém diferentemente deste, que 
se encontra protegido pelo útero materno, deve enfrentar no início da vida o ambiente de múltiplos estímulos da Unidade de Terapia Intensiva Neonatal.

1.2. A Unidade de Terapia Intensiva Neonatal e as experiências de estresse e dor na trajetória inicial de desenvolvimento do neonato pré-termo

A trajetória de desenvolvimento do recém-nascido pré-termo fora da vida uterina inicia-se no microcontexto hospitalar de uma Unidade de Terapia Intensiva Neonatal (UTIN), devido à sua necessidade de receber cuidados intensivos de alta complexidade durante as primeiras semanas ou meses de vida, visto que suas funções fisiológicas ainda não estão amadurecidas suficientemente para sobreviver no ambiente externo (GLASS, 1999).

O neonato pré-termo de muito baixo peso necessita das condições especiais da UTIN para sobreviver, fazendo com que esta seja o seu primeiro contexto de desenvolvimento. De forma paradoxal, ao mesmo tempo em que a UTIN constitui-se em um ambiente de cuidado e proteção ao recém-nascido, também se apresenta como um fator de risco ao desenvolvimento devido aos múltiplos estímulos que provocam dor, estresse e desconforto aos neonatos hospitalizados (ANAND et al., 2006; ANAND; WHIT HALL, 2007; GRUNAU, 2002; GRUNAU; HOLSTI; PETERS, 2006; GRUNAU; TU, 2007; LINHARES et al., 2006). A assistência médica a neonatos pré-termo, especialmente os de peso muito baixo, envolve intervenções invasivas e dolorosas repetidas, as quais ocorrem em um contexto de estresse 
crônico e podem causar dano no desenvolvimento do sistema nervoso do recémnascido (ANAND et al., 2006; COUPERUS; NELSON, 2006; GOFFAUX, et al., 2008; SIMONS; TIBBOEL, 2006; VAN DE VELDE et al., 2006).

Durante esta permanência na UTIN, o neonato pré-termo que se apresenta imaturo, desorganizado e desintegrado em várias funções e sistemas do seu organismo relevantes para o seu desenvolvimento, fica exposto a uma gama de estímulos externos adversos, totalmente diferentes dos experimentados intra-útero, tais como ruído, luminosidade, manipulação e dor, além da separação materna que o priva do contato físico prazeroso pele a pele e da alimentação natural por meio da amamentação (GOULART, 2004b).

Esta estimulação inicial, necessária para investigação diagnóstica ou tratamento, porém aversiva, torna-se preocupante uma vez que neonatos prematuros com menos de 32 semanas de idade gestacional passam na UTIN a maior parte do tempo que corresponderia ao terceiro trimestre de gestação, período sensível em que ocorre um acelerado desenvolvimento cerebral e diferenciação neuronal (COUPERUS; NELSON, 2006; GRUNAU, 2000; LINHARES et al., 2004; STEVENS; ANAND; McGRATH, 2007).

Com o objetivo de quantificar eventos estressores comumente encontrados em UTIN, Newnham, Inder e Milgrom (2009) entrevistaram médicos e enfermeiros de unidades de terapia intensiva neonatais, e identificaram a existência de pelo menos 44 eventos agudos estressores e 24 eventos crônicos estressores realizados em recém-nascidos prematuros hospitalizados em UTIN. Dentre os eventos 
estressores agudos foram destacados lancetagem de calcâneo, acesso venoso periférico e central, acesso arterial periférico, inserção de dreno, punção lombar, punção para coleta de sangue, aspiração, alimentação, exame ocular, cirurgia, radiografia e remoção do neonato da incubadora. Dentre os eventos estressores crônicos foram citados necessidade de ventilação assistida e ocorrência de infecção.

No contexto da UTIN, a experiência de dor é considerada uma das principais condições de estresse para os recém-nascidos prematuros fisiologicamente imaturos (GRUNAU, HOLSTI, PETERS, 2006; LINHARES, 2009). Estudos recentes têm mostrado que mesmo fetos por volta de 18 a 20 semanas de idade gestacional apresentam reações fisiológicas e comportamentais à dor e ao estresse (ANAND; WHIT HALL, 2007; VAN DE VELDE et al., 2006).

Pesquisas realizadas a partir da década de 1990 evidenciaram que recémnascidos possuem um sistema nervoso central mais maduro do que concebido anteriormente (STEVENS; GIBBINS; FRANCK, 2000). Uma das medidas de se comprovar a maturação funcional cerebral, ainda no período fetal, envolve a análise de períodos bem definidos dos estados de vigília e sono, que regulam o funcionamento cortical desde a $28^{a}$ semana de idade pós-concepcional (FELDMAN, 2009; GLASS, 1999).

$\mathrm{Na}$ UTIN, a estimulação frequente e em nível excessivo interfere na autorregulação dos padrões de vigília e sono do recém-nascido. Neonatos pré-termo nascidos com menos de 33 semanas de idade gestacional apresentam 
predominância de sono ativo nas primeiras semanas de idade pós-natal (GLASS, 1999).

Os recém-nascidos, incluindo os nascidos pré-termo, exibem respostas bioquímicas, fisiológicas e comportamentais em reação a procedimentos invasivos e dolorosos (ANAND; WHIT HALL, 2007; GRUNAU et al., 2005; LUCAS-THOMPSON et al., 2008). O substrato anatômico que liga receptores sensitivos dos tecidos ao córtex sensitivo e transmite o impulso nociceptivo surge na vida fetal precoce e durante os primeiros meses de vida pós-natal. A densidade das fibras nociceptivas cutâneas na fase final do período fetal e no neonato é igual ou excede à do adulto, e a dimensão do campo receptivo é semelhante à do adulto (OKADA; TEIXEIRA, 2003).

Embora as vias transmissoras do estímulo doloroso não estejam ainda mielinizadas no feto durante o segundo e terceiro trimestre de gestação, sendo completamente mielinizadas entre a $30^{a}$ e $37^{a}$ semanas de idade gestacional, as fibras nervosas são capazes de conduzir os estímulos dolorosos. A mielinização incompleta ao nascimento não implica em ausência de função, mas em velocidade de condução lenta no trajeto do sistema nervoso central. Sabe-se, no entanto, que no recém-nascido o impulso nervoso percorre uma trajetória de curta distância, o que acaba compensando essa lentidão da transmissão do estímulo (STEVENS; GIBBINS; FRANCK, 2000; SLATER; FITZGERALD; MEEK, 2007).

Os recém-nascidos possuem capacidade neurológica para perceber a dor, mesmo os recém-nascidos prematuros (BARTOCCl et al., 2006). O sistema 
neurobiológico necessário à nocicepção apresenta-se formado entre a $24^{\mathrm{a}}$ a $28^{\mathrm{a}}$ semanas de gestação e as estruturas periféricas e centrais estão presentes e funcionais precocemente na gestação, entre o primeiro e segundo trimestre (GRUNAU, 2002). A partir da $24^{a}$ semana de idade gestacional são identificados neurônios e vias nervosas suficientes para processar a sensação dolorosa no tronco encefálico. Além disso, neurotransmissores relacionados à nocicepção também estão presentes entre a $8^{\mathrm{a}}$ e $14^{\mathrm{a}}$ semana de idade gestacional no feto humano, o que significa capacidade de transmissão de estímulos nociceptivos no cérebro do recém-nascido (GLOVER; FISK, 1999; OKADA, TEIXEIRA, 2003).

Muitos dos componentes neuroanatômicos, fisiológicos e neuroquímicos necessários para o processamento da dor desenvolvem-se durante a gestação, mas não estão totalmente organizados ao nascimento (ANAND et al., 2006; FRANK; MIAKOWSKI, 1997). Os sistemas inibitórios, por exemplo, tornam-se funcionais apenas após as primeiras semanas de vida pós-natal, talvez devido aos baixos níveis de neurotransmissores, ou à baixa atividade dos receptores, o que torna possível haver maior sensibilidade fetal aos estímulos externos dolorosos do que em lactentes. A transmissão do impulso doloroso nos neonatos ocorre inicialmente ao longo das fibras $C$ não mielinizadas em relação às fibras mielinizadas A-delta. Existe menos precisão na transmissão do sinal de dor na medula espinal e faltam os neurotransmissores descendentes. Dessa forma, os recém-nascidos podem perceber a dor mais intensamente do que crianças ou adultos, porque os mecanismos de controle inibitórios são imaturos, limitando sua sensibilidade para 
modular a experiência dolorosa (OKADA, TEIXEIRA, 2003; SLATER; FITZGERALD; MEEK, 2007; VAN DE VELDE et al., 2006).

Os neonatos apresentam a capacidade de responder à estimulação dolorosa, entretanto, esta resposta aparece de uma maneira exagerada e inespecífica, quando comparada à do adulto (FITZGERALD, 1995). A imaturidade do sistema nervoso central do neonato pré-termo resulta, portanto, em dificuldades de enfrentamento da dor e do estresse experimentados na UTIN (ALS et al., 2004).

Muitas vezes, a dor encontra-se inerente aos procedimentos de tratamento intensivo a que os recém-nascidos pré-termo são submetidos enquanto internados na UTIN. Segundo Anand et al. (2006), estudos mostram que neonatos que necessitam de cuidado intensivo podem receber de cinco a 15 procedimentos invasivos e dolorosos ao dia, do tipo punção, introdução de cânula venosa ou arterial, intubação e sucção.

No estudo de Barker e Rutter (1995) foram observados cerca de 3.000 procedimentos invasivos, realizados em 54 bebês durante o período de internação na UTIN, sendo que $74 \%$ desses bebês tinham menos de 31 semanas de idade pósconcepcional. Porter, Wolf e Miller (1998) encontraram que 144 recém-nascidos passaram por mais de 7.000 procedimentos dolorosos desde a admissão até a alta da UTIN, sendo que a maioria destes procedimentos (87\%) era de punção para coleta de sangue. Neonatos com menos de 32 semanas de idade gestacional podem receber, como parte necessária ao seu tratamento médico para assegurar sua sobrevivência, aproximadamente seis procedimentos dolorosos por dia nas 
primeiras semanas de internação na UTIN, podendo chegar a 18 procedimentos dolorosos por dia (GASPARDO; CHIMELLO et al., 2008).

A avaliação de dor em recém-nascidos deve incluir parâmetros fisiológicos, bioquímicos e comportamentais. As respostas fisiológicas do recém-nascido prétermo ao estímulo doloroso agudo são mensuradas por alterações nos sinais vitais tais como frequência cardíaca, frequência respiratória, pressão arterial e saturação de oxigênio (FRANCK; MIAKOWSKI, 1997; BALDA; GUINSBURG, 2004). As respostas bioquímicas relacionam-se ao aumento no nível de cortisol, do hormônio do crescimento e do hormônio antidiurético, além de diminuição da secreção de insulina. As respostas comportamentais aos estímulos dolorosos agudos, por sua vez, são mensuradas pelo movimento motor amplo, reflexo de flexão, estados de vigília e sono, choro e mímica facial (MATHEW; MATHEW, 2003).

Estudos recentes têm demonstrado que os neonatos pré-termo possuem as conexões neuronais necessárias para apresentar ativação cortical durante procedimento doloroso de coleta de sangue (BARTOCCI et al., 2006; SLATER et al., 2006). Após um procedimento de lancetagem de calcâneo, neonatos a partir de 25 semanas de idade pós-concepcional exibiram aumento na concentração de hemoglobina em ambos os hemisférios do córtex somatosensorial, acompanhado de aumento na frequência cardíaca e na atividade facial e diminuição na saturação de oxigênio (BARTOCCl et al., 2006; SLATER et al., 2008).

Além disso, a estimulação tátil não dolorosa para a antissepsia também produziu aumento na concentração de hemoglobina em ambos os hemisférios 
cerebrais, sem produzir mudanças na frequência cardíaca e na saturação de oxigênio (SLATER et al., 2008). A magnitude das respostas dos neonatos aumentou de acordo com a idade gestacional e foi modulada pelo estado comportamental de vigília e sono, ou seja, os neonatos que estavam acordados no momento do procedimento doloroso apresentaram maior resposta de ativação cortical do que neonatos que estavam dormindo. Foi identificado também um decréscimo de latência dos picos de resposta de dor com o aumento da idade gestacional, que foi atribuído à mielinização imatura das trajetórias sensoriais, ao funcionamento imaturo das sinapses e ao pequeno diâmetro dos axônios em neonatos mais imaturos. Apesar da maior latência, as respostas corticais dos neonatos com menor idade gestacional estavam bem definidas (SLATER et al., 2006). As respostas hemodinâmicas no córtex somatosensorial eliciadas por estímulos dolorosos indicam que as respostas à nocicepção alcançam centros cerebrais superiores e não são simplesmente limitadas a respostas reflexas no nível da medula espinhal. (SLATER; FITZGERALD; MEEK, 2007).

Para a melhor compreensão da reatividade à dor dos recém-nascidos prétermo, estudos buscaram avaliar os efeitos de variáveis do organismo, tais como sexo, idade gestacional e índice de gravidade clínica, e de variáveis do contexto ambiental, como as experiências iniciais de dor e estresse ocorridas na UTIN, nas respostas de dor desses neonatos (BALDA; GUINSBURG, 2004; BARTOCCl et al., 2006; EVANS et al., 2005; GIBBINS; STEVENS; BEYENE et al., 2008; GIBBINS; STEVENS; McGRATH et al., 2008; GUINSBURG et al., 2000; GRUNAU et al., 2005, 
2007; HOLSTI et al., 2004, 2005, 2006; STEVENS; FRANCK et al., 2007; STEVENS; McGRATH et al., 2007; VALERI, 2007; WILLIAMS et al., 2009).

No estudo de Bartocci et al. (2006), recém-nascidos pré-termo meninos apresentaram maior reatividade à dor do que meninas durante procedimento de punção venosa. Porém, outros estudos não encontraram diferença entre os sexos na reatividade à dor de recém-nascidos pré-termo (GIBBINS; STEVENS; BEYENE et al., 2008; GRUNAU et al., 2007; HOLSTI et al., 2004, 2006).

Em relação à idade gestacional, Gibbins, Stevens, McGrath et al. (2008) avaliaram reatividade à dor em uma amostra de 161 neonatos, estratificada em quatro grupos, a saber: de 23 a 27 semanas, de 28 a 31 semanas, 32 a 35 semanas, e de 36 a 38 semanas de idade gestacional. Os recém-nascidos dos dois grupos de menor idade gestacional mostraram menor escore de atividade facial e nível de saturação de oxigênio, e maior frequência cardíaca em relação aos recémnascidos dos demais grupos durante procedimento de punção capilar para coleta de sangue.

O estudo de Grunau et al. (2005) analisou a relação entre exposição à dor e reatividade e encontrou que, em neonatos de idade gestacional menor do que 28 semanas, maior exposição à dor foi relacionada significativamente à menor resposta de cortisol plasmático ao estresse e à menor reatividade facial na $32^{\mathrm{a}}$ semana de idade pós-concepcional corrigida para a prematuridade. No grupo de idade gestacional maior do que 28 semanas, maior gravidade clínica foi associada significativamente à menor frequência cardíaca. No grupo de menor idade 
gestacional, após o controle da gravidade clinica e da exposição à morfina, maior exposição à dor neonatal predisse menor resposta ao cortisol. Além disso, após o controle da gravidade clínica, maior número de procedimentos dolorosos após o nascimento predisse menor atividade facial em resposta à dor.

Com o objetivo de verificar as respostas comportamentais e fisiológicas de dor em neonatos pré-termo com muito baixo peso internados em UTIN, em grupos diferenciados tanto quanto ao sexo, como quanto à idade gestacional, Valeri (2007) avaliou as respostas de atividade facial, estado de vigília e sono e frequência cardíaca de 55 neonatos, antes, durante e após uma situação de coleta de sangue. Os resultados deste estudo mostraram que os meninos tenderam a chorar mais do que as meninas no período de recuperação, após o procedimento doloroso. Além disso, observou-se que os neonatos que nasceram com idade gestacional entre 32 a 35 semanas tenderam a apresentar maior reação de dor durante a recuperação do procedimento doloroso em relação aos neonatos que nasceram com idade gestacional abaixo de 32 semanas.

As experiências iniciais e repetidas de dor podem ter efeitos em médio e longo prazo para os recém-nascidos vulneráveis (ANAND, 2000; GRUNAU, 2000; GOFFAUX et al., 2008; SIMONS; TIBBOEL, 2006; VAN DE VELDE et al., 2006; WALKER et al. 2009), tais como diminuição do limiar de dor (GIBBINS; STEVENS; ASZTALOS, 2003; GRUNAU, 2002; HERMANN et al., 2006) e hiperalgesia, caracterizada pelo aumento da dor proveniente do local de uma lesão (ANAND, 1998; GRUNAU, 2002; TADDIO et al., 2009). Procedimentos repetidos, como por 
exemplo, lancetagem do calcâneo, diminuem o limiar do reflexo flexor nos neonatos e geram hiperalgesia secundária, caracterizada por dor proveniente dos tecidos circunvizinhos não danificados, desencadeando respostas comportamentais mais intensas, como retirada rápida do membro e movimentos difusos e globais. A hiperalgesia e a alodínia, caracterizada por dor proveniente de estímulos não dolorosos no local ou ao redor de uma lesão (GOUBET; CLIFTON; SHAH, 2001; REYNOLDS; FITZGERALD, 1995), podem ser claramente demonstrados em neonatos pré-termo extremos após uma lesão tecidual (OKADA, TEIXEIRA, 2003).

O nível de estresse foi avaliado por Grunau, Weinberg e Whitfield (2004), por meio do indicador de cortisol salivar em bebês com oito meses de idade corrigida para a prematuridade em uma fase de linha de base e após a introdução de um novo brinquedo. Nos bebês que nasceram pré-termo, com idade gestacional extremamente baixa, o nível de cortisol foi significativamente mais alto, antes e após a introdução do brinquedo, em relação aos bebês que nasceram com idade gestacional maior e a termo. Esse comportamento hiper-reativo foi associado ao alto número de procedimentos dolorosos a que foram submetidos os bebês nascidos prematuramente, mesmo tendo passado oito meses após o nascimento.

O estudo de Klein et al. (2009), acompanhou longitudinalmente 26 neonatos pré-termo com muito baixo peso, do nascimento à fase pré-escolar, e verificou que a maior reatividade à dor e estresse no período neonatal foi preditora de dimensões do temperamento com mais afeto negativo e impulsividade e menos sociabilidade na fase dos três primeiros anos de idade, demonstrando que a reatividade 
biocomportamental à dor avaliada nos neonatos pré-termo consiste em um precursor de processos de autorregulação desenvolvimentais expressos no temperamento, o qual por sua vez foi preditor de problemas de atenção na fase pré-escolar.

$\mathrm{Na}$ fase escolar, tanto crianças nascidas pré-termo quanto crianças nascidas a termo que foram internadas em UTIN no período neonatal apresentaram respostas alteradas à estimulação térmica dolorosa. Independentemente de terem nascido a termo ou pré-termo, as crianças que haviam sido internadas em UTIN apresentaram maior sensibilização perceptual, o que indica sensibilização do sistema nervoso central de longa duração e mudanças neuroplásticas induzidas das trajetórias de dor (HERMANN et al., 2006).

Sendo assim, experiências dolorosas ocorridas nos períodos iniciais de vida podem comprometer o comportamento futuro do ser humano (ANAND, 1998; GOUFFAX et al., 2008; GRUNAU, 2002; GRUNAU; HOLSTI; PETERS, 2006; HERMANN et al., 2006; KLEIN et al., 2009).

Considerando, portanto, que os procedimentos dolorosos são frequentes no tratamento intensivo dos neonatos pré-termo, avaliar adequadamente a reação à dor e intervir para minimizá-la são tarefas relevantes e necessárias na implementação de estratégias promotoras do desenvolvimento do recém-nascido na UTIN (ANAND et al., 2006; GARDNER; LUBCHENCO, 1998).

Na UTIN, os comportamentos de reação à dor muitas vezes são interpretados pela equipe de saúde como agitação ou irritabilidade, os quais são tratados com sedação do recém-nascido. Porém, este procedimento mostra-se ineficiente para a 
redução da percepção da dor (BROOME; TANZILLO, 1990). Segundo estes autores, a dor é tipicamente categorizada por um repentino início, uma etiologia demonstrável, tal como procedimento nocivo ou lesivo do tecido decorrente de um trauma, enfermidade ou tratamento e com uma evolução limitada e previsível. Por outro lado, a agitação é uma responsividade anormal ao estímulo e é usualmente manifestada por extrema impaciência e tensão. Irritabilidade e agitação podem resultar de uma experiência crônica de dor não tratada em recém-nascido pré-termo, no entanto, a irritabilidade está diretamente associada ao estímulo doloroso. Apesar de muitas vezes os recém-nascidos pré-termo não exibirem as respostas comportamentais de dor, não significa que eles não sintam dor.

Algumas razões para a negligência no manejo para o alívio da dor e estresse em bebês hospitalizados são descritas por Mathew e Mathew (2003), destacandose: falta de conhecimento das intervenções de alívio de dor e métodos de analgesia, falta de conhecimento da equipe de saúde sobre a capacidade do bebê de perceber a dor e de conhecimento das situações clínicas nas quais a dor é percebida, a inabilidade dos bebês em expressar a dor, a atenção médica focada para o tratamento das condições clínicas, a interpretação da expressão de dor do bebê como agitação, a vontade dos cuidadores em realizar os procedimentos rapidamente sem analgesia, a relutância no uso de analgésicos devido aos efeitos adversos e o medo da indução da dependência por opióides.

Chermont et al. (2003) realizaram um estudo para avaliar o conhecimento dos pediatras que atuam em unidades de terapia intensiva relativo à avaliação e o 
tratamento da dor do recém-nascido e verificaram que apesar de $100 \%$ dos pediatras acreditarem que os recém-nascidos sentiam dor, apenas um terço deles declarou conhecer alguma escala para avaliação da dor. Além disso, menos de 10\% dos pediatras referiram usar analgesia para procedimentos de dor tipo punção venosa ou capilar, 30 a $40 \%$ para procedimentos de dor do tipo drenagem de tórax, punção lombar ou dissecação venosa e menos da metade aplicava medidas para alívio da dor no pós-operatório.

Esses resultados são corroborados pelo estudo de Prestes et al. (2005), no qual foram analisadas quatro unidades de terapia intensiva neonatais em Hospitais Universitários quanto a características destas unidades e de seus pacientes, procedimentos potencialmente dolorosos realizados e emprego de analgésicos. Foi verificado que apenas $25 \%$ dos 1.025 pacientes avaliados receberam alguma dose de analgésico por via sistêmica, sendo que, em vários eventos dolorosos, como por exemplo, punções arteriais, venosas, capilares e lombares, nenhuma medicação específica para dor foi administrada.

Em um estudo realizado por Elias et al. (2008), identificou-se discordância significativa na avaliação realizada pelos pais, enfermeiros e pediatras acerca da intensidade da dor sentida por pacientes pré-verbais, o que dificulta a tomada de decisão sobre os tratamentos farmacológicos a serem prescritos para os mesmos.

Os indicadores de dor e estresse são frequentes na UTIN, expondo o neonato pré-termo a condições adversas que precisam ser devidamente discriminadas para o manejo adequado. Durante a realização de procedimentos, os neonatos pré-termo 
sofrem diversas manipulações que podem ter efeitos negativos para sua estabilidade fisiológica e comportamental. No estudo de Holsti et al (2005), foi avaliada a interferência de um procedimento doloroso, realizado anteriormente aos cuidados de rotina da UTIN (troca de fraldas, mensuração da temperatura e higienização), nas respostas fisiológicas e comportamentais de neonatos pré-termo. Os resultados revelaram que, além da dor induzir um aumento da reatividade comportamental e fisiológica em neonatos pré-termo durante a estimulação tátil, os cuidados de rotina quando realizados de maneira agrupada podem se tornar particularmente estressores para neonatos com idade gestacional abaixo de 30 semanas.

Considerando o contexto inicial de desenvolvimento do neonato pré-termo, o ambiente da UTIN apresenta-se sobrecarregado de estímulos estressores, além do manuseio frequente do neonato para a realização de procedimentos dolorosos ou não, os quais dificultam a permanência do recém-nascido no estado de sono profundo, estado comportamental ideal para seu melhor desenvolvimento (AHN, 2006; CAMERON; RAINGANGAR; KHOORI, 2007; HOLSTI et al., 2006; MÖRELIUS et al., 2006; NEWNHAM; INDER; MILGROM, 2009). Além disso, os procedimentos dolorosos sobrepõem ao manuseio a sensação de dor, que de acordo com Grunau (2002), é um dos fatores mais prejudiciais do ambiente extra-uterino e pode alterar o desenvolvimento cerebral em muitos aspectos.

No estudo de Gaspardo, Chimello et al. (2008), no qual 43 neonatos prétermo foram avaliados durante procedimento invasivo e doloroso de punção arterial 
para coleta de sangue, observou-se que os neonatos anteciparam a reação ao estímulo doloroso de punção, apresentando elevação significativa dos indicadores de atividade facial, estado de vigília e sono e frequência cardíaca durante o momento preparatório de antissepsia para a punção.

Recém-nascidos pré-termo, entre a $30^{a}$ e $35^{a}$ semanas de idade pósconcepcional, demonstraram ser capazes de aprender a associar estímulos e antecipar eventos dolorosos da rotina da UTIN (CHIMELLO et al., 2009; GOUBET; CLIFTON; SHAH, 2001). Em um estudo experimental (PORTER; WOLF; MILLER, 1998), investigou-se o efeito do manuseio nas respostas de dor aguda em recémnascidos pré-termo e a termo saudáveis. Quarenta e oito recém-nascidos com aproximadamente quatro dias de idade pós-natal foram randomicamente designados a um grupo que recebeu procedimentos de manuseio antes de uma punção capilar ou a um grupo que passou pela punção capilar sem antes receber os procedimentos de manuseio, referente à manipulação e imobilização semelhantes ao manuseio realizado antes de uma punção lombar. Os resultados mostraram que durante o procedimento de punção capilar, o grupo de bebês que recebeu o manuseio antes do procedimento de punção apresentou maior frequência cardíaca, estado comportamental mais ativado, e maior atividade facial em comparação ao grupo que não foi manuseado.

Considerando a relevância do toque e manuseio nos recém-nascidos prétermo, estudos têm analisado os vários tipos de toque e seus efeitos na desestabilização ou na regulação dos neonatos. O tipo de toque ao neonato deve 
ser adequado ao seu estado de saúde. Em recém-nascidos instáveis fisiologicamente, o toque de afago (alisamento repetitivo em uma única direção), pode provocar desaturação de oxigênio e estresse comportamental. O toque de contensão, por sua vez, caracterizado pela sobreposição das mãos no corpo do neonato tem um efeito positivo na melhora do estresse sofrido pelo neonato internado na UTIN (CAMERON; RAINGANGAR; KHOORI, 2007). As respostas dos neonatos ao manuseio variam de acordo com muitos fatores, tais como maturidade do bebê e história de exposição a procedimentos dolorosos, que devem ser levados em consideração no cuidado do recém-nascido de alto risco (PETERS, 1999).

Com o objetivo de proteger o desenvolvimento dos recém-nascidos pré-termo no contexto hospitalar, Als (2004) desenvolveu, na década de 1980, uma modalidade de intervenção denominada Neonatal Individualized Developmental Care and Assessment Program (NIDCAP). O NIDCAP visa modificar positivamente o ambiente das unidades de terapia intensiva neonatais e envolve, entre outras intervenções, evitar ou neutralizar estímulos adversos (luminosidade, barulho, manuseio frequente e procedimentos dolorosos repetidos), promover a maturação e organização comportamental do bebê facilitando os estados de vigília e sono, conservar a energia do bebê, ensinar os pais a interpretar o comportamento do bebê e dar respostas contingentes aos comportamentos do mesmo (ALS, 2009; McANULTY et al., 2010).

Um recente estudo de revisão bibliográfica (GASPARDO; MARTINEZ; LINHARES, 2010) realizado com o objetivo de analisar criticamente a literatura 
sobre ensaios clínicos randomizados e controlados, publicados no período de 2002 a 2009, sobre a eficácia de intervenções em Cuidado ao Desenvolvimento em recém-nascidos pré-termo em UTIN, encontrou que tais intervenções promoveram melhora em curto prazo nos resultados fisiológicos, comportamentais, neurológicos e clínicos dos recém-nascidos. Os resultados dos estudos mostraram diminuição nos dias de alimentação parenteral e de internação, maior ganho de peso, menos casos de enterocolite necrosante e episódios de apnéia, menor reatividade à dor, maior regulação dos sistemas autonômico, motor e de autorregulação. Além disso, intervenções em Cuidado ao Desenvolvimento podem levar ao melhor desenvolvimento neurocomportamental, neurofisiológico e neuroestrutural dos recém-nascidos, como demonstrado no estudo de Als et al. (2004).

\subsection{Avaliação de dor em neonatos: instrumentos e medidas}

A necessidade de avaliação precisa das reações de dor em recém-nascidos levou a um avanço considerável nos estudos visando estabelecer indicadores de dor neonatal, validação de instrumentos para a avaliação da dor, e mensuração de respostas de dor em neonatos pré-termo e a termo (CRAIG et al., 1993; DUHN; MEDVES, 2004).

Segundo Stevens, Johnston e Gibbins (2000), os principais objetivos da avaliação de dor em neonatos são descrever o fenômeno da dor e os fatores que o influenciam, diagnosticar a necessidade de intervenção, avaliar a eficácia de 
intervenções e examinar o impacto das mesmas. Para a realização destes objetivos, diversos instrumentos para a avaliação de dor em neonatos foram desenvolvidos. Entretanto, a qualidade destas medidas varia consideravelmente e reflete a dificuldade da avaliação da dor em recém-nascidos.

As mudanças na atividade facial, associada aos estados de vigília e sono e índices fisiológicos de frequência cardíaca e saturação de oxigênio têm sido medidas utilizadas como indicadores de dor em recém-nascidos com idade gestacional acima de 28 semanas (MORISON et al., 2001). Devido à complexidade da avaliação de dor em neonatos, recomenda-se que, para esta população, a avaliação seja multidimensional, utilizando-se medidas fisiológicas e biocomportamentais, envolvendo, portanto, diferentes parâmetros unidimensionais (CRAIG et al., 1993; DUHN; MEDVES, 2004).

As medidas unidimensionais são entendidas como um indicador único, por exemplo, frequência cardíaca, um tipo de indicador, como por exemplo, atividade facial, ou uma dimensão única de dor, por exemplo, indicadores comportamentais. Uma medida multidimensional pode ser realizada pelo emprego de várias medidas unidimensionais, ou pela utilização de instrumentos que avaliam diferentes parâmetros em um único escore final (STEVENS; JOHNSTON; GIBBINS, 2000).

Evidências neurológicas e comportamentais demonstram a capacidade de interpretação de dor pelos neonatos pré-termo, entretanto a avaliação de dor nesta população vulnerável e de alto risco torna-se difícil, pois a imaturidade do sistema 
nervoso central limita a maioria dos neonatos a expressar respostas de dor claras e mensuráveis (GIBBINS; STEVENS; ASZTALOS, 2003).

O modelo de avaliação no neonato é determinado por modificações de órgãos, sistemas e comportamentos ocorridos após um estímulo doloroso agudo. Assim, a avaliação da dor aguda do neonato baseia-se em alterações das medidas fisiológicas e biocomportamentais, observadas antes, durante e após a introdução de um estímulo potencialmente doloroso (BALDA; GUINSBURG, 2004).

De acordo com Stevens, Ridell et al. (2007), as escalas validadas para a avaliação de dor aguda-procedural em recém-nascidos baseiam-se em parâmetros biocomportamentais, como por exemplo, Neonatal Facial Coding System (GRUNAU; CRAIG, 1987), Behavioral Pain Scale (POKELA, 1994) e Douleur Aigue du Nouveau-né (CARBAJAL et al., 2005), ou na combinação de parâmetros comportamentais e fisiológicos, tais como Neonatal Infant Pain Scale (LAWRENCE et al., 1993), Premature Infant Pain Profile (STEVENS et al., 1996) e Scale for Use in Newborns (BLAUER; GERSTMANN, 1998).

A escala Neonatal Facial Coding System (NFCS) tem sido amplamente utilizada na avaliação de dor em neonatos, tanto a termo quanto pré-termo, medindo indicadores de mudança comportamental, por meio da expressão facial (GRUNAU; CRAIG, 1987; GRUNAU et al., 1998; GRUNAU; FITZGERALD, ELLWOOD, 2001). A expressão facial do neonato em reação à estimulação dolorosa foi o parâmetro de reatividade que apresentou maior correlação com as respostas hemodinâmicas corticais à dor, de modo que maior atividade facial foi associada à maior nível de 
hemoglobina no córtex somatosensorial (SLATER et al., 2008). Esta escala apresenta boas qualidades psicométricas de validade aparente, convergente, de conteúdo, constructo e discriminativa, além de fidedignidade entre observadores e intraobservadores e aplicabilidade clínica (STEVENS; RIDELL et al., 2007). A escala NFCS pode ser utilizada para análise do comportamento dos neonatos de reação à dor aguda registrado em vídeo-gravação como propõe Grunau e Craig (1987) ou a partir do registro direto à beira do leito realizado por um observador, segundo adaptação de Guinsburg et al. (2000).

No Brasil, estudos sobre avaliação de dor em neonatos tiveram como objetivos validar instrumentos de avaliação (GUINSBURG et al., 2003; GUINSBURG et al., 1997; PEREIRA et al., 1999), avaliar a reatividade de neonatos durante procedimento doloroso (CHIMELLO et al., 2009; GASPARDO; CHIMELLO et al., 2008; KLEIN, 2009), verificar características neonatais e do procedimento doloroso que poderiam interferir na resposta à dor dos neonatos (DELEVATI; BERGAMASCO, 1999; GUINSBURG, 2000; VALERI, 2007) e analisar o uso de intervenção farmacológica (GUINSBURG, 1993) e nãofarmacológica (CASTRAL et al., 2008; CHERMONT et al., 2009; GASPARDO, 2006; LEITE et al., 2009; VIVANCOS, 2008) para o alívio da dor em recémnascidos. 


\subsection{Intervenção não-farmacológica para alívio da dor em neonatos}

A dor não tratada, até mesmo em fase inicial do desenvolvimento, tal como no período neonatal, pode desencadear reorganização estrutural e funcional permanente das vias nervosas nociceptivas, que, por sua vez, afetam futuras experiências de dor do indivíduo (BARBOSA; GUINSBURG, 2003; GOFFAUX et al., 2008; VAN DE VELDE et al., 2006; WALKER et al. 2009).

Segundo Guinsburg e Balda (2003) não há indicações absolutas para o emprego de analgésicos em recém-nascidos, sendo que a decisão a respeito de aliviar a dor do neonato deve ser individualizada, porém não esquecida. Para as autoras, é importante considerar a ocorrência de dor e a necessidade de tratamento em recém-nascidos com enterocolite necrosante, tocotraumatismos, fraturas ou lacerações; em realização de procedimentos dolorosos como drenagem torácica, intubação traqueal eletiva, inserção de cateteres, punção liquórica, múltiplas punções arteriais, venosas e/ou capilares; em realização de procedimentos cirúrgicos de qualquer porte; em recém-nascidos intubados e em ventilação assistida e em neonatos gravemente enfermos que necessitem de vários procedimentos dolorosos.

Estudos demonstram que dores crônicas ou pós-cirúrgicas devem ser tratadas com agentes farmacológicos, como por exemplo, morfina e fentanil, enquanto que as dores agudas ou estresse podem ser manejados com medidas não-farmacológicas de alívio e conforto (ANAND; WHIT HALL, 2007; STEVENS; 
GIBBINS; FRANCK, 2000). Procedimentos de manejo da dor aumentam a homeostase e estabilidade dos recém-nascidos pré-termo e são essenciais para o cuidado e suporte aos neonatos imaturos, a fim de enfrentarem o estresse da UTIN (CORFF; SEIDMAN; VENKATAMARAM, 1995).

Segundo Olkkola e Hamunen (2000), a idade influencia na farmacocinética dos analgésicos. Para esses autores, a eliminação dessas drogas acontece de maneira mais lenta nos neonatos quando comparados com crianças e adultos. Doenças e cirurgias também afetam a distribuição e eliminação de analgésicos. Por estas razões, os recém-nascidos podem se tornar mais susceptíveis aos efeitos adversos dos agentes analgésicos, sendo necessária adequada dosagem e observação para o uso seguro de analgésicos nesta população.

Diversos estudiosos dedicaram-se a verificar o efeito das intervenções nãofarmacológicas no enfrentamento dos neonatos pré-termo ou a termo frente a procedimentos invasivos e dolorosos, tais como posicionamento (Grunau et al., 2004) sucção não-nutritiva (CORBO et al., 2000; STEVENS; YAMADA; OHLSSON, 2001), amamentação (LEITE et al., 2009), contato pele a pele (CASTRAL et al., 2008; CHERMONT et al; 2009; CONG et al., 2009; FREIRE; GARCIA; LAMY, 2008; VIVANCOS, 2008), leite humano (CARBAJAL et al., 2003; ÖRS et al., 1999) e soluções adocicadas, dentre elas glicose (CHERMONT et al., 2009; GUALA et al., 2001; GRADIN; SCHOLLIN, 2005), frutose (AKÇAM, 2004) e solução de sacarose (ACHARYA et al., 2004; GASPARDO, 2006; GIBBINS et al., 2002; GIBBINS; STEVENS, 2003; OGAWA et al., 2005; STEVENS et al., 1999; STEVENS et al., 
2005). As intervenções não-farmacológicas, comportamentais e ambientais, podem ser usadas isoladamente ou de maneira combinada com as intervenções farmacológicas (FRANCK; LAWHON, 1998).

Com o objetivo de avaliar a efetividade do contato pele a pele na diminuição das respostas comportamentais e fisiológicas de dor em neonatos pré-termo durante procedimento de coleta de sangue para triagem neonatal, Castral et al. (2008) verificaram que neonatos com seis semanas ou mais de idade pós-natal, que permaneceram no colo materno durante o procedimento, apresentaram significativamente menos atividade facial, choro e ativação comportamental em comparação aos neonatos que permaneceram nos berços ou incubadoras durante a realização do procedimento doloroso.

As substâncias adocicadas são amplamente estudadas como intervenções não-farmacológicas para o manejo da dor aguda-procedural em neonatos pré-termo (ACHARYA et al., 2004; AXELIN et al., 2009; BAUER et al., 2004; BOYLE et al., 2006; CARBAJAL et al., 2002; FREIRE; GARCIA; LAMY, 2008; GAL et al., 2005; GASPARDO, 2006; GIBBINS et al., 2002; GIBBINS; STEVENS, 2003; McCULLOUGH et al., 2007; OKAN et al., 2007; STEVENS et al., 1999, 2005). Atualmente, a solução de sacarose é a intervenção recomendada como rotina para alívio da dor aguda em neonatos durante procedimentos invasivos e dolorosos em UTIN (AMERICAN ACADEMY OF PEDIATRICS et al., 2000, 2006; BENIS, 2002; HARRISON, 2008; GIBBINS; STEVENS; ASZTALOS, 2003; LAGO et al., 2009; LEFRAK et al., 2006; THOMPSON, 2005; TSAO et al., 2008). 


\subsection{O uso da sacarose no alívio da dor em neonatos}

A sacarose é um dissacarídeo de gosto adocicado, formado por uma molécula de glicose e uma de frutose, produzida pela planta ao realizar o processo de fotossíntese (OKAN et al., 2007).

Os mecanismos de ação de analgesia pelas substâncias adocicadas referemse à oralidade, relacionado a um efeito imediato, no qual a resposta calmante parece ser produzida pelo gosto e pela liberação de endorfinas endógenas, secundária à excitação dos receptores gustativos das papilas linguais pelo gosto doce (JOHNSTON et al., 1999).

De acordo com Ramenghi, Evans e Levene (1999), o efeito analgésico das substâncias adocicadas está relacionado com a percepção gustativa produzida pelas mesmas, e não com o efeito da ingestão ou absorção das substâncias. Neste estudo, neonatos pré-termo que receberam $2 \mathrm{ml}$ de solução de sacarose a $25 \%$ via oral, choraram significativamente menos e apresentaram menor escore no NFCS em relação aos neonatos que receberam água estéril antes de procedimento de punção para coleta de sangue. Entretanto, quando as substâncias foram administradas via sonda orogástrica, não houve diferença estatisticamente significativa entre os grupos.

Alguns autores encontraram menor eficácia da solução de sacarose, administrada via oral, na redução da resposta à dor em neonatos a termo durante procedimento de punção para coleta de sangue, em comparação a outras 
intervenções não-farmacológicas (CARBAJAL et al., 1999; GUALA et al., 2001; GREENBERG, 2002). Carbajal et al. (1999) encontrou que a sucção não-nutritiva foi mais eficaz do que $2 \mathrm{ml}$ de solução de sacarose a $30 \%$ na redução do escore do Douler Aiguë du Nouveau-né, instrumento que avalia parâmetros comportamentais de dor. Guala et al. (2001) encontraram maior eficácia na administração de $2 \mathrm{ml}$ de glicose a 33\% em relação à sacarose na mesma quantidade e concentração, em um estudo no qual foi avaliado o indicador fisiológico de frequência cardíaca. Por sua vez, Greenberg (2002) demonstrou em seus resultados maior eficácia da sucção não-nutritiva acompanhada de açúcar granulado em comparação à administração de $2 \mathrm{ml}$ de solução de sacarose a $12 \%$ na redução do choro dos neonatos.

Por outro lado, diversos estudos encontraram resultados relacionados à eficácia do uso da sacarose no alívio da dor aguda-procedural em recém-nascidos, tanto a termo quanto pré-termo, internados em UTIN (BILGEN et al., 2001; GASPARDO, 2006; ISIK et al., 2000; McCULLOUGH et al., 2008; OKAN et al., 2007).

O estudo de Gaspardo (2006) avaliou a solução de sacarose no alívio da dor em neonatos internados em UTIN. Trinta e três neonatos pré-termo nascidos com muito baixo peso foram distribuídos randomicamente em um grupo experimental e um grupo controle. Em uma primeira avaliação, os neonatos de ambos os grupos não receberam nenhuma intervenção antes do procedimento doloroso de punção para coleta de sangue, a fim de se observar o padrão individual dos mesmos quanto às reações comportamentais e fisiológicas ao procedimento. Posteriormente, no 
segundo dia de avaliação, o grupo experimental recebeu $0,5 \mathrm{ml} / \mathrm{kg}$ de sacarose a $25 \%$, via oral, e o grupo controle recebeu água estéril, dois minutos antes do procedimento doloroso. Os resultados deste estudo revelaram que os neonatos que receberam a solução de sacarose apresentaram diminuição da reatividade biocomportamental de vigília e sono e menores escores de atividade facial, avaliada pelo NFCS, em comparação aos neonatos que receberam água estéril, antes, durante e após o procedimento de punção. Entretanto, o indicador fisiológico de frequência cardíaca não apresentou diferença significativa entre os grupos.

Com a finalidade de determinar a eficácia da solução de sacarose administrada via oral na redução da resposta à dor em neonatos pré-termo durante inserção de sonda orogástrica para alimentação, McCullough et al. (2008) avaliaram 20 neonatos, que receberam de maneira randomizada, $0,5 \mathrm{ml} / \mathrm{kg}$ de solução de sacarose a $24 \%$ ou água estéril, administrada dois minutos antes do procedimento. Os resultados deste estudo revelaram que, quando receberam a sacarose, os neonatos apresentaram diminuição significativa da atividade facial, avaliada pelo NFCS, e da frequência cardíaca em comparação a quando receberam água estéril antes do procedimento.

Em continuidade ao estudo sobre o uso da solução de sacarose, outros estudos compararam o uso da substância a outras intervenções não-farmacológicas para o alívio de dor em neonatos, ou avaliaram a eficácia da sacarose administrada em conjunto a outras intervenções (BILGEN et al., 2001; GIBBINS et al., 2002; 
GORMALLY et al., 2001; ISIK et al., 2000). Os principais resultados destes estudos encontram-se a seguir.

\section{Sacarose e leite humano}

Alguns autores compararam a administração da sacarose com leite humano (BILGEN et al., 2001; STORM; FREMMING, 2002). A eficácia da sacarose e da amamentação na redução da dor em neonatos a termo em situação de punção capilar foi investigada por Bilgen et al. (2001). Os resultados revelaram uma significativa diminuição no tempo de choro nos neonatos que receberam $2 \mathrm{ml}$ de solução de sacarose a $25 \%$, via oral, dois minutos antes do procedimento doloroso, em comparação aos grupos de neonatos que receberam amamentação ou água estéril. O grupo que recebeu a sacarose também apresentou diminuição significativa no tempo de recuperação em comparação aos grupos que receberam leite humano, via seringa, ou água estéril, e diminuição significativa no escore do Infant Body Coding System em comparação aos grupos que receberam leite humano via seringa, amamentação ou água estéril. Este estudo também avaliou possíveis efeitos colaterais causados pela administração da solução de sacarose, por meio da avaliação do desenvolvimento de enterocolite necrosante, não encontrando este tipo de intercorrência nos neonatos.

O efeito da sacarose na resposta de dor em neonatos pré-termo durante punção capilar, e a comparação do efeito desta substância administrada conjuntamente com o leite humano, assim como a solução de sacarose em duas 
doses e concentrações diferentes foram avaliados no estudo de Storm e Fremming (2002). Os resultados indicaram que a duração do choro foi reduzida nos grupos de neonatos que receberam $1 \mathrm{ml}$ de solução de sacarose a $25 \%$ via oral e leite humano via sonda orogástrica, em comparação aos grupos que receberam $2 \mathrm{ml}$ de solução de sacarose a $15 \%$ e grupo controle; portanto, houve menor eficácia da concentração de $15 \%$ em relação à de $25 \%$. Deve-se destacar, no entanto que, nos neonatos que receberam leite humano, via sonda orogástrica, seguido de $1 \mathrm{ml}$ de sacarose a $25 \%$ via oral, a duração do choro foi menor e o estado de vigília e sono menos ativados, quando comparados com os demais grupos estudados.

\section{Sacarose e sucção não-nutritiva}

Estudos compararam a eficácia da solução de sacarose com a intervenção não-farmacológica de sucção não-nutritiva (ELSERAFY et al., 2009; GIBBINS; STEVENS, 2003; GIBBINS et al., 2002). Dois estudos utilizaram a mesma amostra, composta por neonatos pré-termo e a termo, para avaliar a eficácia de $0,5 \mathrm{ml}$ de solução de sacarose a $24 \%$, administrada via oral, em comparação com a sucção não-nutritiva para alívio da dor em procedimento de punção capilar (GIBBINS et al., 2002), assim como para verificar a influência da idade gestacional na eficácia de tais intervenções (GIBBINS; STEVENS, 2003). No estudo de Gibbins et al. (2002) foi encontrada diminuição significativa do escore do Premature Infant Pain Profile após

o procedimento doloroso nos grupos de neonatos que receberam a solução de sacarose seguida de sucção não-nutritiva dois minutos antes do procedimento de 
punção, em comparação aos grupos de neonatos que receberam apenas solução de sacarose ou água estéril seguida de sucção não-nutritiva.

Posteriormente, Gibbins e Stevens (2003) encontraram que a solução de sacarose seguida de sucção não-nutritiva foi a intervenção mais eficaz na redução do escore do Premature Infant Pain Profile aplicado na fase de punção, dentre três grupos de neonatos de idade gestacionais diferentes (27 a 31 semanas, 32 a 35 semanas e 36 a 42 semanas), em relação à sacarose utilizada isoladamente ou água estéril seguida de sucção não-nutritiva. Além disso, os resultados revelaram que em neonatos mais maduros, as respostas fisiológicas e comportamentais ao estímulo doloroso possuíam maior magnitude, e em neonatos menos maduros a administração da sacarose causou um número maior de efeitos colaterais (tosse e vômito). Estas intercorrências não apresentaram significância clínica ou estatística, sustentando a segurança, avaliada em curto prazo, do uso da sacarose.

O objetivo do estudo de Elserafy et al. (2009) foi avaliar o efeito analgésico da sacarose administrada via oral e da sucção não-nutritiva em recém-nascidos prétermo e analisar se existe efeito sinérgico entre essas duas intervenções. Para tanto, 36 neonatos foram distribuídos randomicamente em seis grupos, de acordo com a intervenção recebida dois minutos antes do procedimento de punção para coleta de sangue: $0,5 \mathrm{ml}$ de água estéril com sucção não-nutritiva, $0,5 \mathrm{ml}$ de água estéril sem sucção não-nutritiva, $0,5 \mathrm{ml}$ de sacarose a $24 \%$ com sucção não-nutritiva, $0,5 \mathrm{ml}$ de sacarose a $24 \%$ sem sucção não-nutritiva, apenas sucção não-nutritiva e nenhuma intervenção. Os resultados demonstraram que no grupo que recebeu a solução de 
sacarose a $24 \%$ combinada com a sucção não-nutritiva o escore do Premature Infant Pain Profile no momento da punção foi significativamente mais baixo em relação ao escore dos demais grupos, sugerindo a ocorrência do efeito sinérgico na combinação das intervenções de sacarose e sucção não-nutritiva no alivio da dor em neonatos.

Sacarose, glicose e colostro

A administração da solução de sacarose também foi comparada a outras substâncias não-farmacológicas, tais como colostro (BLASS; MILLER, 2001) e glicose (AKMAN et al., 2002; ISIK et al., 2000; OKAN et al., 2007), as quais poderiam ou não estar associadas à sucção não-nutritiva. O colostro, administrado via seringa ou chupeta não reduziu a duração de choro e expressão facial, avaliada pelo NFCS, dos neonatos a termo em relação ao grupo que recebeu água estéril no momento da punção capilar. Porém, colostro administrado com chupeta preveniu o aumento da frequência cardíaca no momento do estímulo doloroso. Em contraste, $2 \mathrm{ml}$ de sacarose a $12 \%$ administrada via seringa ou chupeta reduziu duração do choro, diminuiu a atividade facial e atenuou o aumento da frequência cardíaca no momento da punção, em relação ao colostro e água estéril (BLASS; MILLER, 2001).

O estudo de Akman et al. (2002) mostrou que os neonatos a termo que receberam $2 \mathrm{ml}$ de solução de sacarose a $12,5 \%$, via oral, seguida de sucção nãonutritiva choraram menos e apresentaram menor escore de atividade facial no NFCS 
durante procedimento de punção capilar em comparação aos neonatos que receberam sacarose, glicose, glicose seguida de sucção não-nutritiva e água estéril.

De acordo com Isik et al. (2000), os neonatos a termo que receberam $2 \mathrm{ml}$ de solução de sacarose a $30 \%$ via oral apresentaram diminuição significativa na duração do choro durante o procedimento doloroso de punção para coleta de sangue em comparação com os grupos que receberam glicose a $10 \%$ e $30 \%$ e grupo controle. Para o indicador de frequência cardíaca, apesar de não haver diferença significativa entre os grupos, a mudança na fase de punção em relação à linha de base foi menor no grupo que recebeu solução de sacarose.

Com o objetivo de avaliar a eficácia de duas soluções adocicadas no alívio da dor em recém-nascidos pré-termo, Okan et al. (2007) avaliaram 31 recém-nascidos em procedimento de punção para coleta de sangue, sendo que dois minutos antes do procedimento, os neonatos receberam via oral, de acordo com uma ordem randômica, $2 \mathrm{ml}$ de solução de sacarose a $20 \%, 2 \mathrm{ml}$ de solução de glicose a $20 \%$, ou $2 \mathrm{ml}$ de água estéril. De acordo com os resultados obtidos, houve uma significativa redução do choro e da atividade facial avaliada pelo NFCS durante o procedimento doloroso tanto no grupo que recebeu a sacarose como no grupo que recebeu a glicose, em comparação ao grupo controle.

\section{Sacarose e colo}

Gormally et al. (2001) avaliaram o uso da solução de sacarose administrada via oral combinada com o posicionamento de neonatos a termo no colo de um adulto 
no momento do procedimento doloroso de punção capilar e identificaram redução do choro durante o procedimento nos grupos de neonatos que receberam $2,5 \mathrm{ml}$ de sacarose a $24 \%$ associada ao colo e sacarose sozinha em comparação aos grupos que receberam água estéril associada ao colo e água estéril sozinha. Em relação à frequência cardíaca, houve redução apenas no grupo de neonatos que recebeu sacarose e colo.

\section{Sacarose e creme anestésico}

Dois estudos avaliaram a eficácia da solução de sacarose quando administrada em conjunto com uma intervenção farmacológica do tipo anestésico tópico local (ABAD et al., 2001; GAL et al., 2005). O primeiro estudo, realizado por Abad et al. (2001) identificou significativa redução da frequência cardíaca e duração do choro nos grupos de neonatos a termo que receberam, dois minutos antes do procedimento de punção venosa, $2 \mathrm{ml}$ de sacarose a $24 \%$ via oral sozinha ou combinada com $1 \mathrm{~g}$ de creme anestésico EMLA (mistura eutética de prilocaína e lidocaína) de uso tópico, após o procedimento doloroso, em comparação com o grupo que recebeu água estéril. Além disso, o creme EMLA aplicado sozinho foi menos eficaz do que a solução de sacarose administrada sozinha ou de forma combinada com creme EMLA. Os resultados revelaram que o creme anestésico EMLA de uso tópico não aumentou o efeito analgésico produzido pela solução de sacarose. 
O segundo estudo teve por objetivo examinar se o uso via oral da solução de sacarose a $24 \%$ em conjunto com o anestésico local durante exame de retinopatia da prematuridade melhora o controle da dor neste exame. Para tanto, 23 neonatos pré-termo foram randomicamente designados para dois grupos, os quais receberam anestésico local em conjunto com $2 \mathrm{ml}$ de solução de sacarose a $24 \%$ ou de água estéril antes do exame de retinopatia da prematuridade. O resultado revelou escore do Premature Infant Pain Profile significativamente menor no grupo de neonatos que recebeu o anestésico local em conjunto com a solução de sacarose (GAL et al., 2005).

Em síntese, de acordo com os achados dos estudos envolvendo a análise da eficácia da solução de sacarose para o alívio da dor em neonatos, pode-se concluir que $2 \mathrm{ml}$ de sacarose a uma concentração de $25 \%$ apresenta eficácia no alívio da dor aguda em procedimentos de rotina da UTIN, tais como punção para coleta de sangue, inserção de sonda orogástrica, injeção e exame de retinopatia da prematuridade, em neonatos a termo e pré-termo. Há um consenso entre os autores de que a sacarose seja administrada via oral, dois minutos antes do procedimento doloroso, na parte anterior da língua dos neonatos.

Outras intervenções não-farmacológicas, dentre elas leite humano, sucção não-nutritiva, colo e creme anestésico, apresentam efeito sinérgico ao efeito analgésico da solução de sacarose quando administradas de maneira combinada. 
Em relação aos indicadores de resposta à dor, os comportamentais, principalmente atividade facial e choro, demonstraram maior sensibilidade para a solução de sacarose durante os procedimentos dolorosos.

Não foram encontrados efeitos colaterais em curto prazo, do tipo tosse, vômito, distensão abdominal e enterocolite necrosante, relacionados ao uso da solução de sacarose.

Com base nessas evidências científicas, a Academia Americana de Pediatria e a Sociedade Pediátrica Canadense (AMERICAN ACADEMY OF PEDIATRICS et al., 2000, 2006) recomendam o uso da solução de sacarose como rotina para alívio da dor em UTIN durante os procedimentos invasivos e dolorosos. Entretanto, pouco ainda se sabe sobre o efeito do uso da sacarose administrada em uso continuado, ou seja, se o efeito de minimizar as reações à dor é mantido ou não ao longo do tempo, bem como sobre a possibilidade de efeitos colaterais (LEEF, 2006).

O uso da sacarose em esquema de doses repetidas

Uma revisão bibliográfica da literatura, exclusivamente de artigos empíricos, publicados entre 1993 e 2004, que foi realizada por Gaspardo, Linhares e Martinez (2005), identificou na época apenas três estudos de um mesmo grupo de pesquisadores sobre o uso da solução de sacarose em esquema de doses repetidas (BOYER et al., 2004; JOHNSTON et al., 1999, 2002). Esses estudos foram realizados com neonatos pré-termo em comparação com um grupo controle de água estéril. 
No estudo de Johnston et al. (1999), as doses repetidas foram administradas via oral três vezes dentro de um mesmo procedimento doloroso de punção capilar, dois minutos antes do procedimento, no momento exato do procedimento e dois minutos após o procedimento doloroso. Os neonatos foram randomicamente distribuídos em três grupos, os quais receberam solução de sacarose na primeira dose e água estéril nas outras duas doses, solução de sacarose nas três doses, ou água estéril nas três doses. Os resultados revelaram que os grupos de neonatos que receberam $0,05 \mathrm{ml}$ de solução de sacarose a $24 \%$, tanto em dose única quanto em doses repetidas, apresentaram menores escores no Premature Infant Pain Profile em relação ao grupo que recebeu apenas água estéril. Este estudo ainda revelou que, nos últimos 30 segundos de avaliação da resposta ao procedimento doloroso, na fase de recuperação, os neonatos que receberam a solução de sacarose em esquema de doses repetidas continuaram a apresentar escores menores no Premature Infant Pain Profile em comparação ao grupo que recebeu apenas uma dose única.

Posteriormente, no estudo de Johnston et al. (2002), os neonatos foram designados randomicamente para o grupo de intervenção, que recebeu a solução de sacarose via oral, e grupo controle, que recebeu água estéril, antes de cada procedimento doloroso durante um período de sete dias. Os procedimentos dolorosos incluíram punção para coleta de sangue, inserção de cateter de acesso central, inserção de sonda orogástrica, aspiração de vias aéreas e remoção de esparadrapos ou eletrodos. Os resultados revelaram que $0,1 \mathrm{ml}$ de solução de 
sacarose a $24 \%$, administrada em esquema de doses repetidas, apresentou eficácia na redução do escore do NFCS durante os procedimentos dolorosos e invasivos de punção capilar, punção venosa e aspiração. Além disso, neste estudo foram examinados os possíveis efeitos colaterais no desenvolvimento neurocomportamental advindos com o uso da sacarose. Os autores encontraram que, embora não tenha sido encontrado nenhum tipo de efeito colateral, alto número de doses (10 doses) (JOHNSTON et al., 2007) foi preditor de baixo escore de desenvolvimento neurocomportamental para as áreas de desenvolvimento motor e vigor, alerta e orientação em bebês com idade pós-concepcional de 36 semanas, e para as áreas de desenvolvimento motor e vigor em bebês com idade pósconcepcional de 40 semanas, segundo o instrumento Neurobehavioral Assessment of the Preterm Infant, além de alto escore no Neurobiological Risk Score em neonatos com duas semanas de idade pós-natal.

O estudo de Boyer et al. (2004), por sua vez, teve por objetivo avaliar a eficácia da solução de sacarose na estabilidade fisiológica dos recém-nascidos. Para tanto, os autores utilizaram-se da amostra e procedimento apresentados no estudo de Johnston et al. (2002). Os resultados mostraram uma correlação negativa significativa entre o desvio padrão da frequência cardíaca e número de doses de sacarose administradas, apenas nos neonatos que receberam grande quantidade de doses de solução de sacarose (nove doses ou mais em 24 horas). Portanto, quanto mais alta a quantidade de doses da solução de sacarose, mais baixo o desvio 
padrão da frequência cardíaca, sugerindo diminuição da variabilidade deste indicador fisiológico.

Outros autores também tiveram por objetivo a avaliação do uso da sacarose em doses repetidas, para o alívio da dor em neonatos pré-termo, porém administrada conjuntamente a outras intervenções (MITCHELL et al., 2004; STEVENS et al., 2005).

O estudo de Mitchell et al. (2004) avaliou a eficácia da sacarose administrada via oral em doses repetidas em 30 neonatos no alívio da dor aguda em exame de retinopatia da prematuridade, que foram randomicamente designados para dois grupos de intervenção. O primeiro grupo recebeu administração de anestesia local, sucção não-nutritiva e três doses de $0,1 \mathrm{ml}$ sacarose a $24 \%$ em intervalos de dois minutos durante a realização do exame. O segundo grupo, por sua vez, recebeu administração de anestesia local, sucção não-nutritiva e três doses de água estéril. Os resultados revelaram que o escore do Premature Infant Pain Profile foi significativamente menor durante a realização do exame no grupo que recebeu as intervenções de anestesia local e sucção não-nutritiva acompanhadas da solução de sacarose, em comparação ao grupo que recebeu as intervenções em conjunto com a água estéril.

No estudo de Stevens et al. (2005) foi verificada menor reatividade à dor, avaliada pelo Premature Infant Pain Profile, nos neonatos que receberam $0,1 \mathrm{ml}$ de sacarose a $24 \%$ via oral seguida de sucção não-nutritiva, antes dos procedimentos dolorosos de punção para coleta de sangue, punção lombar, inserção de cateter e 
remoção de esparadrapo, durante 28 dias consecutivos, em comparação aos neonatos que receberam água estéril seguida de sucção não-nutritiva. Os neonatos também foram avaliados, no $28^{\circ}$ dia de vida, quanto ao desenvolvimento neurocomportamental, a partir do instrumento Neurobiological Risk Score. Os resultados revelaram desenvolvimento neurocomportamental adequado para a idade nos neonatos de ambos os grupos.

Faz-se importante observar que os estudos sobre a administração da solução de sacarose em esquema de doses repetidas, para o alívio da dor aguda em neonatos pré-termo, foram realizados com diferentes tipos de delineamentos e metodologias de estudo. No estudo de Johnston et al. (1999) a solução de sacarose em doses repetidas foi administrada durante um único procedimento doloroso, assim como no estudo de Mitchell et al. (2004), visto que no segundo estudo a sacarose foi administrada em conjunto com outras intervenções. Nos estudos de Johnston et al. (2002) e Boyer et al. (2004), por sua vez, a solução de sacarose foi administrada em todos os procedimentos sofridos pelos neonatos durante um período de sete dias consecutivos. Da mesma forma, Stevens et al. (2005) avaliaram o uso da sacarose administrada em doses repetidas durante 28 dias consecutivos de internação dos neonatos, porém em uso conjunto com a sucção não-nutritiva. Além disso, não houve um consenso no que diz respeito sobre o volume da dose a ser administrada, assim como não se avaliou possíveis efeitos colaterais advindos do uso continuado da solução de sacarose na evolução clínica dos neonatos hospitalizados submetidos à intervenção. 
A solução de sacarose tem sido recomendada como uma modalidade de manejo não-farmacológico de alívio da dor aguda a ser usado no protocolo de rotina na UTIN, porém os estudos sobre o uso da substância em doses repetidas ainda não são conclusivos, com base na literatura. Se o efeito positivo de alívio se mantém com a continuidade do uso da sacarose e qual o efeito na saúde e no desenvolvimento do recém-nascido são questões relevantes a serem investigadas.

Até o momento, são poucos os estudos brasileiros conhecidos que tiveram como objetivo avaliar a eficácia de uma intervenção não-farmacológica para o alívio de dor em neonatos (CASTRAL et al., 2008; CHERMONT et al., 2009; FREIRE; GARCIA; LAMY, 2008; GASPARDO, 2006; LEITE et al., 2009; VIVANCOS, 2008). Quando se considera o uso da solução de sacarose, apenas o estudo de Gaspardo (2006) investigou este tipo de intervenção não-farmacológica, administrada em dose única, em contexto de UTIN.

O presente estudo é uma continuidade desta investigação e está direcionado para atender a duas questões principais. Primeira, avaliar a eficácia do uso continuado da solução de sacarose no alívio da dor em neonatos pré-termo durante procedimento de coleta de sangue em UTIN. Segunda, avaliar as características de evolução clínica e de padrões de alimentação dos neonatos pré-termo relacionadas a possíveis efeitos colaterais advindos do uso continuado da solução de sacarose em procedimentos dolorosos.

O estudo possui duas hipóteses relacionadas às questões apresentadas. A primeira hipótese é a de que solução de sacarose administrada em esquema de 
doses repetidas e usada consecutivamente ao longo de três dias é mais eficaz para o alívio da dor aguda-procedural em neonatos pré-termo em comparação ao uso de água estéril (placebo controle). A segunda hipótese é a de que a administração continuada da solução de sacarose durante procedimentos dolorosos de rotina da UTIN não causa efeitos colaterais para a condição clínica e para o padrão de alimentação dos neonatos submetidos a este tipo de intervenção. 


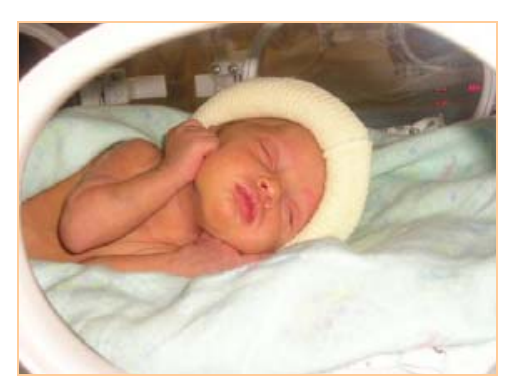

2. OBJETIVOS 
O presente estudo teve por objetivos:

a) Avaliar a eficácia da administração via oral da solução de sacarose a $25 \%$, em esquema de doses repetidas em dias consecutivos no alívio da dor em recémnascidos pré-termo;

b) Avaliar os possíveis efeitos colaterais, na evolução clínica e no padrão de alimentação de recém-nascidos pré-termo, advindos do uso continuado da solução de sacarose para alívio de dor. 


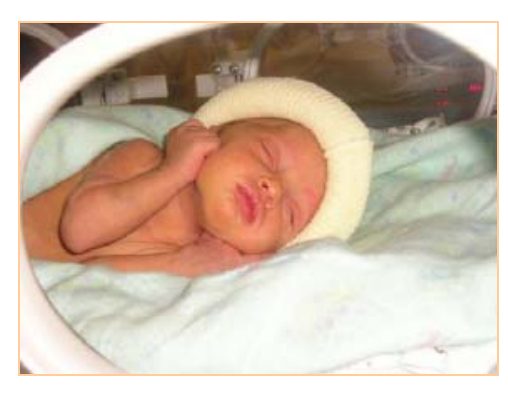

3. MÉTODO 


\subsection{Delineamento do estudo}

O presente estudo trata-se de um ensaio clínico randomizado controlado duplo cego, com comparações entre grupos e intragrupo.

\subsection{Participantes}

Participaram deste estudo 33 neonatos pré-termo com muito baixo peso ao nascimento, internados na Unidade de Terapia Intensiva Neonatal (UTIN) do Hospital das Clínicas da Faculdade de Medicina de Ribeirão Preto da Universidade de São Paulo (HCFMRP/USP).

Os seguintes critérios de inclusão definiram os participantes elegíveis para o estudo: neonatos pré-termo (< 37 semanas de idade gestacional), com muito baixo peso ao nascimento ( $\leq 1.500$ gramas), com idade pós-natal de no máximo 14 dias, nascidos no HCFMRP/USP e internados na UTIN do referido hospital. Além disso, os neonatos deveriam ter prescrição de coleta de sangue diariamente durante o período de quatro dias consecutivos.

Os critérios de exclusão foram os seguintes: malformação congênita, hemorragia peri-intraventricular graus III ou IV, hipoglicemia ou hiperglicemia, uso de medicação do tipo opióide e/ou sedativa e uso de cateter umbilical arterial.

A Figura 1 apresenta a descrição da trajetória de arregimentação dos participantes e composição da amostra. 


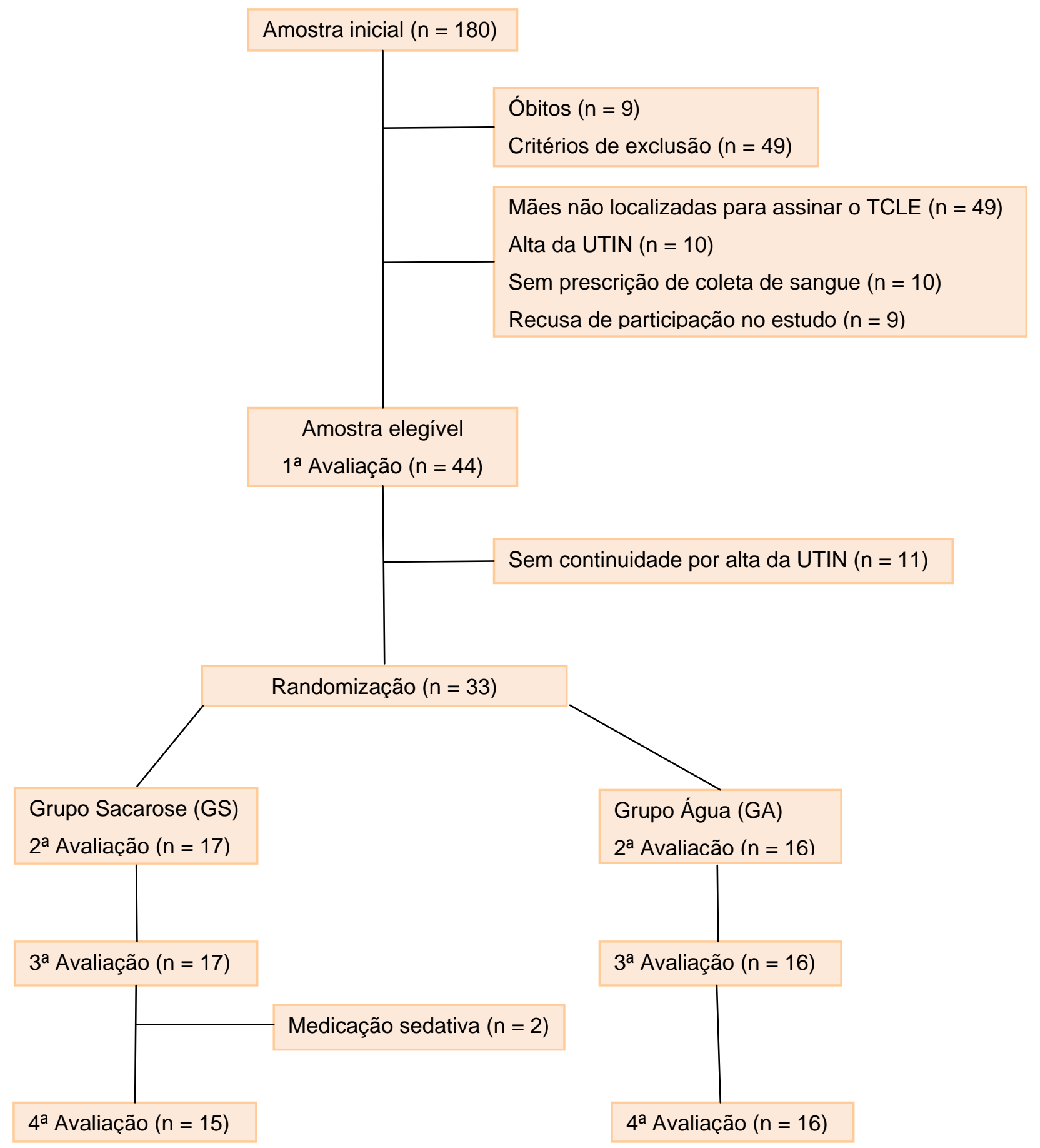

Figura 1 - Percurso de composição da amostra.

Observa-se na Figura 1, que, dos 180 recém-nascidos no período da coleta de dados, nove foram a óbito e 49 foram excluídos de acordo com os seguintes 
critérios: 25 neonatos faziam uso de cateter umbilical arterial nas duas primeiras semanas de vida, 20 neonatos faziam uso de medicação do tipo opióide e/ou sedativa, um neonato apresentou hemorragia peri-intraventricular grau III, um neonato apresentou hiperglicemia, um neonato apresentou hipoglicemia e um neonato apresentou malformação congênita (hidroanencefalia). Além disso, 49 mães não foram encontradas para a assinatura do Termo de Consentimento Livre e Esclarecido (TCLE), 10 recém-nascidos foram encaminhados ao berçário de médio risco antes do período previsto para a coleta de dados, 10 recém-nascidos não necessitavam de coleta de sangue nos dias previstos para a avaliação e nove mães não concordaram com a participação na pesquisa.

A amostra elegível foi composta, portanto, por 44 neonatos, dos quais 11 recém-nascidos receberam alta da UTIN e foram encaminhados ao berçário de médio risco durante o período de coleta de dados. Portanto, houve uma perda amostral de $25 \%$. A amostra final foi então composta por 33 recém-nascidos e, a partir de uma distribuição randômica, 17 recém-nascidos foram designados para o grupo experimental (Grupo Sacarose - GS) e 16 recém-nascidos designados para o grupo controle (Grupo Água - GA). A distribuição dos participantes nos grupos se deu de forma cega em relação ao tipo de substância.

O grupo de neonatos pré-termo que não participou do estudo (Grupo Não Participante - GN) foi semelhante ao grupo de neonatos pré-termo estudado (Grupo Participante - GP) em termos de mediana ou porcentagem das seguintes variáveis: sexo (GN: 52\% meninas; GP: 51\% meninas; $p=0,57$ ), idade gestacional (GN: 30 
semanas [23 - 36 semanas]; GP: 30 semanas [25 - 33 semanas]; $p=0,40$ ) e peso ao nascimento (GN: 1.075 gramas [500 - 1.495 gramas]; GP: 1.135 gramas [640 1.430 gramas]; $p=0,89$ ).

\subsection{Local e contexto do estudo}

A pesquisa foi realizada na Unidade de Terapia Intensiva Neonatal (UTIN) do HCFMRP/USP, vinculada ao Setor de Neonatologia do Departamento de Puericultura e Pediatria da Faculdade de Medicina de Ribeirão Preto da Universidade de São Paulo (FMRP/USP).

O HCFMRP/USP é um hospital geral público, autárquico, ligado à Universidade de São Paulo (USP) para fins de ensino, pesquisa e assistência e vinculado administrativamente à Secretaria do Estado de São Paulo por meio do Decreto $n^{\circ} 26.920$ de 18/03/1987. Tem características de hospital regional e está integrado ao Sistema Único de Saúde (SUS), em nível terciário, atendendo a pacientes do município, de várias cidades da região, bem como de outros estados do país. É constituído por duas unidades prediais, sendo uma localizada no Campus da USP de Ribeirão Preto (12 andares) e outra no centro da cidade de Ribeirão Preto (seis andares). O HCFMRP/USP destina-se ao atendimento de pacientes com alta complexidade.

A Neonatologia do HCFMRP/USP dispõe na Unidade Campus, atualmente, 65 leitos neonatais, sendo 20 leitos na UTIN ( $7^{\circ}$ andar), 27 leitos na Unidade de 
Cuidado Intermediário Neonatal ( $8^{\circ}$ andar) e 18 leitos no alojamento conjunto ( $8^{\circ}$ andar).

O atendimento a neonatos pré-termo com muito baixo peso ao nascimento no HCFMRP/USP conta com equipe multidisciplinar composta por médicos, enfermeiros, psicólogo, fisioterapeuta, assistente social, fonoaudiólogo e nutricionista, que atendem aos bebês desde a UTIN até o follow-up no Ambulatório dos Prematuros, após a alta hospitalar.

\subsection{Aspectos éticos}

O projeto de pesquisa do presente estudo foi aprovado pelo Comitê de Ética em Pesquisa do HCFMRP/USP (ANEXO A), e autorizado pelo Chefe do Serviço de Neonatologia deste hospital (ANEXO B). Antes da realização da coleta de dados, o Termo de Consentimento Livre e Esclarecido (APÊNDICE A) foi firmado com as mães dos neonatos. Neste momento as mães foram orientadas quanto ao objetivo do estudo e procedimento de coleta de dados, e também foram transmitidas às mesmas recomendações sobre a importância do uso da sacarose ser realizada estritamente no período da coleta de dados e em doses pequenas. Estas recomendações tiveram por objetivo evitar que as mães generalizassem e passassem a administrar "água com açúcar" em casa, após a alta do bebê, para situações em que julgasse sobre a ocorrência de dor no mesmo. 


\subsection{Instrumentos e Medidas}

\subsubsection{Atividade Facial}

O indicador comportamental de atividade facial foi utilizado como medida de reatividade à dor aguda, tendo como instrumento de avaliação a escala Neonatal Facial Coding System (NFCS) (GRUNAU; CRAIG, 1987). As normas de aplicação do NFCS estão descritas em um manual de treinamento produzido por Grunau, Fitzgerald e Ellwood (2001) e traduzido com autorização da autora para a língua portuguesa (Brasil) por Linhares e Chimello (2002).

Estudos sobre as qualidades psicométricas do NFCS demonstraram que o instrumento possui fidedignidade quando aplicado à beira do leito (GRUNAU et al., 1998; GUINSBURG et al., 2000), assim como quando aplicado por meio de observação de vídeo-gravação (GRUNAU, CRAIG, 1987), fidedignidade entre observadores e intraobservadores, validade aparente, validade de conteúdo, validade de constructo, validade convergente e validade discriminativa. Também apresenta validade tanto para neonatos a termo quanto para neonatos pré-termo (STEVENS; RIDELL et al., 2007).

As ações faciais que são codificadas pelo instrumento encontram-se a seguir: protuberância de sobrancelha (arqueamento, enrugamento e/ou formação de sulcos verticais acima e entre as sobrancelhas); olhos apertados (aperto da fenda palpebral); sulco nasolabial aprofundado (levantamento e aprofundamento ascendente do sulco nasolabial, como uma linha ou uma ruga, que começa 
adjacente às asas da narina e corre para baixo e exteriormente para além dos cantos dos lábios); lábios entreabertos (boca aberta mais do que os lábios relaxados e distanciados); boca esticada no sentido vertical (tensão no canto dos lábios juntamente com uma tração descendente pronunciada dos maxilares); boca esticada no sentido horizontal (estiramento horizontal dos cantos da boca algumas vezes acompanhado por uma tensão do lábio superior); língua tensa (língua saliente, em concha com a beirada bruscamente tensionada); tremor no queixo (alta frequência de movimentos para cima e para baixo do maxilar inferior) (GRUNAU; FITZGERALD; ELLWOOD, 2001).

No presente estudo, utilizou-se as ações faciais de protuberância de sobrancelha, olhos apertados, sulco nasolabial aprofundado, lábios entreabertos, boca esticada no sentido vertical ou horizontal e língua tensa, como proposto por Peters et al. (2003). As ações faciais foram codificadas como um ou zero (presença / ausência) a cada 10 intervalos de dois segundos, totalizando 20 segundos de observação. Para o cálculo do escore total, somaram-se as ocorrências das ações faciais durante o tempo total de cada intervalo, podendo, este, variar de zero a 70 pontos.

A sensibilidade e especificidade do escore do NFCS foram analisadas a partir de uma curva ROC que determinou os valores da nota de corte para a avaliação da dor na amostra do presente estudo. As fases de Linha de Base (não dor) e Punção (dor) foram usadas nesta análise. Um escore no NFCS de três pontos foi identificado como o melhor valor da nota de corte (Área $\mathrm{ROC}=0,85$; Sensibilidade $=0,76$; 
Especificidade $=0,88 ;$ IC $95 \%=0,75-0,95 ; p=0,0001)$ (GASPARDO, 2006; GASPARDO; CHIMELLO et al., 2008; GUINSBURG, 1999).

\subsubsection{Estado de Vigília e Sono}

O indicador de estado de vigília e sono consiste em uma medida de alerta dos recém-nascidos que complementou a medida de dor obtida pelo NFCS.

De acordo com o estudo de Nijhuis e Van de Pas (1992), os estados de vigília e sono foram codificados utilizando-se o seguinte sistema de classificação: sono profundo (olhos fechados, respiração profunda e regular, sem movimentos); sono ativo (olhos fechados apresentando movimentos rotativos lentos e pequenas contrações, respiração irregular rápida e curta, movimentos grosseiros); sonolência (estado de transição entre vigília e sono em que os olhos abrem e fecham de forma intermitente, movimentos suaves, respiração regular); alerta quieto (olhos abertos, corpo e face relativamente inativos, sem movimentos grosseiros, os estímulos visuais e auditivos evocam respostas); alerta ativo (neonato acordado, olhos abertos, movimentos grosseiros contínuos); choro (fase expiratória definida, seguida por uma breve inspiração, um período de descanso e, de novo, uma fase expiratória, com ou sem padrão melódico).

Os estados de vigília e sono foram mensurados em uma escala ordinal de estágio crescente de ativação biocomportamental, sendo considerados os seguintes valores para os diferentes estados: sono profundo $=1$; sono ativo $=2$; sonolência $=$ $3 ;$ sono quieto $=4 ;$ sono ativo $=5 ;$ choro $=6$. 
Faz-se importante esclarecer que, no presente estudo, o choro nos neonatos intubados foi analisado sem padrão melódico devido a estes não emitirem som durante o choro, conforme realizado por Chang, Anderson e Lin (2002). Além disso, além de ser analisado dentro da escala ordinal de estado de vigília e sono, o choro também foi tratado separadamente, como um indicador específico de dor.

\subsubsection{Frequência Cardíaca}

O indicador fisiológico de frequência cardíaca foi utilizado no presente estudo como uma medida complementar de dor.

A frequência cardíaca normalmente varia em torno de 110 a 160 batimentos por minuto nos recém-nascidos, podendo variar significativamente durante os estados comportamentais de sono profundo ou alerta ativo. A taquicardia, com um ritmo mais acelerado do que 160 batimentos por minuto, pode ser um indício de irritabilidade do sistema nervoso central (FLETCHER, 1999).

\subsubsection{Prontuários do paciente}

Foi realizada uma análise documental autorizada dos prontuários médico e de enfermagem, junto ao HCFMRP/USP, para a obtenção de características de nascimento e de evolução clínica dos recém-nascidos hospitalizados. 


\subsection{Equipamentos}

Foi utilizada uma câmera SONY - Digital Handycan - Modelo DCR - TRV 340, um tripé para posicionamento da câmera e fitas Sony $8 \mathrm{~mm}$ para a realização das filmagens durante a observação sistemática, e um televisor PANASONIC 20 polegadas para a análise dos vídeos para a codificação da atividade facial dos recém-nascidos. Para o registro da frequência cardíaca, foram utilizados monitores Philips V240T, disponíveis na UTIN do HCFMRP/USP, para a monitorização de rotina dos neonatos.

\subsection{Procedimento}

\subsubsection{Estudo piloto}

Para o teste e aperfeiçoamento do procedimento de coleta e análise de dados do presente estudo, no mês anterior ao início da coleta de dados foi realizado um estudo piloto, no qual foram coletados e analisados dados de nove recém-nascidos, que não foram incluídos na amostra final do estudo. Neste momento houve a familiarização da pesquisadora com o local do estudo, equipe da UTIN, técnica de punção para coleta de sangue, identificação dos dados do neonato nos prontuários médico e de enfermagem, além do aprimoramento dos protocolos de registro a serem utilizados na coleta de dados. Também nesta fase foram treinadas as tarefas a serem desenvolvidas pela pesquisadora e pelas auxiliares de pesquisa. 
Nesta fase, a pesquisadora foi treinada pela pesquisadora orientadora do presente estudo para a realização da coleta de dados, organização, análise e interpretação dos dados coletados. Posteriormente, durante a realização do estudo, a pesquisadora realizou, com o apoio da pesquisadora orientadora e de um docente médico neonatologista do Departamento de Puericultura e Pediatria da FMRP/USP,

o treinamento de cinco auxiliares de pesquisa (alunas de mestrado e iniciação científica) que colaboraram com tarefas específicas de coleta e análise de dados do estudo.

\subsubsection{Coleta de dados}

3.7.2.1. Esquema de coleta de dados

Os recém-nascidos foram alocados randomicamente ao grupo experimental (Grupo Sacarose - GS), recebendo solução de sacarose, ou ao grupo controle (Grupo Água - GA), recebendo água estéril. A randomização da amostra obedeceu a uma tabela de números aleatórios produzida por um programa de computador feito especificamente para o estudo. Por se tratar de um estudo duplo cego, as ampolas com as soluções eram idênticas e identificadas como solução A (sacarose) e solução B (água estéril) e os códigos foram entregues pelo laboratório de manipulação dentro de um envelope lacrado (ANEXO C). As ampolas contendo $2 \mathrm{ml}$ de solução de sacarose a $25 \%$ ou $2 \mathrm{ml}$ de água estéril foram fabricadas pelo Laboratório Injectcenter - Manipulação de Injetáveis, da cidade de Ribeirão Preto. 
O esquema da coleta de dados foi realizado em quatro dias consecutivos, utilizando-se um sistema de observação sistemática e estruturada dos recémnascidos no momento da punção para coleta de sangue para a realização de exames de rotina da UTIN. A coleta de sangue era prescrita de acordo com a demanda dos exames clínicos.

O primeiro dia de avaliação teve por objetivo observar o padrão individual dos recém-nascidos quanto à reatividade e recuperação biocomportamental à dor e ao estresse frente ao procedimento doloroso de punção. Neste dia, não houve nenhuma intervenção para alívio de dor.

Ao final da observação sistemática realizada no primeiro dia de coleta de dados, a pesquisadora explicava ao médico responsável pelo atendimento ao recém-nascido sobre os objetivos do estudo. Era solicitado a este que, a partir do dia seguinte, e por um período consecutivo de três dias, fosse prescrita no prontuário do paciente a administração da solução A ou B antes dos procedimentos dolorosos e invasivos especificados em um aviso colocado na incubadora, a saber: punção para coleta de sangue para exames, punção para inserção de cateter de acesso central, inserção de sonda orogástrica, aspiração de vias aéreas e remoção de esparadrapos ou eletrodos (APÊNDICE B). Esses procedimentos foram selecionados de acordo com o estudo de Johnston et al. (2002). A quantidade de solução de sacarose a $25 \%$ administrada era calculada pelo peso do neonato no dia da administração da substância, correspondendo ao volume de 0,5ml/kg. 
Durante toda a fase de coleta de dados foi mantido um caderno (Diário de Campo), com o registro de todos os eventos ocorridos neste período.

\subsubsection{Procedimento de coleta de dados}

Para proceder à coleta de dados, inicialmente a pesquisadora realizava uma pesquisa entre os leitos da UTIN a fim de identificar recém-nascidos elegíveis para a pesquisa. Após a consulta ao prontuário médico e de enfermagem dos neonatos e da inclusão dos mesmos nos critérios estabelecidos, as mães eram localizadas em seus leitos e informadas sobre o objetivo geral do estudo e sobre o procedimento de coleta de dados.

Após a assinatura do Termo de Consentimento Livre e Esclarecido pela mãe do recém-nascido, colocava-se um aviso na incubadora com as datas que seriam realizadas as observações, no momento da coleta de sangue realizada no período da manhã para exames de rotina (APÊNDICE C).

No dia previsto para a primeira avaliação, a pesquisadora e a auxiliar de pesquisa chegavam à UTIN por volta das $07 \mathrm{~h} 00 \mathrm{~min}$ e verificavam se o neonato tinha prescrição médica para coleta de sangue naquele dia. Em caso positivo, também eram verificados os prontuários do paciente, a fim de identificar o estado de saúde deste e a presença de intercorrências que pudessem cancelar a observação.

Em um segundo momento, a pesquisadora anotava nos protocolos a serem usados neste dia, o código do participante, o número do vídeo e da avaliação, a data da observação e o nome dos observadores. 
Posteriormente, a pesquisadora montava o tripé com a filmadora ao lado da incubadora do neonato para o registro da atividade facial, e filmava uma folha de papel (APÊNDICE D), no qual continha códigos para posterior identificação do participante, do sexo do neonato e do grupo a qual este pertencia, do número da avaliação e da fase observada.

Caso o recém-nascido não tivesse a monitorização da frequência cardíaca, solicitava-se a uma auxiliar de enfermagem que colocasse os eletrodos no mesmo e ligasse o monitor cardíaco. Se o neonato estivesse recebendo fototerapia, também era solicitado que a auxiliar desligasse a luz e retirasse o protetor ocular da face do neonato, os quais eram recolocados imediatamente após o término da coleta de dados.

O procedimento de avaliação incluiu cinco fases de observação. Inicialmente, na fase de Linha de Base $(\angle B)$, a face do neonato era filmada durante um período de 10 minutos, sem que houvesse nenhum manuseio do recém-nascido. Definiu-se no projeto de pesquisa que este intervalo deveria ser reduzido caso houvesse necessidade de manuseio do neonato devido a alguma intercorrência do tipo apneia, bradicardia, e queda na saturação de oxigênio.

Terminada a fase LB, a enfermeira iniciava o procedimento de rotina de coleta de sangue do recém-nascido. Então, após o posicionamento da enfermeira e da auxiliar de enfermagem ao lado da incubadora, o tripé com a filmadora era reposicionado para que a filmadora capturasse apenas a face do recém-nascido, impedindo assim que a fase de observação fosse identificada no momento da 
análise da vídeo-gravação. Assim que a enfermeira começava a manusear o neonato, iniciava-se o registro da fase de Preparação para Punção (PP). Esta fase compreendia todo o procedimento de preparação do neonato para a realização da punção para a coleta de sangue, como a localização da veia ou artéria a ser puncionada e a realização da antissepsia com a passagem de algodão embebido em álcool no local a ser realizado a punção.

No momento em que a enfermeira inseria a agulha no recém-nascido para a realização da punção, dava-se início à fase de Punção $(P)$, sendo que se a enfermeira não conseguisse realizar a coleta de sangue na primeira tentativa de punção, considerava-se o início da fase $\mathrm{P}$ nesta primeira tentativa e o término ao final da punção realizada com sucesso, ao retirar a agulha.

Quando a enfermeira terminava o procedimento de punção com a retirada da agulha dava-se início à filmagem da fase de Recuperação com Manuseio (RCM). Esta fase também tinha duração variável e englobava todo o processo de realização do curativo, posicionamento do neonato e fechamento da incubadora pela enfermeira, deixando o recém-nascido em repouso.

Finalmente, quando o recém-nascido encontrava-se novamente dentro da incubadora, sem ser manuseado, era registrada a fase de Recuperação sem Manuseio (RSM). Esta fase teve sua duração controlada pela duração da fase RCM, sendo que na somatória dessas duas fases o tempo de recuperação total registrado foi de 10 minutos. 
A cada fase de observação, além da filmagem da face do recém-nascido, realizava-se o registro das variáveis biocomportamentais de estado de vigília e sono (APÊNDICE E) e frequência cardíaca (APÊNDICE F). Anotava-se, em protocolos específicos o tempo de início e fim da filmagem das cinco fases, de acordo com o tempo de filmagem que era mostrado na filmadora. Para os registros, a pesquisadora ficava responsável pelo protocolo dos estados comportamentais de vigília e sono apresentados pelo neonato em intervalos de dois minutos subdivididos em intervalos de 30 segundos; ao mesmo tempo, a auxiliar de pesquisa, responsável pelo registro da frequência cardíaca, anotava em protocolo específico a frequência cardíaca que aparecia no monitor cardíaco em intervalos de um minuto durante todo o período de duração das fases. A auxiliar de pesquisa também ficava responsável por avisar a pesquisadora da mudança de intervalo de 30 em 30 segundos para que esta mudasse o intervalo de registro do estado comportamental de vigília e sono.

Todos os protocolos utilizados durante os quatro dias de coleta de dados foram colocados dentro de um envelope no qual continha uma capa com alguns dados para identificação do participante, a saber: sexo, idade gestacional, peso ao nascimento, idade pós-natal, adequação do peso para idade gestacional (pequeno para a idade gestacional [PIG] / adequado para a idade gestacional [AIG]), índice de Apgar no $5^{\circ}$ minuto (APÊNDICE G).

Após o primeiro dia de avaliação, nos três dias posteriores e consecutivos de observação sistemática, realizava-se todo o procedimento descrito, acrescentando 
que dois minutos antes da fase $\mathrm{P}$, a enfermeira administrava a solução prescrita ao neonato.

\subsubsection{Coleta de dados do prontuário médico}

Além da coleta de dados por meio de observação sistemática dos recémnascidos, procedeu-se à análise documental dos prontuários médico e de enfermagem, a fim de se obter informações sobre características de nascimento e de evolução clínica do neonato.

O escore de risco neonatal foi mensurado a partir do Clinical Risk Index for Babies (CRIB) (INTERNATIONAL NEONATAL NETWORK, 1993), instrumento aplicável a crianças com peso ao nascer inferior a 1.500 gramas ou idade gestacional menor que 31 semanas, que avalia seis itens fisiológicos, a saber: peso ao nascimento, idade gestacional, presença de anomalias congênitas, fração inspirada de oxigênio máxima e mínima e o pior déficit de base nas primeiras 12 horas após o nascimento (APÊNDICE H). Um escore no CRIB acima de quatro pontos correlaciona-se com altas taxas de mortalidade e morbidade infantil (BRITO et al., 2003).

Em uma primeira fase, foram obtidas, por meio da análise dos prontuários médicos, as características de evolução clínica dos neonatos durante os dias de avaliação, e em especial a quantidade de evacuações, quantidade de vômitos, presença de resíduo na sonda orogástrica, presença de distensão abdominal e presença de hiperglicemia ou hipoglicemia. Foi calculada a quantidade de exposição 
a estímulos dolorosos sofridos pelos neonatos por meio da soma do número de procedimentos invasivos e dolorosos a que os neonatos foram submetidos desde o nascimento até a primeira avaliação e os procedimentos sofridos pelos neonatos nas últimas 24 horas anteriores à realização de cada avaliação. Os procedimentos invasivos e dolorosos incluídos na coleta de dados dos prontuários foram: lancetagem de calcâneo, acesso venoso central, acesso venoso puncionado para nutrição parenteral e medicações, punção para coleta de sangue para exames, punção para inserção de cateter de acesso central, inserção de sonda orogástrica, intubação orotraqueal, inserção de dreno de tórax e aspiração de vias aéreas (APÊNDICE I).

Em uma segunda fase, realizou-se a análise documental dos prontuários médicos, para a obtenção de informações acerca da evolução clínica dos bebês até a alta hospitalar, sendo elas: peso do neonato na $38^{a}$ semana de idade pósconcepcional, tempo para atingir o peso de 1.800 gramas, peso na alta hospitalar, tempo de internação na UTIN e tempo de internação hospitalar, presença de displasia broncopulmonar, retinopatia da prematuridade, hemorragia periintraventricular, enterocolite necrosante, septicemia, cardiopatia e pneumotórax. Em relação ao padrão de alimentação dos bebês, calculou-se o tempo do uso de sonda para alimentação durante o tempo total de internação hospitalar (APÊNDICE J).

A consulta aos prontuários foi realizada por duas auxiliares de pesquisa, a fim de assegurar que a pesquisadora autora fosse "cega" em relação às informações específicas sobre as condições de nascimento e saúde do recém-nascido. As 
auxiliares de pesquisa eram alunas de iniciação científica do curso de Medicina, e foram treinadas por um docente médico neonatologista do Departamento de Puericultura e Pediatria da FMRP/USP.

\subsubsection{Preparação e Análise dos dados}

\subsubsection{Preparação dos dados}

A análise da atividade facial dos recém-nascidos registrada nas vídeogravações foi realizada por três auxiliares de pesquisa treinadas para a utilização da escala NFCS e "cegas" em relação às características do neonato e da coleta de dados sobre os indicadores biocomportamentais de estado de vigília e sono e frequência cardíaca.

Inicialmente, a pesquisadora treinada preparava os protocolos de análise da atividade facial (APÊNDICE K), segundo o procedimento descrito por Grunau, Fitzgerald e Ellwood (2001), com o código do participante, o dia da realização da filmagem e o número do vídeo, dados estes que também estavam contidos na capa da fita $8 \mathrm{~mm}$. Neste protocolo também era registrado pela pesquisadora o tempo de início e término de cada intervalo que deveria ser analisado, referentes aos primeiros 20 segundos de cada fase de observação, ou se a fase tivesse menos de 20 segundos, o tempo total que correspondia à mesma.

Estes protocolos continham dados de diversos participantes e fases de observação, e eram entregues de maneira desordenada para uma segunda 
pesquisadora treinada, com a finalidade de que esta não conseguisse identificar pela sequência temporal a fase do procedimento (LB, PP, P, RCM e RSM) e o participante que estavam sendo analisados.

No momento da análise das vídeo-gravações, a segunda pesquisadora identificava as fitas que deveriam ser analisadas e assistia a cada vídeo-gravação na função "câmera lenta" para facilitar a identificação das atividades faciais contidas no NFCS. Após a análise da atividade facial realizada pela auxiliar de pesquisa, a pesquisadora identificava o participante e as fases de observação correspondentes a cada protocolo, com base nos códigos de identificação.

De um total de 645 vídeo-gravações analisadas, em 16 fases de PP e em 16 fases de RCM no grupo GS e em 12 fases de PP e em 10 fases de RCM no grupo GA, durante os quatro dias de observação, as fases apresentaram duração inferior a 20 segundos (10 intervalos), não sendo possível a realização da análise da atividade facial por todo este período. Por se tratar de dados coletados de grande importância para a análise dos dados, optou-se para a padronização dos resultados, por meio da estimativa do escore da atividade facial que seria atingido no tempo total de 10 intervalos de 2 segundos, de acordo com a pontuação atingida no intervalo analisado:

$$
\text { Escore da atividade facial }=\frac{\text { escore obtido no período analisado } \times 10}{\text { número de intervalos analisados }}
$$


Em relação ao estado de vigília e sono, calculou-se o estado que mais incidiu em cada intervalo de dois minutos, bem como aquele que apresentou maior incidência durante o tempo total de cada fase avaliada nos quatro dias de observação.

Para o indicador de frequência cardíaca, calculou-se a frequência cardíaca média, mínima e máxima de cada fase de avaliação nos quatro dias de observação.

\subsubsection{Análise dos dados}

O índice de fidedignidade da avaliação por meio do NFCS foi realizado a partir da dupla codificação das filmagens de cinco participantes (15\% da amostra total) escolhidos aleatoriamente por avaliadores independentes. Para o cálculo do índice de fidedignidade entre observadores/codificadores foi aplicada a fórmula conservadora do NFCS para vídeo-gravação da atividade facial proposta por Grunau, Fitzgerald e Ellwood (2001) que se encontra a seguir:

$\mathrm{N}^{\circ}$ de expressões (codificadas como 1 ) no qual codificadores 1 e 2 concordaram $\times 2$ $\mathrm{N}^{\circ}$ total de expressões (codificado como 1 ) pelos 2 codificadores

O índice de fidedignidade entre dois observadores/codificadores treinados e experientes no uso do NFCS foi de 93\%. Também foi realizada a análise do índice de fidedignidade entre dois observadores independentes e treinados para a variável de estado de vigília e sono em três participantes (10\% da amostra total), obtendo-se uma porcentagem de acordo entre observadores de $86 \%$. 


\subsubsection{Tratamento estatístico dos dados}

Primeiramente, foi elaborado um banco de dados no Statistical Package for Social Science - SPSS (versão oficial 17.0). Em seguida, os dados foram inseridos nesse banco de dados para serem submetidos ao tratamento de estatística descritiva e inferencial.

A normalidade das variáveis foi testada por meio do Teste de Shapiro-Wilk. A partir da constatação de que as variáveis não possuíam distribuição normal, optouse pela estatística não-paramétrica para as comparações entre grupos e intragrupo.

Para a análise de comparação entre grupos (Grupo Sacarose X Grupo Água), as variáveis de caracterização da amostra e de evolução clínica, bem como as variáveis referentes à reatividade biocomportamental dos recém-nascidos à dor foram analisadas pelo Teste não-paramétrico de Mann-Whitney para amostras independentes para as variáveis contínuas (escore), e pelo Teste de Qui-quadrado para as variáveis categóricas (nota de corte).

Para a análise de comparação intragrupo, as variáveis referentes à reatividade biocomportamental dos recém-nascidos à dor foram analisadas por meio de estatística não-paramétrica com Teste de Friedman e Teste de Wilcoxon, comparando-se, respectivamente, as fases e os dias de avaliação. A análise intragrupo comparou a mesma fase entre os quatro dias de avaliação (1 ${ }^{\mathrm{a}}$ avaliação $\times 2^{\mathrm{a}}$ avaliação $\times 3^{\mathrm{a}}$ avaliação X $4^{\mathrm{a}}$ avaliação), as diferentes fases em cada uma das avaliações (LB X PP X P X RCM X RSM), além da comparação da variável frequência cardíaca entre diversos momentos de uma mesma fase (minuto a minuto).

O nível de significância adotado no presente estudo foi de $5 \%(p \leq 0,05)$. 


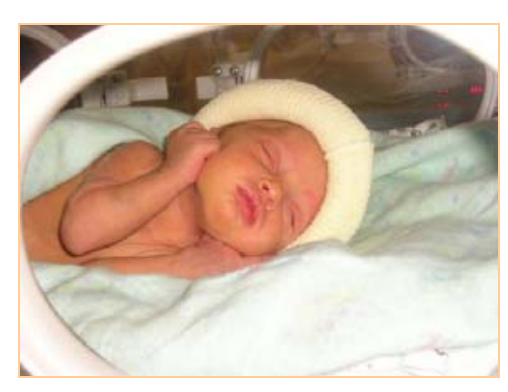

4. RESULTADOS 
Os resultados do presente estudo serão apresentados em quatro seções. $\mathrm{Na}$ primeira seção serão mostrados os dados relativos à caracterização da amostra, incluindo as variáveis neonatais e de evolução clínica dos neonatos do Grupo Sacarose e do Grupo Água.

Na segunda seção será apresentada a história de exposição a procedimentos dolorosos dos recém-nascidos de ambos os grupos, bem como os as principais características do procedimento de punção para coleta de sangue, avaliadas tanto no Grupo Sacarose como no Grupo Água.

$\mathrm{Na}$ terceira seção serão mostrados os dados referentes à reatividade biocomportamental à dor dos recém-nascidos do Grupo Sacarose e Grupo Água, nos quatro dias de avaliação, durante o procedimento de coleta de sangue. Para tanto, serão apresentados os resultados relativos a: a) comparação de cada fase do procedimento entre os dias de avaliação, considerando-se cada grupo separadamente; b) comparação entre as fases do procedimento de cada dia de avaliação, também considerando cada grupo separadamente; c) comparação entre o Grupo Sacarose e Grupo Água, respectivamente, nos quatro dias de avaliação, quanto à reatividade biocomportamental à dor dos neonatos; d) comparação do indicador de frequência cardíaca, minuto a minuto da fase de recuperação, avaliado no primeiro dia de intervenção com sacarose, considerando-se cada grupo separadamente. 
Por fim, na quarta seção será apresentada a evolução clínica dos neonatos de ambos os grupos durante todo o tempo de hospitalização com a finalidade da avaliação dos possíveis efeitos colaterais advindos do uso da solução de sacarose.

\subsection{Caracterização da amostra}

A Tabela 1 apresenta as características da amostra e evolução clínica dos neonatos do Grupo Sacarose e do Grupo Água. 
Tabela 1 - Características da amostra e da evolução clínica dos neonatos do Grupo Sacarose (GS) e do Grupo Água (GA).

\begin{tabular}{|c|c|c|c|}
\hline Características da amostra e evolução clínica & $\begin{array}{c}\text { GS } \\
(n=17)\end{array}$ & $\begin{array}{c}\text { GA } \\
(n=16)\end{array}$ & $\begin{array}{l}\text { Valor de } \mathbf{p} \\
\text { Comparação } \\
\text { entre grupos } \\
\end{array}$ \\
\hline $\begin{array}{l}\text { Sexo } \\
\text { Masculino - } f(\%) \\
\text { Feminino - } f(\%)\end{array}$ & $\begin{array}{l}6(35) \\
11(65)\end{array}$ & $\begin{array}{l}10(62) \\
6(38)\end{array}$ & 0,12 \\
\hline $\begin{array}{l}\text { Idade pós-natal (dias) } \\
\text { Med } \\
\text { (min - max) }\end{array}$ & $\begin{array}{c}2 \\
(1-7)\end{array}$ & $\begin{array}{c}3 \\
(1-12)\end{array}$ & 0,36 \\
\hline $\begin{array}{l}\text { Idade gestacional (semanas) } \\
\text { Med } \\
\text { (min-max) }\end{array}$ & $\begin{array}{c}30 \\
(25-33)\end{array}$ & $\begin{array}{c}31 \\
(27-33)\end{array}$ & 0,20 \\
\hline $\begin{array}{l}\text { Peso ao nascimento (gramas) } \\
\text { Med } \\
\text { (min - max) }\end{array}$ & $\begin{array}{c}995 \\
(640-1.430)\end{array}$ & $\begin{array}{c}1.177 \\
(685-1.360)\end{array}$ & 0,40 \\
\hline $\begin{array}{l}\text { Adequação para a idade gestacional } \\
\text { PIG }-f(\%) \\
\text { AIG }-f(\%)\end{array}$ & $\begin{array}{l}8(47) \\
9(53)\end{array}$ & $\begin{array}{c}11(69) \\
5(31)\end{array}$ & 0,20 \\
\hline $\begin{array}{l}\text { Apgar no } 5^{\circ} \text { minuto (escore) } \\
\text { Med } \\
\text { (min - max) }\end{array}$ & $\begin{array}{c}8 \\
(5-10)\end{array}$ & $\begin{array}{c}9 \\
(6-10)\end{array}$ & 0,95 \\
\hline $\begin{array}{l}\text { Índice de risco clínico neonatal } \\
\text { (escore no CRIB) } \\
\text { Med } \\
\text { (min - max) }\end{array}$ & $\begin{array}{c}4 \\
(0-11)\end{array}$ & $\begin{array}{c}1 \\
(0-13)\end{array}$ & 0,20 \\
\hline Neonatos em ventilação assistida - $f(\%)$ & $17(100)$ & $16(100)$ & \\
\hline Neonatos intubados $-\mathrm{f}(\%)$ & $2(11)$ & $3(18)$ & 0,57 \\
\hline
\end{tabular}

Na Tabela 1 verifica-se que não foram encontradas diferenças significativas entre os grupos GS e GA quanto às características neonatais e de evolução clínica.

De forma similar, em ambos os grupos, os neonatos estavam entre as primeiras duas semanas de vida, e eram compostos por neonatos com idade gestacional em torno de 30 semanas e peso ao nascimento de 1.000 gramas. 
Em relação às características de evolução clínica, nota-se que o Apgar do $5^{\circ}$ minuto foi sugestivo de bom prognóstico, em ambos os grupos, os quais apresentaram índice moderado de risco clínico neonatal. Além disso, é possível observar que $100 \%$ dos neonatos estavam fazendo uso de algum tipo de ventilação assistida, sendo que, destes, $11 \%$ dos neonatos do grupo GS e $18 \%$ dos neonatos do grupo GA estavam intubados.

4.2. História de experiências dolorosas dos recém-nascidos do Grupo Sacarose e Grupo Água

A Tabela 2 apresenta as características da história de exposição a procedimentos dolorosos dos neonatos anterior à primeira avaliação, no Grupo Sacarose e no Grupo Água, relativa à incidência de procedimentos invasivos sofridos desde o nascimento em relação à idade pós-natal e incidência de procedimentos invasivos sofridos nas últimas 24 horas anteriores a cada dia de avaliação. Os procedimentos dolorosos avaliados foram: lancetagem de calcâneo, acesso venoso central, acesso venoso puncionado para nutrição parenteral e medicações, punção para coleta de sangue para exames, punção para inserção de cateter de acesso central, inserção de sonda orogástrica, intubação orotraqueal, inserção de dreno de tórax e aspiração de vias aéreas. 
Tabela 2 - Características da história de exposição a procedimentos dolorosos dos neonatos anterior às avaliações, no Grupo Sacarose (GS) e no Grupo Água (GA).

\begin{tabular}{lccc}
$\begin{array}{l}\text { Características da história de exposição a } \\
\text { procedimentos dolorosos }\end{array}$ & $\begin{array}{c}\text { GS } \\
(n=17)\end{array}$ & $\begin{array}{c}\text { GA } \\
(\mathbf{n}=16)\end{array}$ & $\begin{array}{l}\text { Valor de } \mathbf{p} \\
\text { Comparação } \\
\text { entre grupos }\end{array}$ \\
\hline
\end{tabular}

Ocorrência de procedimentos dolorosos desde o nascimento / idade pós-natal

Med $(\min -\max )$

$\begin{array}{ccc}7 & 5 & 0,65 \\ (3-9) & (1-18) & \end{array}$

Ocorrência de procedimentos dolorosos nas últimas

24 horas anteriores à Avaliação 1

Med

$(\min -\max )$

$\begin{array}{ccc}6 & 2 & 0,90\end{array}$

Ocorrência de procedimentos dolorosos nas últimas

24 horas anteriores à Avaliação 2

Med

$(\min -\max )$

$\begin{array}{ccc}6 & 6 & 0,84 \\ (2-11) & (2-14)\end{array}$

Ocorrência de procedimentos dolorosos nas últimas

24 horas anteriores à Avaliação 3

Med

$(\min -\max )$

$\begin{array}{cc}5 & 6 \\ (2-14) & (1-10)\end{array}$

0,90

Ocorrência de procedimentos dolorosos nas últimas

24 horas anteriores à Avaliação 4

Med

(min - max)

Med = Mediana; $\min =$ valor mínimo; $\max =$ valor máximo.

\begin{tabular}{ccc}
4 & 5 & 0,20 \\
$(1-10)$ & $(1-13)$ & \\
\hline
\end{tabular}

De acordo com os dados apresentados na Tabela 2, ambos os grupos foram comparáveis em relação às características da história anterior de experiências dolorosas, pois não houve diferença estatisticamente significativa entre os grupos.

Os neonatos do grupo GS sofreram em torno de sete procedimentos invasivos por dia desde o nascimento até a primeira avaliação, enquanto que os neonatos do grupo GA sofreram em torno de cinco procedimentos invasivos.

Em relação às ultimas 24 horas anteriores a cada avaliação realizada, os recém-nascidos do grupo GS receberam de quatro a seis procedimentos dolorosos, 
enquanto que os recém-nascidos do grupo GA receberam de dois a cinco procedimentos dolorosos.

A Tabela 3 apresenta os dados referentes à análise comparativa, entre o Grupo Sacarose e Grupo Água, e entre os quatro dias de avaliação, das principais variáveis do procedimento de punção, tais como número de tentativas de punção, duração da fase de punção e tipo de punção realizada. 
Tabela 3 - Características do procedimento de punção do Grupo Sacarose (GS) e Grupo Água (GA) nos quatro dias de avaliação.

\begin{tabular}{|c|c|c|c|c|c|c|c|c|c|c|}
\hline \multirow{2}{*}{$\begin{array}{l}\text { Características } \\
\text { da Punção }\end{array}$} & \multicolumn{2}{|c|}{$\begin{array}{c}\text { Avaliação } 1 \\
\text { (sem intervenção) }\end{array}$} & \multicolumn{2}{|c|}{$\begin{array}{c}\text { Avaliação } 2 \\
\text { (sob intervenção) }\end{array}$} & \multicolumn{2}{|c|}{$\begin{array}{c}\text { Avaliação } 3 \\
\text { (sob intervenção) }\end{array}$} & \multicolumn{2}{|c|}{$\begin{array}{c}\text { Avaliação } 4 \\
\text { (sob intervenção) }\end{array}$} & \multicolumn{2}{|c|}{ Valor de $p$} \\
\hline & $\begin{array}{c}\text { GS } \\
(n=17)\end{array}$ & $\begin{array}{c}\text { GA } \\
(n=16)\end{array}$ & $\begin{array}{c}\text { GS } \\
(n=17)\end{array}$ & $\begin{array}{c}\text { GA } \\
(n=16)\end{array}$ & $\begin{array}{c}\text { GS } \\
(n=17)\end{array}$ & $\begin{array}{c}\text { GA } \\
(n=16)\end{array}$ & $\begin{array}{c}\text { GS } \\
(n=15)\end{array}$ & $\begin{array}{c}\text { GA } \\
(n=16)\end{array}$ & $\begin{array}{l}\text { Comparação } \\
\text { entre grupos }\end{array}$ & $\begin{array}{c}\text { Comparação } \\
\text { intragrupo }\end{array}$ \\
\hline $\begin{array}{l}\text { Tentativas de } \\
\text { punção }\end{array}$ & & & & & & & & & Av. $1=0,12$ & \\
\hline $\begin{array}{l}\text { Med } \\
(\min -\max )\end{array}$ & $\begin{array}{c}2 \\
(1-5)\end{array}$ & $\begin{array}{c}1 \\
(1-3)\end{array}$ & $\begin{array}{c}1 \\
(1-5)\end{array}$ & $\begin{array}{c}1 \\
(1-6)\end{array}$ & $\begin{array}{c}1 \\
(1-4)\end{array}$ & $\begin{array}{c}1 \\
(1-5)\end{array}$ & $\begin{array}{c}1 \\
(1-4)\end{array}$ & $\begin{array}{c}1 \\
(1-4)\end{array}$ & $\begin{array}{l}\text { Av. } 2=0,65 \\
\text { Av.3 }=0,68 \\
\text { Av.4 }=0,83\end{array}$ & $\begin{array}{l}\mathrm{GS}=0,38 \\
\mathrm{GA}=0,70\end{array}$ \\
\hline $\begin{array}{l}\text { Duração da fase } \\
\text { punção } \\
\text { (segundos) }\end{array}$ & & & & & & & & & $\begin{array}{l}\text { Av.1 }=0,06 \\
\text { Av.2 }=0,51\end{array}$ & $\mathrm{GS}=0,93$ \\
\hline $\begin{array}{l}\text { Med } \\
(\min -\max )\end{array}$ & $\begin{array}{c}270 \\
(30-770)\end{array}$ & $\begin{array}{c}77 \\
(39-456)\end{array}$ & $\begin{array}{c}160 \\
(35-1235)\end{array}$ & $\begin{array}{c}174 \\
(43-1010)\end{array}$ & $\begin{array}{c}133 \\
(50-1295)\end{array}$ & $\begin{array}{c}133 \\
(50-1295)\end{array}$ & $\begin{array}{c}123 \\
(35-557)\end{array}$ & $\begin{array}{c}162 \\
(39-660)\end{array}$ & $\begin{array}{l}\text { Av.3 }=0,53 \\
\text { Av.4 }=0,86\end{array}$ & $\mathrm{GA}=0,07$ \\
\hline Tipo de punção & & & & & & & & & Av.1 $=0,85$ & \\
\hline Arterial - f (\%) & $13(76)$ & $13(84)$ & $15(88)$ & $9(55)$ & $13(76)$ & $10(63)$ & $10(67)$ & $9(55)$ & Av. $2=0,10$ & $\mathrm{GS}=0,54$ \\
\hline Venosa - f (\%) & $2(12)$ & $1(5)$ & $1(6)$ & $5(34)$ & $1(6)$ & $4(26)$ & $2(14)$ & $3(19)$ & Av. $3=0,30$ & $\mathrm{GA}=0,19$ \\
\hline Capilar - f (\%) & $2(12)$ & $2(11)$ & $1(6)$ & $2(11)$ & $3(18)$ & $2(11)$ & $3(19)$ & $4(26)$ & Av. $4=0,83$ & \\
\hline
\end{tabular}

Med = Mediana; $\min =$ valor mínimo; $\max =$ valor máximo; $f$ = frequência; $\%=$ porcentagem . 
Segundo os dados apresentados na Tabela 3 , em ambos os grupos o número de tentativas de punção realizada pela enfermeira no momento da coleta de sangue ficou por volta de uma tentativa nos quatro dias de avaliação, sendo que o tipo de punção predominante foi a punção arterial. A duração do procedimento de punção também se manteve semelhante em ambos os grupos, durante os quatro dias de avaliação.

Os grupos GS e GA foram comparáveis, na medida em que não houve diferença estatisticamente significativa entre os grupos, quanto ao número de tentativas de punção, duração da punção e tipo de punção realizada.

A comparação intragrupo das quatro avaliações também não revelou diferenças estatisticamente significativas em ambos os grupos, quanto ao número de tentativas de punção, duração da fase de punção e tipo de punção.

\subsection{Reatividade biocomportamental dos recém-nascidos à dor}

4.3.1. Comparação entre os dias de avaliação, considerando-se cada fase e cada grupo

Com a finalidade de comparar cada fase do procedimento de coleta de sangue nos quatro dias de avaliação, realizou-se a comparação intragrupo dos indicadores biocomportamentais de atividade facial, a partir do escore do NFCS, estado de vigília e sono e frequência cardíaca média, separadamente, no Grupo Sacarose e no Grupo Água. 
Faz-se importante ressaltar que no último dia de avaliação foram coletados os dados de apenas 15 neonatos do Grupo Sacarose, visto que no dia da observação dois neonatos estavam sob uso de medicações sedativas. Além disso, durante a análise das vídeo-gravações para a pontuação do NFCS, foram perdidos dados de três fases de Preparação para Punção no Grupo Sacarose e duas fases no Grupo Água, pois os neonatos apresentavam-se com o rosto encoberto.

\subsubsection{Linha de Base}

Os dados referentes à comparação dos indicadores biocomportamentais de atividade facial, estado de vigília e sono e frequência cardíaca média, na fase de Linha de Base (LB), nos quatro dias de avaliação, para o Grupo Sacarose e Grupo Água encontram-se na Tabela 4. 
Tabela 4 - Indicadores biocomportamentais de atividade facial (escore do NFCS), estado de vigília e sono e frequência cardíaca média, do Grupo Sacarose e Grupo Água, na fase de Linha de Base, nos quatro dias de avaliação.

\begin{tabular}{|c|c|c|c|c|c|}
\hline $\begin{array}{l}\text { Indicadores } \\
\text { Biocomportamentais I } \\
\text { Avaliações }\end{array}$ & $\begin{array}{c}\text { Avaliação } 1 \\
\text { (sem intervenção) }\end{array}$ & $\begin{array}{c}\text { Avaliação } 2 \\
\text { (sob intervenção) }\end{array}$ & $\begin{array}{c}\text { Avaliação } 3 \\
\text { (sob intervenção) }\end{array}$ & $\begin{array}{c}\text { Avaliação } 4 \\
\text { (sob intervenção) }\end{array}$ & $\begin{array}{c}\text { Valor de } \mathbf{p} \\
\text { Comparação intragrupo }\end{array}$ \\
\hline Grupo Sacarose & & & & & \\
\hline $\begin{array}{l}\text { Atividade Facial (escore NFCS) } \\
\text { Med (min - max) }\end{array}$ & $0(0-6)$ & $0(0-33)$ & $0(0-50)$ & $0(0-10)$ & 0,18 \\
\hline $\begin{array}{l}\text { Estado de Vigília e Sono } \\
\text { Med (min - max) }\end{array}$ & $2(1-4)$ & $2(1-6)$ & $2(1-6)$ & $2(1-5)$ & 0,60 \\
\hline $\begin{array}{l}\text { Frequência Cardíaca Média } \\
\text { Med (min - max) }\end{array}$ & $140(129-174)$ & $147(130-169)$ & $146(124-172)$ & 151(124 - 189) & 0,35 \\
\hline Grupo Água & & & & & \\
\hline $\begin{array}{l}\text { Atividade Facial (escore NFCS) } \\
\text { Med (min - max) }\end{array}$ & $0(0-40)$ & 0 & $0(0-50)$ & $0(0-9)$ & 0,30 \\
\hline $\begin{array}{l}\text { Estado de Vigília e Sono } \\
\text { Med (min - max) }\end{array}$ & $2(1-3)$ & $2(1-5)$ & $2(1-5)$ & $2(1-5)$ & 0,95 \\
\hline $\begin{array}{l}\text { Frequência Cardíaca Média } \\
\text { Med (min - max) }\end{array}$ & $145(128-167)$ & $149(100-174)$ & $154(130-180)$ & $155(137-170)$ & 0,15 \\
\hline
\end{tabular}

Med = Mediana; $\min =$ valor mínimo; $\max =$ valor máximo

${ }^{(1)} 1$ = Sono Profundo; 2 = Sono Ativo; 3 = Sonolência; 4 = Alerta Quieto; 5 = Alerta Ativo; 6 = Choro. 
De acordo com os dados apresentados na Tabela 4, verifica-se que na fase LB não houve diferença significativa entre os quatro dias de avaliação nas três variáveis analisadas em ambos os grupos. Este dado demonstra que, em todos os dias de avaliação, os neonatos do grupo GS e GA estavam praticamente sem apresentar atividade facial, em estado de sono ativo e frequência cardíaca média indicativa de baixa reatividade fisiológica antes de todos os procedimentos de punção para coleta de sangue avaliados.

\subsubsection{Preparação para Punção}

Realizou-se a comparação intragrupo dos indicadores biocomportamentais de atividade facial, estado de vigília e sono e frequência cardíaca média, para o Grupo Sacarose e Grupo Água, na fase de Preparação para Punção (PP), nos quatro dias de avaliação. Os dados encontram-se na Tabela 5. 
Tabela 5 - Indicadores biocomportamentais de atividade facial (escore do NFCS), estado de vigília e sono e frequência cardíaca média, do Grupo Sacarose e Grupo Água, na fase de Preparação para Punção, nos quatro dias de avaliação.

\begin{tabular}{|c|c|c|c|c|c|c|c|}
\hline $\begin{array}{l}\text { Indicadores } \\
\text { Biocomportamentais I } \\
\text { Avaliações }\end{array}$ & $\begin{array}{c}\text { Avaliação } 1 \\
\text { (sem intervenção) }\end{array}$ & $\begin{array}{c}\text { Avaliação } 2 \\
\text { (sob intervenção) }\end{array}$ & $\begin{array}{c}\text { Avaliação } 3 \\
\text { (sob intervenção) }\end{array}$ & $\begin{array}{c}\text { Avaliação } 4 \\
\text { (sob intervenção) }\end{array}$ & $\begin{array}{r}\mathbf{V a} \\
\text { Compar }\end{array}$ & $\mathbf{p}_{\text {ragrupo }}$ & $\begin{array}{l}\text { Direção da } \\
\text { diferença }\end{array}$ \\
\hline \multicolumn{8}{|l|}{ Grupo Sacarose } \\
\hline $\begin{array}{l}\text { Atividade Facial (escore NFCS) } \\
\text { Med (min - max) }\end{array}$ & $6(0-50)$ & $0(0-28)$ & 0 & $0(0-50)$ & 0,0001 & $\begin{array}{c}0,02 \\
0,005 \\
0,03\end{array}$ & $\begin{array}{l}\text { Av. } 1>A v .2 \\
\text { Av. } 1>A v .3 \\
\text { Av. } 1>\text { Av. } 4\end{array}$ \\
\hline $\begin{array}{l}\text { Estado de Vigília e Sono } \\
\text { Med (min - max) }\end{array}$ & $2(2-6)$ & 2 & $2(1-4)$ & $2(1-6)$ & 0,10 & & \\
\hline $\begin{array}{l}\text { Frequência Cardíaca Média } \\
\text { Med (min - max) }\end{array}$ & $152(135-167)$ & $156(142$ - 179) & $153(107-180)$ & $167(136-189)$ & 0,02 & $\begin{array}{l}0,02 \\
0,02\end{array}$ & $\begin{array}{l}\text { Av. } 1<\text { Av. } 2 \\
\text { Av. } 1<A v .4\end{array}$ \\
\hline \multicolumn{8}{|l|}{ Grupo Água } \\
\hline $\begin{array}{l}\text { Atividade Facial (escore NFCS) } \\
\text { Med ( } \min -\max )\end{array}$ & $6(0-50)$ & $0(0-44)$ & $0(0-50)$ & $0(0-35)$ & 0,33 & & \\
\hline $\begin{array}{l}\text { Estado de Vigília e Sono } \\
\text { Med (min - max) }\end{array}$ & $5(2-6)$ & $2(1-6)$ & $2(2-6)$ & $2(2-6)$ & 0,24 & & \\
\hline $\begin{array}{l}\text { Frequência Cardíaca Média } \\
\text { Med (min - max) }\end{array}$ & $151(111-182)$ & $155(132-166)$ & 159(104 - 188) & $164(142-171)$ & 0,20 & & \\
\hline
\end{tabular}

Med = Mediana; $\min$ = valor mínimo; $\max =$ valor máximo.

${ }^{(1)} 1$ = Sono Profundo; 2 = Sono Ativo; 3 = Sonolência; 4 = Alerta Quieto; 5 = Alerta Ativo; 6 = Choro. 
Os dados apresentados na Tabela 5 revelam que, na fase PP, momento em que se realiza a antissepsia que antecede o procedimento de punção, os neonatos do Grupo GS apresentaram uma diminuição significativa da atividade facial entre o primeiro dia de avaliação (sem intervenção) e os três dias consecutivos, nos quais foi administrada a solução de sacarose dois minutos antes do procedimento. Por outro lado, os neonatos apresentaram frequência cardíaca média significativamente mais baixa no primeiro dia de avaliação, em comparação ao segundo e quarto dias. Em relação ao estado de vigília e sono, os neonatos estiveram basicamente em sono ativo, antes do procedimento doloroso, em todos os dias de avaliação.

Os neonatos que receberam água estéril antes do procedimento doloroso no segundo, terceiro e quarto dias de avaliação, apresentaram um padrão de atividade biocomportamental semelhante antes do procedimento doloroso, nos diferentes dias de avaliação.

\subsubsection{Punção}

Foi realizada a comparação intragrupo dos indicadores biocomportamentais atividade facial, estado de vigília e sono e frequência cardíaca média, para o Grupo Sacarose e Grupo Água, na fase de Punção (P), nos quatro dias de avaliação. Os dados encontram-se na Tabela 6. 
Tabela 6 - Indicadores biocomportamentais de atividade facial (escore do NFCS), estado de vigília e sono e frequência cardíaca média, do Grupo Sacarose e Grupo Água, na fase de Punção, nos quatro dias de avaliação.

\begin{tabular}{|c|c|c|c|c|c|c|c|}
\hline $\begin{array}{l}\text { Indicadores } \\
\text { Biocomportamentais I } \\
\text { Avaliações }\end{array}$ & $\begin{array}{c}\text { Avaliação } 1 \\
\text { (sem intervenção) }\end{array}$ & $\begin{array}{c}\text { Avaliação } 2 \\
\text { (sob intervenção) }\end{array}$ & $\begin{array}{c}\text { Avaliação } 3 \\
\text { (sob intervenção) }\end{array}$ & $\begin{array}{c}\text { Avaliação } 4 \\
\text { (sob intervenção) }\end{array}$ & $\begin{array}{r}\text { Va } \\
\text { Compar }\end{array}$ & $\begin{array}{l}\mathbf{p} \\
\text { ragrupo }\end{array}$ & $\begin{array}{l}\text { Direção da } \\
\text { diferença }\end{array}$ \\
\hline \multicolumn{8}{|l|}{ Grupo Sacarose } \\
\hline $\begin{array}{l}\text { Atividade Facial (escore NFCS) } \\
\text { Med ( } \min -\max \text { ) }\end{array}$ & $45(0-50)$ & $0(0-35)$ & $0(0-36)$ & $0(0-50)$ & 0,001 & $\begin{array}{c}0,002 \\
0,003 \\
0,01\end{array}$ & $\begin{array}{l}\text { Av.1>Av. } 2 \\
\text { Av. } 1>A v .3 \\
\text { Av.1>Av. } 4\end{array}$ \\
\hline $\begin{array}{l}\text { Estado de Vigília e Sono }{ }^{(1)} \\
\text { Med (min - max) }\end{array}$ & $6(2-6)$ & $2(2-6)$ & $2(2-6)$ & $2(1-6)$ & 0,0001 & $\begin{array}{l}0,002 \\
0,002 \\
0,005\end{array}$ & $\begin{array}{l}\text { Av. } 1>A v .2 \\
\text { Av. } 1>A v .3 \\
\text { Av. } 1>A v .4\end{array}$ \\
\hline $\begin{array}{l}\text { Frequência Cardíaca Média } \\
\text { Med (min - max) }\end{array}$ & $164(138-186)$ & 161(145 - 183) & $162(107-179)$ & 171(131 - 200) & 0,33 & & \\
\hline \multicolumn{8}{|l|}{ Grupo Água } \\
\hline $\begin{array}{l}\text { Atividade Facial (escore NFCS) } \\
\text { Med (min - max) }\end{array}$ & $33(0-50)$ & $15(0-50)$ & $1(0-50)$ & $15(0-50)$ & 0,90 & & \\
\hline $\begin{array}{l}\text { Estado de Vigília e Sono }{ }^{(1)} \\
\text { Med (min - max) }\end{array}$ & $6(2-6)$ & $6(2-6)$ & $2(2-6)$ & $5(2-6)$ & 0,20 & & \\
\hline $\begin{array}{l}\text { Frequência Cardíaca Média } \\
\text { Med (min - max) }\end{array}$ & $157(130-186)$ & $162(134-188)$ & $166(136-196)$ & $169(146-179)$ & 0,37 & & \\
\hline
\end{tabular}

Med = Mediana; $\min$ = valor mínimo; $\max =$ valor máximo.

(1) 1 = Sono Profundo; 2 = Sono Ativo; 3 = Sonolência; 4 = Alerta Quieto; 5 = Alerta Ativo; 6 = Choro. 
A partir dos dados apresentados na Tabela 6 pode-se afirmar que os neonatos dos grupos GS e GA apresentaram padrões de reatividade comportamental diferentes na fase $\mathrm{P}$, na qual é realizado o procedimento doloroso de punção para coleta de sangue, quando comparado o primeiro dia de avaliação (sem intervenção), com os demais dias em que a sacarose ou a água estéril foram administradas. No grupo GS os neonatos foram significativamente menos reativos do ponto de vista comportamental, apresentando-se em estado de sono ativo e com baixa atividade facial nas punções dos dias em que a sacarose foi administrada, em comparação a primeira punção avaliada. Esta alteração não ocorreu nos neonatos do grupo GA, que permaneceram com um padrão de ativação comportamental semelhante em todas as punções avaliadas. Para o indicador fisiológico de frequência cardíaca média não houve diferença significativa entre os dias de avaliação na fase $\mathrm{P}$, em ambos os grupos.

\subsubsection{Recuperação com Manuseio}

Realizou-se a comparação intragrupo dos indicadores biocomportamentais de atividade facial, estado de vigília e sono e frequência cardíaca média, para o Grupo Sacarose e Grupo Água, na fase de Recuperação com Manuseio (RCM), nos quatro dias de avaliação. Os dados encontram-se na Tabela 7. 
Tabela 7 - Indicadores biocomportamentais de atividade facial (escore do NFCS), estado de vigília e sono e frequência cardíaca média, do Grupo Sacarose e Grupo Água, na fase de Recuperação com Manuseio, nos quatro dias de avaliação.

\begin{tabular}{|c|c|c|c|c|c|c|c|}
\hline \multirow[t]{2}{*}{$\begin{array}{l}\text { Indicadores } \\
\text { Biocomporta } \\
\text { Avaliações }\end{array}$} & \multirow[t]{2}{*}{$\begin{array}{c}\text { Avaliação } 1 \\
\text { (sem intervenção) }\end{array}$} & \multirow[t]{2}{*}{$\begin{array}{c}\text { Avaliação } 2 \\
\text { (sob intervenção) }\end{array}$} & \multirow[t]{2}{*}{$\begin{array}{c}\text { Avaliação } 3 \\
\text { (sob intervenção) }\end{array}$} & \multirow[t]{2}{*}{$\begin{array}{c}\text { Avaliação } 4 \\
\text { (sob intervenção) }\end{array}$} & \multicolumn{2}{|c|}{$\begin{array}{c}\text { Valor de p } \\
\text { Comparação intragrupo }\end{array}$} & \multirow[t]{2}{*}{$\begin{array}{c}\text { Direção da } \\
\text { diferença }\end{array}$} \\
\hline & & & & & & & \\
\hline $\begin{array}{l}\text { Atividade Facial (escore NFCS) } \\
\text { Med (min - max) }\end{array}$ & $30(0-51)$ & $0(0-30)$ & 0 & $0(0-30)$ & 0,002 & $\begin{array}{c}0,009 \\
0,005 \\
0,01\end{array}$ & $\begin{array}{l}\text { Av. } 1>A v .2 \\
\text { Av. } 1>A v .3 \\
\text { Av. } 1>A v .4\end{array}$ \\
\hline $\begin{array}{l}\text { Estado de Vigília e Sono } \\
\text { Med (min - max) }\end{array}$ & $6(2-6)$ & $2(2-6)$ & $2(2-4)$ & $2(2-6)$ & 0,007 & $\begin{array}{c}0,04 \\
0,005 \\
0,01\end{array}$ & $\begin{array}{l}\text { Av. } 1>A v .2 \\
\text { Av. } 1>A v .3 \\
\text { Av. } 1>A v .4\end{array}$ \\
\hline $\begin{array}{l}\text { Frequência Cardíaca Média } \\
\text { Med (min - max) }\end{array}$ & $168(139-199)$ & $164(146-190)$ & $165(142-174)$ & $160(125$ - 197) & 0,26 & & \\
\hline Grupo Água & & & & & & & \\
\hline $\begin{array}{l}\text { Atividade Facial (escore NFCS) } \\
\text { Med (min - max) }\end{array}$ & $15(0-50)$ & $1(0-50)$ & $0(0-50)$ & $21(0-50)$ & 0,46 & & \\
\hline $\begin{array}{l}\text { Estado de Vigília e Sono }{ }^{(1)} \\
\text { Med (min - max) }\end{array}$ & $3(2-6)$ & $3(2-6)$ & $4(2-6)$ & $3(2-6)$ & 0,92 & & \\
\hline $\begin{array}{l}\text { Frequência Cardíaca Média } \\
\text { Med (min - max) }\end{array}$ & $162(138-189)$ & 165 (132 - 199) & $164(138-205)$ & $166(148-197)$ & 0,16 & & \\
\hline
\end{tabular}


Assim como verificado na fase $P$, os dados apresentados na Tabela 7 demonstram que, na fase RCM, em que se realiza o curativo após a punção para coleta de sangue, os neonatos do grupo GS foram significativamente menos reativos, tanto na atividade facial como no estado de vigília e sono, nos dias em que a sacarose foi administrada em comparação ao primeiro dia de avaliação. Esta alteração não ocorreu nos neonatos do grupo GA, que apresentaram o mesmo padrão de reatividade comportamental durante a realização do curativo, em todos os dias de avaliação. O indicador fisiológico de frequência cardíaca média não mostrou diferença significativa entre os dias de avaliação, em ambos os grupos.

\subsubsection{Recuperação sem Manuseio}

Realizou-se a comparação intragrupo dos indicadores biocomportamentais de atividade facial, estado de vigília e sono e frequência cardíaca média, para o Grupo Sacarose e Grupo Água, na fase de Recuperação sem Manuseio (RSM), nos quatro dias de avaliação. Os dados encontram-se na Tabela 8. 
Tabela 8 - Indicadores biocomportamentais de atividade facial (escore do NFCS), estado de vigília e sono e frequência cardíaca média, do Grupo Sacarose e Grupo Água, na fase de Recuperação sem Manuseio, nos quatro dias de avaliação.

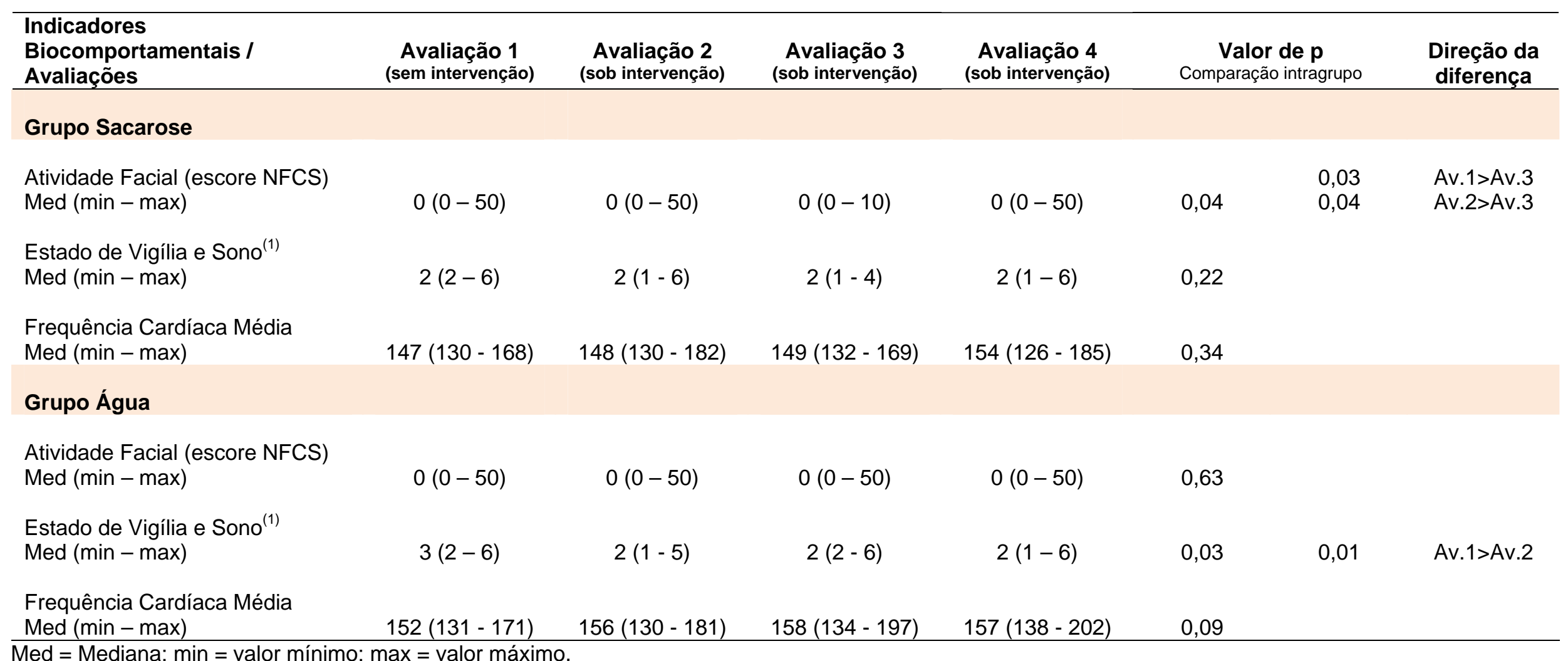

Med = Mediana; $\min =$ valor mínimo; max = valor máximo.

${ }^{(1)} 1$ = Sono Profundo; 2 = Sono Ativo; 3 = Sonolência; 4 = Alerta Quieto; 5 = Alerta Ativo; 6 = Choro. 
A análise dos dados apresentados na Tabela 8 mostra que os neonatos do grupo GS, quando em repouso, após o término de todo o procedimento doloroso (fase RSM) tiveram uma diminuição significativa da atividade facial apenas no terceiro dia de avaliação, em comparação aos demais dias. Em relação às variáveis estado de vigília e sono e frequência cardíaca média, os neonatos comportaram-se de maneira semelhante nos quatro dias de avaliação, independente da administração da solução de sacarose antes do procedimento doloroso.

No grupo de neonatos que recebeu água estéril no segundo, terceiro e quarto dias de avaliação, houve diferença significativa entre o primeiro e segundo dias de observação apenas no estado de vigília e sono, sendo que no primeiro dia os neonatos se apresentaram em estado comportamental de sonolência, e no segundo dia em sono ativo, enquanto permaneciam em repouso após a realização do procedimento doloroso. Nas demais variáveis avaliadas, atividade facial e frequência cardíaca média, os neonatos não apresentaram alterações na reatividade durante os quatro dias de avaliação.

4.3.2. Comparação entre as fases do procedimento de coleta de sangue de cada dia de avaliação

Com a finalidade de comparar as diferentes fases do procedimento de coleta de sangue dentro dos quatro dias de avaliação, realizou-se a comparação intragrupo dos indicadores biocomportamentais de atividade facial, a partir do escore do NFCS, 
estado de vigília e sono e frequência cardíaca média, separadamente, no Grupo Sacarose e no Grupo Água.

\subsubsection{Atividade Facial}

Realizou-se a comparação intragrupo do indicador biocomportamental de atividade facial, a partir do escore do NFCS, em termos de mediana, para o Grupo Sacarose e Grupo Água, entre as fases Linha de Base, Preparação para Punção, Punção, Recuperação com Manuseio e Recuperação sem Manuseio, em cada dia de avaliação. Os dados encontram-se na Figura 2. 

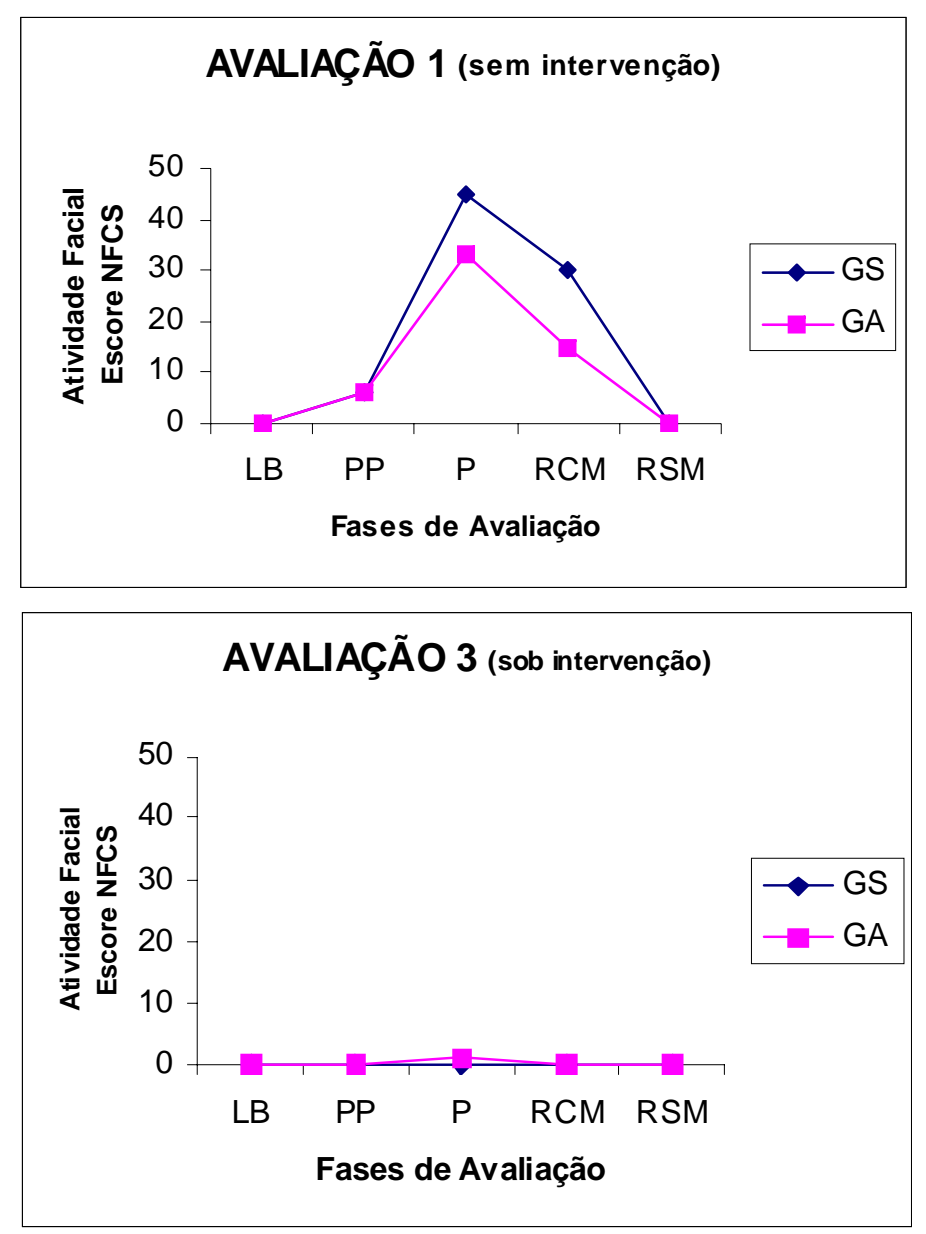
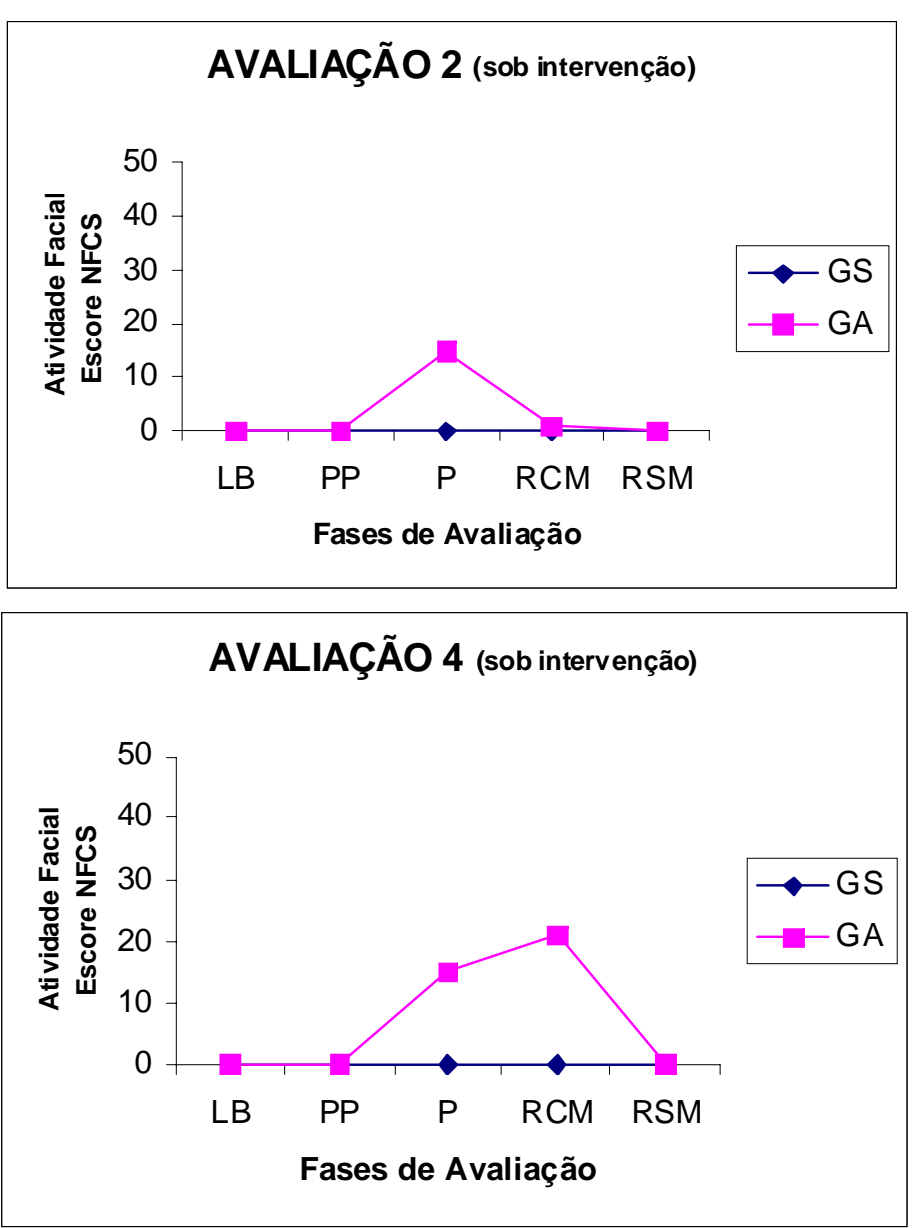

Figura 2 - Indicador biocomportamental de atividade facial (escore NFCS), no Grupo Sacarose (GS) e Grupo Agua (GA) entre as fases Linha de Base (LB), Preparação para Punção (PP), Punção (P), Recuperação com Manuseio (RCM) e Recuperação sem Manuseio (RSM), em cada dia de avaliação. 
Os dados apresentados na Figura 2 revelam que no primeiro dia de observação (Avaliação 1), sem administração da solução de sacarose, os neonatos do grupo GS apresentaram o indicador de dor atividade facial, avaliado pelo escore do NFCS, significativamente diferente entre as fases avaliadas $(p=0,002)$. O escore na fase LB foi significativamente menor em relação às fases $\mathrm{PP}(p=0,007), \mathrm{P}(p=$ 0,002), RCM $(p=0,003)$ e RSM $(p=0,04)$. No grupo GA, os escores do NFCS apresentaram as mesmas características dos escores encontrados no grupo GS. Também neste grupo o escore da atividade facial foi significativamente diferente entre as fases avaliadas $(p=0,001)$. O escore na fase LB foi significativamente menor em relação às fases $\operatorname{PP}(p=0,05), \mathrm{P}(p=0,002)$, e $\operatorname{RCM}(p=0,01)$, na fase $\mathrm{PP}$ significativamente menor do que na fase $\mathrm{P}(p=0,004)$ e na fase $\mathrm{P}$ significativamente maior do que na fase RSM $(p=0,02)$.

Na Avaliação 2, em que foi administrada a solução de sacarose, não houve diferença significativa entre as fases avaliadas no grupo GS, visto que os neonatos apresentaram uma mediana zero do escore do NFCS $(p=0,30)$. No grupo GA, o padrão de diferença entre as fases no escore do NFCS se manteve $(p=0,004)$. 0 escore na fase LB foi significativamente menor em relação às fases $\mathrm{PP}(p=0,04), \mathrm{P}$ $(p=0,007)$ e $\operatorname{RCM}(p=0,01)$, na fase PP significativamente menor do que na fase $\mathrm{P}$ $(p=0,05)$ e na fase $\mathrm{P}$ significativamente maior do que na fase $\operatorname{RSM}(p=0,05)$.

No terceiro dia de observação (Avaliação 3), apesar de as medianas continuarem sendo zero na pontuação do NFCS para o grupo GS, houve diferença estatisticamente significativa entre as fases $(p=0,001)$. O escore da fase LB foi 
significativamente menor em relação às fases $\operatorname{PP}(p=0,04)$ RCM $(p=0,04)$ e RSM $(p$ $=0,04)$, na fase PP significativamente menor em relação à fase $\mathrm{P}(p=0,02)$ e na fase $\mathrm{P}$ significativamente maior em relação às fases $\operatorname{RCM}(p=0,02)$ e $\operatorname{RSM}(p=0,02)$. Esta diferença está relacionada à amplitude do escore do NFCS apresentar-se mais elevada nas fases de LB e $P$ em relação aos escores das demais fases. No grupo GA não houve diferença estatisticamente significativa entre as fases $(p=0,20)$.

No último dia de observação (Avaliação 4), não houve diferença significativa entre as fases no grupo GS $(p=0,70)$, o qual apresentou a mediana do escore do NFCS de todas as fases igual à zero. Para o grupo GA, houve novamente diferença significativa entre as fases $(p=0,004)$. O escore da fase LB foi significativamente menor em relação às fases $\mathrm{P}(p=0,01)$ e RCM $(p=0,007)$, na fase PP significativamente menor em relação à fase $\mathrm{P}(p=0,01)$, na fase $\mathrm{P}$ significativamente menor em relação à fase $\operatorname{RCM}(p=0,03)$ e maior em relação à fase $\operatorname{RSM}(p=0,03)$ e na fase $\operatorname{RCM}$ significativamente maior em relação à fase $\operatorname{RSM}(p=0,05)$.

\subsubsection{Estado de Vigília e Sono}

Realizou-se a comparação intragrupo do indicador biocomportamental estado de vigília e sono, em termos de mediana, para o Grupo Sacarose e Grupo Água, entre as fases Linha de Base, Preparação para Punção, Punção, Recuperação com Manuseio e Recuperação sem Manuseio, em cada dia de avaliação. Os dados encontram-se na Figura 3. 

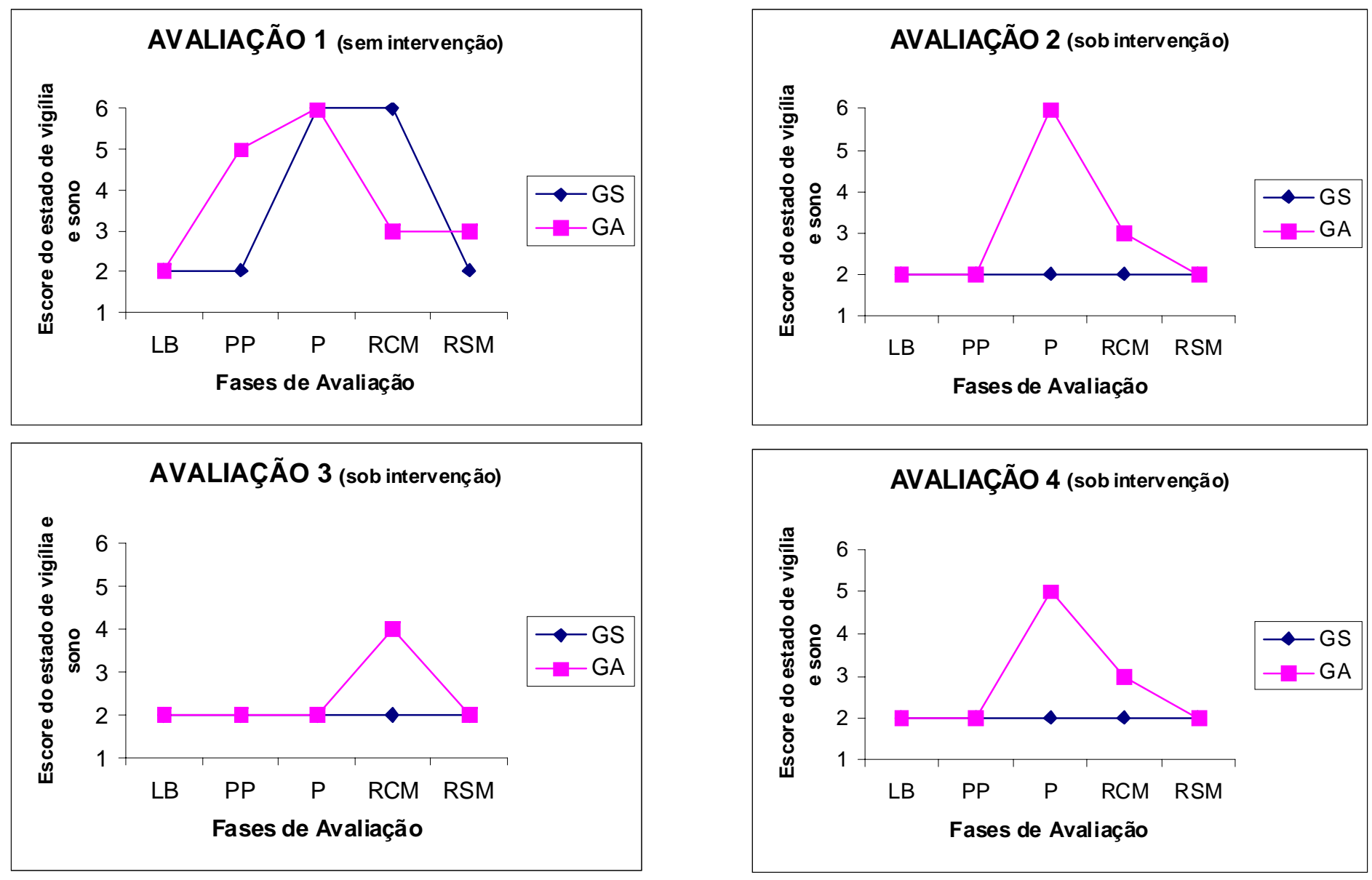

Figura 3 - Indicador biocomportamental de estado de vigília e sono, no Grupo Sacarose (GS) e Grupo Água (GA) entre as fases Linha de Base (LB), Preparação para Punção (PP), Punção (P), Recuperação com Manuseio (RCM) e Recuperação sem Manuseio (RSM), em cada dia de avaliação.

( 1 = Sono Profundo; 2 = Sono Ativo; 3 = Sonolência; 4 = Alerta Quieto; 5 = Alerta Ativo; 6 = Choro) 
De acordo com os dados apresentados na Figura 3 é possível observar que no primeiro dia de avaliação, sem administração da solução de sacarose, os neonatos do grupo GS apresentaram estados de vigília e sono significativamente diferentes entre as fases avaliadas $(p=0,0001)$. Na fase LB, os neonatos apresentaram significativamente menor ativação biocomportamental em relação às fases $\mathrm{PP}(p=0,01), \mathrm{P}(p=0,0001)$ e RCM $(p=0,003)$. Na fase $\mathrm{P}$ os neonatos mostraram-se significativamente mais ativado do que na fase $\operatorname{PP}(p=0,007)$ e na fase RSM $(p=0,01)$. Na fase RCM observou-se maior ativação biocomportamental nestes neonatos em relação à fase RSM $(p=0,004)$.

No grupo GA, a mediana do escore do estado de vigília e sono apresentou-se de maneira semelhante ao encontrado no grupo GS, pois houve diferença significativa entre as fases avaliadas $(p=0,002)$. O escore na fase LB foi significativamente relativo à menor ativação biocomportamental em relação às fases $\mathrm{PP}(p=0,003), \mathrm{P}(p=0,002), \operatorname{RCM}(p=0,005)$ e RSM $(p=0,01)$, e na fase $\mathrm{P}$ significativamente mais ativado em relação à fase $\operatorname{RSM}(p=0,02)$.

Nos três dias que se sucederam ao primeiro dia de avaliação, não houve diferença significativa entre as fases avaliadas no grupo que recebeu a solução de sacarose, visto que os neonatos apresentaram mediana do escore do estado de vigília e sono igual a 2, correspondente ao estado de sono ativo $(p=0,40, p=0,20$, $p=0,40$, respectivamente)

No grupo de neonatos que recebeu água estéril (GA), o padrão de diferença entre as fases no escore do estado de vigília e sono se manteve nos três dias 
consecutivos ( $p=0,0001, p=0,02, p=0,0001$, respectivamente). No segundo dia de avaliação, o escore na fase LB foi significativamente relativo à menor ativação biocomportamental em relação às fases $\operatorname{PP}(p=0,05), \mathrm{P}(p=0,002)$ e $\operatorname{RCM}(p=$ 0,01). Na fase PP os neonatos apresentaram-se significativamente menos ativado em relação à fase $\mathrm{P}(p=0,02)$ e mais ativado do que na fase $\operatorname{RSM}(p=0,01)$. Na fase $\mathrm{P}$ houve maior ativação significativa em relação às fases $\operatorname{RCM}(p=0,04)$ e $\operatorname{RSM}$ $(p=0,002)$ e na fase $\mathrm{RCM}$ em relação à fase $\operatorname{RSM}(p=0,007)$. No terceiro dia de avaliação novamente o escore na fase LB foi significativamente relativo à menor ativação biocomportamental em relação às fases $\operatorname{PP}(p=0,04), \mathrm{P}(p=0,03)$, e RCM $(p=0,04)$. Da mesma maneira, na fase RCM houve maior ativação biocomportamental significativa quando comparada à fase $\operatorname{RSM}(p=0,05)$. No quarto dia de avaliação, os neonatos continuaram a apresentar-se significativamente menos ativados na fase LB em relação às fases $\mathrm{PP}(p=0,02), \mathrm{P}(p=0,002)$ e $\mathrm{RCM}$ $(p=0,03)$. Na fase $\mathrm{P}$ os neonatos apresentaram-se significativamente mais ativados em relação às fases $\operatorname{PP}(p=0,02)$ e $\operatorname{RSM}(p=0,002)$, e na fase $\mathrm{RCM}$ em relação à fase $\operatorname{RSM}(p=0,02)$.

Os neonatos do grupo GA apresentaram um padrão com diferença estatisticamente significativa entre os estados de vigília e sono apresentados nas fases avaliadas, durante os quatro dias de observação. Basicamente, estes neonatos demonstraram um padrão de reatividade biocomportamental maior nas fases de $P$ e RCM, e de menor reatividade na fase $L B$, em relação às demais fases, nos quatro dias de observação. 


\subsubsection{Frequência Cardíaca Média}

Por fim, realizou-se a comparação intragrupo do indicador fisiológico de frequência cardíaca média, para o Grupo Sacarose e Grupo Água, em termos de mediana, entre as fases Linha de Base, Preparação para Punção, Punção, Recuperação com Manuseio e Recuperação sem Manuseio, em cada dia de avaliação. Os dados encontram-se na Figura 4. 

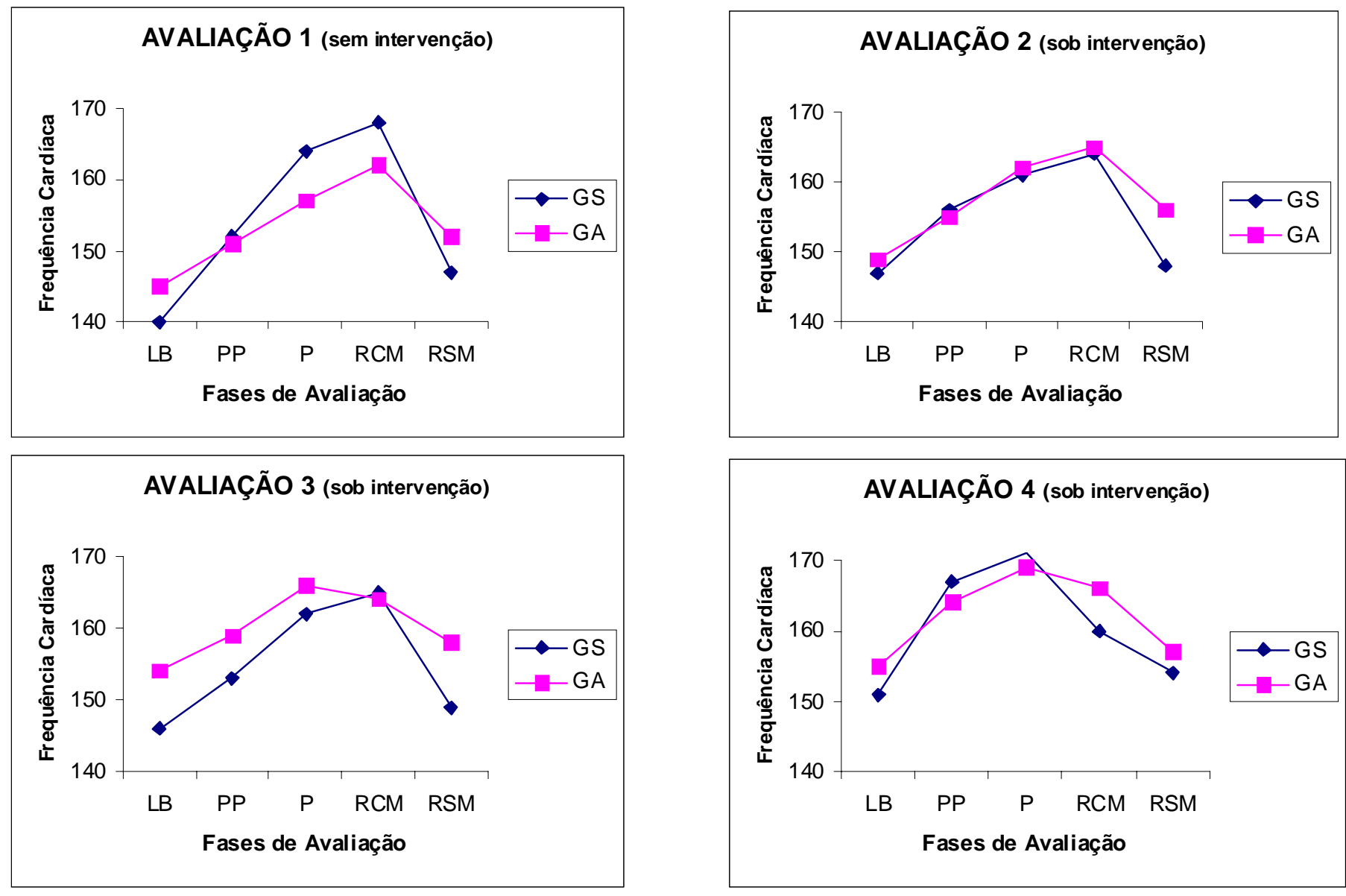

Figura 4 - Indicador fisiológico de frequência cardíaca média, no Grupo Sacarose (GS) e Grupo Água (GA) entre as fases Linha de Base (LB), Preparação para Punção (PP), Punção (P), Recuperação com Manuseio (RCM) e Recuperação sem Manuseio (RSM), em cada dia de avaliação. 
A partir dos dados apresentados na Figura 4 observa-se que nos quatro dias de avaliação, independente da administração da solução de sacarose ou água estéril, os neonatos dos grupos GS e GA apresentaram um padrão semelhante de alteração da frequência cardíaca média. Houve diferença estatisticamente significativa entre as fases nos quatro dias de avaliação (GS: $p=0,0001 ; G A: p=$ $0,0001, p=0,0001, p=0,001, p=0,0001$, respectivamente).

No grupo GS foram encontrados os resultados a seguir. Na primeira avaliação, os neonatos na fase LB apresentaram frequência cardíaca média significativamente menor do que nas fases $\mathrm{PP}(p=0,05), \mathrm{P}(p=0,002)$, e RCM $(p=$ $0,001)$; na fase PP menor do que nas fases $\mathrm{P}(p=0,001)$ e RCM $(p=0,002)$; na fase $\mathrm{P}$ significativamente maior do que na fase $\operatorname{RSM}(p=0,004)$ e na fase $\mathrm{RCM}$ significativamente maior do que na fase $\operatorname{RSM}(p=0,0001)$.

Na segunda avaliação, os neonatos apresentaram na fase LB frequência cardíaca média significativamente menor do que nas fases PP $(p=0,006), \mathrm{P}(p=$ $0,001), \operatorname{RCM}(p=0,001)$ e RSM $(p=0,04)$; na fase PP significativamente menor do que na fase $\mathrm{P}(p=0,007)$; na fase $\mathrm{P}$ significativamente maior do que na fase RSM ( $p$ $=0,006)$ e na fase RCM significativamente maior do que na fase $\operatorname{RSM}(p=0,002)$.

$\mathrm{Na}$ terceira avaliação, os neonatos apresentaram na fase LB frequência cardíaca média significativamente menor do que nas fases PP $(p=0,04), \mathrm{P}(p=$ $0,02)$ e RCM $(p=0,008)$; na fase PP significativamente menor do que nas fases $\mathrm{P}(p$ $=0,006)$ e $\operatorname{RCM}(p=0,03)$ e maior do que na fase $\operatorname{RSM}(p=0,02)$ e na fase RSM significativamente menor do que nas fases $\mathrm{P}(p=0,005)$ e RCM $(p=0,002)$. 
$\mathrm{Na}$ quarta avaliação, por sua vez, os neonatos apresentaram frequência cardíaca média significativamente menor na fase LB em relação às fases $\mathrm{PP}(p=$ $0,001), \mathrm{P}(p=0,003)$ e $\mathrm{RCM}(p=0,006)$ e na fase RSM significativamente menor do que nas fases $\operatorname{PP}(p=0,001), \mathrm{P}(p=0,001)$ e $\operatorname{RCM}(p=0,003)$.

No grupo GA observou-se os resultados a seguir. Na primeira avaliação, os neonatos na fase LB apresentaram frequência cardíaca média significativamente menor do que nas fases $\mathrm{P}(p=0,002), \operatorname{RCM}(p=0,001)$ e $\operatorname{RSM}(p=0,02)$; na fase PP menor do que nas fases $\mathrm{P}(p=0,001)$ e RCM $(p=0,008)$; na fase $\mathrm{P}$ significativamente maior do que na fase $\operatorname{RSM}(p=0,02)$ e na fase $\mathrm{RCM}$ significativamente maior do que na fase $\operatorname{RSM}(p=0,006)$.

$\mathrm{Na}$ segunda avaliação, os neonatos apresentaram na fase LB frequência cardíaca média significativamente menor do que nas fases $\mathrm{P}(p=0,002)$ e $\operatorname{RCM}(p=$ 0,006); na fase PP significativamente menor do que nas fases $\mathrm{P}(p=0,001)$ e $\mathrm{RCM}$ $(p=0,01)$; na fase $\mathrm{P}$ significativamente maior do que na fase $\operatorname{RSM}(p=0,02)$ e na fase RCM significativamente maior do que na fase $\operatorname{RSM}(p=0,02)$.

$\mathrm{Na}$ terceira avaliação, a frequência cardíaca média apresentada pelos neonatos na fase LB foi significativamente menor do que nas fases $\mathrm{P}(p=0,04) \mathrm{e}$ $\operatorname{RCM}(p=0,004)$ e na RCM significativamente maior do que na fase $\operatorname{RSM}(p=$ 0,001).

Finalmente, no quarto dia de avaliação, os neonatos apresentaram frequência cardíaca média na LB significativamente menor do que nas fases $\mathrm{PP}(p=0,02), \mathrm{P}(p$ $=0,0001)$ e RCM $(p=0,001)$; na fase PP significativamente menor do que na fase $\mathrm{P}$ 
$(p=0,003)$ e maior do que na fase $\operatorname{RCM}(p=0,01)$; na fase RSM significativamente menor do que na fase $\mathrm{P}(p=0,01)$ e RSM $(p=0,003)$.

Portanto, os neonatos de ambos os grupos demonstraram um padrão de frequência cardíaca média mais elevada nas fases de $\mathrm{P}$ e RCM, e de menor ativação na fase LB, em relação às demais fases, nos quatro dias de avaliação, com ou sem intervenção de sacarose.

\subsubsection{Comparação entre os grupos Sacarose e Água, nos quatro dias de avaliação}

Realizou-se a comparação dos indicadores biocomportamentais de atividade facial (escore NFCS), estado de vigília e sono e frequência cardíaca média, entre o Grupo Sacarose e Grupo Água, em cada fase do procedimento de coleta de sangue, nos quatro dias de avaliação. Para tanto, foram estabelecidas as notas de corte de cada uma dessas variáveis indicativas de reatividade à dor relacionada ao procedimento.

\subsubsection{Atividade Facial}

A Figura 5 apresenta a porcentagem de ocorrência do escore do NFCS igual ou acima de três pontos, indicativo de dor, no Grupo Sacarose e Grupo Água nas fases de Linha de Base, Preparação para Punção, Punção, Recuperação com Manuseio e Recuperação sem Manuseio, nos quatro dias de avaliação. 

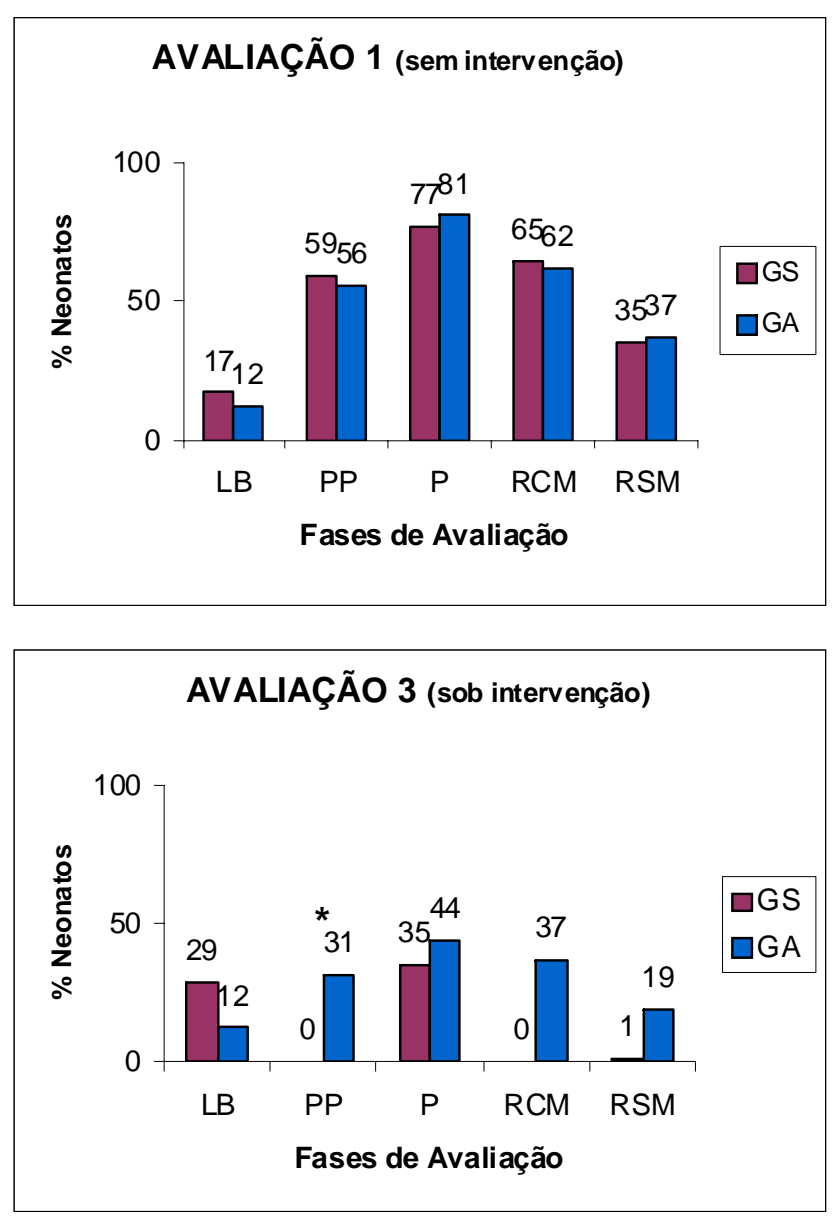
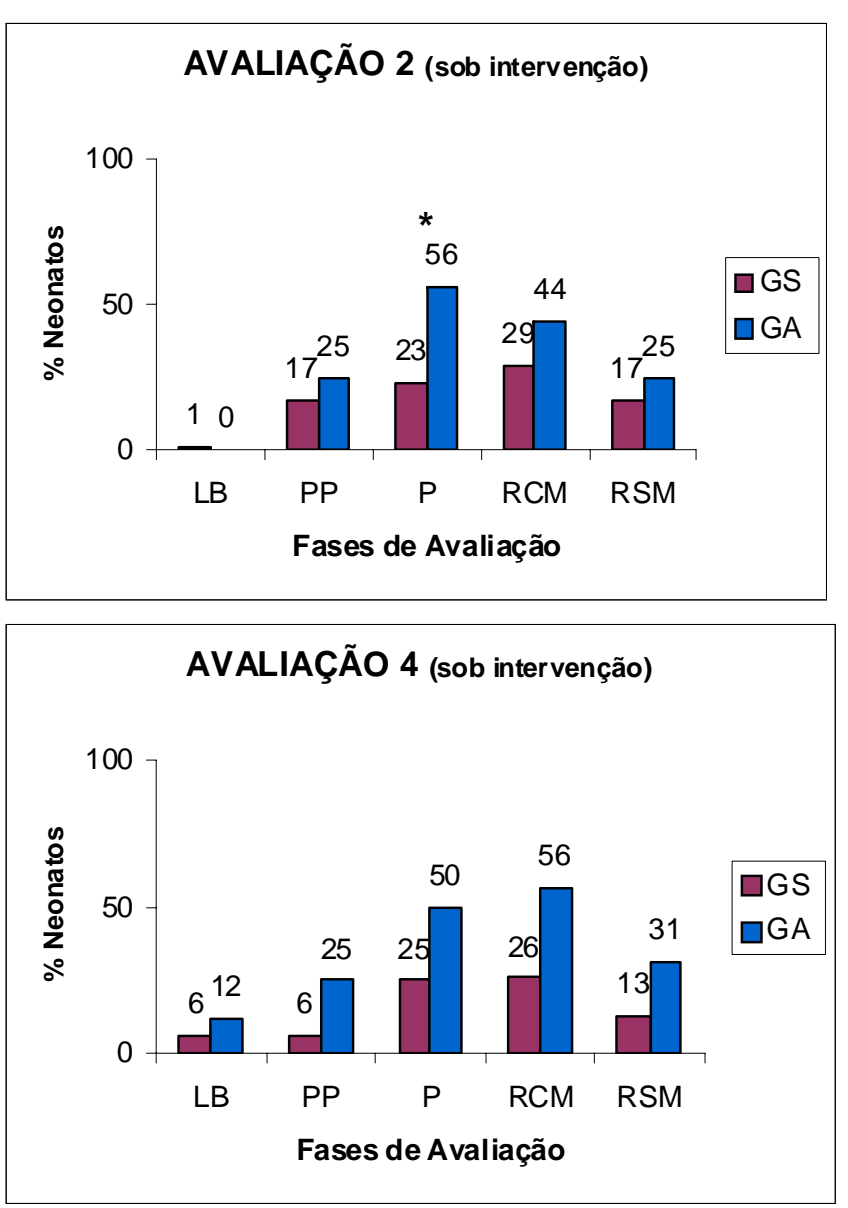

Figura 5 - Porcentagem de neonatos (\%) com escore do NFCS igual ou acima de três pontos no Grupo Sacarose (GS) e Grupo Água (GA) nas fases de Linha de Base (LB), Preparação para Punção (PP), Punção (P), Recuperação com Manuseio (RCM) e Recuperação sem Manuseio (RSM), nos quatro dias de avaliação ( $\left.{ }^{*} p \leq 0,05\right)$. 
Constata-se pela análise dos dados apresentados na Figura 5 que, no primeiro dia de avaliação, os grupos GS e GA não apresentaram diferença estatisticamente significativa quanto à porcentagem de neonatos que recebeu escore do NFCS $\geq 3$, sendo que a maior porcentagem ocorreu nas fases P e RCM, em relação às demais fases, em ambos os grupos. Isso revela que os grupos eram comparáveis inicialmente com relação a esta variável.

No segundo dia de avaliação, no entanto, primeiro dia de intervenção, os grupos apresentaram diferença significativa na fase $\mathrm{P}$ (GS $=23 \%, \mathrm{GA}=56 \% ; p=$ 0,05), o que demonstra que o grupo que recebeu a intervenção de solução de sacarose dois minutos antes da realização do procedimento doloroso de punção apresentou uma porcentagem significativamente menor de neonatos que pontuou escore do NFCS $\geq 3$ em comparação ao grupo que recebeu água estéril. Nas outras fases de avaliação, os grupos não apresentaram diferença estatisticamente significativa.

No terceiro dia de avaliação, novamente os grupos apresentaram diferença significativa em relação à porcentagem de neonatos que pontuou escore do NFCS $\geq$ 3, agora na fase $\mathrm{PP}(\mathrm{GS}=0, \mathrm{GA}=31 \% ; p=0,02$ ). Para as demais fases, os grupos foram estatisticamente semelhantes. Na fase RCM verifica-se, entretanto, uma tendência à diferença significativa entre os grupos $(p=0,09)$, sendo que no grupo GS a porcentagem de neonatos que pontuou escore do NFCS $\geq 3$ foi menor em relação ao grupo GA. 
No quarto dia de avaliação, os grupos GS e GA não apresentaram diferença estatisticamente significativa quanto à porcentagem de neonatos que recebeu escore do NFCS $\geq 3$ em nenhuma das fases avaliadas. Entretanto, percebe-se uma maior porcentagem de neonatos no grupo GA com escore do NFCS $\geq 3$ nas fases $P$ e RCM, com tendência à significância ( $p=0,08 ; p=0,09$, respectivamente).

Devido ao fato de cinco participantes do total da amostra (15\%) estar intubados no momento da coleta de dados, sendo dois neonatos (11\%) do Grupo Sacarose e três neonatos (18\%) do Grupo Água, optou-se também pela realização de uma segunda forma de análise do escore do NFCS, utilizando apenas as ações faciais superiores, a saber: protusão da sobrancelha, olhos apertados e sulco nasolabial aprofundado, visto que o tubo endotraqueal poderia interferir na expressão e identificação das expressões faciais referentes a lábios abertos, boca esticada e língua tensa.

A análise da atividade facial apenas da face superior dos neonatos dos grupos GS e GA revelou o mesmo padrão de atividade encontrada na análise completa da atividade facial, que incluía as sete expressões faciais. Isto revela que o fato dos neonatos estarem intubados não interferiu no resultado do escore total do NFCS, sendo possível a utilização das expressões da face inferior na análise das vídeo-gravações nesta amostra. 


\subsubsection{Estado de Vigília e Sono}

Com a finalidade de verificar o nível de ativação dos neonatos, foram analisados os participantes que apresentaram o conjunto de estados de alerta quieto, alerta ativo e choro. Foi calculada a porcentagem de neonatos que apresentaram um destes três estados nas diferentes fases avaliadas, durante os quatro dias de avaliação.

A Figura 6 apresenta a porcentagem de neonatos com estados de vigília e sono relativos com alto nível de ativação no Grupo Sacarose e Grupo Água nas fases de Linha de Base, Preparação para Punção, Punção, Recuperação com Manuseio e Recuperação sem Manuseio, nos quatro dias de avaliação. 

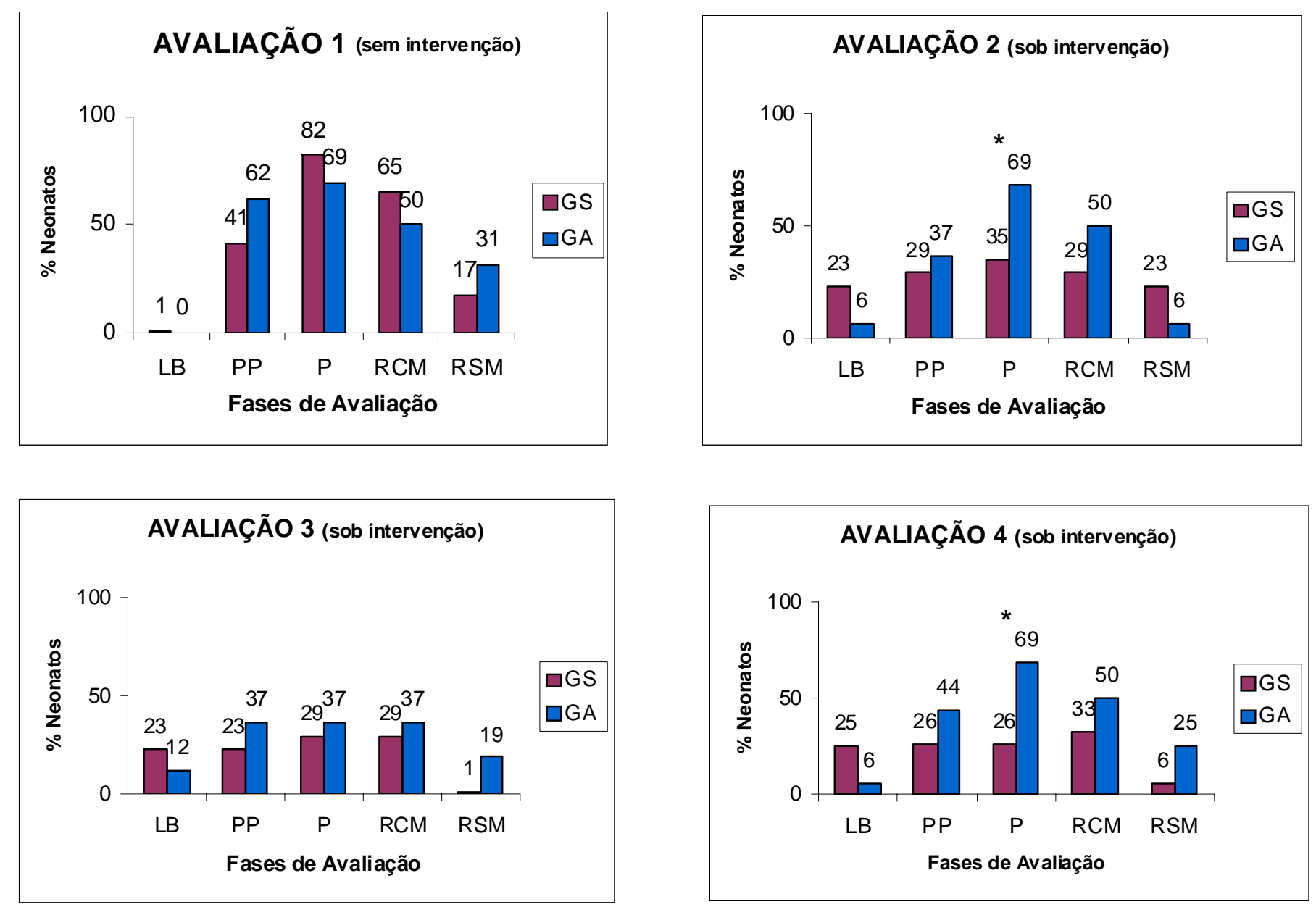

Figura 6 - Porcentagem de neonatos com alto nível de ativação no Grupo Sacarose (GS) e Grupo Água (GA) nas fases de Linha de Base (LB), Preparação para Punção (PP), Punção (P), Recuperação com Manuseio (RCM) e Recuperação sem Manuseio (RSM), durante os quatro dias de avaliação ( $\left.{ }^{*} p \leq 0,05\right)$. 
A Figura 6 mostra que os grupos GS e GA não apresentaram diferença estatisticamente significativa quanto ao nível de ativação biocomportamental de estado de vigília e sono no primeiro dia de avaliação, sendo que a porcentagem maior ocorreu nas fases $\mathrm{P}$ e RCM em relação às demais fases em ambos os grupos. Este dado revela que os grupos eram comparáveis inicialmente com relação a esta variável.

No segundo dia de avaliação (primeiro dia de intervenção), os grupos apresentaram diferença significativa na fase $\mathrm{P}(\mathrm{GS}=35 \%, \mathrm{GA}=69 \% ; p=0,05)$, demonstrando que no momento do procedimento doloroso, o grupo que recebeu a intervenção de solução de sacarose apresentou uma porcentagem significativamente menor de neonatos em estado de alerta em comparação ao grupo que recebeu água estéril. Nas demais fases de avaliação, os grupos não apresentaram diferença estatisticamente significativa.

No terceiro dia de avaliação, os grupos GS e GA não apresentaram diferença estatisticamente significativa quanto à porcentagem de neonatos que apresentaram estados de alerta em nenhuma das fases avaliadas.

No quarto dia de avaliação, os grupos voltaram a apresentar diferença significativa em relação à porcentagem de neonatos que estavam em estados ativados novamente na fase $\mathrm{P}(\mathrm{GS}=26 \%, \mathrm{GA}=69 \% ; p=0,02)$; isto revela uma porcentagem significativamente menor de neonatos em estado de ativação biocomportamental no grupo GS em comparação ao grupo GA. Nas demais fases, os grupos foram estatisticamente semelhantes. 
A análise de ativação biocomportamental do estado de vigília e sono também foi analisada a partir da porcentagem de neonatos que apresentou estado de choro nas cinco fases dos quatros dias de avaliação, em ambos os grupos.

A Figura 7 apresenta a porcentagem de neonatos em estado de choro no Grupo Sacarose e Grupo Água nas fases de Linha de Base, Preparação para Punção, Punção, Recuperação com Manuseio e Recuperação sem Manuseio, nos quatro dias de avaliação. 

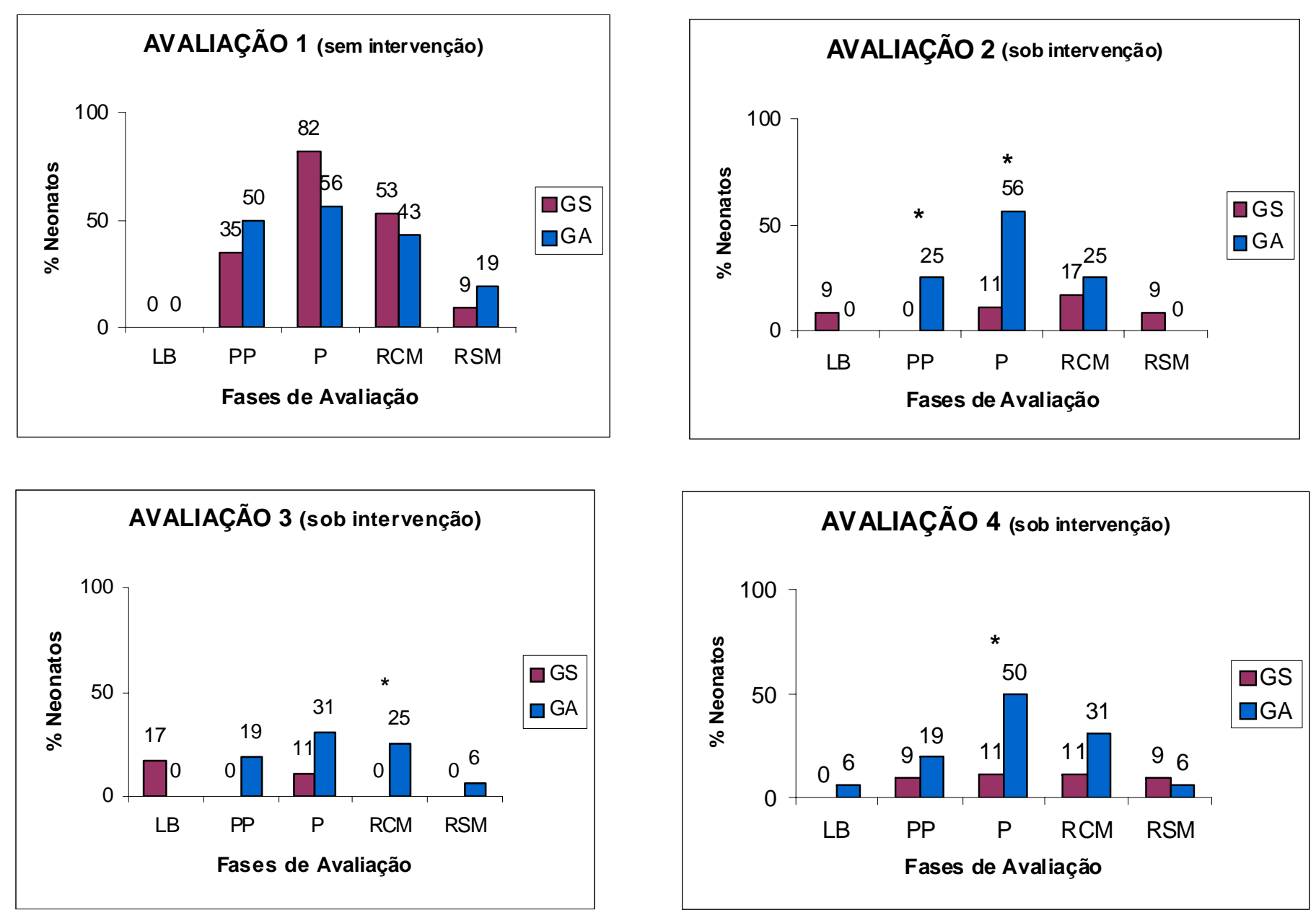

Figura 7 - Porcentagem de neonatos com estado biocomportamental de choro no Grupo Sacarose (GS) e Grupo Água (GA) nas fases de Linha de Base (LB), Preparação para Punção (PP), Punção (P), Recuperação com Manuseio (RCM) e Recuperação sem Manuseio (RSM), nos quatro dias de avaliação ( $\left.{ }^{*} p \leq 0,05\right)$. 
Os dados apresentados na Figura 7 revelam que em relação à porcentagem de neonatos que chorou nos grupos GS e GA, não houve diferença estatisticamente significativa no primeiro dia de avaliação, sendo que a porcentagem maior ocorreu na fase $P$ em ambos os grupos, em relação às demais fases. Isso revela que os grupos eram comparáveis inicialmente com relação a esta variável.

No segundo dia de avaliação, no entanto, os grupos apresentaram diferença significativa nas fases PP e P (GS $=0, \mathrm{GA}=25 \% ; p=0,04 ; \mathrm{GS}=11 \%, \mathrm{GA}=56 \% ; p$ $=0,009$, respectivamente), o que demonstra que durante toda a realização do procedimento doloroso, o grupo que recebeu água estéril apresentou uma porcentagem significativa maior de neonatos que choraram em comparação ao grupo que recebeu sacarose. Para as demais fases de avaliação, não houve diferença estatisticamente significativa entre os grupos.

No terceiro dia de avaliação, os grupos GS e GA apresentaram diferença estatisticamente significativa quanto à porcentagem de neonatos que choraram no momento imediato ao término do procedimento de punção, na fase RCM (GS = 0, $\mathrm{GA}=25 \% ; p=0,04)$, sendo que novamente no grupo que recebeu água estéril a porcentagem de neonatos que choraram foi significativamente maior em comparação ao grupo que recebeu sacarose. Em relação às outras fases de avaliação, os grupos não apresentaram diferença estatisticamente significativa.

No quarto dia de avaliação, os grupos voltaram a apresentar diferença significativa em relação à porcentagem de neonatos que choraram na fase $\mathrm{P}$ (GS = $11 \%, \mathrm{GA}=50 \% ; p=0,03)$; isto revela uma porcentagem significativamente maior de 
neonatos em estado de choro no grupo GA em comparação ao grupo GS. Para as demais fases, os grupos foram estatisticamente semelhantes.

\subsubsection{Frequência Cardíaca Média}

Considerando que a frequência cardíaca igual ou acima de 160 batimentos por minuto é caracterizada como taquicardia em neonatos pré-termo, e pode refletir em irritabilidade do sistema nervoso central, calculou-se a porcentagem de neonatos que apresentou média da frequência cardíaca de 160 batimentos por minuto ou mais nas diferentes fases avaliadas, durante os quatro dias de coleta de dados.

A Figura 8 apresenta a porcentagem de neonatos com média da frequência cardíaca de 160 batimentos por minuto ou mais no Grupo Sacarose e Grupo Água nas fases de Linha de Base, Preparação para Punção, Punção, Recuperação com Manuseio e Recuperação sem Manuseio, nos quatro dias de avaliação. 

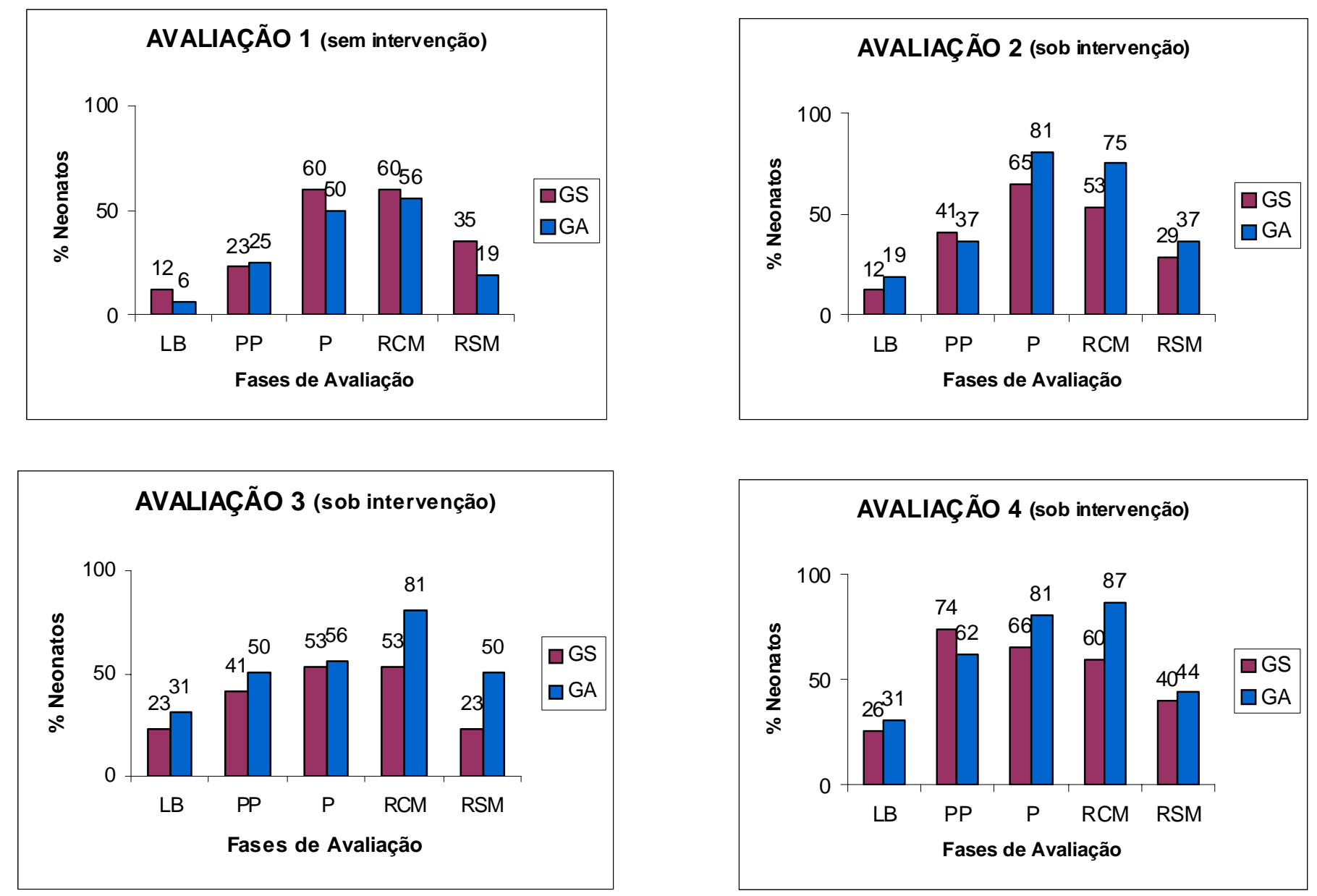

Figura 8 - Porcentagem de neonatos com média da frequência cardíaca igual ou acima de 160 batimentos por minuto no Grupo Sacarose (GS) e Grupo Água (GA) nas fases de Linha de Base (LB), Preparação para Punção (PP), Punção (P), Recuperação com Manuseio (RCM) e Recuperação sem Manuseio (RSM), nos quatro dias de avaliação. 
Pode-se observar na Figura 8 que os grupos GS e GA não apresentaram diferença estatisticamente significativa em nenhum dos quatro dias de avaliação no que se refere à porcentagem de neonatos, considerando a média da frequência cardíaca igual ou maior a 160 batimentos por minuto.

É possível verificar que em todos os dias de avaliação, independente da administração da solução de sacarose ou água estéril antes do procedimento doloroso, a porcentagem de neonatos apresentando média da frequência cardíaca igual ou superior a 160 batimentos por minuto foi semelhante nos dois grupos, com baixa porcentagem na fase LB, elevando na fase PP, apresentando as porcentagens mais altas nas fases $\mathrm{P}$ e RCM, voltando a diminuir na fase RSM.

4.3.4. Indicador fisiológico de frequência cardíaca avaliado na fase de recuperação do primeiro dia de intervenção Grupo Sacarose / Grupo Água

Com a finalidade de analisar especificamente os padrões de recuperação dos neonatos após o procedimento de punção para coleta de sangue, realizou-se a comparação intragrupo, em ambos os grupos, entre a mediana do indicador frequência cardíaca média na fase de Linha de Base e a mediana da frequência cardíaca mensurada minuto a minuto, durante todo o período de Recuperação (fases de Recuperação com Manuseio e Recuperação sem Manuseio), no segundo dia de avaliação, no qual foi realizada a primeira intervenção com a solução de sacarose. 
Os dados relacionados à comparação intragrupo do indicador fisiológico de frequência cardíaca, para o Grupo Sacarose, entre a fase de Linha de Base e os 10 minutos de recuperação encontram-se na Figura 9 e os mesmos dados referentes ao Grupo Água encontram-se na Figura 10. 


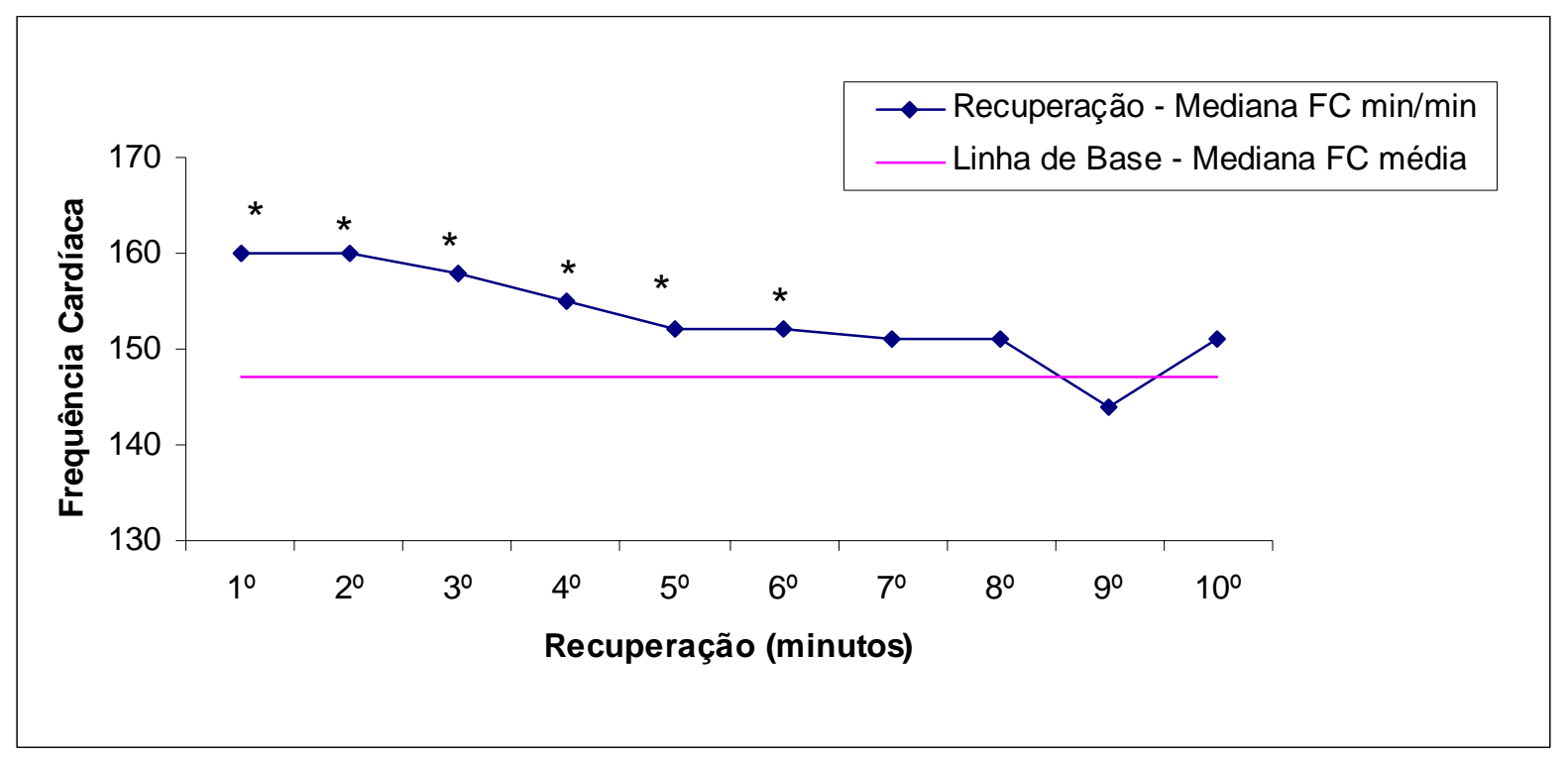

Figura 9 - Indicador fisiológico de frequência cardíaca (FC), no Grupo Sacarose, entre a fase Linha de Base e minuto a minuto da fase de Recuperação (Recuperação com Manuseio e Recuperação sem Manuseio). " $p \leq 0,05$

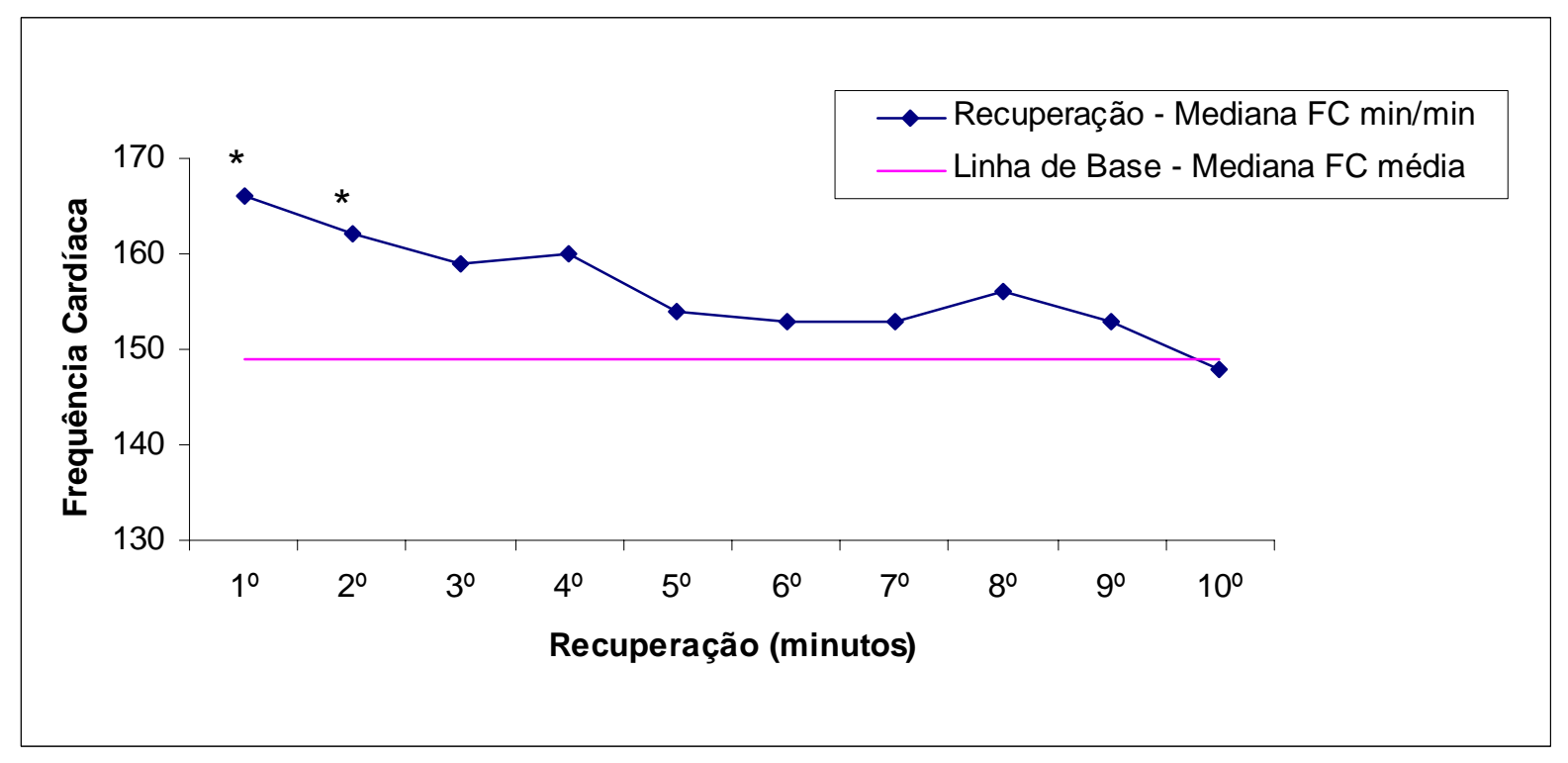

Figura 10 - Indicador fisiológico de frequência cardíaca $(F C)$, no Grupo Água, entre a fase Linha de Base e minuto a minuto da fase de Recuperação (Recuperação com Manuseio e Recuperação sem Manuseio). " $p \leq 0,05$ 
Verifica-se, a partir dos dados mostrados na Figura 9, que, no primeiro minuto da recuperação do procedimento doloroso, os recém-nascidos do grupo GS apresentavam frequência cardíaca de 160 batimentos por minuto, sendo este um valor sugestivo de taquicardia. A partir do segundo minuto, no entanto, inicia-se um declínio gradual da frequência cardíaca até o término do período total de recuperação. No $10^{\circ}$ minuto, a frequência cardíaca foi de 151 batimentos por minuto, havendo, portanto, uma redução de nove batimentos por minuto considerando-se desde o início até o final do período de recuperação.

Além disso, é possível observar que houve uma diferença significativa das frequências cardíacas dos neonatos desde o primeiro ao sexto minuto da recuperação, as quais estavam elevadas em relação à frequência cardíaca média da fase de LB $(p=0,003, p=0,008, p=0,02, p=0,01, p=0,02, p=0,004$, respectivamente). A ausência de diferença estatisticamente significativa a partir do sétimo minuto aponta que, a partir deste momento, os recém-nascidos passaram a apresentar a frequência cardíaca da recuperação semelhante à apresentada anteriormente na fase LB.

Os dados apresentados na Figura 10 indicam que, no início da recuperação do procedimento doloroso, os recém-nascidos do grupo GA estavam com frequência cardíaca de 166 batimentos por minuto, sendo este também um valor sugestivo de taquicardia. Como verificado no grupo GS, a partir do segundo minuto, inicia-se, nos neonatos do grupo GA, um declínio gradual da frequência cardíaca até o término do período total de recuperação. No $10^{\circ}$ minuto, a frequência cardíaca foi de 148 
batimentos por minuto, havendo, portanto, uma redução de 18 batimentos por minuto considerando-se desde o início até o final do período de recuperação.

Em segundo lugar, observa-se que houve, no grupo GA, uma diferença significativa das frequências cardíacas dos neonatos no primeiro e segundo minutos da recuperação, as quais estavam elevadas em relação à frequência cardíaca média da fase de LB ( $p=0,002, p=0,01$, respectivamente). A partir do terceiro minuto do período de recuperação, a frequência cardíaca dos recém-nascidos passou a ser semelhante à apresentada pelos mesmos na fase LB.

A partir da consideração de que os recém-nascidos fisiologicamente recuperados apresentam frequência cardíaca abaixo de 160 batimentos por minuto, é possível observar que os neonatos de ambos os grupos se recuperaram, do ponto de vista fisiológico, do procedimento de punção. Porém, o Grupo Sacarose iniciou a fase de recuperação com frequência cardíaca mais baixa do que o Grupo Água. Além disso, o Grupo Sacarose atingiu uma frequência cardíaca abaixo do indicado para taquicardia no terceiro minuto da recuperação, enquanto que o Grupo Água chegou a este padrão no quinto minuto da recuperação.

4.4. Evolução clínica dos neonatos durante a hospitalização e possíveis efeitos colaterais advindos do uso da solução de sacarose

Com a finalidade de avaliar a ocorrência de possíveis efeitos colaterais advindos do uso da solução de sacarose em esquema de doses repetidas, realizou- 
se a comparação entre o Grupo Sacarose e Grupo Água das características de evolução clínica dos neonatos relativa à incidência de resíduos na sonda orogástrica, vômito e presença de distensão abdominal.

Inicialmente, com a finalidade de se estabelecer uma linha de base anterior ao uso da sacarose, verificou-se a ocorrência dessas variáveis, em ambos os grupos, desde o nascimento até a primeira avaliação. Os dados estão apresentados na Tabela 9.

Tabela 9 - Características de evolução clínica dos neonatos do Grupo Sacarose (GS) e do Grupo Água (GA), avaliadas desde o nascimento até as últimas 24 horas anteriores à primeira avaliação.

\begin{tabular}{|c|c|c|c|}
\hline Características de evolução clínica & $\begin{array}{c}\text { GS } \\
(n=17)\end{array}$ & $\begin{array}{c}\text { GA } \\
(n=16)\end{array}$ & $\begin{array}{l}\text { Valor de p } \\
\text { Comparação } \\
\text { entre grupos } \\
\end{array}$ \\
\hline $\begin{array}{l}\text { Ocorrência de resíduo na sonda orogást } \\
\text { Med } \\
(\min -\max )\end{array}$ & $\begin{array}{c}1 \\
(0-12)\end{array}$ & $\begin{array}{c}2 \\
(0-19)\end{array}$ & 0,15 \\
\hline $\begin{array}{l}\text { Ocorrência de vômito } \\
\text { Med } \\
(\min -\max )\end{array}$ & $\begin{array}{c}0 \\
(0-2)\end{array}$ & $\begin{array}{c}0 \\
(0-5)\end{array}$ & 0,72 \\
\hline Presença de distensão abdominal f (\%) & $1(6)$ & $4(25)$ & 0,15 \\
\hline
\end{tabular}

De acordo com os dados apresentados na Tabela 9, os grupos foram comparáveis em relação às características de evolução clínica avaliadas desde o nascimento até as últimas 24 horas anteriores à primeira avaliação, pois não houve diferença estatisticamente significativa entre os grupos. 
Em ambos os grupos, houve baixa incidência de resíduos na sonda orogástrica, assim como ocorrência de vômitos. Além disso, a maioria dos neonatos não apresentou distensão abdominal desde o nascimento até o primeiro dia de avaliação.

Também foram analisados os dados referentes à evolução clínica dos recémnascidos do Grupo Sacarose e Grupo Água nas últimas 24 horas anteriores a cada um dos quatro dias de avaliação. Os dados encontram-se na Tabela 10. 
Tabela 10 - Características de evolução clínica dos neonatos do Grupo Sacarose (GS) e do Grupo Água (GA), avaliadas nas últimas 24 horas anteriores a cada dia de avaliação.

\begin{tabular}{|c|c|c|c|c|c|c|c|c|c|}
\hline \multirow{2}{*}{ Características de evolução clínica } & \multicolumn{2}{|c|}{$\begin{array}{c}\text { Avaliação 1 } \\
\text { (sem intervenção) }\end{array}$} & \multicolumn{2}{|c|}{$\begin{array}{c}\text { Avaliação } 2 \\
\text { (sob intervenção) }\end{array}$} & \multicolumn{2}{|c|}{$\begin{array}{c}\text { Avaliação 3 } \\
\text { (sob intervenção) }\end{array}$} & \multicolumn{2}{|c|}{$\begin{array}{c}\text { Avaliação } 4 \\
\text { (sob intervenção) }\end{array}$} & \multirow{2}{*}{$\begin{array}{l}\text { Valor de } \mathbf{p} \\
\text { Comparação } \\
\text { entre grupos }\end{array}$} \\
\hline & $\begin{array}{c}\text { GS } \\
(n=17)\end{array}$ & $\begin{array}{c}G A \\
(n=16)\end{array}$ & $\begin{array}{c}\text { GS } \\
(n=17)\end{array}$ & $\begin{array}{c}\text { GA } \\
(n=16)\end{array}$ & $\begin{array}{c}\text { GS } \\
(n=17)\end{array}$ & $\begin{array}{c}G A \\
(n=16)\end{array}$ & $\begin{array}{c}\text { GS } \\
(n=15)\end{array}$ & $\begin{array}{c}\text { GA } \\
(n=16)\end{array}$ & \\
\hline $\begin{array}{l}\text { Ocorrência de resíduo na sonda orogástrica } \\
\text { Med } \\
\text { (min - max) }\end{array}$ & $\begin{array}{c}1 \\
(0-4)\end{array}$ & $\begin{array}{c}2 \\
(0-7)\end{array}$ & $\begin{array}{c}2 \\
(0-4)\end{array}$ & $\begin{array}{c}0 \\
(0-3)\end{array}$ & $\begin{array}{c}1 \\
(0-5)\end{array}$ & $\begin{array}{c}0 \\
(0-5)\end{array}$ & $\begin{array}{c}0 \\
(0-4)\end{array}$ & $\begin{array}{c}0 \\
(0-3)\end{array}$ & $\begin{array}{l}\text { Av. } 1=0,34 \\
\text { Av. } 2=0,15 \\
\text { Av. } 3=0,32 \\
\text { Av. } 4=0,83\end{array}$ \\
\hline $\begin{array}{l}\text { Ocorrência de vômitos } \\
\text { Med } \\
\text { (min - max) }\end{array}$ & $\begin{array}{c}0 \\
(0-1)\end{array}$ & $\begin{array}{c}0 \\
(0-3)\end{array}$ & $\begin{array}{c}0 \\
(0-1)\end{array}$ & 0 & $\begin{array}{c}0 \\
(0-1)\end{array}$ & $\begin{array}{c}0 \\
(0-1)\end{array}$ & 0 & $\begin{array}{c}0 \\
(0-1)\end{array}$ & $\begin{array}{l}\text { Av. } 1=0,98 \\
\text { Av. } 2=0,79 \\
\text { Av. } 3=0,98 \\
\text { Av. } 4=1,00\end{array}$ \\
\hline Presença de distensão abdominal f (\%) & $2(12)$ & $3(19)$ & 0 & $3(19)$ & $2(12)$ & $2(13)$ & 0 & $2(13)$ & $\begin{array}{l}\text { Av. } 1=0,57 \\
\text { Av. } 2=0,06 \\
\text { Av. } 3=0,94 \\
\text { Av. } 4=0,15\end{array}$ \\
\hline
\end{tabular}

Med = Mediana; min = valor mínimo; max = valor máximo; $f$ = frequência; $\%$ = porcentagem . 
Verifica-se na Tabela 10 que não houve diferença estatisticamente significativa entre os grupos GS e GA, nas quatro avaliações, no que se refere às características de evolução clínica de incidência de resíduos na sonda orogástrica, incidência de vômitos e presença de distensão abdominal.

Além da análise das características de evolução clínicas dos recém-nascidos descritas anteriormente, foi realizada também uma comparação entre os neonatos do Grupo Sacarose e Grupo Água em relação a um segundo conjunto de variáveis, referentes à evolução clínica e ao padrão de alimentação dos neonatos, durante todo o período de hospitalização. Faz-se importante esclarecer que se constatou o óbito pós-alta de dois neonatos do grupo GA, devido a complicações referentes à patologia de displasia broncopulmonar. Os dados encontram-se na Tabela 11. 
Tabela 11 - Características de evolução clínica e de padrão de alimentação dos neonatos do Grupo Sacarose (GS) e do Grupo Água (GA), avaliadas durante o período de hospitalização.

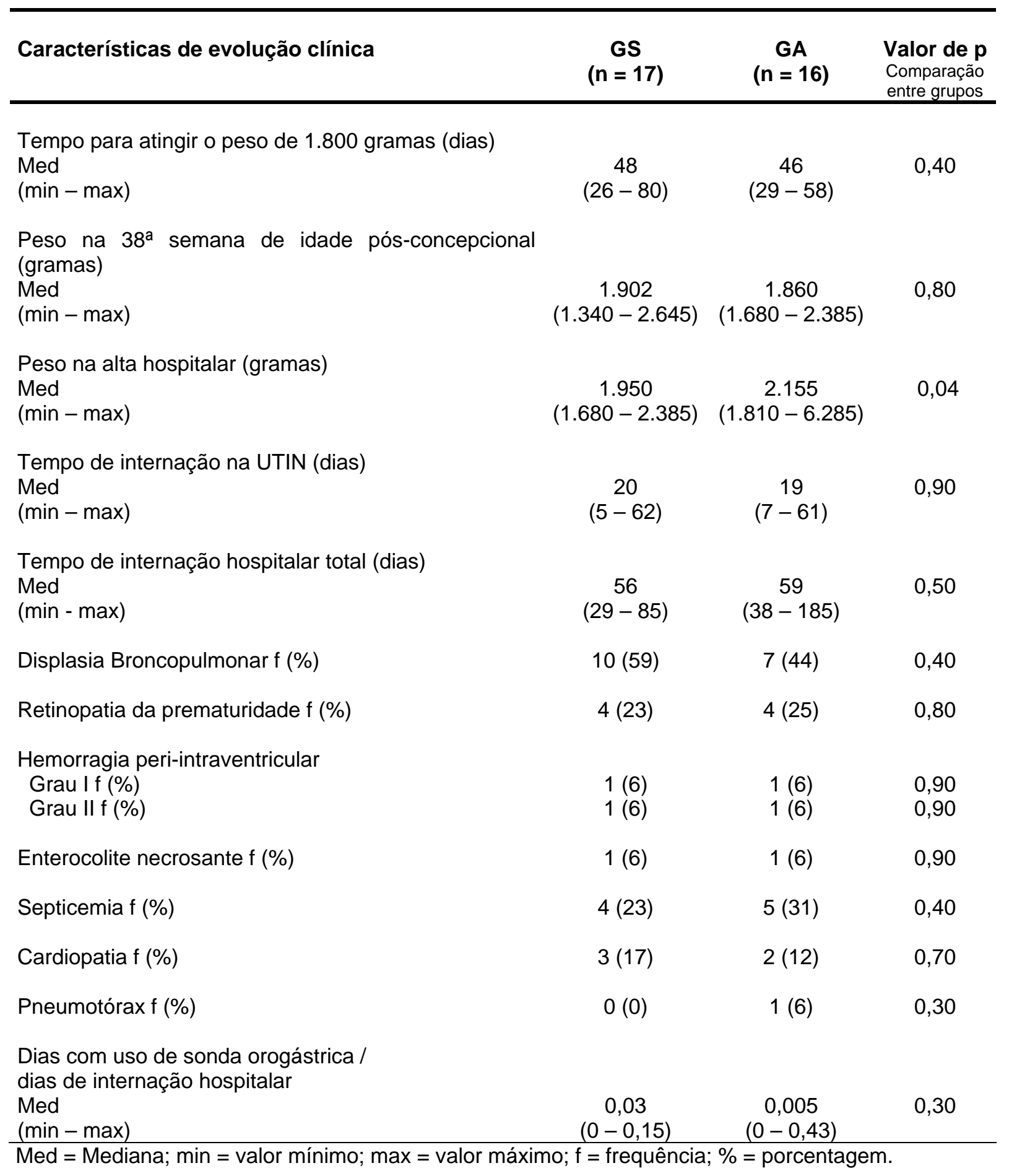


Pode-se observar, pela análise dos dados mostrados na Tabela 11, que os neonatos de ambos os grupos demoraram por volta de seis semanas pós-natal para atingir o peso de 1.800 gramas, e na $38^{\mathrm{a}}$ semana de idade pós-concepcional apresentavam peso em torno de 1.900 gramas.

Houve uma diferença estatisticamente significativa entre os grupos em relação ao peso na alta hospitalar, sendo que neste momento os bebês do grupo GA estavam pesando mais do que os bebês do grupo GS. Entretanto, visto que um participante do grupo GA permaneceu 185 dias hospitalizado, 100 dias a mais do que o participante que ficou mais tempo hospitalizado no grupo GS, contatou-se que seu peso na alta também foi expressivamente elevado em relação aos demais participantes da amostra (6.285 gramas). Dessa maneira, realizou-se a comparação entre os grupos do indicador peso na alta hospitalar excluindo-se este participante, não sendo constatada diferença significativa entre os grupos.

Em relação ao tempo de internação hospitalar, em ambos os grupos, os bebês permaneceram em média três semanas na UTIN e nove semanas no hospital, entre internação na UTIN e no berçário de médio risco.

Quanto às patologias observadas em ambos os grupos, houve uma baixa frequência em relação a todas as patologias avaliadas (displasia broncopulmonar, retinopatia da prematuridade, hemorragia peri-intraventricular, enterocolite necrosante, septicemia, cardiopatia e pneumotórax).

Para o indicador de alimentação utilizado no estudo, referente à necessidade dos neonatos em utilizar a sonda orogástrica para alimentação durante o tempo total de hospitalização, também foi possível identificar que não houve diferença significativa entre os grupos. 


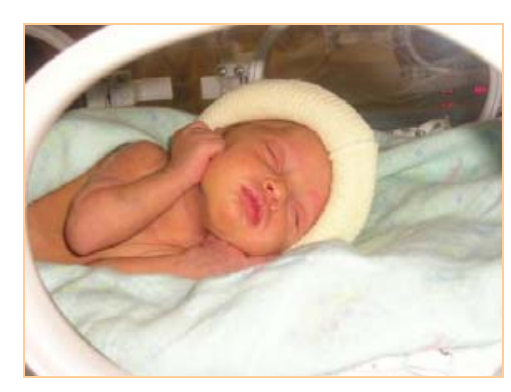

5. DISCUSSÃO 
O presente estudo teve por objetivo responder a duas questões principais, a saber: a) o uso de $0,5 \mathrm{ml} / \mathrm{kg}$ de solução de sacarose a $25 \%$, administrada via oral em esquema de doses repetidas e dias consecutivos, é eficaz para o alívio da dor em recém-nascidos pré-termo com muito baixo peso ao nascer internados em UTIN? b) a administração continuada da solução de sacarose durante procedimentos dolorosos de rotina da UTIN causa efeitos colaterais?

Em resposta à primeira questão, os resultados referentes a partir do segundo dia de avaliação sugerem que os neonatos que receberam $0,5 \mathrm{ml} / \mathrm{kg}$ de solução de sacarose a $25 \%$, via oral, em esquema de doses repetidas em dias consecutivos, dois minutos antes do procedimento doloroso de punção para coleta de sangue, apresentaram, durante $\mathrm{o}$ procedimento, indicadores biocomportamentais de atividade facial e estado de vigília e sono em menores escores em relação aos escores apresentados pelos mesmos neonatos no primeiro dia de avaliação, sem administração de sacarose. Entretanto, em relação ao indicador fisiológico de frequência cardíaca média, não houve alteração do padrão de resposta apresentado pelos neonatos no primeiro dia de avaliação em comparação aos demais dias, visto que a frequência cardíaca continuou elevada, mesmo com a administração da solução de sacarose.

Em contraste aos neonatos que receberam a solução de sacarose, os neonatos que receberam água estéril antes do procedimento doloroso de punção para coleta de sangue apresentaram um padrão de elevação das respostas 
biocomportamentais e fisiológica durante o procedimento, nos quatro dias de avaliação.

Os neonatos do grupo experimental (Grupo Sacarose) apresentaram mediana do escore do NFCS indicativa de ausência de dor não só no momento da punção para coleta de sangue, mas também nos momentos em que houve o manuseio da enfermeira para a antissepsia, anterior à punção, e para o curativo, posterior à mesma, diferente das medianas indicativas de dor apresentadas nestas fases no primeiro dia de avaliação, sem intervenção.

Este resultado é similar ao encontrado por Johnston et al. (2002), em um estudo no qual houve a administração de $0,1 \mathrm{ml}$ de solução de sacarose a $24 \%$ em esquema de doses repetidas. Nos neonatos pré-termo que receberam a substância, o escore do NFCS foi reduzido durante os procedimentos dolorosos de punção capilar, punção venosa e aspiração, em relação aos neonatos que receberam água estéril. Stevens et al. (2005) também verificaram menor reatividade à dor, avaliada pelo PIPP, nos neonatos pré-termo que receberam $0,1 \mathrm{ml}$ de sacarose a $24 \%$ seguida de sucção não-nutritiva, antes de procedimentos dolorosos, durante 28 dias consecutivos, em comparação aos neonatos que receberam os cuidados de rotina da UTIN, porém, neste caso, a intervenção de sacarose não foi exclusiva.

Corroborando esses achados, a porcentagem de neonatos que apresentou escore do NFCS igual ou acima de três pontos, indicativo de dor, foi menor no Grupo Sacarose, em comparação ao Grupo Água, em todos os procedimentos avaliados de 
punção para coleta de sangue, os quais compreendem desde o processo de antissepsia até a finalização do curativo.

Portanto, pode-se afirmar que, nos neonatos que receberam a solução de sacarose a $25 \%$, em esquema de doses repetidas, dois minutos antes dos procedimentos invasivos e dolorosos realizados durante três dias consecutivos, o escore da atividade facial, mensurado a partir da escala NFCS, foi menor do que nos neonatos que receberam água estéril, quando avaliados imediatamente antes, durante e após a realização do procedimento doloroso de punção para coleta de sangue.

Estes resultados sugerem que a solução de sacarose atuou na diminuição da atividade facial dos neonatos não apenas no momento do procedimento doloroso, mas durante a preparação para a realização do mesmo, assim como durante o processo de recuperação do neonato, mesmo com o manuseio da enfermeira para a realização do curativo e posicionamento do recém-nascido na incubadora, durante os três dias em que foi realizada a intervenção.

Em relação ao indicador biocomportamental de estado de vigília e sono, os neonatos avaliados no presente estudo exibiram o estado comportamental de sono ativo, indicativo de baixa ativação comportamental, em todos os momentos das avaliações em que houve a administração da solução de sacarose antes do procedimento doloroso de punção. No grupo controle (Grupo Água), porém, os neonatos reagiram, no momento do procedimento doloroso, com maior ativação biocomportamental. 
No primeiro dia de avaliação, no qual a avaliação dos neonatos de ambos os grupos foi realizada sem nenhuma intervenção prévia à realização do procedimento doloroso, os neonatos apresentaram ativação biocomportamental semelhante entre os grupos nas diversas fases de avaliação. A partir do segundo dia de avaliação, início da administração da solução de sacarose e água estéril nota-se que durante todo o tempo em que foi realizado o procedimento doloroso, os neonatos do Grupo Sacarose permaneceram em sono ativo, estado biocomportamental menos reativo do que o sono ativo e o choro, apresentados pelos neonatos do Grupo Água.

No momento imediatamente posterior à realização do procedimento doloroso, durante a recuperação do neonato, ainda com o manuseio da enfermeira, o Grupo Sacarose mostrou-se menos reativo em relação ao Grupo Água, nos três dias consecutivos de administração das intervenções.

Os resultados encontrados no presente estudo, em relação ao indicador de estado de vigília e sono, sugerem que os neonatos que receberam a solução de sacarose apresentaram estados biocomportamentais significativamente menos ativados, durante e após a realização do procedimento doloroso, em comparação aos neonatos que receberam água estéril.

Ainda em relação aos resultados obtidos a partir da avaliação do estado de vigília e sono, a porcentagem de neonatos do Grupo Sacarose que apresentou estados biocomportamentais relativos a alto nível de ativação (alerta quieto, alerta ativo e choro) foi menor no momento da punção, durante os quatro dias consecutivos de avaliação, em comparação à porcentagem de neonatos do Grupo 
Água. Além disso, durante os três dias em que houve a administração da solução de sacarose para estes neonatos, a porcentagem de participantes que apresentou estados biocomportamentais relativos a alto nível de ativação continuou sendo menor em comparação ao grupo de neonatos que recebeu água estéril, no momento de antissepsia e durante a recuperação do neonato ainda com o manuseio da enfermeira para a realização do curativo.

Sendo assim, sugere-se que a solução de sacarose permitiu uma diminuição da ativação dos neonatos no momento do procedimento doloroso. Além disso, agiu também no fenômeno de antecipação da reação à dor frente ao manuseio para a preparação do mesmo e na organização comportamental dos neonatos no momento da recuperação, ainda com o manuseio da enfermeira para a realização do curativo.

Portanto, é possível afirmar que, nos neonatos que receberam a solução de sacarose antes dos procedimentos invasivos e dolorosos realizados durante três dias consecutivos, a ativação biocomportamental foi menor do que nos neonatos que receberam água estéril, quando avaliados imediatamente antes, durante e após a realização do procedimento doloroso de punção para coleta de sangue.

Este resultado torna-se relevante, visto que em estudos anteriores que avaliaram a eficácia da solução de sacarose para o alívio de dor em neonatos prétermo, a avaliação do estado de vigília e sono foi realizada apenas no momento anterior à realização do procedimento doloroso, a fim de identificar se havia semelhança entre os recém-nascidos em relação a esta variável (ACHARYA et al., 2004; JOHNSTON et al., 1997; McCULLOUGH et al., 2007; OKAN et al., 2007; 
RAMENGHI et al., 1996). Em outros estudos, a avaliação do estado de vigília e sono foi realizada como parte do instrumento multidimensional Premature Infant Pain Profile, o qual inclui também outros indicadores comportamentais e fisiológicos (BOYLE et al., 2006; GAL et al., 2005; GIBBINS et al., 2002; GIBBINS; STEVENS, 2003; JOHNSTON et al., 1999; MITCHELL et al., 2004; STEVENS et al., 1999; STEVENS et al., 2005). A análise do escore único de dor nestes estudos não permitiu a análise do indicador de estado de vigília e sono isoladamente.

Os dados referentes à porcentagem de neonatos em estado biocomportamental de choro, nos grupos GS e GA, nas diversas fases dos quatro dias de avaliação reforçam os achados da eficácia da sacarose. No primeiro dia de avaliação, o qual foi realizado com a finalidade de avaliação do padrão individual do neonato quanto às reações biocomportamentais e fisiológica ao procedimento doloroso, a porcentagem de neonatos que chorou em ambos os grupos foi semelhante nas cinco fases avaliadas.

Entretanto, a partir do segundo dia de avaliação, com o início da intervenção da solução de sacarose e água estéril, a porcentagem de neonatos que chorou no Grupo Sacarose passou a ser menor em comparação à porcentagem de neonatos que chorou no Grupo Água.

Este dado confirma resultados apresentados em estudos anteriores no que diz respeito à diminuição do tempo de choro durante a realização do procedimento de punção em neonatos pré-termo que receberam solução de sacarose, em comparação a neonatos que receberam água estéril (ACHARYA et al., 2004; 
McCULLOUGH et al., 2007; RAMENGHI; EVANS; LEVENE, 1999) ou outras intervenções não-farmacológicas, tais como anestésico local (ABAD et al., 1996), glicose (RAMENGHI et al., 1996) e leite humano (STORM; FREMMING, 2002).

O choro, segundo Ludinton-Hoe, Cong e Hashemi (2002), apresenta conseqüências imediatas e de longo prazo, levando a: aumento na frequência cardíaca e pressão sanguínea, redução do nível de oxigenação, elevação da pressão sanguínea cerebral, aumento do nível de cortisol salivar, dispêndio de reservas de energia e oxigênio, prejuízo cerebral, disfunção cardíaca, entre outros.

Considerando que neonatos pré-termo com muito baixo peso estão sob intervenção de ventilação assistida, o dispêndio desnecessário de energia é prejudicial para o ganho de peso e desenvolvimento. Portanto, torna-se imprescindível a adoção de medidas de prevenção e alívio de choro sempre que o recém-nascido for manuseado para a realização de procedimentos na UTIN.

Em relação ao indicador fisiológico de frequência cardíaca, os resultados encontrados no presente estudo não seguiram a mesma direção dos indicadores biocomportamentais de atividade facial e estado de vigília e sono. A frequência cardíaca média dos neonatos de ambos os grupos mostrou-se bastante semelhante no primeiro dia de avaliação, no qual não houve intervenção, em todas as fases avaliadas. Este padrão permaneceu nos três dias em que foi administrada a solução de sacarose e água estéril antes da realização do procedimento doloroso.

Em ambos os grupos, os neonatos apresentaram frequência cardíaca média mais elevada nas fases de Preparação para Punção, Punção e Recuperação com 
Manuseio, em comparação às fases nas quais não houve manipulação dos mesmos pela enfermeira, ou seja, Linha de Base e Recuperação sem Manuseio.

Em continuidade à análise do indicador fisiológico de frequência cardíaca, a porcentagem de neonatos que apresentou frequência cardíaca média igual ou acima de 160 batimentos por minuto, característico de taquicardia para esta população, foi comparada entre os grupos, nas diversas fases avaliadas, durante os quatro dias consecutivos de avaliação. Da mesma maneira, os resultados revelaram não haver diferença entre os grupos em nenhum momento da avaliação, sendo que a maioria dos recém-nascidos de ambos os grupos apresentaram frequência cardíaca média característica de taquicardia nas fases de Punção e Recuperação com Manuseio em todos os dias de avaliação.

Este dado é similar ao encontrado por Ramenghi et al. (1996), em um estudo em que os autores mensuraram, entre outros indicadores, a frequência cardíaca de neonatos pré-termo em procedimento de punção capilar, com a finalidade de avaliar o efeito de $1 \mathrm{ml}$ de solução de sacarose a $25 \%$. Os autores encontraram que, independente dos neonatos terem recebido solução de sacarose ou água estéril, a frequência cardíaca foi a mesma tanto durante a intervenção quanto durante a recuperação. Johnston et al. (1997) também não encontraram diferença estatística na frequência cardíaca de neonatos pré-termo que receberam $0,05 \mathrm{ml}$ de solução de sacarose a $24 \%$, neonatos que foram balançados a partir de um colchão de ar ligado a um respirador, posicionado em cima do colchão de algodão do berço aquecido, 
neonatos que receberam as duas intervenções não-farmacológicas em conjunto, ou neonatos que receberam água estéril antes do procedimento de punção capilar.

Alguns estudos realizados com neonatos pré-termo demonstram que outros indicadores fisiológicos, como a saturação de oxigênio, parecem não sofrer o efeito da solução de sacarose na diminuição de seus níveis frente a estímulos invasivos e dolorosos (ACHARYA et al., 2004).

Tais resultados reforçam a explicação formulada por Gaspardo, Linhares e Martinez (2005), de que os indicadores comportamentais se mostram mais sensíveis à interferência da solução de sacarose em comparação aos indicadores fisiológicos.

Com o objetivo de avaliar a eficácia da solução de sacarose administrada em esquema de doses repetidas na estabilidade fisiológica de neonatos pré-termo, Boyer et al. (2004) encontraram uma correlação negativa significativa entre o desvio padrão da frequência cardíaca dos recém-nascidos e número de doses de sacarose administradas, apenas nos recém-nascidos que receberam grande quantidade de doses de solução de sacarose (nove doses ou mais dentro de 24 horas). Portanto, quanto mais alta a quantidade de doses da solução de sacarose, mais baixo o desvio padrão da frequência cardíaca, sugestivo de diminuição da variabilidade.

Cabe ressaltar que, no presente estudo, as doses de solução de sacarose não excederam a $1 \mathrm{ml}$, pois o cálculo da dose realizado foi de $0,5 \mathrm{ml} / \mathrm{kg}$, o que leva a supor que a frequência cardíaca dos neonatos que receberam a sacarose pode não ter sido significativamente reduzida em relação aos neonatos que receberam água estéril devido à dose administrada não ser alta. Porém, a administração de uma 
dose maior de solução de sacarose, em esquema de doses repetidas, para neonatos pré-termo que sofreram em média seis procedimentos dolorosos ao dia, poderia comprometer o uso da substância com segurança à saúde dos recémnascidos, de acordo com Johnston et al. (2002).

Além disso, a frequência cardíaca não é uma medida específica de dor, diferentemente do indicador comportamental de atividade facial, e pode sofrer alterações de uma série de outros estímulos que não o estímulo doloroso, os quais podem interferir na análise deste indicador. O aumento da frequência cardíaca no neonato que passa por um procedimento doloroso pode refletir, além de uma resposta à dor aguda, resposta ao estresse e desconforto a que são submetidos os recém-nascidos durante a realização do procedimento.

A elevação da frequência cardíaca como uma resposta ao estresse relacionado aos eventos estressores repetitivos sofridos pelos neonatos na UTIN pode ser identificada a partir de resultados encontrados no presente estudo. No Grupo Sacarose, a frequência cardíaca média dos neonatos se apresentou menos elevada no primeiro dia de avaliação em relação aos demais, durante a antissepsia. No Grupo Água, por sua vez, com o passar dos dias, houve uma aumento gradual do indicador de frequência cardíaca média, em todas as fases avaliadas.

Talvez estes resultados reflitam uma maneira de reação dos neonatos a um evento estressor repetitivo, visto que a punção para coleta de sangue é um dos procedimentos mais freqüentes da UTIN. Esta resposta de elevação gradual da frequência cardíaca ao longo dos dias de avaliação pode estar relacionada a uma 
resposta condicionada às experiências de dor anteriores (GOUBET; CLIFTON; SHAH, 2001).

O fato do indicador fisiológico de frequência cardíaca média não ter sido amenizado pelo uso da sacarose, na amostra estudada, tanto durante o procedimento doloroso como durante a recuperação pós-procedimento, levantou a questão sobre o tempo necessário para a recuperação destes neonatos para atingir a estabilidade fisiológica após a punção para coleta de sangue. A dúvida referiu-se se a sacarose não produziu o efeito de regular a ativação fisiológica, ou se o tempo de 10 minutos após a punção teria sido suficiente para os recém-nascidos se recuperarem fisiologicamente do procedimento doloroso. Para sanar tal dúvida, analisou-se o tempo de recuperação total de 10 minutos, minuto a minuto, e encontrou-se que todos os neonatos conseguiram recuperar o estado fisiológico, de forma a ter atingido um padrão da frequência cardíaca semelhante ao da fase de Linha de Base, independente da administração de solução de sacarose ou de água estéril antes do procedimento doloroso.

Mais especificamente, pode-se observar que os neonatos do Grupo Água atingiram a recuperação fisiológica, após o procedimento doloroso, mais rapidamente em Grupo Sacarose, mesmo tendo iniciado esta fase com uma frequência cardíaca mais elevada. Porém, se considerarmos como fisiologicamente recuperados os recém-nascidos que apresentam frequência cardíaca abaixo de 160 batimentos por minuto, temos que o Grupo Água chegou a este padrão no $5^{\circ}$ minuto da recuperação, enquanto que o Grupo Sacarose atingiu uma frequência cardíaca 
abaixo do indicado para taquicardia já no $3^{\circ}$ minuto da recuperação. Portanto, é possível afirmar que a sacarose agiu no sentido de reduzir o tempo necessário para o recém-nascido se recuperar e atingir a estabilidade fisiológica após passar pelo procedimento doloroso de punção.

A elevação da frequência cardíaca traduz-se em ativação do neonato, o que pode levar a um dispêndio de energia, causando instabilidade na evolução clínica em neonatos vulneráveis. Portanto, como sugerido por Als et al. (2004), torna-se imprescindível o uso de medidas de conforto, como por exemplo, a solução de sacarose, com a finalidade de atenuar indicadores biocomportamentais e fisiológicos de dor, estresse e desconforto apresentados pelos neonatos internados em UTIN.

Outras intervenções não-farmacológicas, tais como leite humano via sonda nasogástrica, sucção não-nutritiva e colo, apresentam efeito sinérgico ao efeito analgésico da solução de sacarose, quando administrados de maneira combinada (BLASS; WATT, 1999; GIBBINS et al., 2002; OVERGAARD; KNUDSEN, 1999; STEVENS et al., 1999; STEVENS et al., 2005; STORM; FREMMING, 2002).

Cabe ressaltar que, no Grupo Água, parece ter havido uma tendência à diminuição dos escores dos indicadores biocomportamentais, comparando-se os indicadores apresentados pelos neonatos no primeiro dia de intervenção, no qual não houve administração da solução de sacarose ou água estéril com os demais dias, no qual as substâncias foram administradas. Tal fato pode sugerir a explicação de que, ao receberem a água estéril, os neonatos foram estimulados à sucção, e esta pode ter atuado como uma variável de amenização da dor e estresse sofridos 
pelos recém-nascidos durante o processo de realização do procedimento de punção, como descrito por Corbo et al. (2000). Porém, o grupo que recebeu a solução de sacarose, no presente estudo, apresentou resultados mais efetivos do que o grupo que recebeu água estéril.

A segunda questão a qual o presente estudo buscou responder refere-se aos possíveis efeitos colaterais advindos da administração da solução de sacarose em esquema de doses repetidas nos recém-nascidos pré-termo. Para tanto, inicialmente foram avaliadas características de evolução clínica dos mesmos, tais como incidência de resíduo na sonda orogástrica e de vômitos, e presença de distensão abdominal, durante os quatro dias de avaliação. A análise de comparação entre os grupos revelou que tais variáveis não foram influenciadas pela administração da solução, o que sugere que a sacarose não causou efeitos colaterais em curto prazo aos neonatos.

Estudos que avaliaram a segurança do uso da sacarose em dose única para a saúde dos recém-nascidos, imediatamente após o uso da substância, obtiveram resultados semelhantes no que diz respeito à ausência de vômito (GIBBINS; STEVENS, 2003; GIBBINS et al., 2002).

Considerando a possibilidade de efeitos colaterais surgirem não imediatamente após a administração da solução de sacarose, mas sim durante todo período de internação dos neonatos, visto que a sacarose foi administrada em esquema de doses repetidas, outras variáveis relacionadas à evolução clínica e ao padrão de alimentação dos recém-nascidos foram analisadas e comparadas entre 
os grupos. Tais análises revelaram que a utilização da solução de sacarose em esquema de doses repetidas não interferiu no ganho de peso e no tempo de internação dos neonatos, bem como no desenvolvimento de patologias, tais como displasia broncopulmonar, retinopatia da prematuridade, hemorragia periintraventricular, enterocolite necrosante, septicemia, cardiopatia, e pneumotórax. Além disso, também foi verificado que o uso da substância não interferiu no padrão de alimentação dos bebês, avaliado pela permanência do uso da sonda orogástrica durante o período de internação.

Faz-se importante considerar que apenas em relação ao peso na alta hospitalar os grupos diferiram, sendo que a mediana do Grupo Água foi maior do que a mediana do Grupo Sacarose. Este dado está relacionado ao fato de que um neonato do Grupo Água permaneceu internado por um longo período de seis meses, o que acarretou que seu peso no momento da alta fosse maior em relação aos demais participantes desta amostra. Ao se realizar a mesma análise excluindo-se este participante, os grupos passaram a ser comparáveis também para esta variável.

Em síntese, as hipóteses formuladas pelo presente estudo puderam ser confirmadas na medida em que a solução de sacarose administrada em esquema de doses repetidas e usada consecutivamente, ao longo de três dias, foi eficaz no alívio da dor dos recém-nascidos pré-termo, sem trazer prejuízos a curto prazo para a saúde dos recém-nascidos submetidos à intervenção. Portanto, a sacarose mostrou eficácia sem efeitos colaterais imediatos. 
Apesar de os achados assegurarem o uso da sacarose no alívio da dor, frente às condições clínicas imediatas dos neonatos, em curto prazo, a avaliação da eficácia da administração da substância em doses repetidas deve aprofundar a compreensão dos possíveis efeitos colaterais do ponto de vista do desenvolvimento da criança, a médio e longo prazo.

Johnston et al. (2002) avaliaram neonatos pré-termo que receberam solução de sacarose ou água estéril, antes de cada procedimento invasivo, durante um período de sete dias. Em relação aos possíveis efeitos colaterais da sacarose, os autores encontraram que um alto número de doses de sacarose, equivalente a 10 doses (JOHNSTON et al., 2007), foi preditor de baixo escore de desenvolvimento neurocomportamental para as áreas de desenvolvimento motor e vigor, alerta e orientação em bebês com idade pós-concepcional de 36 semanas, e para as áreas de desenvolvimento motor e vigor em bebês com idade pós-concepcional de 40 semanas, segundo o instrumento Neurobehavioral Assessment of the Preterm Infant. Entretanto, é preciso considerar que os neonatos que receberam mais doses de sacarose podem ser aqueles mais graves, e que, portanto, necessitaram passar por mais procedimentos dolorosos e invasivos. Sendo assim, o resultado negativo na avaliação neurocomportamental pode estar relacionado ao quadro de saúde do bebê, e não necessariamente à quantidade de sacarose ingerida.

Por outro lado, Stevens et al. (2005) não encontraram diferença no escore do Neurobiological Risk Score entre os neonatos pré-termo aos 28 dias de vida que receberam o cuidado padrão da UTIN, $0,1 \mathrm{ml}$ de sacarose oral seguida de sucção 
não-nutritiva ou água estéril seguida de sucção não-nutritiva antes de todos os procedimentos dolorosos sofridos pelos neonatos durante o tempo de internação na UTIN.

Em 2008, os principais achados do presente estudo foram publicados por Gaspardo, Miyase et al. (2008). Posteriormente, outros estudos foram publicados, assegurando a eficácia do uso continuado da sacarose em neonatos hospitalizados (CIGNACCO et al., 2009; HARRISON et al., 2009; TADDIO et al., 2008; TADDIO et al., 2009).

A eficácia da solução de sacarose administrada via oral e em esquema de doses repetidas, na redução da dor aguda em recém-nascidos pré-termo, nas primeiras duas semanas de vida submetidos a procedimentos de punção capilar para coleta de sangue, foi investigada por Cignacco et al. (2009). Os resultados revelaram uma estabilidade na produção de cortisol salivar, nos neonatos que receberam a sacarose, mensurada antes e após a realização dos procedimentos dolorosos.

O efeito da sacarose administrada via oral e em esquema de doses repetidas, na resposta de dor aguda de recém-nascidos hospitalizados por um período de 28 dias e submetidos a procedimentos de punção para coleta de sangue foi avaliado no estudo de Harrison et al. (2009). Os resultados não indicaram mudanças significativas na atividade facial e duração do choro, antes e após os procedimentos dolorosos, nos neonatos que receberam a solução de sacarose antes dos procedimentos dolorosos. 
Uma importante questão avaliada nos estudos de Taddio et al. (2008) e Taddio et al. (2009) refere-se à segurança do uso da solução de sacarose em doses repetidas em recém-nascidos a termo de mães diabéticas. Os três estudos utilizaram a mesma amostra para avaliar a eficácia de $2 \mathrm{ml}$ de solução de sacarose a $24 \%$, administrada via oral, em comparação com água estéril, para o alívio da dor dos recém-nascidos em procedimentos dolorosos de punção e injeção realizados durante os dois primeiros dias de vida. No estudo de Taddio et al. (2008) foi encontrada diminuição significativa do escore do Premature Infant Pain Profile após os procedimentos dolorosos de punção nos grupos de neonatos de mães diabéticas e não-diabéticas que receberam a solução de sacarose em comparação aos neonatos que receberam água estéril. Não foi encontrada diferença significativa no nível de glicemia entre os recém-nascidos de mães diabéticas que receberam sacarose ou água estéril.

O objetivo do estudo de Taddio et al. (2009), por sua vez, foi determinar o efeito da exposição a procedimentos dolorosos e o efeito analgésico da sacarose no desenvolvimento da hiperalgesia nos recém-nascidos de mães diabéticas e nãodiabéticas. Os resultados demonstraram que todos os recém-nascidos que receberam cinco procedimentos dolorosos ou mais durante dois dias de internação apresentaram maior duração de choro e escores mais elevados no Premature Infant Pain Profile, em comparação aos recém-nascidos que receberam até quatro procedimentos dolorosos no mesmo período. A solução de sacarose agiu na redução das respostas de dor dos recém-nascidos de mães diabéticas e não- 
diabéticas que receberam a substância antes dos procedimentos dolorosos, em comparação aos recém-nascidos que receberam água estéril. Entretanto, a diferença nas respostas de dor entre os grupos, quando divididos pelo número de procedimentos dolorosos recebidos, continuou a existir, demonstrando que a solução de sacarose não preveniu a hiperalgesia. Neste aspecto, deve-se ressaltar que esta é uma importante consequência negativa dos procedimentos dolorosos repetidos em fase inicial do desenvolvimento. Portanto, não basta utilizar a solução de sacarose; deve-se, paralelamente ao uso da substância para o alívio da dor, racionalizar a realização de múltiplos procedimentos dolorosos.

Portanto, os achados do presente estudo a respeito da eficácia e segurança do uso da sacarose em esquema de doses repetidas devem ser contextualizados a partir da abordagem do Cuidado desenvolvimental individualizado e centrado na familia de bebês pré-termo de muito baixo peso em UTIN, sistematizada por Als (1982, 2004, 2009). De acordo com os princípios do Cuidado Desenvolvimental, deve-se promover a regulação biocomportamental e o desenvolvimento dos neonatos hospitalizados a partir de intervenções realizadas no ambiente da UTIN, tais como: redução do barulho, luz e movimentação de pessoas, além do oferecimento de intervenções não-farmacológicas aos neonatos, como a solução de sacarose, a sucção não-nutritiva e o contato pele a pele com a mãe (GASPARDO; MARTINEZ; LINHARES, 2010). A utilização de intervenções de alívio de dor é fundamental, assim como a regularização e racionalização do toque e manuseio no recém-nascido vulnerável internado em UTIN. 
Dessa maneira, apenas a informação encontrada no primeiro dia de avaliação, sobre a desestabilização do neonato com o manuseio para a antissepsia, já é suficiente para se propor estratégias de cuidado ao desenvolvimento, racionalizando os manuseios desnecessários ao neonato durante procedimentos na UTIN, aliviando e promovendo intervenções de conforto nas fases contíguas ao procedimento doloroso. A desestabilização implica em consumo de energia desnecessário em um organismo vulnerável como o do recém-nascido pré-termo (LINHARES, 2009).

A exposição aos estímulos provenientes do ambiente extra-uterino desencadeia nos recém-nascidos respostas relacionadas à autorregulação fisiológica, que consiste em processos e funcionamentos do sistema nervoso parassimpático. Esses, por sua vez, exercem um importante papel na etiologia dos comportamentos regulatórios iniciais que sustentam os vínculos sociais, como o estado de vigília e sono, a atividade motora e a emoção (FELDMAN, 2009). A compreensão das reações do recém-nascido e sua capacidade de interagir e autorregular o seu comportamento permitem a identificação de alterações no seu desenvolvimento inicial que podem estar relacionadas à exposição à dor e ao estresse (WARNOCK, 2003).

De acordo com Linhares et al. (2006), a trajetória de desenvolvimento do neonato pré-termo, os quais necessitam de internação em UTIN, se inicia em um microcontexto permeado pela presença contínua de diversos estímulos estressantes, tais como procedimentos médicos frequentes, manuseios invasivos e 
dolorosos, excesso de estimulação luminosa e sonora. Dessa forma, além do fator de risco biológico da prematuridade, tais experiências podem caracterizar-se como um risco ambiental adicional no curso do desenvolvimento do recém-nascido vulnerável, ocasionando efeitos negativos a curto e longo prazo, como o comprometimento dos processos de autorregulação (ANAND, 2000; 2006; GRUNAU, 2000; 2002; GOFFAUX et al., 2008; SAMEROFF, 2010; SIMONS; TIBBOEL, 2006; VAN DE VELDE et al, 2006).

De forma relevante, a Teoria do Caos e sua influência no desenvolvimento foi apresentada recentemente por Evans e Wachs (2010), ampliando a compreensão do desenvolvimento de indivíduos em condições altamente estressoras. Segundo os autores, contextos caóticos são caracterizados por ambientes físicos e humanos de grande instabilidade diária, sem regularidade temporal e estrutural, predominando no microssistema a variabilidade de cuidadores, alta densidade de pessoas, barulho, alta complexidade visual e a excessiva estimulação, que podem afetar diretamente os processos de desenvolvimento regulatórios do indivíduo.

Para Sameroff (2010), o caos interfere no fluxo de informações necessárias a autorregulação e corregulação do indivíduo, o que demonstra uma relação estreita para a compreensão do desenvolvimento do bebê pré-termo que experimenta uma grande imaturidade biológica, vulnerabilidade que ameaça a sua sobrevivência e adaptação, assim como a exposição ao ambiente altamente estressor durante a internação hospitalar na UTIN. 
Portanto, recém-nascidos pré-termo sentem dor e são capazes de expressar reações de dor a nível fisiológico e comportamental. Tais reações podem ser avaliadas e devem ser aliviadas visando a proteção ao recém-nascido, não só das adversidades da hospitalização, mas também do seu desenvolvimento futuro.

Sendo assim, faz-se importante o uso de medidas de conforto para o manejo da dor e estresse durante procedimentos invasivos e dolorosos, pelos profissionais da UTIN, com a finalidade de facilitar a organização e autorregulação dos neonatos pré-termo, a fim de promover o seu desenvolvimento (GASPARDO; MARTINEZ; LINHARES, 2010, KLEIN; GASPARDO; LINHARES, no prelo). Como os recémnascidos internados na UTIN estão privados do contato pele a pele, do colo materno e da amamentação devido à instabilidade clínica, o uso de intervenções nãofarmacológicas com a finalidade de promover a regulação fisiológica e comportamental destes recém-nascidos tornam-se imprescindíveis.

As capacidades autorregulatórias da criança são fortemente influenciadas pela experiência de regulação oferecida pelos cuidadores. No início do desenvolvimento, a regulação humana se move de processos primários para processos psicológicos e sociais, sendo que o que começa como um processo de regulação da temperatura, fome e alerta logo se torna a regulação da atenção, do comportamento e das interações sociais (FELDMAN, 2009; SAMEROFF, 2009).

Dessa forma, a assistência ao recém-nascido prematuro deve transcender as questões relacionadas à sobrevivência para fornecer respostas adequadas de suporte ao seu desenvolvimento e qualidade de vida. Visto que as crianças nascidas 
prematuramente podem experimentar desvantagens para o seu desenvolvimento futuro, com alto custo tanto para o próprio indivíduo, como para as áreas da Educação e Saúde, torna-se imprescindível a implantação de intervenções preventivas em fases iniciais do desenvolvimento (JOBE, 2001; PETROU; SACH; DAVIDSON, 2001).

Partindo-se deste pressuposto, a intervenção preventiva para problemas de desenvolvimento em neonatos pré-termo vulneráveis deve ser considerada desde a admissão dos mesmos na UTIN. Os profissionais da equipe de saúde no contexto da UTIN assumem o papel de correguladores ou cuidadores primários do neonato, podendo modular suas respostas no nível comportamental, emocional, neuroendócrino e parassimpático, por meio de estratégias de alívio da dor e do estresse. 


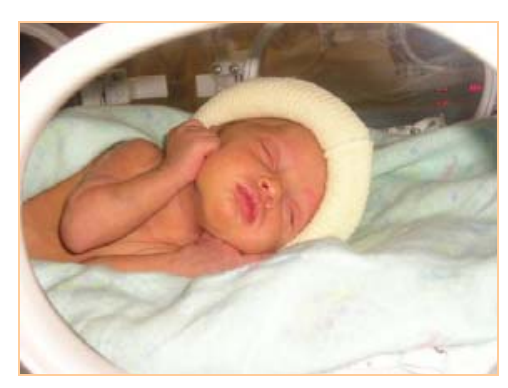

6. CONSIDERAÇÕES FINAIS 


\subsection{Considerações metodológicas}

Estudos realizados com neonatos pré-termo, para a avaliação da eficácia da solução de sacarose frente a outras intervenções não-farmacológicas, realizaram a análise intragrupo geralmente entre as fases de linha de base, punção e recuperação para a verificação de diferenças do mesmo indicador de resposta à dor entre as diferentes fases de avaliação (ABAD et al., 1996; BUCHER et al., 1995; ELSERAFY et al., 2009; JOHNSTON et al., 1999; OKAN et al., 2007; RAMENGHI; EVANS; LEVENE, 1999; RAMENGHI et al., 1996; STEVENS et al., 1999; STORM; FREMMING, 2002). Neste sentido, o que o presente estudo traz de novo na metodologia em relação aos demais é a subdivisão das fases de Linha de Base, Preparação para Punção, Punção, Recuperação com Manuseio, e Recuperação sem Manuseio.

Este esquema de divisão de fases permitiu a identificação das alterações biocomportamentais e fisiológica do neonato, bem como da eficácia da solução de sacarose, em relação aos indicadores biocomportamentais analisados, não só no momento do procedimento doloroso, mas também nos momentos em que houve o manuseio da enfermeira para a realização da antissepsia, e após a realização do mesmo, enquanto esta realizava o curativo.

Os indicadores de resposta à dor apresentados pelos neonatos revelaram que os neonatos já responderam com elevação destes indicadores ao manuseio da enfermeira para a preparação para a punção, como uma resposta de antecipação ao 
evento doloroso. Nas fases de recuperação, os neonatos apresentaram maior ativação biocomportamental e fisiológica no momento em que ainda estavam sendo manuseados pela enfermeira, em relação ao momento de recuperação no qual já estavam em repouso na incubadora.

Além disso, esta divisão de fases também permitiu verificar que a solução de sacarose continuou a reduzir os indicadores biocomportamentais de dor avaliados durante a recuperação do neonato, mesmo quando ainda manuseado pela enfermeira para a realização do procedimento doloroso e posicionamento na incubadora. Até onde se sabe, em nenhum dos estudos encontrados na literatura sobre a eficácia do uso da sacarose na redução de respostas de dor em neonatos houve a análise da fase de recuperação subdividida em recuperação com e sem manuseio.

Pode-se destacar como uma vantagem metodológica a análise multidimensional de dor no neonato pré-termo de muito baixo peso ao nascer, a partir de medidas unidimensionais, o que permitiu a análise dos indicadores biocomportamentais e fisiológico separadamente. Dessa forma foi possível perceber a eficácia da sacarose frente aos indicadores de estado de vigília e sono e atividade facial, este específico de dor.

A maneira como a solução de sacarose foi administrada no presente estudo, em esquema de doses repetidas, durante três dias consecutivos, para todos os procedimentos invasivos e dolorosos que causam dor aguda aos neonatos, é inovadora quando comparada aos demais estudos nos quais a intervenção de 
sacarose também foi administrada em esquema de doses repetidas (BOYER et al., 2004; JOHNSTON et al., 1999, 2002; MITCHELL et al., 2004; STEVENS et al., 2005)

Nos estudos de Johnston et al. (1999) e Mitchell et al. (2004), a solução de sacarose em doses repetidas foi administrada durante um único procedimento doloroso. Nos estudos de Johnston et al. (2002) e Boyer et al. (2004), por sua vez, a solução de sacarose foi administrada em todos os procedimentos sofridos pelos neonatos durante um período de sete dias consecutivos, entretanto não houve nos estudos um primeiro dia relativo à linha de base dos neonatos para posterior comparação, sem a administração da intervenção. Da mesma forma, Stevens et al. (2005) avaliaram o uso da sacarose administrada em doses repetidas durante 28 dias consecutivos de internação dos neonatos, porém em uso conjunto com outra intervenção não-farmacológica de sucção não-nutritiva.

O presente estudo demonstrou, a partir da metodologia utilizada, que o uso da sacarose em doses repetidas manteve o seu efeito de alívio de dor sem efeitos clínicos colaterais, preservando, portanto, o princípio de maior benefício e menor custo. O teste de uma dose menor do que a documentada na literatura pode ser considerado como uma grande contribuição para estudos com neonatos pré-termo. Estudos anteriores usaram $2 \mathrm{ml}$ de solução de sacarose a $25 \%$ em esquema de dose única (GASPARDO; LINHARES; MARTINEZ, 2005), enquanto nesse estudo foi usado $0,5 \mathrm{ml} / \mathrm{kg}$ de sacarose a $25 \%$, ajustada ao peso do neonato. Esse ajuste foi importante na medida em que $2 \mathrm{ml}$ de sacarose em esquema de administração de 
doses repetidas seria excessivo, considerando que os neonatos sofreram em média seis procedimentos dolorosos por dia.

Outro aspecto que pode ser considerado como um avanço no presente estudo refere-se à realização da curva ROC para o estabelecimento do ponto de maior sensibilidade e especificidade da nota de corte da atividade facial indicativa de dor em neonatos pré-termo. O estudo anterior de Grunau et al. (1998) mostrou que o escore de três pontos era indicativo de dor na escala NFCS, adaptado para dor aguda-procedural, na forma validada para aplicação à beira do leito. Nesta forma, a medida variava de zero a oito pontos, baseada na presença ou ausência das reações faciais previstas no NFCS. Dessa forma, o estudo trouxe uma contribuição metodológica, pois a curva ROC indicou que o escore de três pontos também foi encontrado para o NFCS aplicado na forma original, validada para aplicação com vídeo-gravação da face do neonato, permitindo a análise posterior por examinador "cego" em relação à situação da coleta de dados. O escore de três pontos no NFCS demonstrou ter sensibilidade e especificidade para indicação de nota de corte entre presença e ausência de dor.

Por fim, o estudo também identificou que o tempo de 10 minutos de recuperação foi suficiente para os recém-nascidos se recuperarem fisiologicamente do procedimento doloroso de punção.

Em síntese, o presente estudo avançou em relação aos estudos anteriores considerando diversos aspectos, a saber: a análise multidimensional de dor em neonatos a partir de indicadores unidimensionais; a análise da eficácia da solução 
de sacarose em esquema de doses repetidas em diferentes procedimentos dolorosos realizados em dias consecutivos; a análise de possíveis efeitos colaterais em curto prazo, imediatos ao uso da intervenção e durante todo o período de hospitalização dos neonatos; a determinação de dose de $0,5 \mathrm{ml} / \mathrm{kg}$ para uso em esquema repetido com recém-nascidos pré-termo; a identificação de nota de corte sensível e específica para avaliar a dor em neonatos pré-termo com o uso do NFCS; a definição de tempo para recuperação do indicador fisiológico de frequência cardíaca para atingir o padrão basal anterior ao procedimento doloroso; e a definição de fases do procedimento de avaliação de dor em diferentes tipos de punção.

Deve-se levar em consideração, como um limite do estudo, o fato de não ser possível o controle da realização das punções por uma única enfermeira, o que gerou uma falta de uniformidade e homogeneidade do procedimento doloroso, variável controlada em outros estudos (JOHNSTON et al., 1997; RAMENGHI et al., 1996). Entretanto, as punções foram realizadas por enfermeiras experientes e treinadas.

Como um segundo limite do estudo deve-se considerar o reduzido tamanho da amostra obtida, decorrente do rigor dos critérios de exclusão, os quais tiveram por objetivo evitar que variáveis de evolução clínica do neonato pudessem interferir nos indicadores de dor apresentados. Porém, a amostra de conveniência do estudo pode ser considerada representativa da população de neonatos com menor índice de risco clínico, sendo estes os que realmente se beneficiam com o uso da solução de sacarose na UTIN. Os neonatos com maior comprometimento clínico necessitam 
de medidas farmacológicas para o controle da dor, visto que são expostos a uma variedade de procedimentos que causam dores mais intensas em comparação a procedimentos que causam dores mais leves ou apenas desconforto.

\subsection{Desdobramentos para a prática}

Os resultados do presente estudo trouxeram contribuições para a prática clínica na medida em que foram revertidos diretamente para a melhoria de práticas em prol da qualidade de vida de recém-nascidos prematuros vulneráveis.

Após publicação parcial dos resultados desse estudo, no artigo de Gaspardo, Miyase et al. (2008) (ANEXO D), os coordenadores e a equipe multidisciplinar da UTIN do HCFMRP/USP reestruturaram o protocolo mínimo de intervenção farmacológica e não-farmacológica dessa unidade, adotando o uso da solução de sacarose como uma intervenção não-farmacológica de rotina para o alívio da dor aguda nos neonatos pré-termo internados submetidos a procedimentos invasivos e dolorosos.

Estudos publicados posteriormente à implantação da solução de sacarose neste serviço reforçam, a partir dos resultados favoráveis encontrados, a eficácia e segurança do uso da intervenção não-farmacológica de sacarose em recémnascidos hospitalizados em UTIN, por longos períodos de internação (CIGNACCO et al., 2009; HARRISON et al., 2009; TADDIO et al., 2008; TADDIO et al., 2009). 
O impacto das reações de dor exibidas pelos neonatos participantes deste estudo, as quais foram avaliadas inclusive em procedimentos não dolorosos que envolviam apenas o manuseio destes pela equipe de enfermagem, levou também à implantação de outras intervenções relacionadas ao Cuidado Desenvolvimental na UTIN do HCFMRP/USP. Realizou-se um treinamento dos profissionais da equipe multidisciplinar fixa da unidade, que incluiu desde a sensibilização dos profissionais para a abordagem desse assunto, até a ação de tomada de decisões para mudanças efetivas tanto na prática como no ambiente da UTIN.

Sendo assim, um conjunto de medidas foi adotado em parceria com a equipe de profissionais de saúde da UTIN, a saber: redução de estímulos luminosos e sonoros; redução e agrupamentos de procedimentos dolorosos ou que causam desconforto e manuseios; estimulação e favorecimento de visitas das mães aos recém-nascidos; estimulação ao aleitamento materno; favorecimento, sempre que indicado, do contato pele a pele entre mãe e recém-nascido.

Além disso, os coordenadores e a equipe multidisciplinar da UTIN do HCFMRP/USP desenvolveram um manual denominado Manejo comportamental e ambiental na UTIN do HCFMRP-USP (GASPARDO et al., 2009 não publicado) com o objetivo de orientar profissionais de outras equipes do referido hospital que atuam na UTIN sobre a importância de terem uma conduta voltada a minimizar os efeitos negativos dos estímulos estressantes e dolorosos no estado clínico e desenvolvimento dos recém-nascidos hospitalizados. 


\subsection{Desdobramentos para a pesquisa - questões futuras}

O presente estudo contribuiu para a elucidação de aspectos importantes relacionados à avaliação da dor em recém-nascidos pré-termo e ao manejo da dor neonatal pelo uso da intervenção não-farmacológica de solução de sacarose administrada em doses repetidas. No entanto, algumas questões ainda necessitam ser exploradas em estudos futuros, como por exemplo:

1) Recém-nascidos pré-termo apresentam diferenciação de reatividade e regulação biocomportamental à dor e ao estresse de acordo com características individuais, tais idade gestacional, peso ao nascimento e risco clínico neonatal?

2) A história de exposição a procedimentos dolorosos na fase inicial de desenvolvimento de crianças nascidas prematuras têm influência a médio e longo prazo nos aspectos de saúde e desenvolvimento dessas crianças?

3) A administração de $0,5 \mathrm{ml} / \mathrm{kg}$ de solução de sacarose em esquema de doses repetidas é eficaz para o alívio de dor em recém-nascidos a termo ou em bebês que permanecem internados por longos períodos na UTIN?

4) O uso da solução de sacarose em esquema de doses repetidas causa algum efeito colateral a médio e longo prazo na sensibilização à dor das crianças submetidas à intervenção na fase inicial do desenvolvimento, ou em aspectos da saúde e desenvolvimento dessas crianças? 


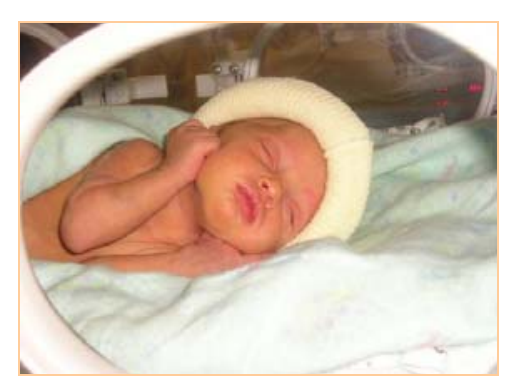

REFERÊNCIAS BIBLIOGRÁFICAS 
$A B A D, F$. et al. Oral sweet solution reduces pain-related behavior in preterm infants. Acta Paediatrica, Stockholm, v. 85, n. 7, p. 854-858, 1996.

ABAD, F. et al. Oral sucrose compares favorably with lidocaine-prilocaine cream for pain relief during venopuncture in neonates. Acta Paediatrica, Stockholm, v. 90, n. 2, p. 160-165, 2001.

ACHARYA, A. B. et al. Oral sucrose analgesia for preterm infant venopuncture. Archives of Disease in Childhood, Fetal and Neonatal Edition, London, v. 89, n. 1, p. 17-18, 2004.

ACHENBACH, T. M. Developmental Psychopathology. In: BORNSTEIN, M. H.; LAMB, M. E. (Orgs.) Developmental Psychopathology: an advanced textbook. New York: Lawrence Erlbaum Associates Publishers, 1992. p. 629-676.

AHN, Y. The relationship between behavioral states and pain response to various NICU procedures in premature infants. Journal of Tropical Pediatrics, Oxford, v. 52, n. 3, p. 201-205, 2006.

AKÇAM, M. Oral fructose solution as an analgesic in the newborn: a randomized, placebo-controlled and masked study. Pediatrics International, Tokyo, v. 46, n. 4, p. 459-462, 2004.

AKMAN, I. et al. Sweet solutions and pacifiers for pain relief in newborn infants. Journal of Pain, lowa, v. 3, n. 3, p. 199-202, 2002.

ALMEIDA, P. A. M. Aspectos obstétricos da prematuridade. In: PAQUI, P. (Org.) O pré-termo: morbidade, diagnóstico e tratamento. São Paulo: Roca, 2003. p. 1-22.

ALS, H. Toward a synactive theory of development: promise for the assessment and support of infant individuality. Infant Mental Health Journal, New York, v. 3, n. 4, p. 229-243, 1982. 
ALS, H. NIDCAP: testing the effectiveness of a relationship-based comprehensive intervention. Pediatrics, Illinois, v. 124, n.4, p. 1208-1210, 2009.

ALS, H. et al. Early experience alters brain function and structure. Pediatrics, Illinois, v. 113 , n. 4 , p. 846-857, 2004.

AMERICAN ACADEMY OF PEDIATRICS et al. Prevention and management of pain and stress in the neonate. Pediatrics, Illinois, v. 105, n. 2, p. 454-461, 2000.

AMERICAN ACADEMY OF PEDIATRICS et al. Prevention and management of pain in the neonate: an update. Pediatrics, Illinois, v. 118, n. 5, p. 2231-2241, 2006.

ANAND, K. J. S. Clinical importance of pain and stress in preterm neonates. Biology of the Neonate, Basel, v. 73, n. 1, p. 1-9, 1998.

ANAND, K. J. S. Effects of perinatal pain and stress. In: MAYER, E. A.; SAPER, C. B. (Orgs.) Progress in brain research. Amsterdam: Elsevier Science, 2000. v. 122, p. 117-129.

ANAND, K. J. S.; WHIT HALL, R. W. Controversies in neonatal pain: an introduction. Seminars in Perinatology, Burlington, v. 31, n. 5, p. 273-274, 2007.

ANAND, K. J. S. et al. Summary proceedings from the neonatal pain-control group. Pediatrics, Illinois, v. 117, n. 3, p. 9-22, 2006.

ANDERSON, P. J. et al. Executive functioning in school-aged children who were born very preterm or with extremely low birth weight in the 1990s. Pediatrics, Illinois, v. 114, n. 1, p. 50-57, 2004.

APGAR, V. A proposal for a new method of evaluation of the newborn infant. Current Researches in Anesthesia and Analgesia, San Francisco, v. 32, n. 4, p. 260-267, 1953. 
AXELIN, A. et al. Oral glucose and parental holding preferable to opioid in pain management in preterm infants. The Clinical Journal of Pain, Seattle, v. 25, n. 2, p. 138-145, 2009.

AYLWARD, G. P. Methodological issues in outcome studies of at-risk infants. Journal of Pediatric Psychology, Cary, v. 27, n. 1, p.37-45, 2002.

AYLWARD, G. P. Neurodevelopmental outcomes of infants born prematurely. Journal of Developmental and Behavioral Pediatrics, Baltimore, v. 26, n. 6, p. 427440, 2005.

BALDA, R. C. X.; GUINSBURG, R. Avaliação da dor no período neonatal. In: KOPELMAN, B. I. et al. (Orgs.) Diagnóstico e tratamento em neonatologia. São Paulo: Atheneu, 2004. cap. 71, p. 577-585.

BARBOSA, V. C.; FORMIGA, C. K. M. R.; LINHARES, M. B. M. Avaliação das variáveis clínicas e neurocomportamentais de recém-nascidos pré-termo. Revista Brasileira de Fisioterapia, São Carlos, v. 11, n. 4, p. 275-281, 2007.

BARBOSA, S. M. M.; GUINSBURG, R. Dor de acordo com as faixas etárias pediátricas. In: TEIXEIRA, M. J. et al. (Orgs.) Dor: contexto interdisciplinar. Curitiba: Editora Maio, 2003. cap. 38, p. 535-546.

BARKER, D.; RUTTER, N. Exposure to invasive procedures in neonatal intensive care unit admission. Archives of Disease in Childhood, Fetal and Neonatal Edition, London, v. 72, n. 1, p. 47-48, 1995.

BARTOCCI, M. et al. Pain activates cortical areas in the preterm newborn brain. Pain, Seattle, v. 122, n. 1-2, p. 109-117, 2006.

BAUER, K. et al. Oral glucose before venepuncture relieves neonates of pain, but stress is still evidenced by expenditure, and heart rate. Pediatric Research, Hagerstown, v. 55, n. 4, p. 695-700, 2004. 
BAYLESS, S.; STEVENSON, J. Executive functions in school age children born prematurely. Early Human Development, Limerick, v. 83, n. 4, p. 247-254, 2007.

BENIS, M. M. Efficacy of sucrose as analgesia for procedural pain in neonates. Advances in Neonatal Care, Lebanon, v. 2, n. 2, p. 93-100, 2002.

BILGEN, H. et al. Comparison of sucrose, expressed breast milk, and breast-feeding on the neonatal response to heel prick. Journal of Pain, lowa, v. 2, n. 5, p. 301-305, 2001.

BLASS, E. M.; MILLER, L. W. Effects of colostrum in newborn humans: dissociation between analgesic and cardiac effects. Journal of Developmental and Behavioral Pediatrics, Baltimore, v. 22, n. 6, p. 385-390, 2001.

BLASS, E. M.; WATT, L. B. Suckling- and sucrose-induced analgesia in human newborns. Pain, Seattle, v. 83, n. 3, p. 611-623, 1999.

BLAUER, T.; GERSTMANN, D. A simultaneous comparison of three neonatal pain scales during common NICU procedures. The Clinical Journal of Pain, Seattle, v. 14, n. 1, p. 39-47, 1998.

BORDIN, M. B. M.; LINHARES, M. B. M.; JORGE, S. M. Aspectos cognitivos e comportamentais na média meninice de crianças nascidas pré-termo e com muito baixo peso. Psicologia: Teoria e Pesquisa, Brasília, v. 17, n. 1, p. 49-57, 2001.

BOYER, K. et al. Does sucrose analgesia promote physiologic stability in preterm neonates? Biology of the Neonate, Basel, v. 85, n. 1, p. 26-31, 2004.

BOYLE, E. M. et al. Sucrose and non-nutritive sucking for the relief of pain in screening for retinopathy of prematurity: a randomized controlled trial. Archives of Disease in Childhood, Fetal and Neonatal Edition, v. 91, p. 166-168, 2006. 
BRASIL. Ministério da Saúde. Cadernos de Informações de Saúde. Versão de junho de 2008. Disponível em: http://tabnet.datasus.gov.br/tabdata/cadernos/cadernosmap.htm. Acesso em: 30 de junho de 2010.

BRITO, A. et al. Escore CRIB, peso ao nascer e idade gestacional na avaliação do risco de mortalidade neonatal. Revista de Saúde Pública, São Paulo, v. 37, n. 5, p. 597-602, 2003.

BROOME, M.; TANZILLO, H. Differentiating between pain and agitation in premature neonates. The Journal of Perinatal and Neonatal Nursing, Frederick, v. 4, n. 1, p. 53$62,1990$.

BRUGGINK, J. L. M. et al. Quantitative aspects of the early motor repertorie in preterm infants: do they predicty minor neurological dysfunction at school age? Early Human Development, Limerick, v. 85, n. 1, p. 25-36, 2008.

BUCHER, H. et al. Sucrose reduces pain reaction to heel lancing in preterm infants: A placebo-controlled, randomized and masked study. Pediatric Research, Hagerstown, v. 38, n. 3, p. 332-335, 1995.

CALKINS, S. Regulatory competence and early disruptive behavior problems: the role of physiological regulation. In: OLSON, S. L.; SAMEROFF, A. J. Biopsychosocial regulatory processes in the development of childhood behavioral problems. New York: Cambridge University Press, 2009. p. 86-107.

CAMERON, E. C.; RAINGANGAR, V.; KHOORI, N. Effects of handling procedures on pain responses of very low birth weight infants. Pediatric Physical Therapy, Alexandria, v. 19, n. 1, p. 40-47, 2007.

CARBAJAL, R. et al. Randomized trial of analgesic effects of sucrose, glucose, and pacifiers in term neonates. Britsh Medical Journal, London, v. 319, p. 1393-1397, 1999. 
CARBAJAL, $R$. et al. Crossover trial of analgesic efficacy of glucose and pacifier in very preterm neonates during subcutaneous injections. Pediatrics, Illinois, v. 110, n. 2, p. 389-393, 2002.

CARBAJAL, R. et al. Analgesic effect of breast feeding in term neonates: randomized controlled trial. Britsh Medical Journal, London, v. 326, n. 1, p. 1-5, 2003.

CARBAJAL, $R$. et al. Morphine does not provide adequate analgesia for acute procedural pain among preterm neonates. Pediatrics, Illinois, v. 115, n. 6 , p. 14941500, 2005.

CARVAlho, A. E. V.; LinhaReS, M. B. M.; MARTineZ, F. E. História de desenvolvimento e comportamento de crianças nascidas pré-termo e baixo peso (< 1.500g). Psicologia: Reflexão e Crítica, Porto Alegre, v. 14, n. 1, p. 1-33, 2001.

CASTRAL, T. C. et al. The effects of skin-to-skin contact during acute pain in preterm newborns. European Journal of Pain, Berlin, v. 12, n. 4, p. 464-471, 2008.

CHANG, Y. J.; ANDERSON, G. C.; LIN, C. H. Effects of prone and supine positions on sleep state and stress responses in mechanically ventilated preterm infants during the first postnatal week. Journal of Advanced Nursing, Oxford, v.40, n. 2, p.161-169, 2002.

CHERMONT, A. G. et al. O que os pediatras conhecem sobre avaliação da dor no recém-nascido? Jornal de Pediatria, Rio de Janeiro, v. 79, n. 3, p. 265-272, 2003.

CHERMONT, A. G. et al. Skin-to skin contact and/or oral $25 \%$ dextrose for procedural pain relief for term newborn infant. Pediatrics, Illinois, v. 124, n. 6, p. 1101-1107, 2009.

CHIMELLO, J. T. et al. Pain reactivity and recovery in preterm neonates: latency, magnitude, and duration of behavioral responses. Early Human Development, Limerick, v. 85, n. 5, p. 313-318, 2009. 
CIGNACCO, E. et al. Variability in pain response to a non-pharmacological intervention across repeated routine pain exposure in preterm infant: a feasibility study. Acta Paediatrica, Stockholm, v. 98, n. 5, p. 842-846, 2009.

CLARK, C. A. C. et al. Development of emotional and behavioral regulation in children born extremely preterm and very preterm: biological and social influences. Child Development, Massachusetts, v. 79, n. 5, p. 1444-1462, 2008.

CONG, $X$. et al. Kangaroo care modifies preterm infant heart rate variability in response to heel stick pain: pilot study. Early Human Development, v. 85, n.9, p. 561$567,2009$.

COOKE, W.; FOULDER-HUGHES, L. Growth impairment in the very preterm and cognitive and motor performance at 7 years. Archives of Disease in Childhood, London, v. 88, n. 6, n. 482-487, 2003.

CORBO, M. et al. Nonnutritive sucking during heelstick procedures decreases behavioral distress in the newborn infant. Biology of the Neonate, Basel, v. 77, n. 3, p. 162-167, 2000.

CORFF, K.; SEIDMAN, R.; VENKATARAMAN, M. P. Facilitated tucking: a nonpharmacological comfort measure for pain in preterm neonates. Journal of Obstetric, Gynecology and Neonatal Nursing, Philadelphia, v. 24, n. 2, p. 143-145, 1995.

COUPERUS, J. W.; NELSON, C. A. Early brain development and plasticity. In: McCARTNEY, K.; PHILLIPS, D. (Orgs.). Blackwell handbook of early childhood development. Malden: Blackwell Publishing, 2006. p. 85-105.

CRAIG, K. D. et al. Pain in the preterm neonate: behavioral and physiological indices. Pain, Seattle, v. 52, n. 3, p. 287-299, 1993. 
DELEVATI, N. M.; BERGAMACO, N. H. P. Pain in the neonate: an analysis of facial movements and crying in response to nociceptive stimuli. Infant Behavior and Development, Hyattsville, v. 22, n. 1, p. 137-143, 1999.

do ESPÍRITO SANTO, J. L.; PORTUGUEZ, M. W.; NUNES, M. L. Cognitive and behavioral status of low birth weight preterm children raised in a developing country at preschool age. Jornal de Pediatria, Rio de Janeiro, v. 85, n. 1, p. 35-41, 2009.

DUHN, L. J.; MEDVES, J. M. A systematic integrative review of infant pain assessment tools. Advances in Neonatal Care, Lebanon, v. 4, n. 3, p. 126-140, 2004.

ELIAS, L. S. D. T. et al. Discordância entre pais e profissionais de saúde quanto à intensidade da dor do recém-nascido criticamente doente. Jornal de Pediatria, Rio de Janeiro, v. 84, n. 1, p. 35-40, 2008.

ELSERAFY, F. A. et al. Oral sucrose and a pacifier for pain relief during simple procedures in preterm infants: a randomized controlled trial. Annals of Saudi Medicine, Riyadh, v. 29, n. 3, p. 184-188, 2009.

EVANS, G. W.; WACHS, T. D. Chaos and its influence on children's development: an ecological perspective. Washington: American Psychological Association. 2010.

EVANS, J. C. et al. Longitudinal comparison of preterm pain response to repeated heelsticks. Pediatric Nursing, Philadelphia, v. 31, n. 3, p. 216-221, 2005.

FELDMAN, R. The development of regulatory functions from birth to 5 years: insights from premature infants. Child Development, Massachusetts, v. 80, n. 2, p. 544-561, 2009.

FITZGERALD, M. Foetal pain: an update of current scientific knowledge. London: Department of Health, 1995. 
FLETCHER, M. Avaliação física e classificação. In: AVERY, G.; FLETCHER, M. (Orgs.) Neonatologia: fisiopatologia e tratamento do recém-nascido. Rio de Janeiro: Medsi, 1999. p. 269-79.

FRAGA, D. A. et al. Desenvolvimento de bebês prematuros relacionado a variáveis neonatais e maternas. Psicologia em Estudo, Maringá, v.13, n.2, p. 335-344, 2008a.

FRAGA, D. A. et al. Desenvolvimento de bebês nascidos pré-termo e indicadores emocionais maternos. Psicologia Reflexão e Crítica, Porto Alegre, v.21, n.1, p. 33$41,2008 \mathrm{~b}$.

FRANCK, L. S.; LAWHON, G. Enviromental and behavioral strategies to prevent and manage neonatal pain. Seminars in Perinatology, Burlington, v. 22, n. 5, p. 434-443, 1998.

FREIRE, N. B.; GARCIA, J. B.; LAMY, Z. C. Evaluation of analgesic effect of skin-toskin contact compared to oral glucose in preterm neonates. Journal of Pain, lowa, $v$. 139, n. 1, p. 28-33, 2008.

GAL, P. et al. Efficacy of sucrose to reduce pain in premature infants during eye examinations for retinopathy of prematurity. The Annals of Pharmacotherapy, Cincinnati, v. 39, n. 6, p. 1029-1033, 2005.

GARDNER, S. L.; LUBCHENCO, L. O. The neonatal and the environment: impact on development. In: MERENSTEIN, G. B.; GARDNER, S. L. Handbook of neonatal intensive care. Toronto: Mosby, 1998. p. 197-241.

GASPARDO, C. M. Dor em neonatos pré-termo em Unidade de Terapia Intensiva Neonatal: avaliação e intervenção com sacarose. 2006. 167 f. Dissertação (Mestrado em Ciências Médicas) - Faculdade de Medicina de Ribeirão Preto, Universidade de São Paulo, Ribeirão Preto, 2006. 
GASPARDO, C. M.; CHIMELLO, J. T. et al. Pain and tactile stimuli during arterial puncture in preterm neonates. Pain, Seattle, v. 15, n. 1, p. 58-64, 2008.

GASPARDO, C. M.; LINHARES, M. B. M.; MARTINEZ, F. E. A eficácia da sacarose no alívio de dor em neonatos: revisão sistemática da literatura. Jornal de Pediatria, Rio de Janeiro, v. 81, n. 6, p. 435-442, 2005.

GASPARDO, C. M.; MARTINEZ, F. E.; LINHARES, M. B. M. Cuidado ao desenvolvimento: intervenções de proteção ao desenvolvimento inicial de recémnascidos pré-termo. Revista Paulista de Pediatria, São Paulo, v. 28, n. 1, p. 77-85, 2010.

GASPARDO, C. M.; MIYASE, C. I. et al. Is pain relief equally efficacious and free of side effects with repeated doses of oral sucrose in preterm neonates? Pain, Seattle, v. 137, n. 1, p. $16-25,2008$.

GASPARDO, C. M. et al. Manejo comportamental e ambiental na UTIN do HCFMRP-USP. Ribeirão Preto, 2009. Não publicado.

GIBBINS, S.; STEVENS, B. J. The influence of gestational age on the efficacy and short-term safety of sucrose for procedural pain relief. Advances in Neonatal Care, Lebanon, v. 3, n. 5, p. 241-249, 2003.

GIBBINS, S.; STEVENS, B. J.; ASZTALOS, E. Assessment and management of acute pain in high-risk neonates. Expert Opinion of Pharmacotherapy, New York, v. 4, n. 4, p. 475-483, 2003.

GIBBINS, S.; STEVENS, B.; BEYENE, J. et al. Pain behaviours in extremely low gestational age infants. Early Human Development, Limerick, v. 84, n. 7, p. 451-458, 2008.

GIBBINS, S.; STEVENS, B.; McGRATH, P. J. et al. Comparison of pain responses in infants of different gestational ages. Neonatology, Basel, v. 93, n. 1, p. 10-18, 2008. 
GIBBINS, S. et al. Efficacy and safety of sucrose for procedural pain relief in preterm and term neonates. Nursing Research, Philadelphia, v. 51, n. 6, p. 375-382, 2002.

GLASS, P. O recém-nascido vulnerável e o ambiente na Unidade de Tratamento Intensivo Neonatal. In: AVERY, G. B.; FLETCHER, M. A.; MacDONALD, M. G. Neonatologia: fisiopatologia e tratamento do recém-nascido. 4 ed. São Paulo: Medsi, 1999. p. 79-96.

GLOVER, V.; FISK, N. M. Fetal Pain: implications for research and practice. British Journal of Obstetrics and Gynaecology, Oxford, v. 106, p. 881-886, 1999.

GOFFAUX, P. et al. Preterm births: can neonatal pain alter the development of endogenous gating systems? European Journal of Pain, Berlin, v. 12, n. 7, p. 945$951,2008$.

GORMALLY, S. et al. Contact and nutrient care giving effects on newborn infant pain responses. Developmental Medicine and Child Neurology, London, v. 43, n. 1, p. 2838, 2001.

GOUBET, N.; CLIFTON, R.; SHAH, B. Learning about pain in preterm newborns. Developmental and Behavioral Pediatrics, Baltimore, v. 22, n. 6, p. 418-424, 2001.

GOULART, A. L. Caracterização da população neonatal. In: KOPELMAN, B. I. et al. (Orgs.) Diagnóstico e tratamento em neonatologia. São Paulo: Atheneu, 2004a. cap. 1, p. 3-11.

GOULART, A. L. Assistência ao recém-nascido pré-termo. In: KOPELMAN, B. I. et al. (Orgs.) Diagnóstico e tratamento em neonatologia. São Paulo: Atheneu, 2004b. cap. 3, p. 17-23.

GRADIN, M.; SCHOLLIN, J. The role of endogenous opióides in mediating pain reduction by oral administered glucose among newborns. Pediatrics, Illinois, v. 115, n. 4, p. 1004-1007, 2005. 
GRAY, R. F.; INDURKHYA, A.; McCORMICK, M.C. Prevalence, stability, and predictors of clinically significant behavior problems in low birth weight children at 3 , 5, and 8 years of age. Pediatrics, Illinois, v. 114, n. 3, p. 736-743, 2004.

GREENBERG, C. S. A sugar-coated pacifier reduces procedural pain in newborns. Pediatric Nursing, Philadelphia, v. 28, n. 3, p. 271-277, 2002.

GRUNAU, R. E. Long-term consequences of pain in human neonates. In: ANAND, K. J. S.; STEVENS, B. J.; McGRATH, P. J. (Orgs.) Pain in neonates. Northelands: Elsevier Science, 2000, vol. 10, p. 55-76.

GRUNAU R. E. Early pain in preterm infants: a model of long-term effects. Clinics in Perinatology, Philadelphia, v. 29, n. 3, p. 373-394, 2002.

GRUNAU, R. E.; CRAIG, K. D. Pain expression in neonates: facial action and cry. Pain, Seattle, v. 28, n. 3, p. 395-410, 1987.

GRUNAU, R. E.; FITZGERALD, C.; ELLWOOD, A. Neonatal Facial Coding System Training Manual. Vancouver, 2001. Traduzido por LINHARES, M. B. M; CHIMELLO, J. T. 2002. Não publicado.

GRUNAU, R. E.; HOLSTI, L.; PETERS, J. W. B. Long-term consequences of pain in human neonates. Seminars in Fetal and Neonatal Medicine, London, v. 11, n. 4, p. 268-275, 2006.

GRUNAU, R. E.; TU, M. T. Long-term consequences of pain in human neonates. In: ANAND, K. J. S.; STEVENS, B. J.; McGRATH, P. J. (Orgs.). Pain research and clinical management: pain in neonates and infants. 3rd ed. 2007. Philadelphia: Elsevier Science, cap. 4, p. 45-55.

GRUNAU, R. E.; WEINBERG, J.; WHITFIELD, M. F. Neonatal procedural pain and preterm infant cortisol response to novelty at 8 months. Pediatrics, Illinois, v. 114, n. 1, p. 77-84, 2004. 
GRUNAU, R. E. et al. Bedside application of the Neonatal Facial Coding System in pain assessment of premature neonates. Pain, Seattle, v. 76, n. 3, p. 277-286, 1998.

GRUNAU, R. E. et al. Does prone or supine position influence pain responses in preterm infants at 32 weeks gestational age? The Clinical Journal of Pain, Seattle, v. 20, n. 2, p. 76-82, 2004.

GRUNAU, R. E. et al. Neonatal procedural pain exposure predicts lower cortisol and behavioral reactivity in preterm infants in the NICU. Pain, Seattle, v. 113, n. 3, p. 293300, 2005.

GRUNAU, R. E. et al. Altered basal cortisol levels at 3, 6, 8 and 18 months in infants born at extremely low gestational age. Journal of Pediatrics, Hartford, v. 150, n. 2, p. 151-156, 2007.

GUALA, A. et. al. Glucose or sucrose as an analgesic for newborns: a randomized controlled blinded trial. Minerva Pediatrics, Torino, v. 53, n. 4, p. 271-274, 2001.

GUINSBURG, R. Dor no recém-nascido prematuro intubado e ventilado: avaliação multidimensional e resposta à analgesia com fentanyl. 1993. 221 f. Tese (Doutorado) - Escola Paulista de Medicina, Universidade Federal de São Paulo, São Paulo, 1993.

GUINSBURG, R. Avaliação e tratamento da dor no recém-nascido. Jornal de Pediatria, Rio de Janeiro, v. 75, n. 3, p. 149-160, 1999.

GUINSBURG, R. Dor no recém-nascido. In: RUGOLO, L. M. S. S. Manual de neonatologia da Sociedade Brasileira de Pediatria de São Paulo. Rio de Janeiro: Revinter, 2000. p. 63-68.

GUINSBURG, R. et al. Reliability of two behavioral tools to assess pain in preterm neonates. São Paulo Medical Journal, São Paulo, v. 121, n. 2, p. 72-76, 2003. 
GUINSBURG, R. et al. Aplicação das escalas comportamentais para a avaliação da dor em recém-nascidos. Jornal de Pediatria, Rio de Janeiro, v. 73, n. 6, p. 411-418, 1997.

GUINSBURG, R. BALDA, R. C. X. Dor em neonatologia. In: TEIXEIRA, M. J. et al. (Orgs.) Dor: contexto interdisciplinar. Curitiba: Editora Maio, 2003. cap. 39, p. 547554.

GUINSBURG, R. et al. Differences in pain expression between male and female newborn infants. Pain, Seattle, v. 85, n. 1-2, p. 127-133, 2000.

GUTMAN, L. M.; SAMEROFF, A. J.; COLE, R. Academic growth curve trajectories from 1st grade to 12th grade: Effects of multiple social risk factors and preschool child factors. Developmental Psychology, Michigan, v. 39, n. 4, p. 777-790, 2003.

HACK, M. et al. Chronic conditions, functional limitations, and special health care needs of school-aged children born with extremely low-birth-weight in the 1990s. Journal of the American Medical Association, Chicago, v. 294, n. 3, p. 318-325, 2005.

HACK, M. et al. Behavioral outcomes of extremely low birth weight children at age 8 years. Journal of Developmental and Behavioral Pediatrics, Baltimore, v. 30, n. 2, p. 122-130, 2009.

HALPERN, R.; FIGUEIRAS, A. C. M. Environmental influences on child mental health. Jornal de Pediatria, Rio de Janeiro, v. 80, supl. 2, p. 104-110, 2004.

HALPERN, R. et al. Fatores de risco para suspeita de atraso do desenvolvimento neuropsicomotor aos 12 meses de vida. Jornal de Pediatria, Rio de Janeiro, v. 76, n. 6, p. 421-428, 2000. 
HALPERN, R. et al. Fatores de risco para suspeita de atraso no desenvolvimento neuropsicomotor aos 12 meses de vida. Revista Chilena de Pediatria, Santiago, v. 73, n. 5, p. 529-539, 2002.

HARRISON, D. Oral sucrose for pain management in infants: myths and misconception. Journal of Neonatal Nursing, Cambridge, v. 14, n. 2, p. 39-46, 2008.

HARRISON, D. et al. Repeated doses of sucrose in infants continue to reduce procedural pain during prolonged hospitalizations. Nursing Research, Philadelphia, v. 58, n. 6, p. 427-434, 2009.

HERMANN, C. et al. Long-term alteration of pain sensitivity in school-aged children with early pain experiences. Pain, Seattle, v. 125, n. 3, p. 278-285, 2006.

HOLSTI, L. et al. Specific newborn individualized developmental care assessment program are associated with acute pain in preterm infants in the Neonatal Intensive Care Unit. Pediatrics, Illinois, v. 114, n. 1, p. 65-72, 2004.

HOLSTI, L. et al. Prior pain induces heightened motor responses during clustered care in preterm infants in the NICU. Early Human Development, Limerick, v. 81, n. 3, p. 293-302, 2005.

HOLSTI, L. et al. Behavioral responses to pain are heightened after clustered care in preterm infants born between 30 and 32 weeks gestational age. The Clinical Journal of Pain, Seattle, v. 22, n. 9, p. 757-764, 2006.

INTERNATIONAL NEONATAL NETWORK. The CRIB (Clinical Risk Index for Babies) score: a tool for assessing initial neonatal risk and comparing performance of neonatal intensive care units. The Lancet, New York, v. 342, p. 193-198, 1993.

ISIK, U. et al. Comparison of oral glucose and sucrose solutions on pain response in neonates. Journal of Pain, lowa, v. 1, n. 4, p. 275-278, 2000. 
JOBE, A. H. Predictors of outcomes in preterm infants which ones and when? Pediatrics, Illinois, v. 138, n. 2, p. 153-156, 2001.

JOHNSON, S. Cognitive and behavioural outcomes following very preterm birth. Seminars in Fetal and Neonatal Medicine, London, v.12, n. 5, p. 363-373, 2007.

JOHNSTON, C. C. et al. Effectiveness of oral sucrose and simulated rocking on pain response in preterm neonates. Pain, Seattle, v. 72, n. 1-2, p. 193-199, 1997.

JOHNSTON, C.C. et al. Effect of repeated doses of sucrose during heel stick procedure in preterm neonates. Biology of the Neonate, Basel, v. 75 , n. 3, p. $160-$ 166, 1999.

JOHNSTON, C. C. et al. Routine sucrose analgesia during the first week of life in neonates younger than 31 weeks' postconceptional age. Pediatrics, Illinois, v.110, n. 3, p. 523-528, 2002.

JOHNSTON, C. C. et al. How much sucrose is too much sucrose. Pediatrics, Illinois, v. 119, n. 1, p. 226, 2007.

KEENAN, K. et al. Context matters: exploring definitions of a poorly modulated stress response. In: OLSON, S. L.; SAMEROFF, A. J. Biopsychosocial regulatory processes in the development of childhood behavioral problems. New York: Cambridge University Press, 2009. p. 38-56.

KLEIN, V. C. Reatividade à dor, temperamento e comportamento na trajetória de desenvolvimento de neonatos pré-termo até a fase pré-escolar. 2009. $241 \mathrm{f}$. Tese (Doutorado em Ciências Médicas) - Faculdade de Medicina de Ribeirão Preto, Universidade de São Paulo, Ribeirão Preto, 2009.

KLEIN, V. C.; GASPARDO, C. M.; LINHARES, M. B. M. Dor, autorregulação e temperamento em recém-nascidos pré-termo com alto risco neonatal. Psicologia: Reflexão e Crítica, Porto Alegre, v. 24, n. 3, 2011. No prelo. 
KLEIN, V. C.; LINHARES, M. B. M. Temperamento, comportamento e experiência dolorosa na trajetória de desenvolvimento da criança. Paidéia - Cadernos de Psicologia e Educação, Ribeirão Preto, v. 17, n. 36, p. 33-44, 2007.

KLEIN, V. C.; LINHARES, M. B. M. Reactividade à dor e temperamento em crianças nascidas pré-termo. Dor, Lisboa, v. 17, p. 5-9, 2010.

KLEIN, V. C. et al., Reactivity and recovery from pain and distress in the neonatal period as early predictors of temperament of toddlers born preterm. Early Human Development, Limerick, v. 85, n. 9, p. 569-576, 2009.

LAGO, P. et al. Guidelines for procedural pain in the newborn. Acta Paediatrica, Stockholm, v. 98, n. 6, p. 932-939, 2009.

LAWRENCE, J. et al. The development of a tool to assess neonatal pain. Neonatal Network, Califórnia, v. 12, n. 6, p. 59-66, 1993.

LEEF, K. H. Evidence-based review of oral sucrose administration to decrease the pain response in newborn infants. Neonatal Network, California, v. 25, n. 4, p. 275284, 2006.

LEFRAK, L. et al. Sucrose analgesia: identifying potentially better practices. Pediatrics, Illinois, v. 118, p. 197-202, 2006.

LEITE, A. M. et al. Effects of breastfeeding on pain relief in full-term newborns. The Clinical Journal of Pain, Seattle, v. 25, n. 9, p. 827-832, 2009.

LIMA, E.V. et al. Sobrevida de recém-nascidos de muito baixo peso em maternidade privada de nível terciário. Revista Paulista de Pediatria, São Paulo, v. 24, n. 2, p. 155-162, 2006. 
LINHARES, M. B. M. Vulnerabilidade, risco e proteção no desenvolvimento de crianças nascidas pré-termo. 2008. 362 f. Tese (Livre-Docência) - Faculdade de Medicina de Ribeirão Preto, Universidade de São Paulo, Ribeirão Preto, 2009.

LINHARES, M. B. M. et al. Desenvolvimento de bebês nascidos pré-termo no primeiro ano de vida. Paidéia - Cadernos de Psicologia e Educação, Ribeirão Preto, v. 13, n. 25, p. 59-72, 2003.

LINHARES, M. B. M. et al. A compreensão do fator de risco da prematuridade sob a ótica desenvolvimental. In: MARTURANO, E. M.; LINHARES, M. B. M.; LOUREIRO, S. R. (Orgs.) Vulnerabilidade e proteção: indicadores na trajetória de desenvolvimento do escolar. São Paulo: Casa do Psicólogo, 2004. cap. 1, p. 11-38.

LINHARES, M. B. M. et al. Desenvolvimento psicológico na fase escolar de crianças nascidas pré-termo em comparação com crianças nascidas a termo. Psicologia: Reflexão e Crítica, Porto Alegre, v. 18, n. 1, p. 109-117, 2005.

LINHARES, M. B. M. et al. Psicologia pediátrica em neonatologia de alto risco: promoção precoce do desenvolvimento de bebês prematuros. In: CREPALDI, M. A.; LINHARES, M. B. M.; PEROSA, G. B. (Orgs.) Temas em psicologia pediátrica. São Paulo: Casa do Psicólogo, 2006. p. 109-145.

LORENZ, J. M. Survival of the extremely preterm infant in North America in the 1900s. Clinics in Perinatology, Philadelphia, v. 27, n. 2, p. 255-262, 2000.

LUCAS-THOMPSON, R. et al. Developmental changes in the responses of preterm infants to a painful stressor. Infant Behavior and Development, Hyattsville, v. 31, n. 4, p. 614-623, 2008.

LUDINGTON-HOE, S. M.; CONG, X.; HASHEMI, F. Infant crying: nature, physiologic consequences, and select interventions. Neonatal Network, Califórnia, v. 21, n. 2, p. 29-36, 2002. 
LUTHAR, S. S.; SAWYER, J. A.; BROWN, P.J. Conceptual issues in studies of resilience. Past, present, and future research. Annals New York Academy of Sciences, New York, v. 1094, p. 105-115, 2006.

LUU, T. M. et al. Lasting effects of preterm birth and neonatal brain hemorrhage at 12 years of age. Pediatrics, Illinois, v. 123, n. 3, p. 1037-1044, 2009.

MARLOW, N. et al. Neurologic and developmental disability at six years of age after extremely preterm birth. The New England Journal of Medicine, Waltham, v. 352, n. 1, p. 9-19, 2005.

MARTINS, I. B. M.; LINHARES, M. B. M.; MARTINEZ, F. E. Indicadores de desenvolvimento na fase pré-escolar de crianças nascidas pré-temo. Psicologia em Estudo, Maringá, v. 10, n. 2, p. 235-243, 2005.

MASTEN, A. S.; GERWITZ, A. H. Vulnerability and resilience in early child development. In: MACCARTNEY, K.; PHILLIPS, D. (Orgs.) Blackwell handbook of early childhood development psychology. Victoria: Blackwell Publishing, 2006. p. 2243.

MASTEN, A. S.; OBRADOVI'C, J. Competence and resilience in development. Annals New York Academy of Sciences, New York, v. 1094, p. 13-27, 2006.

MATHEW, P. J.; MATHEW, J. L. Assessment and management of pain in infants. Postgraduate Medical Journal, Leicester, v. 79, n. 934, p. 438-443, 2003.

McANULTY, G.B. et al. Effects of the newborn individualized developmental care and assessment program (NIDCAP) at age 8 years: preliminary data. Clinical Pediatrics, Philadelphia, v. 49, n. 3, p. 258-270, 2010.

McCULLOUGH, S. et al. Lingual sucrose reduces the pain response to nasogastric tube insetion: a randomised clinical trial. Archives of Disease in Childhood, Fetal and Neonatal Edition, London, v. 93, p. 100-103, 2007. 
MINDE, K. Prematurity and serious medical conditions in infancy: implications for development, behavior and intervention. In ZEANAH, C. Handbook of infant mental health. New York: The Guilford Press, 2000. p. 176-194.

MITTCHEL, A. et al. Analgesic effects of oral sucrose and pacifier during eye examinations for retinopathy of prematurity. Pain Management Nursing, Lenexa, v. 5, n. 4, p. 160-168, 2004.

MÖRELIUS, E. et al. Is a nappy change stressful to neonates? Early Human Development, Limerick, v. 82, n. 10, p. 669-676, 2006.

MORISON, S. J. et al. Relationships between behavioral and cardiac autonomic reactivity to acute pain in preterm infants. The Clinical Journal of Pain, Seattle, v. 17, n. 4, p. 350-358, 2001.

MORISON, S. J. et al. Are there developmentally distinct motor indicators of pain in preterm infants? Early Human Development, Limerick, v. 72, n. 2, p. 131-46, 2003.

NEUBAUER, A. P.; VOSS, W.; KATTNER, E. Outcome of extremely low birth weight survivors at school age: the influence of perinatal parameters on neurodevelopment. European Journal of Pediatrics, Berlin, v. 167, n. 1, p. 87-95, 2008.

NEWNHAM, C. A.; INDER, T. E.; MILGROM, J. Measuring preterm cumulative stressors within the NICU: the neonatal infant stressor scale. Early Human Development, Limerick, v. 85, n.9, p. 549-555, 2009.

NIJHUIS, J.; VAN de PAS, M. Behavioral states and their ontogeny: human studies. Seminnars in Perinatology, Burlington, v. 16, n. 4, p. 206-210, 1992.

NOBRE, F. D. A. et al. Estudo longitudinal do desenvolvimento de crianças nascidas pré-termo no primeiro ano pós-natal. Psicologia: Reflexão e Crítica, Porto Alegre, v. 22, n. 3, p. 362-369, 2009. 
NURU-JETER, A. M. et al. Socioeconomic predictors of health and development in middle childhood: variations by socioeconomic status measure and race. Issues in Comprehensive Pediatric Nursing, New York, v. 33, n. 2, p. 59-81, 2010.

OGAWA, S. et al. Venepuncture is preferable to heel lance for blood sampling in term neonates. Archives of Disease in Childhood, Fetal and Neonatal Edition, London, v. 90, p. 432-436, 2005.

OKADA, M.; TEIXEIRA, M. J. Desenvolvimento do sistema nociceptivo e supressor da dor. In: TEIXEIRA, M. J. et al. (Orgs.). Dor: contexto interdisciplinar. Curitiba: Editora Maio, 2003. cap. 5, p. 89-117.

OKAN, F. et al. Analgesia in preterm newborns: the comparative effects of sucrose and glucose. European Journal of Pediatric, Berlin, v. 166, n. 10, p. 1017-1024, 2007.

OLKKOLA, K. T.; HAMUNER, K. Pharmacokinetics and pharmacodynamics of analgesic drugs. In: ANAND, K. J. S.; STEVENS, B. J.; McGRATH, P. J. (Orgs.). Pain in neonates, Northelands: Elsevier Science, 2000, v. 10, p. 135-158.

OLSON, S. I. et al. Self-regulatory processes in the development of disruptive behavior problems: the preschool to school transition. In: OLSON, S. L.; SAMEROFF, A. J. (Orgs.). Biopsychosocial regulatory processes in the development of childhood behavioral problems. New York: Cambridge University Press, 2009, p. 144-185.

ÖRS, R. et al. Comparison of sucrose and human milk on pain response in newborns. European Journal of Pediatric, Berlin, v. 158, n. 1, p. 63-66, 1999.

OVERGAARD, C.; KNUDSEN, A. Pain-relieving effect of sucrose in newborns during heel prick. Biology of the Neonate, Basel, v. 75, p. 279-284, 1999. 
PARRY, G.; TUCKER, J.; TARNOW-MORDI, W. O. CRIB II: an update of the clinical risk index for babies score. The Lancet, New York, v. 361, n. 9371, p. 1789-1791, 2003.

PEREIRA, A. L. S. T. et al. Validity and physiologic parameters for acute pain assessment of term newborn infants. São Paulo Medicine Journal, São Paulo, v. 117, n. 2, p. 72-80, 1999.

PETERS, K. L. Infant handling in the NICU: does developmental care make a difference? An evaluative review of the literature. The Journal of Perinatal and Neonatal Nursing, Frederick, v. 13, n. 3, p. 83-109, 1999.

PETERS, J. W. B. et al. Neonatal Facial Coding System for assessing postoperative pain in infants: item reduction is valid and feasible. The Clinical Journal of Pain, Seattle, v. 19, n. 6, p. 353-363, 2003.

PETROU, S.; SACH, T.; DAVIDSON, L. The long-term cost of preterm birth and low birth weight: results of a systematic review. Child: Care, Health and Development, Oxford, v. 27, n. 2, p. 97-115, 2001.

PINHEIRO, J. M. The Apgar cycle: a new view of a familiar scoring system. Archives of Disease in Childhood, Fetal and Neonatal Edition, London, v. 94, n. 1, p. 70-72, 2009.

POKELA, M. Pain relief can reduce hypoxemia in distressed neonates during routine treatment procedures. Pediatrics, Illinois, v. 93, n. 3, p. 379-383, 1994.

PORTER, F. L.; WOLF, C.; MILLER, J. P. The effect of handling and immobilization on the response to acute pain in newborn infants. Pediatrics, Illinois, v. 102, n. 6, p. 1383-1389, 1998. 
PRESTES, A. C. et al. The frequency of pharmacological pain relief in university neonatal intensive care units. Jornal de Pediatria, Rio de Janeiro, v. 81, n. 5, p. 405410, 2005.

PRIOR, M. et al. Influences on communicative development at 24 months of age: Child temperament, behaviour problems, and maternal factors. Infant Behavior and Development, Hyattsville, v. 31, n. 2, p. 270-279, 2008.

RAMENGHI, L. A.; EVANS, D.; LEVENE, M. I. "Sucrose analgesia": absorptive mechanism or taste perception? Archives of Disease Childhood, Fetal and Neonatal Edition, London, v. 80, n. 2, p. 146-147, 1999.

RAMENGHI, L. A. et al. Reduction of pain response in premature infants using intraoral sucrose. Archives of Disease Childhood, Fetal and Neonatal Edition, London, v. 74, n. 2, p. 126-128, 1996.

RESEGUE, R.; PUCCINI, R. F.; SILVA, E. M. K. Risk factors associated with developmental abnormalities among high-risk children attended at a multidisciplinary clinic. São Paulo Medical Journal, São Paulo, v. 126, n. 1, p. 4-10, 2008.

REYNOLDS, M. L.; FITZGERALD, M. Long-term sensory hyperinervation following neonatal skin wounds. The Journal of Comparative Neurology, Boston, v. 358, n. 4 , p. 487-498, 1995.

RICHARDSON, K. D. et al. Score for neonatal acute physiologic severity index for neonatal care. Pediatrics, Illinois, v. 91, n. 3, p. 617-623, 1993.

RICHARDSON, K. D. et al. SNAP-II and SNAPPE-II: Simplified newborn illness severity and mortality risk scores. Journal of Pediatrics, Hartford, v. 138, n. 1, p. 92100, 2001. 
ROTHBART, M. K.; BATES, J. E. Temperament. In: DAMON, W.; LERNER, R. M. EISENBERG, N. (Orgs.). Handbook of child psychology: social, emotional and personality development. New York: John Wiley and Sons, 2006. p. 99-165.

RUGOLO, L. M. S. S. Crescimento e desenvolvimento a longo prazo do prematuro extremo. Jornal de Pediatria, Rio de Janeiro, v. 81, n. 1, p. 101-110, 2005.

RUTTER, M. Implications of resilience concepts for scientific understanding. Annals New York Academy of Sciences, New York, v. 1094, p. 1-12, 2006.

RUTTER, M.; SROUFE, L. A. Developmental Psychopathology: concepts and challenges. Development and Psychopathology, Cambridge, v. 12, n. 3, p. 265-296, 2000.

SALT, A.; REDSHAW, M. Neurodevelopmental follow-up after preterm birth: followup after two years. Early Human Development, Limerick, v. 82, n. 3, p. 185-197, 2006.

SAMARA, M.; MARLOW, N.; WOLKE, D. Pervasive behavior problems at 6 year of age in a total population sample of children born at $<25$ weeks of gestation. Pediatrics, Illinois, v. 122, n. 3, p. 562-573, 2008.

SAMEROFF, A. J. Developmental systems and psychopathology. Development and Psychopathology, Cambridge, v. 12, n. 3, p. 297-312, 2000.

SAMEROFF, A. J. Conceptual issues in studying the development of self-regulation. In: OLSON, S. L.; SAMEROFF, A. J. Biopsychosocial regulatory processes in the development of childhood behavioral problems. New York: Cambridge University Press, 2009. p. 1-18.

SAMEROFF, A. J. Dynamic developmental systems: chaos and order. In: EVANS, G. W.; WACHS, T. D. Chaos and its influence on children's development: an ecological 
perspective. Washington: American Psychological Association, 2010. cap. 16, p. 255-264.

SAMEROFF, A. J.; ROSENBLUM, K. L. Psychosocial constraints on the development of resilience. Annals New York Academy of Sciences, New York, n. 1094, p. 116-124, 2006.

SIMONS, S. H. P.; TIBBOEL, D. Pain perception development and maturation. Seminars in Fetal and Neonatal Medicine, London, v. 11, n. 4, p. 227-231, 2006.

SLATER, R.; FITZGERALD, M.; MEEK, J. Can cortical responses following noxious stimulation inform us about pain processing in neonates? Seminars in Perinatology, Burlington, v. 31, n. 5, p. 298-302, 2007.

SLATER, R. et al. Cortical pain responses in human infants. The Journal of Neuroscience, Washington, v. 26, n. 14, p. 3662-3666, 2006.

SLATER, R. et al. How well do clinical pain assessment tools reflect pain in infants? PLoS Medicine, Cambridge, v. 5, n. 6, p. 928-933, 2008.

SPITTLE, A. J. et al. Predicting motor development in very preterm infants at 12 months' corrected age: the role of qualitative magnetic resonance imaging and general movements' assessment. Pediatrics, Illinois, v. 123, n. 2, p. 512-517, 2009.

STEVENS, B. J.; ANAND, K. J. S.; McGRATH, P. J. An overview of pain in neonates and infants. In: ANAND, K. J. S.; STEVENS, B. J.; McGRATH, P. J. (Orgs.). Pain research and clinical management: pain in neonates and infants. Philadelphia: Elsevier Science, 3 rd ed. 2007. cap. 1, p. 1-9.

STEVENS, B. J.; FRANCK, L. et al. Determining the structural of acute pain responses in vulnerable neonates. Canadian Journal of Nursing Research, Montreal, v. 39, n. 2, p. 32-47, 2007. 
STEVENS, B. J.; GIBBINS, S.; FRANCK, L. S. Treatment of pain in the neonatal intensive care unit. Pediatric Clinical North American, Maryland, v. 47, n. 3, p. 63350, 2000.

STEVENS, B. J.; JOHNSTON, C. C.; GIBBINS, S. Pain assessment in neonates. In: ANAND, K. J. S; STEVENS, B. J; McGRATH, P. J. (Orgs.). Pain in neonates. Northelands: Elsevier Science, 2000, cap. 10, p. 101-134.

STEVENS, B. J.; McGRATH, P. J. et al. Determining behavioural and physiological responses to pain in infants at risk for neurological impairment. Pain, Seattle, v. 127, n. 1-2, p. 94-102, 2007.

STEVENS, B. J.; RIDELL, R. R. P. et al. Assessment of pain in neonates infants. In: ANAND; K. J. S.; STEVENS, B. J.; McGRATH, P. J. Pain research and clinical management: pain in neonatal and infant. Philadelphia: Elsevier Science, 3rd ed. 2007, cap. 6, p. 67-90.

STEVENS, B. J.; YAMADA, J.; OHLSSON, A. Sucrose for analgesia in newborn infants undergoing painful procedures. Cochrane Database of Systematic Review, Oxford, v. 4, CD001069, 2001.

STEVENS, B. J. et al. Premature infant pain profile: development and initial validation. The Clinical Journal of Pain, Seattle, v. 12, n. 1, p. 13-22, 1996.

STEVENS, B. J. et al. The efficacy of developmentally sensitive interventions and sucrose for relieving procedural pain in very low birth weight neonates. Nursing Research, Philadelphia, v. 48, n. 1, p. 35-43, 1999.

STEVENS, B. J. et al. Consistent management of repeated procedural pain with sucrose in preterm neonates: is it effective and safe for repeated use over time? The Clinical Journal of Pain, Seattle, v. 21, n. 6, p. 543-548, 2005. 
STORM, H.; FREMMING, A. Food intake and oral sucrose in preterm prior to heel prick. Acta Paediatrica, Stockholm, v. 91, n. 5, p. 555-560, 2002.

SUN, J.; MOHAY, H.; O'CALLAGHAN, M. A comparison of executive function in very preterm and term infants at eight months corrected age. Early Human Development, Limerick, v. 85, n. 4, p. 225-230, 2008.

TADDIO, A. et al. Effectiveness of sucrose analgesia in newborns undergoing painful medical procedures. Canadian Medical Association Journal, Ottawa, v. 179, n. 1, p. 37-43, 2008.

TADDIO, A. et al. Influence of repeated painful procedures and sucrose analgesia on the development of hyperalgesia in newborn infants. Pain, Seattle, v. 144, n. 1-2, p. 43-48, 2009.

TAYLOR, G. H. et al. Consequences and risks of $<1000-\mathrm{g}$ birth weight for neuropsychological skills, achievement, and adaptive functioning. Journal of Developmental and Behavioral Pediatrics, Baltimore, v. 27, n. 6, p. 459-469, 2006.

THOMPSON, D. G. Utilizing an oral sucrose solution to minimize neonatal pain. Journal for Specialists in Pediatric Nursing, Aurora, v. 10, n. 1, p. 3-10, 2005.

TSAO, J. et al. A review of CAM for procedural pain in infancy: part I. Sucrose and non-nutritive sucking. Evidence-based Complementary and Alternative Medicine, Oxford, v. 5, n. 4, p. 371-381, 2008.

VALERI, B. O. Reações de dor em neonatos pré-termo diferenciados quanto ao sexo, e à idade gestacional. 2007. 70 f. Monografia (Conclusão de Curso) Faculdade de Filosofia, Ciências e Letras de Ribeirão Preto, Universidade de São Paulo, Ribeirão Preto, 2007.

VAN DE VELDE, M. C. et al. Fetal pain perception and pain management. Seminars in Fetal and Neonatal Medicine, London, v. 11, n. 4, p. 232-236, 2006. 
VAN DE WEIJER-BERGSMA, E.; WIJNROKS, L.; JONGMANS, M. J. Attention development in infant and preschool children born preterm: a review. Infant Behavior and Development, Hyattsville, v. 31, n. 3, p. 333-351, 2008.

VIVANCOS, R. B. Z. Efeito do contato pele a pele imediato ao nascimento na reatividade à dor dos recém-nascidos durante a vacina contra Hepatite B. 2008. 129 f. Dissertação (Mestrado em Enfermagem em Saúde Pública) - Escola de Enfermagem de Ribeirão Preto, Universidade de São Paulo, Ribeirão Preto, 2008.

VOLPI, S. C. P. et al. Acquisition of motor abilities up to independent walking in very low birth weight preterm infants. Jornal de Pediatria, Rio de Janeiro, v. 86, n. 2, p. 143-148, 2010.

WALKER, S. M. et al. Long-term impact of neonatal intensive care and surgery on somatosensory perception in children born extremely preterm. Pain, Seattle, v. 141, n. 1-2, p. 79-87, 2009.

WARNOCK, F. An ethogram of neonatal distress behavior in response to acute pain (newborn male circumcision). Infant Behavior and development, Hyattsville, v. 26, p. 398-420, 2003.

WHITFIELD, M. F.; GRUNAU, R. E. Behavior, pain perception, and the extremely low-birth weight survivor. Clinics and Perinatology, Philadelphia, v. 27, n. 2, p. 363379, 2000.

WILLIAMS, A. L. et al. The behavioral pain response to heelstick in preterm neonates studied longitudinally: description, development, determinants, and components. Early Human Development, Limerick, v. 85, n. 6. p. 369-374, 2009.

WOLKE, D. et al. Specific language difficulties and school achievement in children born at 25 weeks of gestation or less. Journal of Pediatrics, Hartford, v. 15, n. 2, p. 256-262, 2008. 
YUNES, M. A.; SZYMANSKI, H. Resiliência: noção, conceitos afins e considerações críticas. In: TAVARES, J. Resiliência e educação. São Paulo: Cortez, 2001. p.13-42.

ZOMIGNANI, A. P.; ZAMBELLI, H. J. L.; ANTONIO, M. A. R. G. M. Desenvolvimento cerebral em recém-nascidos prematuros. Revista Paulista de Pediatria, São Paulo, v. 27, n. 2, p. 198-203, 2009. 


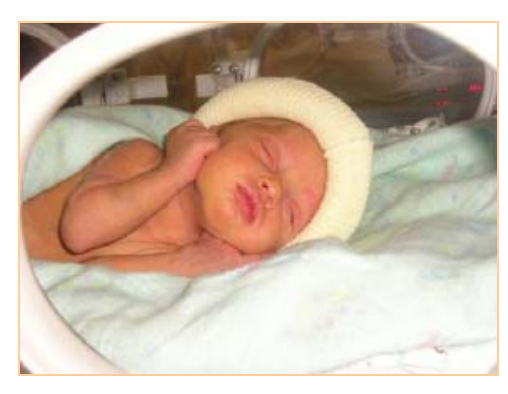

APÊNDICES 


\title{
APÊNDICE A - Termo de Consentimento Livre e Esclarecido
}

\author{
Termo de Consentimento Livre e Esclarecido
}

\section{TÍTULO DO PROJETO}

Intervenção não-farmacológica no alívio da dor em recém-nascidos pré-termo: avaliação do efeito de solução de sacarose em doses repetidas.

\section{OBJETIVOS E JUSTIFICATIVA}

O objetivo deste estudo é verificar o efeito da solução de sacarose (uma espécie de água com açúcar) administrada em doses repetidas no alívio da dor em recém-nascidos pré-termo, em situação de procedimento doloroso de coleta de sangue em Unidade de Terapia Intensiva Neonatal (UTIN). O estudo prevê a comparação do recém-nascido com ele mesmo em diferentes momentos durante o período de internação na UTIN, e a comparação entre dois grupos. Um grupo irá receber a sacarose e o outro grupo receberá somente água. Este estudo justifica-se pela necessidade de se avaliar se o procedimento de tomar a sacarose em doses repetidas de fato tem o efeito de aliviar a dor que os recém-nascidos podem sentir durante a coleta de sangue na UTIN.

\section{PROCEDIMENTOS}

Serão avaliados 50 recém-nascidos pré-termo com menos de 1.500 gramas internados na UTIN do HCFMRP-USP. Destes, 25 serão participantes do grupo de intervenção com sacarose (GS) e 25 participantes do grupo controle sem sacarose (GA). Os participantes serão caracterizados quanto ao sexo, idade gestacional, peso ao nascimento, adequação do peso para a idade gestacional, avaliação do índice de gravidade do estado de saúde do recém-nascido, tempo de internação na UTIN e medicações recebidas. Esses dados serão importantes para analisar os dados encontrados. A coleta de dados será realizada no momento em que os recém-nascidos serão submetidos ao procedimento de coleta de sangue para exames de rotina na UTIN, através de punção. Os recém-nascidos serão filmados para auxiliar as expressões do rosto e um observador anotará se ele está dormindo ou acordado e os sinais de batimento cardíaco registrado em aparelho da UTIN. Serão estabelecidas cinco fases em cada observação da coleta de sangue, com duração total estimada de trinta minutos: 10 minutos antes da punção, 10 minutos durante e 10 minutos após o procedimento de coleta de sangue. Os 25 recém-nascidos do grupo de intervenção (GS) serão submetidos à intervenção nãofarmacológica de alívio da dor durante a coleta de sangue para exames de rotina na UTIN. Será administrada pela boca uma solução de sacarose, dois minutos antes da punção. O grupo controle (GA), formado por 25 recém-nascidos realizará os procedimentos rotineiros de coleta de sangue, sem receber a solução de sacarose, recebendo apenas água. Os recém-nascidos serão sorteados para fazer parte de um ou de outro grupo. Os recém-nascidos deverão ser avaliados em quatro dias consecutivos, de preferência após a internação na UTIN.

\section{DESCONFORTOS E RISCOS ESPERADOS}

Não haverá desconforto ou risco para os recém-nascidos na aplicação da intervenção, uma vez que esta consiste na administração de uma solução de sacarose, a qual já foi demonstrada não ter efeito negativo para o estado de saúde do recém-nascido. 


\section{BENEFÍCIOS}

Os benefícios para os recém-nascidos e suas famílias serão decorrentes do nosso maior conhecimento sobre intervenção para o alívio da dor em procedimentos invasivos e dolorosos a que são submetidos freqüentemente os recém-nascidos pré-termo internados em UTIN. Caso seja provado o efeito positivo em doses repetidas, poderá ser adotado como rotina para todos os recém-nascidos que passam na UTIN do HCFMRP-USP e em outras semelhantes a esta.

\section{GARANTIA DE ACESSO}

Em qualquer etapa do estudo, o responsável legal pelo paciente terá acesso aos profissionais responsáveis pela pesquisa, para esclarecimento de eventuais dúvidas. Os pesquisadores principais responsáveis pelo projeto são a Psicóloga Professora Dra. Maria Beatriz Martins Linhares, do Departamento de Neurologia, Psiquiatria e Psicologia Médica, que pode ser encontrada na Rua Tenente Catão Roxo, 2650, telefone 36024610 e o Pediatra Neonatologista Professor Dr. Francisco Eulógio Martinez, do Departamento Puericultura e Pediatria do HCFMRP-USP, que pode ser encontrado no HC-Campus $7^{\circ}$ andar, telefone 36022576 / 36022486 / 36022479. Se houver alguma consideração ou dúvida sobre a ética da pesquisa, entre em contato com o Comitê de Ética do Hospital das Clínicas da Faculdade de Medicina de Ribeirão Preto - USP.

\section{LIBERDADE DE RETIRAR O CONSENTIMENTO}

É garantida a liberdade da retirada de consentimento a qualquer momento, deixando de participar do estudo, sem prejuízo direto à continuidade de seu tratamento no hospital.

\section{DIREITO DE CONFIDENCIALIDADE}

As informações obtidas serão analisadas em conjunto com a de outros pacientes, não sendo divulgada a identificação de nenhum paciente, salvo os pesquisadores responsáveis envolvidos no projeto e seus colaboradores de pesquisa.

\section{COMPROMISSO DE ATUALIZAR A INFORMAÇÃO}

O representante legal do paciente tem o direito de ser mantido atualizado sobre os resultados parciais da pesquisa.

\section{DESPESAS E COMPENSAÇÕES}

Não há despesas pessoais para os participantes, em qualquer fase do estudo. Também não há compensação financeira relacionada à sua participação. Se existir qualquer despesa adicional, ela será absorvida pelo orçamento da pesquisa.

\section{DANOS PESSOAIS}

Em caso de dano pessoal, diretamente causado pelos procedimentos ou tratamentos propostos neste estudo (nexo causal comprovado), o participante tem direito a tratamento médico na instituição HCFMRP-USP.

\section{COMPROMISSO DO PESQUISADOR}

O pesquisador se compromete a utilizar os dados e o material coletado apenas para esta pesquisa e divulgações acadêmicas científicas relacionadas. 
Acredito ter sido suficientemente informado a respeito das informações que li ou que foram lidas para mim, descrevendo o estudo "Intervenção não-farmacológica no alívio da dor em recém-nascidos pré-termo: avaliação do efeito de solução de sacarose em doses repetidas”.

Ficaram claros, para mim os propósitos do estudo, os procedimentos a serem realizados, seus desconfortos e riscos, as garantias de confidencialidade e de esclarecimentos permanentes.

Ficou claro também que minha participação é isenta de despesas e que tenho garantia de acesso a tratamento hospitalar se necessário.

Concordo, voluntariamente, em participar deste estudo, estando ciente que poderei retirar meu consentimento a qualquer momento, antes ou durante o mesmo, sem penalidades, prejuízo ou perda de qualquer benefício que possa ter adquirido, ou no atendimento neste serviço.

$\overline{\text { Assinatura do representante legal do paciente }}$

Data

Declaro que obtive de forma apropriada e voluntária o Consentimento Livre e Esclarecido desse representante legal, para participação nesse estudo.

Assinatura do pesquisador do estudo

Data

\section{TERMO DE CONSENTIMENTO}

$\mathrm{Eu}$,

responsável pelo menor declaro ter lido a carta de informação a respeito do projeto "Intervenção não-farmacológica no alívio da dor em recém-nascidos prétermo: avaliação do efeito de solução de sacarose em doses repetidas”. Estou esclarecido (a) a respeito do estudo proposto, sem dúvidas, e autorizo a realização do procedimento conforme descrito. Fui informado (a) que posso negar-me a participar do estudo ou dele retirar-me quando julgar conveniente, sem que haja prejuízo no atendimento neste serviço.

Ribeirão Preto, de de 20

Parentesco com o paciente 
APÊNDICE B - Aviso incubadora para administração de intervenção

PROJETO ALÍVIO DE DOR

Linhares e Martinez, 2003

\author{
ATENÇÃO \\ FAVOR ADMINISTRAR TODOS OS DIAS \\ SOLUÇÃO X DOSE $=$
}

NO PERÍODO DE A

VIA ORAL NA PARTE ANTERIOR DA LÍNGUA

2 MINUTOS ANTES DE:

1- Punção venosa

2- Punção arterial

3- Punção capilar

4- Injeção

5- Introdução de cânula intravenosa

6- Introdução de cânula endotraqueal

7- Introdução da sonda orogástrica

8- Aspiração do tubo endotraqueal

9- Remoção de esparadrapo ou de eletrodo 
APÊNDICE C - Aviso incubadora para filmagem

PROJETO ALÍVIO DE DOR (Linhares e Martinez 2003)

FAVOR REALIZAR A COLETA DE SANGUE PRESCRITA PARA O PERÍODO DA MANHÃ NA PRESENÇA DA DRA. BEATRIZ LINHARES PARA OBSERVAÇÃO E FILMAGEM DO NEONATO

FAVOR DEIXAR O NEONATO NO MONITOR CARDÍACO

OBRIGADO, DR. FRANCISCO MARTINEZ

DATAS:

$1^{\circ}$ DIA

$2^{\circ}$ DIA

$3^{\circ} D I A$

$4^{\circ} D I A$ 
APÊNDICE D - Dados da filmagem

DATA

VT

CÓDIGO 
APÊNDICE E - Protocolo de coleta de dados estado de vigília e sono

Código

Data da Avaliação

Avaliador

Avaliação no.

VT

Fase - LINHA DE BASE

Início ${ }^{-}$Término

\begin{tabular}{|c|c|c|c|c|c|c|}
\hline \multirow[b]{2}{*}{ ESTADO VS } & $\begin{array}{l}1-2 \\
\min \end{array}$ & $\begin{array}{l}3-4 \\
\min \end{array}$ & $\begin{array}{l}5-6 \\
\min \end{array}$ & $\begin{array}{l}7-8 \\
\min \end{array}$ & $\begin{array}{l}9-10 \\
\min \end{array}$ & $\begin{array}{l}\text { Resultado } \\
\text { Final }\end{array}$ \\
\hline & & & & & & $\begin{array}{l}\text { Incidência } \\
\text { da fase } \\
\text { predom. }\end{array}$ \\
\hline Sono Profundo SP & & & & & & \multirow{2}{*}{ SP } \\
\hline Sono Ativo SA & & & & & & \\
\hline \multicolumn{6}{|l|}{ Sonolento S } & \multirow{2}{*}{$\mathbf{S}$} \\
\hline \multicolumn{6}{|l|}{ Alerta Quieto AQ } & \\
\hline \multicolumn{6}{|l|}{ Alerta Ativo AA } & $\mathrm{AQ}$ \\
\hline Choro C & & & & & & AA \\
\hline \multicolumn{7}{|c|}{$\begin{array}{l}\text { Incidência predominante no } \\
\text { intervalo de tempo }\end{array}$} \\
\hline \multicolumn{7}{|l|}{$\begin{array}{l}\text { POSIÇÃO NA } \\
\text { INCUBADORA }\end{array}$} \\
\hline \multicolumn{7}{|l|}{ Prono } \\
\hline \multicolumn{7}{|l|}{ Supino } \\
\hline Lado & & & & & & \\
\hline
\end{tabular}

\begin{tabular}{|l|l|l|}
\hline NÍVEL DE VESTIMENTA & \multicolumn{1}{|c|}{ SIM } & NÃO \\
\hline Sem Roupa & & \\
\hline Fralda & & \\
\hline Com Roupa & & \\
\hline Coberto & & \\
\hline Enrolado no Cueiro & & \\
\hline
\end{tabular}


Código

Data da Avaliação_

Avaliador

Avaliação no.

VT

Fase - PUNÇÃo

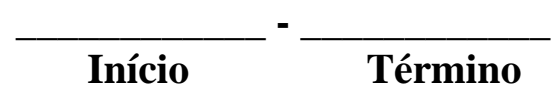

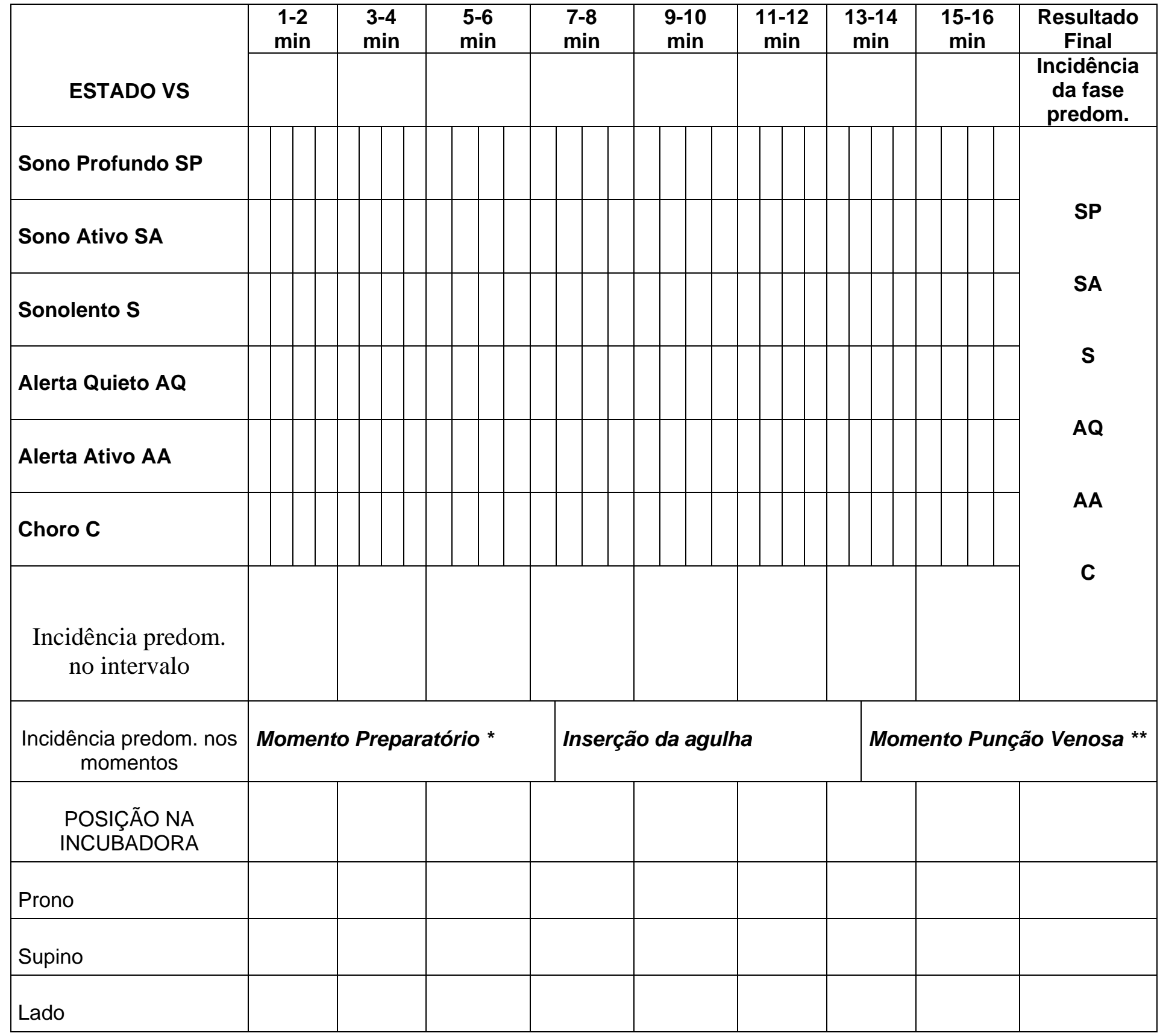

Tentativas

Tipo da Punção

Peso do dia:

Dose:

* Momento início até inserção da agulha

** Momento desde inserção até remoção da agulha 
Código

Data da Avaliação_

Avaliador

Avaliação no.

VT

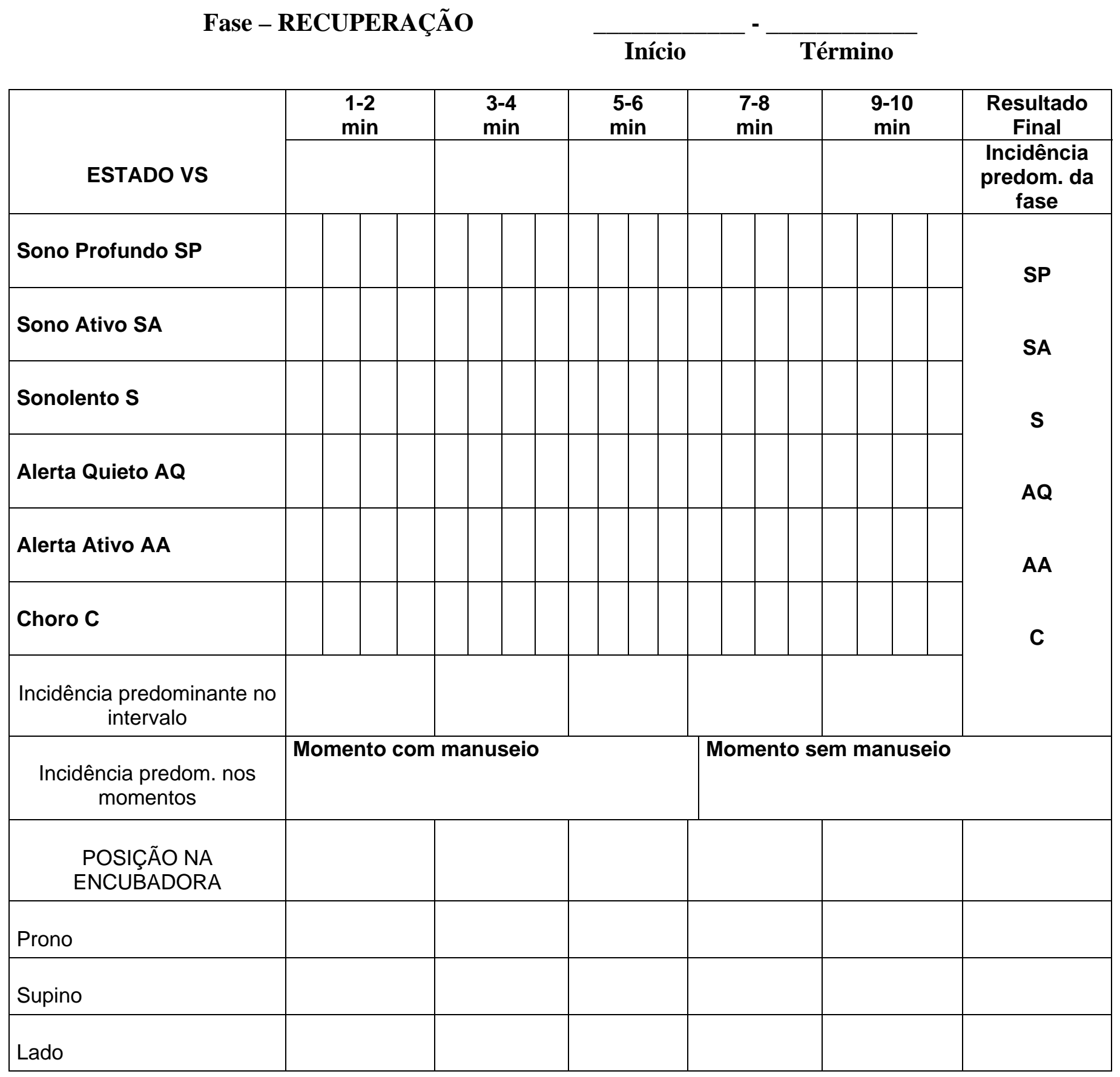


APÊNDICE F - Protocolo de coleta de dados frequência cardíaca

Código Data da Avaliação

Avaliador

Avaliação no.

VT

FREQÜÊNCIA CARDÍACA

\begin{tabular}{|c|c|c|c|c|c|c|c|c|c|}
\hline $\begin{array}{c}\text { TEMPO } \\
\text { INÍCIO/FIM }\end{array}$ & $\begin{array}{c}\text { FASE DA } \\
\text { AVALIAÇÃO }\end{array}$ & $\begin{array}{l}1-2 \\
\min \end{array}$ & $\begin{array}{l}3-4 \\
\text { min }\end{array}$ & $\begin{array}{l}\text { 5-6 } \\
\text { min }\end{array}$ & $\begin{array}{c}7-8 \\
\min \end{array}$ & $\begin{array}{l}\text { 9-10 } \\
\text { min }\end{array}$ & $\begin{array}{l}\text { Média da } \\
\text { Fase }\end{array}$ & $\begin{array}{l}\text { Média do } \\
\text { Momento }\end{array}$ & \\
\hline & Linha de Base & & & & & & $\min / \max$ & & \\
\hline & Punção & & & & & & $\min / \max$ & $\begin{array}{l}\text { Preparação } \\
\text { Punção }\end{array}$ & $\begin{array}{l}\text { Inserção } \\
\text { agulha }\end{array}$ \\
\hline & Recuperação & & & & & & $\min / \max$ & $\begin{array}{l}\text { Momento } \\
\text { com } \\
\text { manuseio }\end{array}$ & $\begin{array}{l}\text { Momento } \\
\text { sem } \\
\text { manuseio }\end{array}$ \\
\hline
\end{tabular}

Tempo início da inserção da agulha:

Tempo da remoção da agulha:

Tempo início do momento da recuperação sem manuseio: 
APÊNDICE G - Ficha de identificação do participante

Código Data da Avaliação

Avaliador

\begin{tabular}{|c|c|}
\hline \multicolumn{2}{|c|}{ Dados de Identificação } \\
\hline Nome do neonato & RG- HC \\
\hline Nome da mãe & \\
\hline Data de nascimento & $\begin{array}{ll}\text { Sexo } & \text { FEM } \square \text { MASC } \square\end{array}$ \\
\hline Data de internação / / & Idade pós-gestacional \\
\hline $\begin{array}{l}\text { IG } 1^{\circ} \_2^{\circ} \_3^{\circ} \_4^{\circ}-5^{\circ}- \\
\text { ANOTAR -Método de identificação da IG: } \\
1^{\circ} \mathrm{US} / 2{ }^{\circ} \text { Ballard (48h) } / 3^{\circ} \text { Dubowitz/ } 4^{\circ} \text { Capurro (16 h) / } \\
5^{\circ} \text { DUM }\end{array}$ & $\begin{array}{l}\text { Peso de nascimento } \\
\text { Apgar } 5^{\circ} \mathrm{min}\end{array}$ \\
\hline PIG $\quad \square$ AIG $\square$ & CRIB $=$ \\
\hline
\end{tabular}

\begin{tabular}{|l|l|l|}
\hline Data & Avaliação & Horas de Vida \\
\hline & $\mathbf{1}^{\mathbf{a}}$. Avaliação & \\
\hline & $\mathbf{2}^{\mathrm{a}}$. Avaliação & \\
\hline & $3^{\mathrm{a}}$. Avaliação & \\
\hline & $\mathbf{4}^{\mathrm{a}}$. Avaliação & \\
\hline
\end{tabular}

\begin{tabular}{llll} 
Condições do Neonato: & Intubado & $\square \operatorname{sim}$ & $\square$ não \\
& Com Fita Adesiva & $\square \operatorname{sim}$ & $\square$ não \\
& Outros & & \\
\hline
\end{tabular}

\section{Condições da Observação}


APÊNDICE H - Índice de Risco Clínico Neonatal (CRIB)

Código do Participante:

Data da coleta de informação do prontuário:

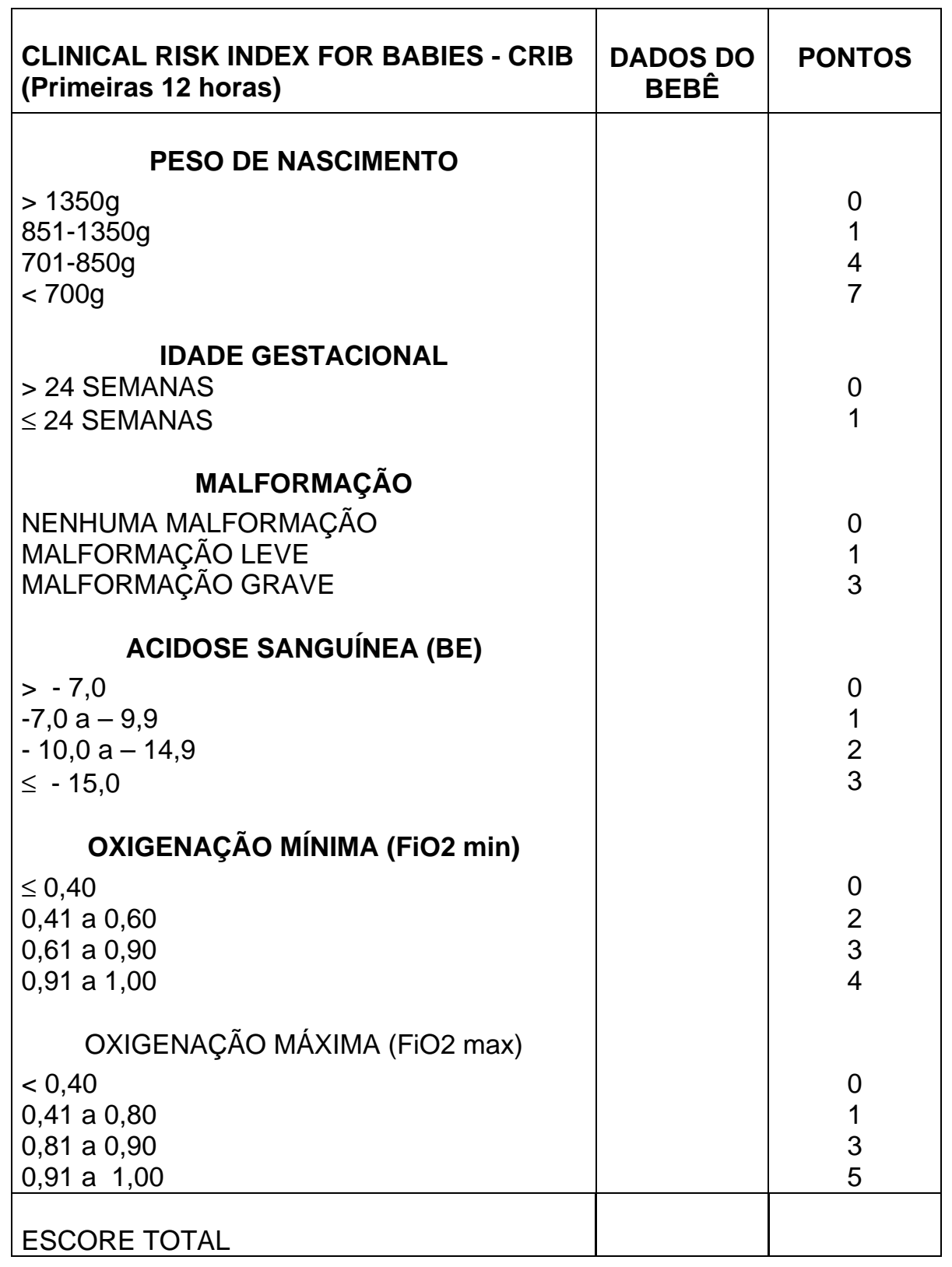




\section{APÊNDICE I - Protocolo de coleta de dados evolução clínica 1}
Código
Data da Avaliação

Avaliador

\begin{tabular}{|c|c|c|c|c|}
\hline DADOS PRONTUÁRIO MÉDICO/ENFERMAGEM & $1^{\mathrm{a}}$ AVAL. & $2^{\mathrm{a}}$ AVAL. & $3^{\mathrm{a}}$ AVAL. & $4^{\mathrm{a}}$ AVAL. \\
\hline \multicolumn{5}{|c|}{$\begin{array}{l}N^{0} \text { de procedimentos invasivos e dolorosos do nascimento até a } \\
\text { primeira avaliação }\end{array}$} \\
\hline \multicolumn{5}{|c|}{$\mathrm{N}^{\circ}$ de procedimentos invasivos e dolorosos nas últimas $24 \mathrm{hs}$} \\
\hline \multicolumn{5}{|l|}{ Ventilação Mecânica (dias) } \\
\hline \multicolumn{5}{|l|}{ Consistência das fezes nas últimas 24hs } \\
\hline \multicolumn{5}{|l|}{$\mathrm{N}^{\circ}$ de evacuações nas últimas $24 \mathrm{hs}$} \\
\hline \multicolumn{5}{|l|}{$\begin{array}{l}\text { Alimentação mista/enteral } \\
\text { E Enteral (LNO/leite cru) } \\
\text { P Parenteral (NPT) } \\
N^{0} \text { dias na parenteral }\end{array}$} \\
\hline \multicolumn{5}{|l|}{ Tempo de Intubação (nºdias) } \\
\hline $\begin{array}{l}\text { Medicações nas últimas 24hs } \\
\text { (NOME E VIA) } \\
\text { O Oral } \\
\text { E Endovenosa } \\
\text { I Intramuscular } \\
\text { EN Enteral }\end{array}$ & & & & \\
\hline
\end{tabular}


APÊNDICE J - Protocolo de coleta de dados evolução clínica 2

\begin{tabular}{|c|c|c|}
\hline $\begin{array}{l}\text { Data de nascimento: } \\
\text { Registro Projeto Dor: }\end{array}$ & Registro HC: & \\
\hline VARIÁVEIS & $\begin{array}{l}\text { UNIDADE DE } \\
\text { MEDIDA }\end{array}$ & REGISTRO \\
\hline \multicolumn{3}{|c|}{ FASE NEONATAL ATÉ A ALTA HOSPITALAR } \\
\hline Idade gestacional & Dias & \\
\hline Peso ao nascimento & Gramas & \\
\hline Adequação IG/Peso & PIG/AIG & \\
\hline $\begin{array}{l}\text { Peso- } 38^{\circ} \text {. sem de idade pós- } \\
\text { concepcional }\end{array}$ & Gramas & \\
\hline Peso na alta hospitalar & Gramas & \\
\hline Data da alta hospitalar & Data & \\
\hline Tempo de internação-UTIN & Dias & \\
\hline Tempo de internação total & Dias & \\
\hline $\begin{array}{l}\text { Tempo para atingir } \\
\text { peso }=1800 \mathrm{~g}\end{array}$ & Dias & \\
\hline CRIB & Escore & \\
\hline Apgar $5^{\circ} . \min$ & Escore & \\
\hline \multicolumn{3}{|l|}{ Alimentação: } \\
\hline Início da enteral & Data & \\
\hline Início e término da parenteral & Datas & \\
\hline Data saída da sonda & Data & \\
\hline Início amamentação & Data & \\
\hline Tempo de Ventilação: & Dias & \\
\hline Tempo de Intubação & Dias & \\
\hline \multicolumn{3}{|l|}{ Problemas: } \\
\hline Broncodisplasia & Data & \\
\hline Retinopatia & Sim/Não & \\
\hline Hemorragia intracraniana & Sim/Não/grau & \\
\hline Enterocolite necrosante & Sim/Não & \\
\hline Sepse clínica & Sim/Não & \\
\hline Cardiopatia & Sim/Não/tipo & \\
\hline Pneumotorax & Sim/Não & \\
\hline \multicolumn{3}{|l|}{ Tratamentos/procedimentos } \\
\hline Cirurgia & Data/ tipo & \\
\hline & & \\
\hline
\end{tabular}


APÊNDICE K - Protocolo de análise NFCS

AVALIADOR:

DATA:

\begin{tabular}{|c|l|l|l|}
\hline \multicolumn{2}{|c|}{ VIDEO } & \multicolumn{2}{l}{ FASE } \\
\multicolumn{1}{|c|}{ Intervalo } & Tempo Inicio & Tempo Final & \\
\hline 1 & & & \\
\hline 2 & & & \\
\hline 3 & & & \\
\hline 4 & & & \\
\hline 5 & & & \\
\hline 6 & & & \\
\hline 7 & & & \\
\hline 8 & & & \\
\hline 9 & & & \\
\hline 10 & & & \\
\hline & & & \\
\hline
\end{tabular}

ESCORE

\section{TOTAL}

\begin{tabular}{|c|c|c|c|c|c|c|}
\hline Olhos & Naso & Lábios & Boca V & Boca $H$ & Língua T. & Escore \\
\hline & & & & & & \\
\hline & & & & & & \\
\hline & & & & & & \\
\hline & & & & & & \\
\hline & & & & & & \\
\hline & & & & & & \\
\hline & & & & & & \\
\hline & & & & & & \\
\hline & & & & & & \\
\hline & & & & & & \\
\hline
\end{tabular}

CÓDIGO:

DATA da COLETA:

LEGENDA DO CONTEXTO:

0 = Nada na boca; 1 = Chupeta; 2 = Tubo; 3 = Sonda; 4 = Mão/Dedo do RN na boca; 5 = CPAP; 6 = Capela; 7 = Bigodinho; $\mathrm{PJ}=$ Dado Prejudicado 


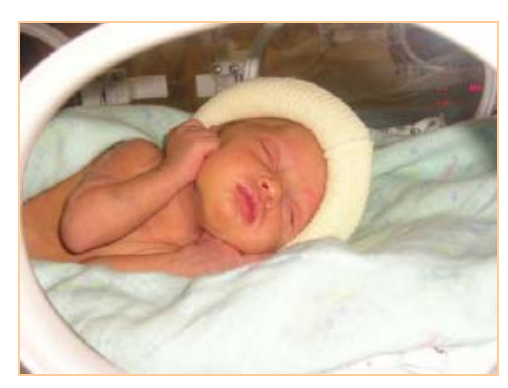

ANEXOS 


\section{ANEXO A - Aprovação do Comitê de Ética}

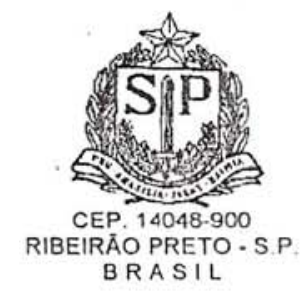

Ofício $n^{\circ} 554 / 2003$

$\mathrm{CEP} / \mathrm{CDGC}$

Prezada Senhora:

\author{
HOSPITAL DAS CLINICAS DA FACULDADE DE MEDICINA \\ DE RIBEIRAAO PRETO DA UNIVERSIDADE DE SÄO PAULO \\ CAMPUS UNIVERSITÁRIO - MONTE ALEGRE \\ FONE: 602-1000-FAX (016) 633-1144
}

Ribeirão Preto, 13 de março de 2003

O trabalho intitulado "INTERVENÇÃO NÃO-

FARMACOLÓGICA NO ALÍVIO DA DOR EM RECÉM-NASCIDOS PRÉTERMO: AVALIAÇÃO DO EFEITO DE SOLUÇÃO DE SACAROSE EM DOSES REPETIDAS", foi analisado pelo Comitê de Ética em Pesquisa, em sua $149^{a}$ Reunião Ordinária realizada em 10/03/2003, e enquadrado na categoria: APROVADO, de acordo com o Processo HCRP $n^{\circ} 1659 / 2003$.

Aproveito a oportunidade para apresentar a Vossa Senhoria protestos de estima c consideração.

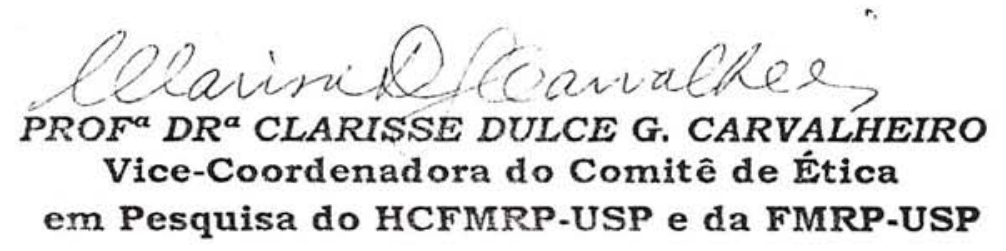

Ilustríssima Senhora

Prof" Dr" MARIA BEATRIZ MARTINS LINHARES

Depto. de Neurologia, Psiquiatria e Psicologia Médica

Em mãos 


\section{ANEXO B - Autorização do Chefe do Serviço de Neonatologia}

UNIVERSIDADE DE SÃO PAULO
FACULDADE DE MEDICINA DE RIBEIRÃO PRETO
DEPARTAMENTO DE PUERICULTURA E PEDIATRIA

Autorizamos a realização do projeto de pesquisa intitulado "Intervenção não-farmacológica no alivio da dor em recém-nascidos prétermo: avaliação do efeito da solução de sacarose em doses repetidas" no Setor de Neonatologia do HCFMRP do Departamento de Neurologia, Psiquiatria e Psicologia Médica da Faculdade de Medicina de Ribeirão PretoUSP, sob a responsabilidade dos pesquisadores Profa. Dra. Maria Beatriz Martins Linhares e Prof. Dr. Francisco Eulógio Martinez, com a participação auxiliares de pesquisa.

Ribeirão Preto, 26 do janeiro de 2003

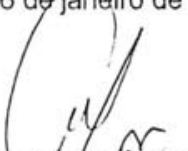

Prof. Dr. SALIMIMYYSES'JORGE

Chefe do Setor de Neonatologiz- HCFMRP-USP (1)

Chefe do Departamento de Puericultura e Pediatria- FMRP-USP 


\section{ANEXO C - Laudo de identificação das substâncias}

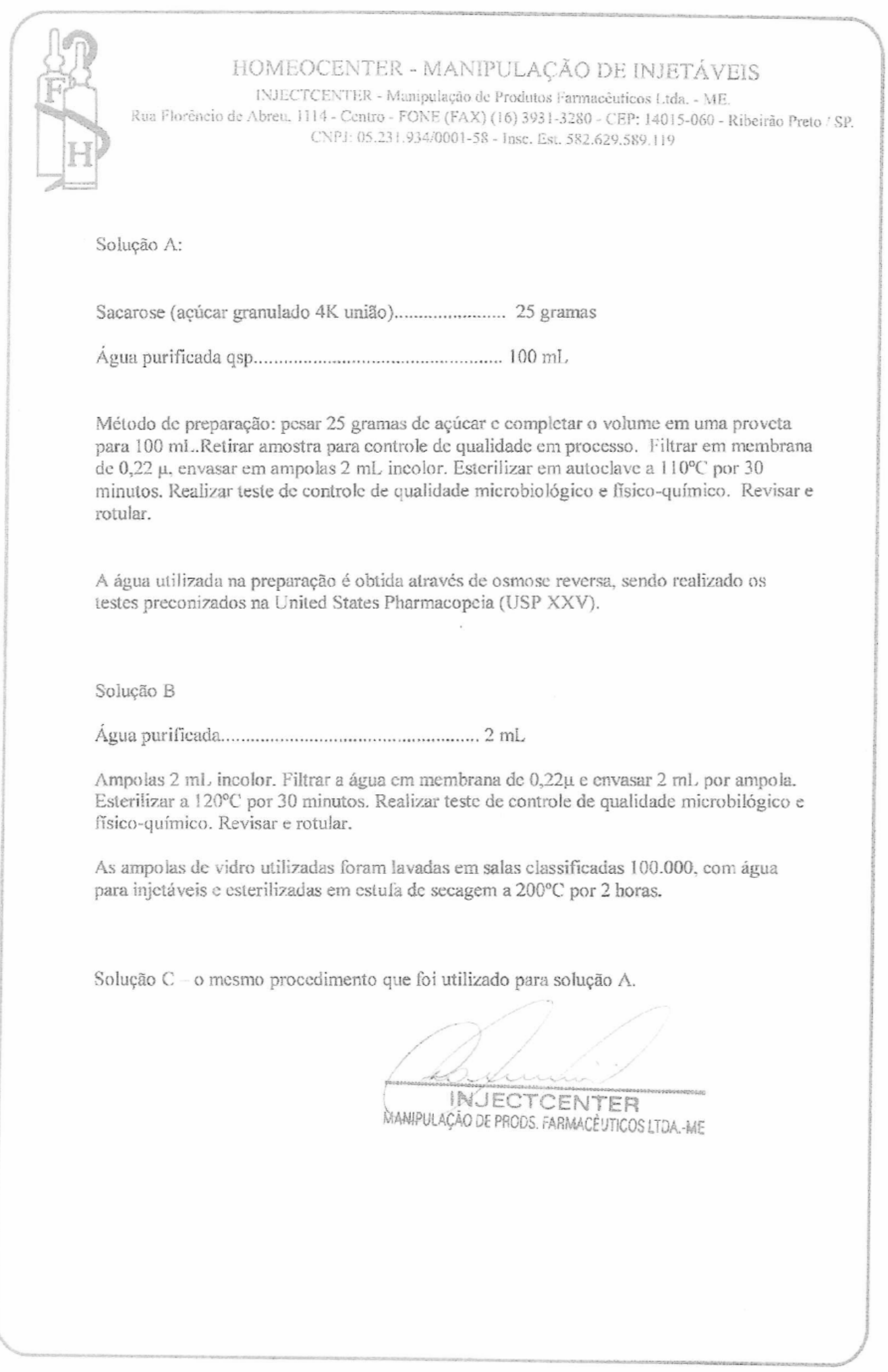




\title{
ANEXO D - Artigo publicado
}

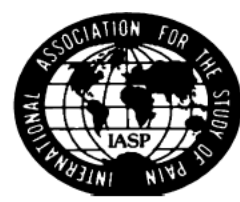

\section{Is pain relief equally efficacious and free of side effects with repeated doses of oral sucrose in preterm neonates?}

\author{
Cláudia Maria Gaspardo a, Catia Isumi Miyase a, Juliana Thomazatti Chimello a, \\ Francisco Eulógio Martinez ${ }^{\mathrm{b}}$, Maria Beatriz Martins Linhares ${ }^{\mathrm{a}, *}$ \\ ${ }^{a}$ Department of Neurology, Psychiatry and Medical Psychology, School of Medicine of Ribeirão Preto, University of São Paulo-SP, Brazil \\ ${ }^{\mathrm{b}}$ Department of Pediatrics, School of Medicine of Ribeirão Preto, University of São Paulo-SP, Brazil \\ Received 27 March 2007; received in revised form 26 June 2007; accepted 31 July 2007
}

\begin{abstract}
The aim of the present study was to examine the efficacy and potential side effects of repeated doses of oral sucrose for pain relief during procedures in NICU. Thirty-three preterm neonates were randomly allocated in blind fashion into two groups, the sucrose group ( $\mathrm{SG}=17$ ) and the control group $(\mathrm{CG}=16)$. The responses of neonates to pain and distress were assessed during blood collection on four consecutive assessment (ass.) days. For the first assessment, the neonates did not receive any solution before the blood collection procedure. During the next three days, the $\mathrm{SG}$ received oral sucrose $(25 \% ; 0.5 \mathrm{ml} / \mathrm{kg})$ and the CG received sterile water, 2 min before each minor acute painful procedure. The neonates were evaluated during blood collection each morning. The assessment was divided into five phases: Baseline (BL), Antisepsis (A), Puncture (P), Dressing (D), and Recovery (R). The neonates' facial activity (NFCS), behavioral state, and heart rate were evaluated. The data analysis used cut-off scores for painful and distressful responses. No side effects of using sucrose were detected. There were significantly fewer SG neonates with facial actions signaling pain than CG neonates in P (ass.2) and in A (ass.3). We found significantly fewer SG neonates in the awake state than CG neonates in P (ass.2 and ass.4). There were significantly fewer SG neonates crying during A (ass.2), P (ass.2 and ass.4), and D (ass.3). There was no statistical difference between-groups for physiological response. The efficacy of sucrose was maintained for pain relief in preterm neonates with no side effects.

(c) 2007 International Association for the Study of Pain. Published by Elsevier B.V. All rights reserved.
\end{abstract}

Keywords: Pain; Sucrose; Repeated doses; Preterm; Very low birth weight; NICU

\section{Introduction}

Repeated exposure to painful experiences may have long-term effects on the pain system (Anand, 2000; Grunau, 2000, 2002) and development (Grunau et al., 2004),

\footnotetext{
${ }^{*}$ Corresponding author. Address: Laboratório de Pesquisa em Prevenção de Problemas de Desenvolvimento e Comportamento da Criança, Avenida Tenente Catão Roxo, 2650, Prédio da Saúde Mental, Faculdade de Medicina de Ribeirão Preto, USP, Campus Universitário Monte Alegre, Ribeirão Preto, CEP 14051-140, SP, Brasil. Tel.: +55 163602 4610/3637 2702; fax: +55 163602 4607/3602 4504 .

E-mail address: linhares@fmrp.usp.br (M.B. Martins Linhares).
}

such as reduction of pain threshold (Grunau, 2002; Gibbins et al., 2003) and hyperalgesia (Anand, 1998; Grun$\mathrm{au}, 2002$ ). There have been considerable advances in establishing validated measures for pain assessment of preterm and full-term infants (Stevens et al., 2007). Pain relief increases the homeostasis and stability of neonates; it is essential for the care and support of immature infants so that they can survive the distress associated with neonatal intensive care (Corff et al., 1995).

The American Academy of Pediatrics and Canadian Pediatric Society (2000) recommend the use of sucrose solution for routine pain relief during invasive and painful procedures. The $2-\mathrm{ml}$ single dose of $25 \%$ sucrose used 
for preterm neonates has been reported to have analgesic properties during painful events (for a review, see Gaspardo et al., 2005).

The analgesic effects of repeated doses of sucrose during painful procedures in preterm infants have been analyzed in a few studies using different methodological procedures (Johnston et al., 1999; Johnston et al., 2002; Boyer et al., 2004; Mitchell et al., 2004; Stevens et al., 2005).

Although the guidelines of the Pediatrics Societies for pain management recommend the use of sucrose solution for pain relief during painful procedures, the use of repeated doses of sucrose with preterm neonates requires further investigation. To date, the findings regarding maintained efficacy and the potential side effects of sucrose used exclusively have been inconclusive.

The aim of the present study was to assess the efficacy of giving repeated doses of oral sucrose to neonates for pain relief during painful procedures and to determine whether there are any negative side effects. In the current study we tested the hypotheses that: (1) sucrose given in a repeat-dose schedule and used consecutively over three days is efficacious for pain relief in preterm neonates (2) the continuous administration of sucrose during painful procedures does not have adverse effects on the health of neonates.

\section{Methods}

\subsection{Study design}

Randomized, double-blind, placebo-controlled trial.

\subsection{Sample}

Thirty-three preterm $(<37$ weeks gestational age) and very low birth weight $(<1500 \mathrm{~g})$ neonates born between April 2003 and September 2005 and hospitalized in the Neonatal Intensive Care Unit (NICU) of the Hospital of Clinics, School of Medicine, University of São Paulo at Ribeirão Preto were studied. The neonates who had major congenital anomalies, intraventricular hemorrhage (grade III/IV) and hypoglycemia, hyperglycemia, or who were on opioid or sedative medications and umbilical catheter in the first and second weeks of life were excluded. The ventilated neonates were included in the study, as done in the study by Boyer et al. (2004) and Stevens et al. (2005).

The recruitment of the infants, the excluded participation and the random allocation are shown in Fig. 1.

Of 180 preterm and very low birth weight births during the study period, 49 neonates were excluded $(25$ with umbilical catheter, 20 on opioid or sedative medication, one with grade III intraventricular hemorrhage, one with hyperglycemia, one with hypoglycemia, and one with major congenital anomaly), and 9 deaths occurred. Also, 78 of the remaining 122 neonates could not be included in the study for other reasons: 49 mothers were discharged without signing the informed consent form, 10 neonates were taken to an intermediary special care nursery before data collection, 10 neonates had no blood collection prescription, and 9 mothers did not agree to participation in the study.

Of the 44 neonates who remained, 11 were discharged from the NICU while the data collection was in progress. The final sample was thus composed of 33 neonates, who were randomly allocated into two groups in blind fashion: the sucrose group (SG; $n=17$ ) and the control group (CG; $n=16$ ).

Comparison was done between the sample of infants that dropped out of the study (S-OUT) and the sample that completed the study (S-IN). The S-OUT sample was similar to the S-IN sample regarding gender (S-OUT: $52 \%$ female; SIN: $51 \%$ female; $p=0.57$ ) and median values of gestational age (S-OUT: 30 weeks; S-IN: 30 weeks; $p=0.40$ ) and birth weight (S-OUT $=1,075 \mathrm{~g} ; \mathrm{S}-\mathrm{IN}=1,135 \mathrm{~g} ; p=0.89$ ).

\subsection{Ethical approval}

The study was approved by the Clinical Research Ethics Board of the Hospital of Clinics, School of Medicine, University of São Paulo at Ribeirão Preto, and informed consent was obtained from all parents prior to participation.

\subsection{Measures and procedure}

Data collection was carried out between 7:00 and 9:00 a.m. during blood collection due to clinical demands of neonates. The neonates were evaluated for four consecutive days. At the first assessment, the neonates did not receive any solutions in order to observe the individual patterns of behavioral and physiological responses of the infants during the painful procedure of blood collection.

Each infant was left undisturbed prior to an evaluation session. The assessment procedure was divided into five phases: Baseline (BL), Antisepsis (A) covering the period of handling the neonate for antisepsis prior to puncture, Puncture (P), Dressing (D) covering the period from handling the neonate for dressing until positioning to rest in the isolette, and Recovery $(\mathrm{R})$. The period for recording the BL was standardized as $10 \mathrm{~min}$. The time periods for $\mathrm{A}$ and $\mathrm{P}$ depended on the time used for the procedures of antisepsis and puncture. The total time for D plus R was standardized as $10 \mathrm{~min}$. The blood collection procedures were carried out by five trained nurses of the NICU staff who had a high degree of expertise.

The Neonatal Facial Coding System (NFCS) (Grunau and Craig, 1987) was used for assessment of pain responses by analysis of facial actions, which were recorded using a digital video camera at the bedside. Seven facial actions were analyzed, including brow bulge, eye squeeze, nasolabial furrow, open mouth, vertical mouth stretch, horizontal mouth stretch, and taut tongue. Each facial action was scored by observing the videotape for the first $20 \mathrm{~s}$ of each phase (Baseline, Antisepsis, Puncture, Dressing, and Recovery). Each 20-s recording was divided into ten 2-s segments to be analyzed independently by two coders as 1 or 0 (occurred, or did not occur). The coders were blinded regarding the assessment phases, medical information, and the characteristics of infants. In order to calculate the total score, all seven facial actions during the 10 segments of $2 \mathrm{~s}$ for each event were summed, leading to a total 


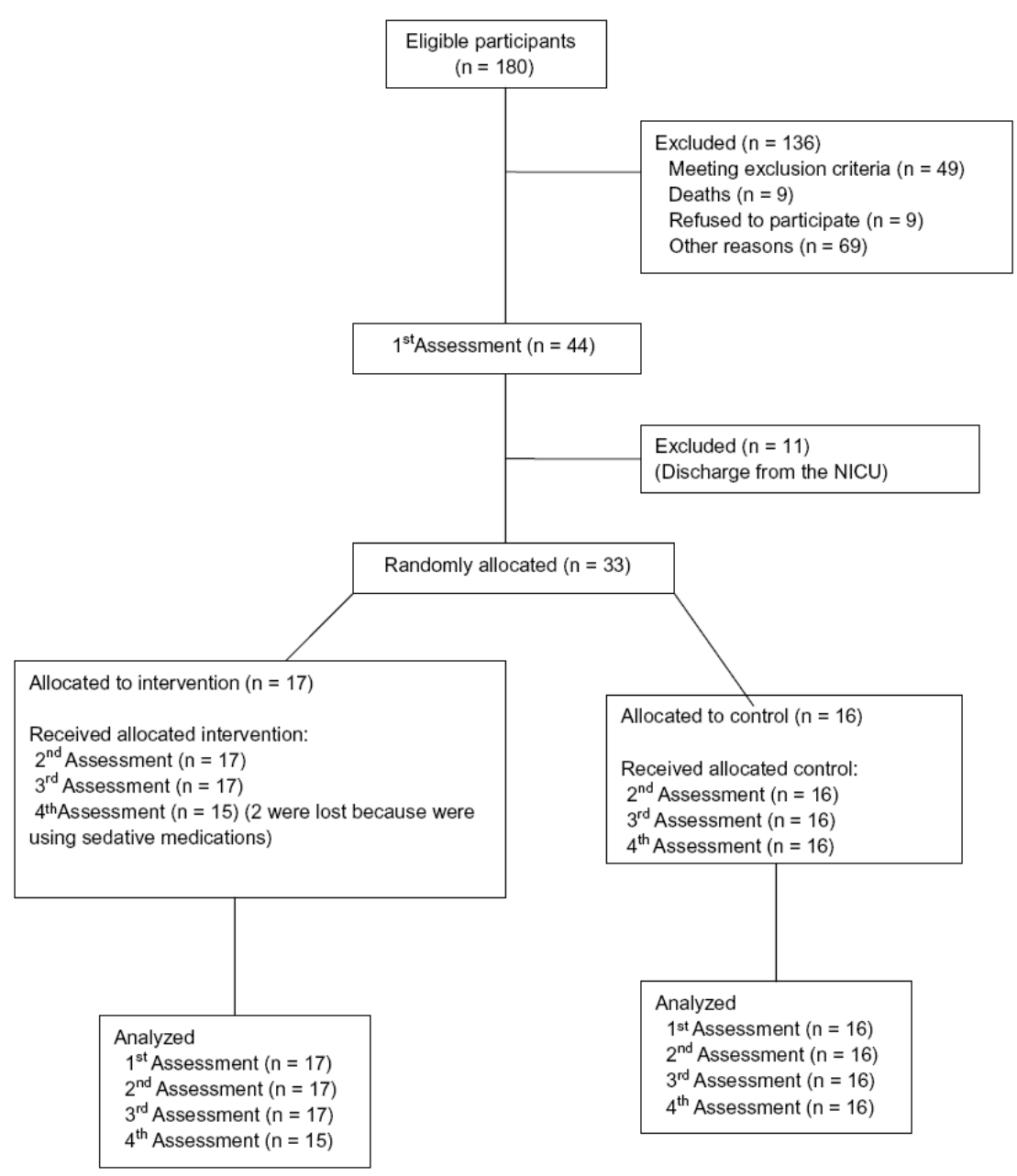

Fig. 1. Selection of the study participants.

score that could range from 0 to 70 (Grunau et al., 2001). The reliability analysis followed the conservative NFCS formula of Grunau and Craig (1987) for videotaped facial activity. The reliability coding between two trained and independent coders was carried out on $10 \%$ of the study sample, with a reliability coefficient of $93 \%$.

Heart rate and sleep-wake states were recorded at the bedside. The heart rate was monitored with a Philips V240T and recorded by the observer each minute. Then the average heart rate was calculated in each phase of the four assessments. The analysis of heart rate took into account the value of 160 beats per minute that has been suggested to be an indictor of many conditions, including central nervous system irritability in neonates (Fletcher, 1994). Infant sleep-wake states (Murdoch and Darlow, 1984) were coded from systematic observation of the neonates using the following system: deeply asleep $=1$; actively asleep $=2$; drowsy $=3$; quietly alert $=4$; actively alert $=5$, and crying $=6$. To record the crying state, the cry facial mimic and irregular breathing with or without vocal sound were monitored (Chang et al., 2002). Sleep-wake states were coded by a trained coder using a record sheet divided into intervals of $30 \mathrm{~s}$. The behavioral state scored at each phase of the procedure was established by choosing the highest incidence found in all intervals. The reliability coding between two trained and independent coders was $86 \%$.

On the second day, the neonates were randomly allocated into two groups according to a computer-generated randomization list. This was a statistical series based on random sampling of numbers generated in a computer laboratory at University. The groups were given the designations "Solution A" and "Solution B" in order to ensure that the content of the treatments would be hidden from all investigators. The coordinator kept a sealed envelope with the key to the identity of the substances encoded by the laboratory; it was only opened after the data analysis. According to the order in which the births occurred and after the informed consent form had been signed, each neonate was allocated to a group following the list of random numbers.

Over three consecutive days, the SG received 25\% sucrose in a dose of $0.5 \mathrm{ml} / \mathrm{kg}$ for each painful procedure as follows: venipuncture, arterial puncture, heel-lance, intravenous cannulation, endotracheal tube introduction, endotracheal tube 
suctioning, gavage insertion for feeding, and removal of electrode leads and tape. The CG received sterile water $(0.5 \mathrm{ml} /$ $\mathrm{kg}$ ) for the same set of procedures. These procedures were selected based on the study of Johnston et al. (2002).

Prospective review of medical charts was carried out independently by a blinded and trained researcher physician. Infant characteristics and neonatal health status including gender, gestational age at birth, birth weight, fifth-minute Apgar score, number of invasive painful procedures since birth (venipuncture, arterial puncture, heel-lance, intravenous cannulation, endotracheal tube introduction, endotracheal tube suctioning, gavage insertion for feeding, removal of tape, and electrode leads), days of mechanical ventilation, and score of illness severity in the Clinical Risk Index for Babies (CRIB) (Cockburn et al., 1993) were obtained. In addition, clinical development of the infants was reviewed in order to assess the potentially adverse side effects of sucrose, focusing on residue in stomach, vomiting, evacuation, abdominal distension, and necrotizing enterocolitis.

\subsection{Data analysis}

The Statistical Package for the Social Sciences (SPSS) version 12.0 was used for data analysis. The sensitivity and specificity of the variable NFCS score was analyzed from the ROC curve in order to find the cut-off value of pain for the study sample. Baseline (no pain) vs. Puncture (pain) phases were used in this analysis. A score of 3 was chosen as the best cut-off value $($ ROC area $=0.85$; Sensitivity $=0.76$; Specificity $=0.88 ;$ IC $95 \%=0.75-0.95 ; p \leqslant 0.0001)$. The ShapiroWilk test was used in order to verify the normal distribution of the data, and according to this result a non-parametric statistical approach was adopted.

In the descriptive statistical analysis, the percentage of neonates for the categorical variables and the median for the continuous variables were calculated. The percentage of neonates with NFCS score $\geqslant 3$, heart rate $\geqslant 160$ beats per min (tachycardia), behavioral state $\geqslant 4$ (quietly awake, actively awake, and crying) in the ordinal scale from 1 to 6 , and in the crying state specifically was calculated. The between-groups comparison ( $\mathrm{SG}$ vs. CG) was analyzed using the Mann-Whitney test for continuous variables and the Chi-square test for categori- cal variables. The within-group comparison was examined using Friedman and Wilcoxon tests for repeated analysis of continuous variables. The association between dependent variables (NFCS, behavioral state, and heart rate), infant variables (sex and gestational age) and puncture characteristics (type and duration) was calculated by Spearman Correlation test. The significance level for the study was set at $5 \%$.

\section{Results}

\subsection{Characteristics of preterm infants and neonatal health status}

Table 1 shows some characteristics of preterm infants and health status from birth until the first assessment day. There were no statistically significant differences between groups for any of these characteristics, or for health status. In both groups, the infants were in the first two weeks of postnatal age. The neonates had a median of 30 weeks of gestational age and weighed around $1 \mathrm{~kg}$ at birth. The fifth-minute Apgar and CRIB scores revealed favorable prognosis for clinical progress. In addition, the infants were exposed to around six painful procedures per day, such as venipuncture, arterial puncture, heel-lance, intravenous cannulation, endotracheal tube introduction, endotracheal tube suctioning, gavage insertion for feeding, and removal of tape and electrode leads. In both groups, there was a low frequency of residue in stomach, vomiting, and abdominal distension.

\subsection{Possible side effects during the intervention schedule with sucrose}

Table 2 presents some clinical characteristics and health status of the neonates included in the SG and the CG, assessed during the $24 \mathrm{~h}$ prior to each assessment. There were no statistically significant differences between and within groups regarding the number of painful procedures, number of days in mechanical venti-

Table 1

Characteristics of preterm infants and neonatal health status for sucrose group and control group

\begin{tabular}{|c|c|c|c|}
\hline Infant characteristics and neonatal health status & Sucrose $(n=17)$ & Control $(n=16)$ & $p$-Value \\
\hline Postnatal age at first assessment (days), median (range) & $2(1-7)$ & $3(1-12)$ & 0.36 \\
\hline Sex (male/female; \%) & $35 / 65$ & $62 / 38$ & 0.12 \\
\hline Gestational age (weeks), median (range) & $30(25-33)$ & $31(27-33)$ & 0.20 \\
\hline Birth weight (grams), median (range) & $995(640-1430)$ & $1,177(685-1360)$ & 0.40 \\
\hline Appropriate for gestational age, $\mathrm{f}(\%)$ & $9(53)$ & $5(31)$ & 0.20 \\
\hline Fifth-minute Apgar score, median (range) & $8(5-10)$ & $9(6-10)$ & 0.95 \\
\hline Clinical Risk Index for Babies (CRIB score), median (range) & $4(0-11)$ & $1(0-13)$ & 0.20 \\
\hline Mechanical ventilation (days), median (range) & $1(1-5)$ & $2(1-10)$ & 0.36 \\
\hline Number of painful procedures per day ${ }^{\mathrm{a}}$, median (range) & $7(3-9)$ & $5(1-18)$ & 0.65 \\
\hline Stomach residue, median (range) & $1(0-12)$ & $2(0-19)$ & 0.18 \\
\hline Vomiting, median (range) & $0(0-2)$ & $0(0-5)$ & 0.73 \\
\hline Abdominal distension, $\mathrm{f}(\%)$ & $1(6)$ & $4(25)$ & 0.15 \\
\hline
\end{tabular}

${ }^{a}$ Sum of painful procedures (venipuncture, arterial puncture, heel-lance, intravenous cannulation, endotracheal tube introduction, endotracheal tube suctioning, gavage insertion for feeding, or removal of electrode leads or tape) divided by postnatal age. 
Table 2

Characteristics of neonatal health status detected $24 \mathrm{~h}$ prior to each assessment for sucrose group and control group

\begin{tabular}{|c|c|c|c|c|c|c|c|c|}
\hline \multirow[t]{2}{*}{$\begin{array}{l}\text { Characteristics of neonatal health status } \\
\text { ( } 24 \mathrm{~h} \text { prior to each assessment) }\end{array}$} & \multicolumn{2}{|c|}{$\begin{array}{l}\text { First assessment } \\
\text { (No intervention) }\end{array}$} & \multicolumn{2}{|c|}{ Second assessment } & \multicolumn{2}{|c|}{ Third assessment } & \multicolumn{2}{|c|}{ Fourth assessment } \\
\hline & $\begin{array}{l}\text { Sucrose } \\
(n=17)\end{array}$ & $\begin{array}{l}\text { Control } \\
(n=16)\end{array}$ & $\begin{array}{l}\text { Sucrose } \\
(n=17)\end{array}$ & $\begin{array}{l}\text { Control } \\
(n=16)\end{array}$ & $\begin{array}{l}\text { Sucrose } \\
(n=17)\end{array}$ & $\begin{array}{l}\text { Control } \\
(n=16)\end{array}$ & $\begin{array}{l}\text { Sucrose } \\
(n=15)\end{array}$ & $\begin{array}{l}\text { Control } \\
(n=16)\end{array}$ \\
\hline Number of painful procedures ${ }^{\mathrm{a}}$, median (range) & $6(2-11)$ & $6(2-16)$ & $6(2-11)$ & $6(2-14)$ & $5(2-14)$ & $6(1-10)$ & $4(1-10)$ & $5.5(1-13)$ \\
\hline Mechanical ventilation (days), median (range) & $2(1-6)$ & $3(1-11)$ & $3(1-7)$ & $3.5(1-12)$ & $4(1-8)$ & $4(1-13)$ & $5(1-9)$ & $5(1-14)$ \\
\hline Number of evacuations, median (range) & $1(0-4)$ & $1(0-4)$ & $1(0-6)$ & $2(0-5)$ & $1(0-6)$ & $1(0-8)$ & $1(0-6)$ & $2(0-7)$ \\
\hline Abdominal distention, $\mathrm{f}(\%)$ & $2(12)$ & $3(19)$ & 0 & $3(19)$ & $2(12)$ & $2(13)$ & 0 & $2(13)$ \\
\hline
\end{tabular}

${ }^{a}$ Sum of painful procedures (venipuncture, arterial puncture, heel-lance, intravenous cannulation, endotracheal tube introduction, endotracheal tube suctioning, gavage insertion for feeding, removal of electrode leads or tape).

lation, number of evacuations, whether or not residue in stomach was detected, vomiting, and abdominal distention. During the study period, none of the neonates suffered necrotizing enterocolitis.

\subsection{Comparison of behavioral and physiological pain responses between groups - sucrose group vs. control group}

Fig. 2 shows the percentages of neonates in the SG and CG with NFCS score equal to or above 3 in the Baseline, Antisepsis, Puncture, Dressing, and Recovery phases for the four days of assessment. On the first assessment day, there was no statistically significant difference between groups. For all phases of the procedure, there were similar proportions of neonates with pain indicators in both groups. Both groups showed a high percentage of neonates with NFCS score $\geqslant 3$ in the puncture phase. Also, more than $50 \%$ of SG and CG neonates had NFCS score $\geqslant 3$ in the A and D phases. As expected, the two groups were comparable regarding the facial activity in the first assessment (before intervention).

On the second day of assessment when the interventions with sucrose or sterile water began, there was a statistically significant difference between groups in the Puncture phase ( $\mathrm{SG}=23 \%, \quad \mathrm{CG}=56 \%$; $p=0.05)$. The proportion of neonates showing pain responses (NFCS $\geqslant 3$ points) was lower in the $\mathrm{SG}$ than in the CG.

On the third day of assessment, there was a statistically significant difference between groups regarding the percentage of neonates with $\mathrm{NFCS} \geqslant 3$ in the Antisepsis phase ( $\mathrm{SG}=0 \%, \mathrm{CG}=31 \% ; p=0.02$ ). In the Dressing phase, a trend of a difference between groups was apparent: the proportion of SG neonates with NFCS $\geqslant 3$ was lower than for $\mathrm{CG}$ neonates $(p=0.09)$.

Finally, on the fourth assessment day, no statistically differences were found between groups. Otherwise, there was a trend with a lower percentage of SG neonates than

NFCS score $\geq 3$

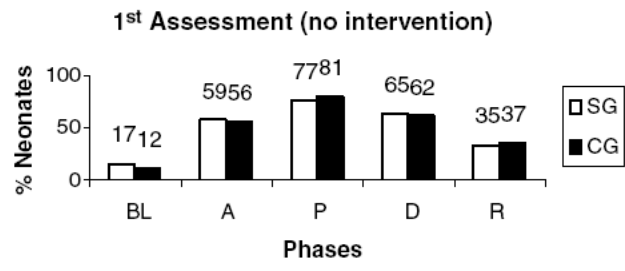

$3^{\text {rd }}$ Assessment (sucrose $\mathrm{x}$ water)

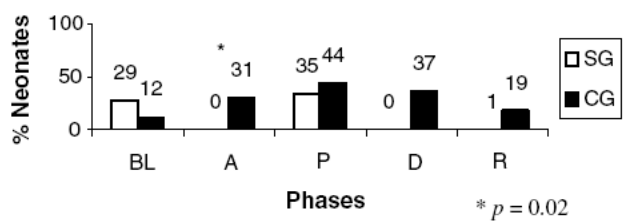

$2^{\text {nd }}$ Assessment (sucrose $\mathrm{x}$ water)

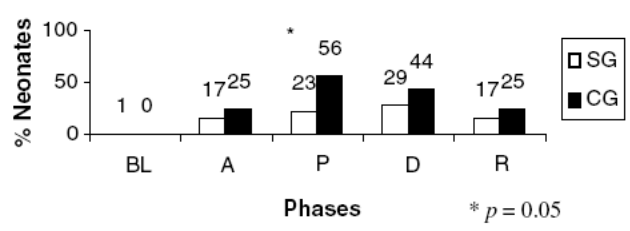

$4^{\text {th }}$ Assessment (sucrose $x$ water)

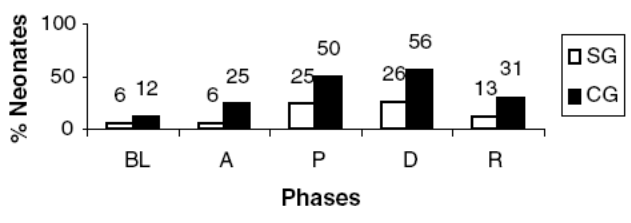

Fig. 2. Percentage of neonates with NFCS score $\geqslant 3$ at Baseline (BL), Antisepsis (A), Puncture (P), Dressing (D), and Recovery (R) in the four assessments. SG, sucrose group; CG, control group. 


\section{Activated behavioral state \\ (quiet awake, active awake, or crying)}

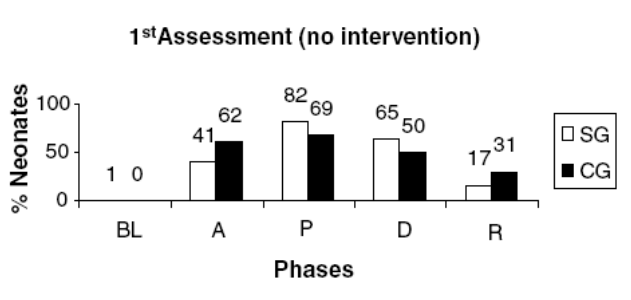

$3^{\text {rd }}$ Assessment (sucrose $\mathrm{x}$ water)

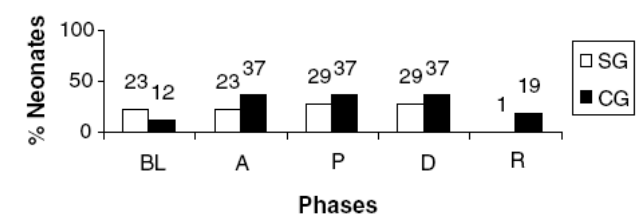

$2^{\text {nd }}$ Assessment (sucrose $\mathrm{x}$ water)

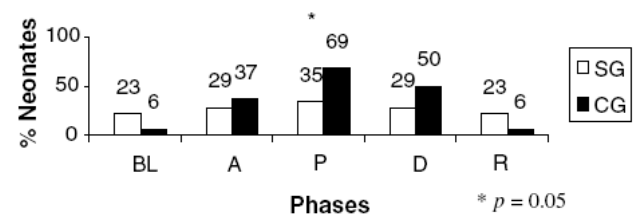

$4^{\text {th }}$ Assessment (sucrose $\mathrm{x}$ water)

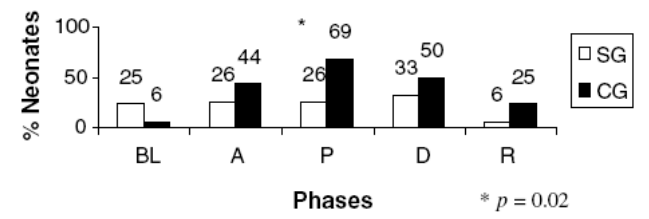

Fig. 3. Percentage of neonates with highly activated level (behavioral state $\geqslant 4$ ) at Baseline (BL), Antisepsis (A), Puncture (P), Dressing (D), and Recovery (R) in the four assessments. SG, sucrose group; CG, control group.

CG neonates having NFCS $\geqslant 3$ in the Puncture $(p=0.08)$ and Dressing phases $(p=0.09)$.

Fig. 3 shows the percentages of neonates who exhibited active behavioral states during the Baseline, Antisepsis, Puncture, Dressing, and Recovery phases in the four assessments. As expected, there was no difference between groups on the first day of assessment; these data reveal that the two groups were comparable regarding the behavioral state of the neonates.

In the second and fourth assessments, statistically significant differences between groups were found in the
Puncture phase specifically. The percentage of SG neonates with activated behavioral state was lower than the corresponding percentage for $\mathrm{CG}$ neonates (SG: $35 \%$, CG: $69 \%, p=0.05$ [second assessment]; and SG: $26 \%$, CG: $69 \%, p=0.02$ [fourth assessment]). Otherwise, there were no significant differences between groups in the third assessment.

Fig. 4 shows the percentages of neonates who cried during Baseline, Antisepsis, Puncture, Dressing, and Recovery phases in the four assessments. As expected, no difference between groups was found on the first $1^{\text {st }}$ Assessment (no intervention)

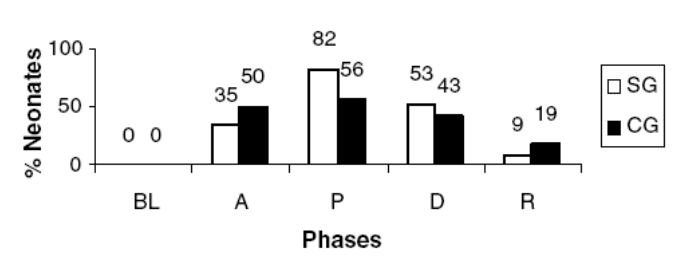

$3^{\text {rd }}$ Assessment (sucrose $\mathrm{x}$ water)

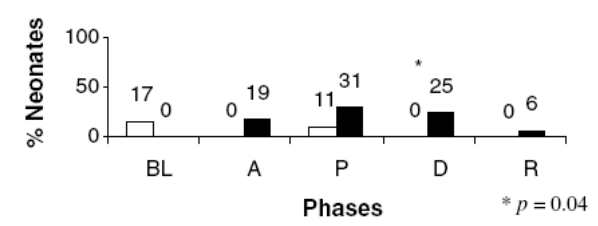

Crying

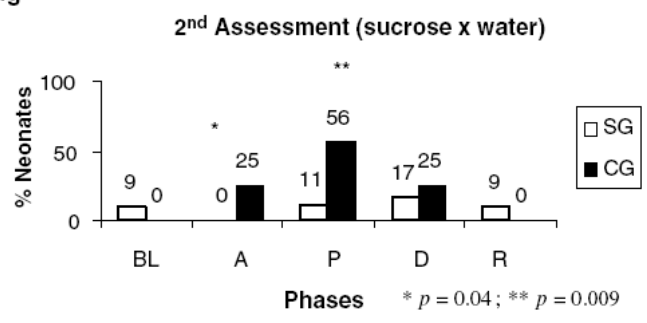

$4^{\text {th }}$ Assessment (sucrose $x$ water)

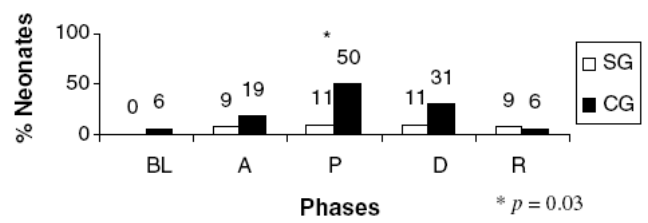

Fig. 4. Percentage of neonates crying at Baseline (BL), Antisepsis (A), Puncture (P), Dressing (D), and Recovery (R) in the four assessments. SG, sucrose group; $\mathrm{CG}$, control group. 

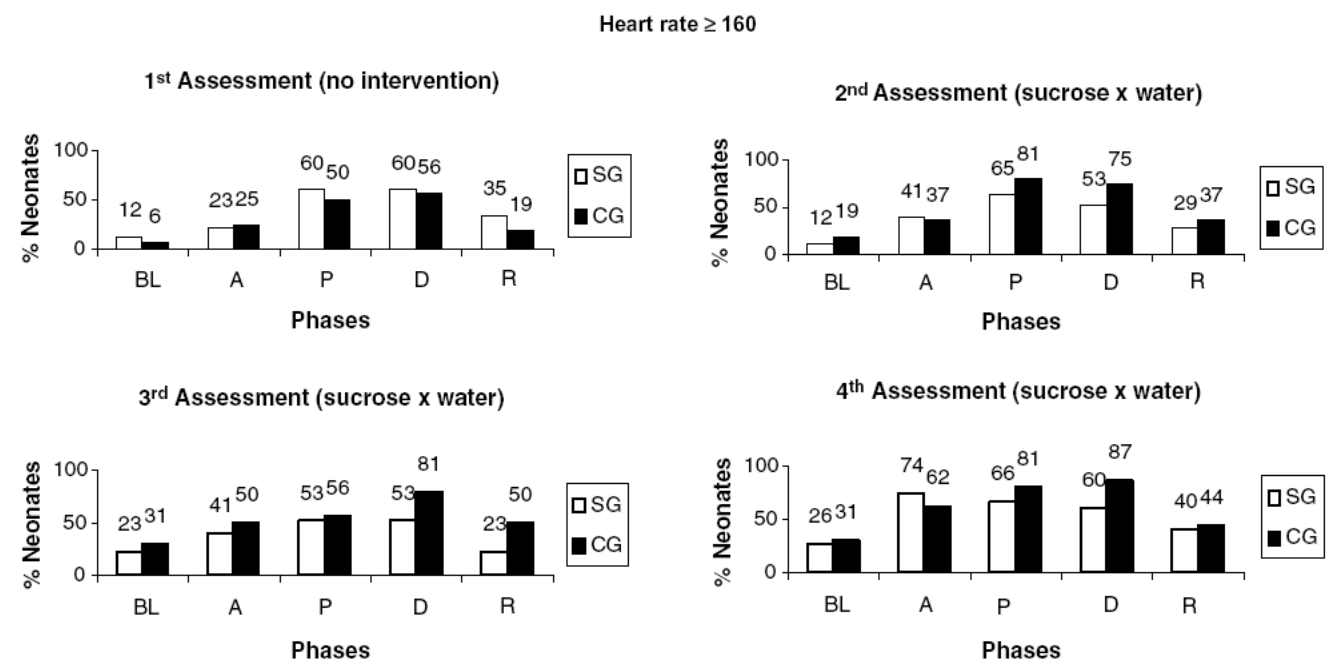

$4^{\text {th }}$ Assessment (sucrose $\mathrm{x}$ water)

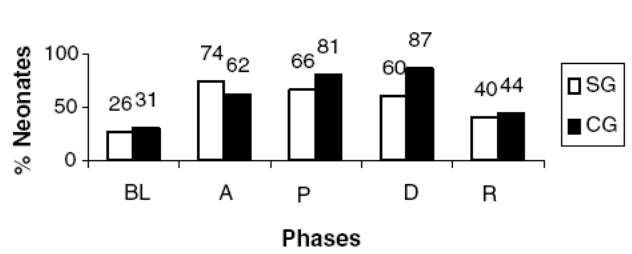

Fig. 5. Percentage of neonates with heart rate $\geqslant 160$ at Baseline (BL), Antisepsis (A), Puncture (P), Dressing (D), and Recovery (R) in the four assessments. SG, sucrose group; CG, control group.

assessment day; the SG and CG were comparable regarding crying behavior.

On the second assessment day, there was a statistically significant difference between groups in both the Antisepsis and Puncture phases (SG: $0 \%$, CG: $25 \%$, $p=0.04$; and SG: $11 \%$, CG: $56 \%, p=0.009$, respectively). On the third assessment day, a difference between groups was found in the Dressing phase (SG: $0 \%$, CG: $25 \%, p=0.04$ ). In addition, on the fourth day of assessment a difference between groups was detected in the Puncture phase (SG: $11 \%$, CG: $50 \%$, $p=0.03$ ).

Fig. 5 shows the percentages of $\mathrm{SG}$ and $\mathrm{CG}$ neonates with a heart rate of $\geqslant 160$ beats per min, indicating tachycardia, in the Baseline, Antisepsis, Puncture, Dressing, and Recovery phases over the four days of assessment. There were no differences between groups on all assessment days.

\subsection{Characteristics of the Puncture phase procedure}

Table 3 shows the characteristics of Puncture phase in the sucrose and control groups. The predominant type of puncture was arterial. In both groups, the number of trials for a successful puncture procedure was around one on each of the four assessment days. The duration of the Puncture phase was between 1 and $5 \mathrm{~min}$. There were no significant differences between groups concerning the main characteristics of the puncture procedure.

In addition to the data shown previously, there were no statistically significant correlations between, respectively, NFCS score, behavioral state score, average heart rate, and infant each variable (sex and gestational age) for both groups over the four days of assessment. No correlations between dependent variables and puncture characteristics were found (data not shown).

Table 3

Characteristics of puncture in sucrose group (SG) and control group (CG)

\begin{tabular}{|c|c|c|c|c|c|c|c|c|}
\hline \multirow[t]{2}{*}{ Characteristics of puncture } & \multicolumn{2}{|c|}{$\begin{array}{l}\text { First assessment (no } \\
\text { intervention) }\end{array}$} & \multicolumn{2}{|c|}{ Second assessment } & \multicolumn{2}{|c|}{ Third assessment } & \multicolumn{2}{|c|}{ Fourth assessment } \\
\hline & $\begin{array}{l}\text { SG } \\
(n=17)\end{array}$ & $\begin{array}{l}\mathrm{CG} \\
(n=16)\end{array}$ & $\begin{array}{l}\text { SG } \\
(n=17)\end{array}$ & $\begin{array}{l}\mathrm{CG} \\
(n=16)\end{array}$ & $\begin{array}{l}\text { SG } \\
(n=17)\end{array}$ & $\begin{array}{l}\mathrm{CG} \\
(n=16)\end{array}$ & $\begin{array}{l}\text { SG } \\
(n=15)\end{array}$ & $\begin{array}{l}\mathrm{CG} \\
(n=16)\end{array}$ \\
\hline \multicolumn{9}{|l|}{ Type of punture } \\
\hline Arterial, f (\%) & $13(76)$ & $13(84)$ & $15(88)$ & $9(55)$ & $13(76)$ & $10(63)$ & $10(67)$ & $9(55)$ \\
\hline Venipuncture, f $(\%)$ & $2(12)$ & $1(5)$ & $1(6)$ & $5(34)$ & $1(6)$ & $4(26)$ & $2(14)$ & $3(19)$ \\
\hline Heel-lance, f (\%) & $2(12)$ & $2(11)$ & $1(6)$ & $2(11)$ & $3(18)$ & $2(11)$ & $3(19)$ & $4(26)$ \\
\hline $\begin{array}{l}\text { Number of trials for successful } \\
\text { puncture, median (range) }\end{array}$ & $2(1-5)$ & $1(1-3)$ & $1(1-5)$ & $1(1-6)$ & $1(1-4)$ & $1(1-5)$ & $1(1-4)$ & $1(1-4)$ \\
\hline $\begin{array}{l}\text { Total time of blood collection ( } \mathrm{min} \text { ), } \\
\text { median (range) }\end{array}$ & $\begin{array}{l}4.5 \\
(0.5-12.83)\end{array}$ & $\begin{array}{l}1.29 \\
(0.65-7.6)\end{array}$ & $\begin{array}{l}2.66 \\
(0.58-20.58)\end{array}$ & $\begin{array}{l}2.02 \\
(0.66-11.3)\end{array}$ & $\begin{array}{l}2.9 \\
(0.71-16.83)\end{array}$ & $\begin{array}{l}2.21 \\
(0.83-21.58)\end{array}$ & $\begin{array}{l}2.05 \\
(0.58-9.28)\end{array}$ & $\begin{array}{l}2.7 \\
(0.65-11)\end{array}$ \\
\hline
\end{tabular}




\section{Discussion}

After clear demonstration of the pain relieving effect of oral sucrose, the American Academy of Pediatrics and Canadian Pediatric Society (2000) recommended the use of sucrose solution as routine pain relief in NICU during invasive and painful procedures. This recommendation raised two concerns that the present study has attempted to address: the possibility of side effects due to administration of repeated doses of sucrose in preterm infants, and the possibility of diminishing or extinguishing the pain relieving effect after intensive use of sucrose. Fortunately, neither of these fears appears to have been well-founded, based on the results of our short-term study.

It is important to comment on some methodological aspects of the present study design. Of 180 preterm and very low birth weight births during the period of the study, only 33 infants were actually included in the study. Restrictive exclusion criteria were used to select the sample, but this was absolutely necessary to control the potential confounding variables. Previous studies (Mitchell et al., 2004; Holsti et al., 2005) have used sample sizes of preterm infants similar to that of the present study.

The time frame used for data collection in the present study should also be highlighted. First, the procedure was divided into five phases, which made it possible to assess the effect of sucrose on behavioral responses in detail. For each evaluation, pain responses at baseline and in the puncture and recovery phases were obtained, as seen in most studies, but our study also included the phases involving nurses' touch contact for antisepsis and dressing. Using this methodology it was possible to demonstrate that procedures commonly seem as non-noxious, such as antisepsis, could provoke infants' responses of facial activity and activated behavioral state; probably these behaviors act as an anticipatory distress for painful stimulus.

Second, the neonates' pain response patterns were established prior to interventions with sucrose or sterile water. This is a relevant methodological precaution in order to arrive at a better understanding of the data obtained. This approach is new compared to the sucrose studies of Johnston et al. (2002), Boyer et al. (2004).

Another consideration was the difference in the working definition of repeated doses schedule that was used in the present study as compared to the studies of Johnston et al. (1999) and Mitchell et al. (2004). In these studies, the repeated doses of sucrose were defined as three times in one painful procedure. Differently, in the current study, as in the study of Stevens et al. (2005), the doses of sucrose were administered repeatedly in every painful procedure over consecutive days.

The present study and the study of Stevens et al. (2005) both showed that sucrose was efficacious for pain relieving. The specific contribution of our study was that we analyzed exclusively sucrose in comparison to sterile water, whereas Stevens et al. (2005) used combined sucrose plus pacifier in the same group in comparison with pacifier plus water and standard care.

The cut-off value of 3 for the NFCS score used in the present study was derived from the sensitivity and specificity obtained from the ROC curve. The value found was the same as that recommended previously by Grunau and Craig (1987).

The dose of sucrose used in the present study must be considered. Originally, a dose of $2 \mathrm{ml}$ sucrose was recommended (as seen in the review of Gaspardo et al., 2005). We considered that using this dose might present a problem in the study design when using repeated doses of sucrose, because the vulnerable neonates would receive a high amount of sucrose on the same day. The dose of $25 \%$ sucrose $(0.5 \mathrm{ml} / \mathrm{kg})$ turned out to be sufficiently efficacious for pain relief.

Despite the fact that on average, infants received around six doses of $25 \%$ sucrose a day (at $0.5 \mathrm{ml} / \mathrm{kg}$ ) during the study period (with one child receiving 14 doses in one day), there were no short-term negative effects on the clinical health status of neonates. Necrotizing enterocolitis was of the highest concern. Fortunately, such pathology was not encountered during study. It must be emphasized that the sample size was not large enough to rule out the possibility of this undesirable side effect. In accordance with our results, the previous studies of Ramenghi et al. (1996), Acharya et al. (2004) and Stevens et al. (2005) also found no adverse effects of sucrose, such as necrotizing enterocolitis.

In a double-blind, randomized, controlled trial Johnston et al. (2002) found some side effects of sucrose within $48 \mathrm{~h}$ regarding developmental outcomes in preterm neonates who were born at $<31$ weeks' post-conceptional age. From the large list of predictor variables for the regression analyses (sucrose vs. water) on the performance in the Neurobehavioral Assessment of the Preterm Infant the only variable that was found to predict neurobehavioral outcomes was the higher number of repeated doses of sucrose $(0.1 \mathrm{ml}$ of $24 \%$ sucrose). The effect was detected in terms of alertness and orientation in infants at 36 weeks postnatal age, and in terms of motor development and vigor at both 36 and 40 weeks.

Regarding the effect of repeated doses of sucrose on pain relief, the present study has demonstrated that the effect is maintained over a period of at least three days. The present study has improved our knowledge about the behavioral state of neonates in comparison to previous studies. In the studies of Ramenghi et al. (1996), Johnston et al. (1997), and Acharya et al. (2004), the behavioral state was analyzed particularly to assess the baseline behavior prior to a painful proce- 
dure, in order to control for this variable in different groups of the sample study. In the studies of Johnston et al. (1999), Stevens et al. (1999), Gibbins et al. (2002), Gibbins and Stevens (2003), Mitchell et al. (2004), Gal et al. (2005), and Stevens et al. (2005), the behavioral state was included in a multidimensional instrument (PIPP). This is the sum, in a single score, of different items such as contextual, physiological, and behavioral indicators, which turn difficult to identify the specific contribution of these three different parameters of infant's responses to painful stimulus. In the present study, the behavioral state was analyzed as a separated unidimensional measure. In addition, the behavioral assessment state was analyzed during the whole procedure of blood collection, from baseline to post-puncture recovery phase, in order to follow the neonates' neurobehavioral regulation.

Regarding the crying behavioral state specifically, the SG showed a lower percentage of the neonates crying than the CG. The effect was detected prior to puncture (i.e., during antisepsis), during blood collection, and post-puncture (during dressing management). The finding of efficacy of sucrose in reducing the duration of crying in preterm infants has been published previously (Abad et al., 1996; Ramenghi et al., 1996; Ramenghi et al., 1999; Storm and Fremming, 2002; Acharya et al., 2004).

There was no statistical difference between groups in heart rate during the four days of assessment. It must to be pointed out that the physiological parameters, including heart rate, do not have specificity for pain measurement. Heart rate could be used as a complementary measure in the pain assessments; in fact, it is a better sign of distress than specific pain responses. Implementation of other forms of pain relieving management is probably necessary to address neonates' distress and discomfort. Contention management or non-nutritive sucking has been proposed (Als, 1982; Franck and Miakowski, 1997).

Three other aspects should be considered. The $10 \mathrm{~min}$ of data collection during recovery phase might be insufficient for stabilization of the neonates' heart rate after the puncture procedure. For analyses of heart rate, it might be necessary to have a more specific design, as in the study of Oberlander and Saul (2002). Also, the dose of $25 \%$ sucrose $(0.5 \mathrm{ml} / \mathrm{kg})$ may be insufficient for physiological stabilization of the neonates. Ramenghi et al. (1996) assessed the efficacy of using $0.1 \mathrm{ml}$ of $25 \%$ sucrose in counteracting pain by using the heart rate of preterm neonates before, during, and after heel-lance for blood collection. They described similar results to those presented is this study. Also, Acharya et al. (2004) found that within groups, the heart rate of preterm neonates decreased significantly during the venipuncture when they had received $2 \mathrm{ml}$ of $25 \%$ oral sucrose $2 \mathrm{~min}$ before the procedure. One must take into account that using higher doses of sucrose could be a problem in studies using repeated-dose schedule.

In conclusion, the use of sucrose for minor pain in the daily routine of NICU was found to be effective and had no short-term side effects on the health status of the neonates. Consequently, the findings of this study can be extrapolated to neonates with similar health characteristics. The ecological validity of the study, which was developed in the natural contextual environment of NICU, would argue for the generalization of the trial findings. In future studies, the assessment of other distressful procedures commonly seem as non-noxious and the medium- and long-term effects of sucrose on children's health and development should be addressed.

\section{Acknowledgement}

This study was supported by the Foundation for Support of Research in the State of São Paulo, Brazil (FAPESP), the National Council of Science and Technology Development (CNPq), and the Foundation for Support of Teaching, Research and Assistance of the University Hospital of Clinics (FAEPA).

The authors are grateful for the contributions made by Vivian C. Klein (doctoral student in Mental Health at the Ribeirão Preto Medical Faculty, University of São Paulo) and by Thaís S. Cugler (medical student at the Ribeirão Preto Medical Faculty, University of São Paulo).

The authors thank the staff of the Neonatology Service at the General Hospital of the School of Medicine, University of São Paulo at Ribeirão Preto, and the families for allowing their babies to participate in this study.

\section{References}

Abad F, Díaz N, Domenech E, Robayna M, Rico J. Oral sweet solution reduces pain-related behavior in preterm infants. Acta Paediatr 1996;85:854-8.

Acharya A, Annamali S, Taub N, Field D. Oral sucrose analgesia for preterm infant venopuncture. Arch Dis Child Fetal Neonate 2004;89:17-8.

Als H. Toward a synactive theory of development: promise for the assessment and support of infant individuality. Infant Mental Health J 1982;3:229 43 .

American Academy of Pediatrics and Canadian Pediatric Society. Prevention and management of pain and stress in the neonate. Pediatrics 2000;105:454 461.

Anand KJS. Clinical importance of pain and stress in preterm neonates. Biol Neonate 1998;73:1-9.

Anand KJS. Effects of perinatal pain and stress. In: Mayer EA, Saper CB, eds. Progress in Brain Research Amsterdam: Elsevier Science, 2000, pp. 117-29.

Boyer K, Johnston C, Walker C, Filion F, Sherrard A. Does sucrose analgesia promote physiologic stability in preterm neonates? Biol Neonate 2004;85:26-31. 
Chang YJ, Anderson GC, Lin CH. Effects of prone and supine positions on sleep state and stress responses in mechanically ventilated preterm infants during the first postnatal week. J Adv Nurs 2002;40:161-9.

Cockburn F, Cooke R, Gamsu H, Greenough A, Hopkins A, Mcintosh N, et al. The CRIB (Clinical Index for Babies) score: a tool for assessing initial neonatal risk and comparing performance of neonatal intensive care units. Lancet 1993;342:193-8.

Corff K, Seidman R, Venkataraman M. Facilitated tucking: a nonpharmacological comfort measure for pain in preterm neonates. $\mathbf{J}$ Obst Gynecol Neon Nurs 1995;24:143-5.

Fletcher M. Physical assessment and classification. In: Avery G, Fletcher M, editors. Neonatology: pathophysiology and management of the newborn. Philadelphia: Lippincott Co; 1994, pp. 269-88.

Franck L, Miakowski C. Measurement of neonatal responses to painful stimuli: a research review. J Pain Sympt Manag 1997:14:343-78.

Gal P, Kissling G, Young W, Dunaway K, Marsh V, Jones S, et al. Efficacy of sucrose to reduce pain in premature infants during eye examinations for retinopathy of prematurity. Ann Pharmacother 2005;39:1029-33.

Gaspardo CM, Linhares MB, Martinez FE. The efficacy of sucrose for the relief of pain in neonates: a systematic review of the literature. $\mathbf{J}$ Pediatr (Rio J) 2005;81:435-42.

Gibbins S, Stevens B. The influence of gestational age on the efficacy and short-term safety of sucrose for procedural pain relief. Adv Neon Care 2003;3:241-9.

Gibbins S, Stevens BJ, Asztalos E. Assessment and management of acute pain in high-risk neonates. Expert Opin Pharmacother 2003;4:475-83.

Gibbins S, Stevens B, Hodnett E, Pinelli J, Ohlsson A, Darlington G. Efficacy and safety of sucrose for procedural pain relief in preterm and term neonates. Nurs Res 2002;51:375-82.

Grunau RE. Long-term consequences of pain in human neonates. In: Anand KJS, Stevens BJ, McGrath PJ, editors. Pain in neonates. Amsterdam: Elsevier Science; 2000, pp. 45-55.

Grunau RE. Early pain in preterm infants: a model of long-term effects. Clin Perinatol 2002;29:373-94

Grunau RE, Craig K. Pain expression in neonates: facial action and cry. Pain 1987;28:395-410.

Grunau RE, Fitzgeralg C, Ellwood A. Neonatal Facial Coding System, Training Manual. Vancouver: Biobehavioral Research Unit, Centre for Community Health \& Health Evaluation Research, British Columbia Research Institute for Children's \& Women's Health, 2001 (unpublished manuscript).
Grunau RE, Weinberg J, Whitfield M. Neonatal procedural pain and preterm infant cortisol response to novelty at 8 months. Pediatrics 2004; 114:77-84.

Holsti L, Grunau RE, Oberlander TF, Whitfield MF. Prior pain induces heightened motor responses during clustered care in preterm infants in the NICU. Early Hum Dev 2005;81: 293-302.

Johnston C, Filion F, Snider L, Majnemer A, Limperopoulos C, Walker C. Routine sucrose analgesia during the first week of life in neonates younger than 31 weeks' postconceptional age. Pediatrics 2002;110:523-8.

Johnston C, Stremler R, Horton L, Friedman A. Effect of repeated doses of sucrose during heel stick procedure in preterm neonates. Biol Neonate 1999;75:160-6.

Johnston C, Stremler R, Stevens B, Horton L. Effectiveness of oral sucrose and simulated rocking on pain response in preterm neonates. Pain 1997;72:193-9.

Mitchell A, Stevens B, Mugnan N, Johnson W, Lobert S, Boss B. Analgesic effects of oral sucrose and pacifier during eye examinations for retinopathy of prematurity. Pain Manag Nurs 2004;5:160-8.

Murdoch DR, Darlow BA. Handling during neonatal intensive care. Arch Dis Child 1984;59:957-61.

Oberlander T, Saul JP. Methodological consideration for the use of heart variability as a measure of pain reactivity in vulnerable infants. Clin Perinatol 2002;29:427-43.

Ramenghi L, Evans D, Levene M. "Sucrose analgesia": absorptive mechanism or taste perception? Arch Dis Child Fetal Neonate 1999;80:146-7.

Ramenghi L, Wood C, Griffith G, Levene M. Reduction of pain response in premature infants using intraoral sucrose. Arch Dis Child Fetal Neonate 1996;74:126-8.

Stevens B, Johnston C, Franck L, Petryshen P, Jack A, Foster G. The efficacy of developmentally sensitive interventions and sucrose for relieving procedural pain in very low birth weight neonates. Nurs Res 1999;48:35-43.

Stevens B, Ridell R, Oberlander T, Gibbins S. Assessment of pain in neonates and infants. In: Anand KJS, Stevens BJ, McGrath PJ, editors. Pain in neonates and infants. Amsterdam: Elsevier Science; 2007, pp. 67-90.

Stevens B, Yamada J, Beyene J, Gibbins S, Petryshen P, Stinson J, et al. Consistent management of repeated procedural pain with sucrose in preterm neonates: is it effective and safe for repeated use over time? Clin J Pain 2005;21:543-8.

Storm H, Fremming A. Food intake and oral sucrose in preterm prior to heel prick. Acta Paediatr 2002;91:555-60. 